\title{
Simulation and Optimization of High-Penetration Wind and Solar Energy for the Canadian High Arctic Research Station
}

by

Michael David Brown

A thesis submitted to the Faculty of Graduate and Postdoctoral Affairs in partial fulfillment of the requirements for the degree of

Master of Applied Science

in

Sustainable Energy

\author{
Carleton University \\ Ottawa, Ontario
}

(C)2018

Michael David Brown 


\begin{abstract}
This thesis explores the potential for renewable wind and solar energy to meet the electrical demand of the Canadian High Arctic Research Station, the Government of Canada's new flagship Arctic research facility located in Cambridge Bay, Nunavut. Time-series simulation models based on measured weather data and simulated energy demand were constructed in TRNSYS. The models were then coupled with GenOpt to optimize system configuration with respect to net present cost using the particle swarm optimization technique. The results suggest that renewable energy can meet a portion of the demand more costeffectively than diesel generation alone; however, a major challenge is the ability of the local grid to absorb surplus renewable power. Increasing the renewable penetration rate at the station beyond about $65 \%$ is not economically feasible with the generating and storage technologies considered in this thesis. Policy considerations regarding implementation of renewable energy in Nunavut were also discussed.
\end{abstract}


For Nunavummiut 


\section{Acknowledgements}

Thank you to my thesis advisor, Dr. Cynthia Cruickshank. I wouldn't have finished this work if it weren't for her guidance, patience, and support during this lengthy endeavour.

To the people of Cambridge Bay, who were so very welcoming during my stays in the community, I am deeply appreciative. I hope this work will contribute in its own small way to a more sustainable future for the community and the territory.

To all my colleagues on the CHARS project, it was a privilege to work with you and I can't stress enough how much I learned from everyone. I hope our paths cross again. I would like to specifically thank my mentors over the years - Rein, Santino, Matthew, and Mark.

Another thank you is due to my co-authors on some related papers - Alain, Robyn, Jean-François, Guillaume, and Dr. Cruickshank.

I would like to thank the Department of Indigenous and Northern Affairs Canada and the Natural Sciences and Engineering Research Council of Canada for funding support.

It goes without saying, but I will anyway - thank you to Mom, Dad, and brother Steve. I'm looking forward to walks in the old-growth with you soon.

Finally, thank you to Andrew for everything over the years, and I hope many more to come. 


\section{Table of Contents}

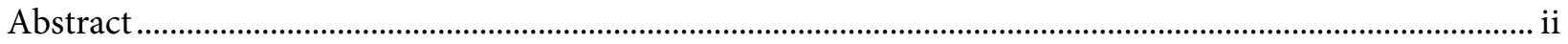

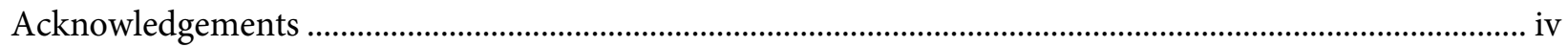

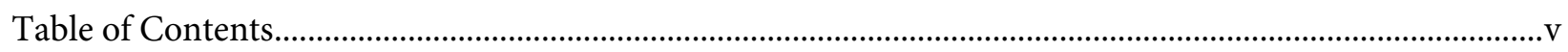

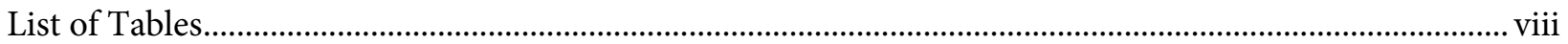

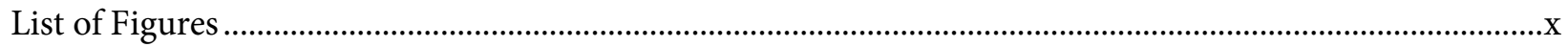

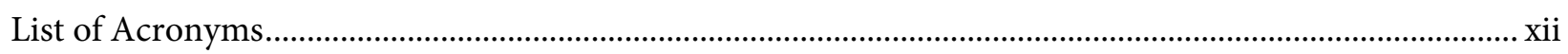

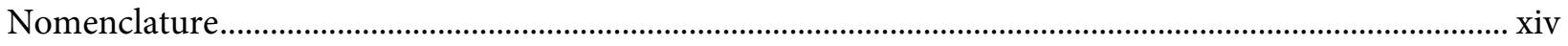

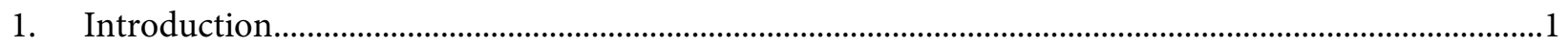

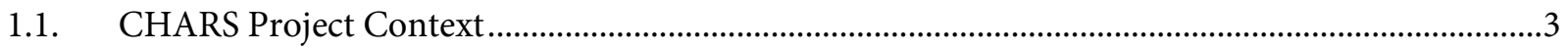

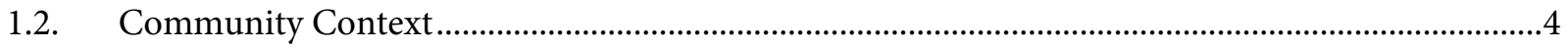

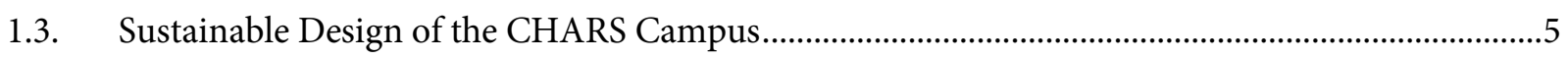

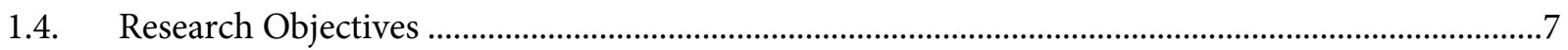

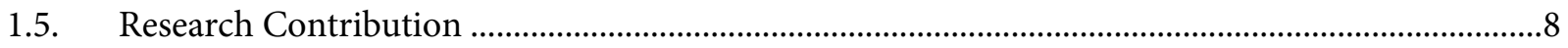

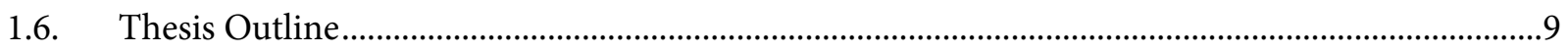

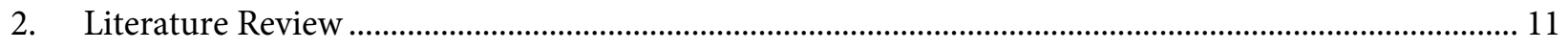

2.1. Simulation of Hybrid Renewable Energy Systems........................................................................ 11

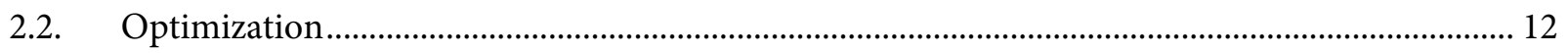

2.3. Wind and Solar Energy in Diesel-Electric Grids in the Arctic...................................................... 18

2.3.1. Wind and Solar Energy in the North American Arctic ................................................................ 19

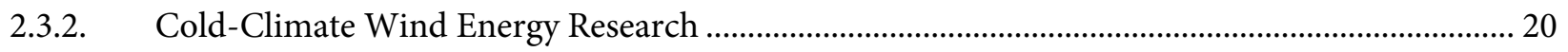

2.3.3. Hybrid Systems Modelling in the Arctic ..................................................................................... 21

3. Energy Conversion for Electric Power Generation ............................................................................. 24 


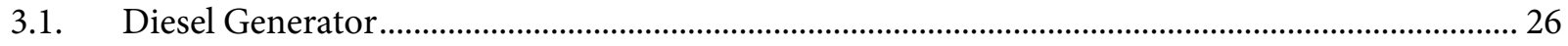

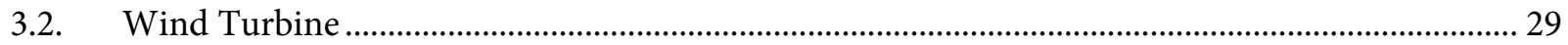

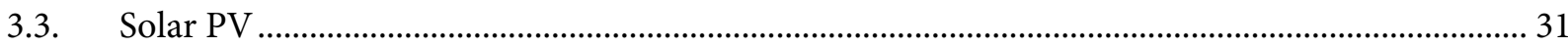

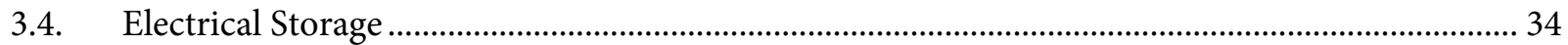

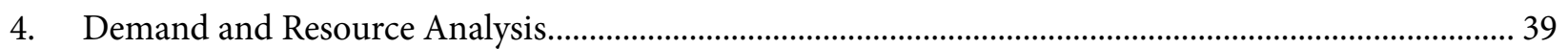

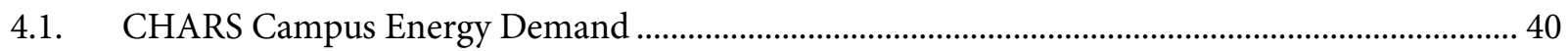

4.2. Statistical and Actual Meteorological Year Weather Files ............................................................. 42

4.3. Cambridge Bay Weather Monitoring and Data ............................................................................. 43

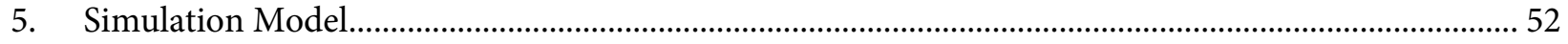

5.1. Controller Model \& Dispatch Strategy ......................................................................................... 57

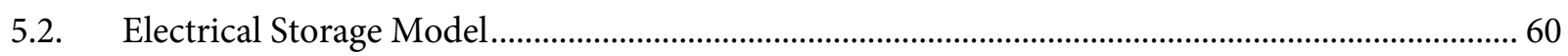

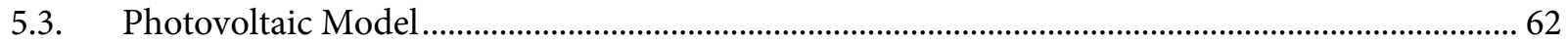

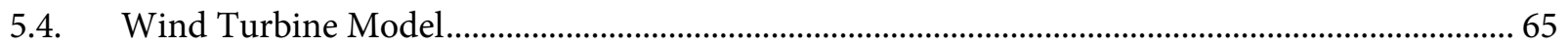

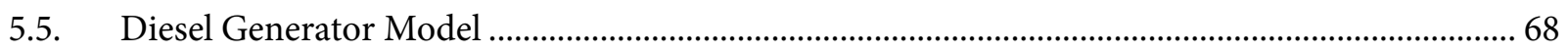

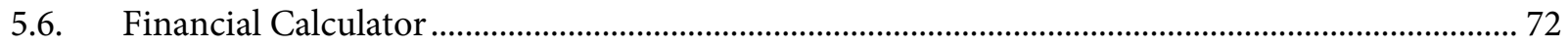

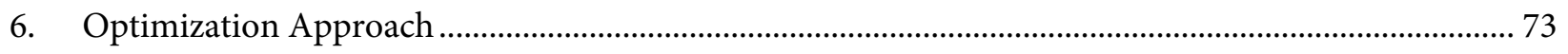

6.1. Particle Swarm Optimization with Discrete Variables..................................................................... 73

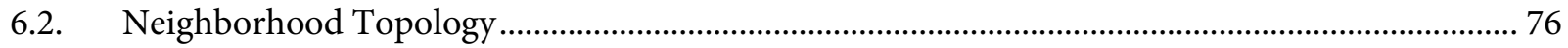

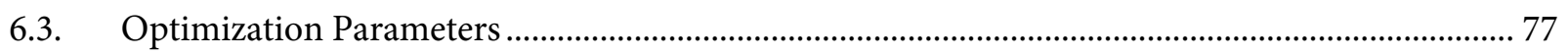

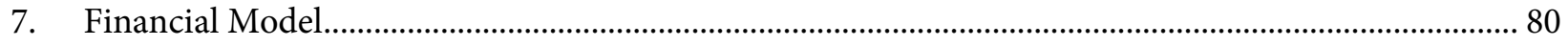

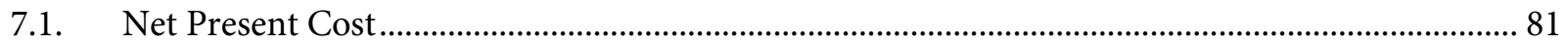

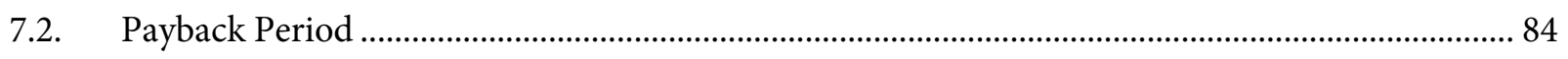

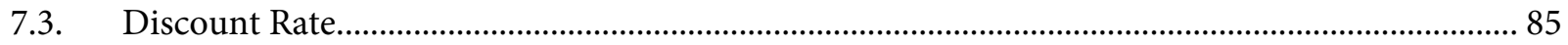

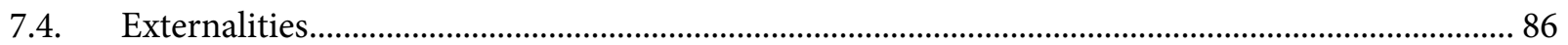




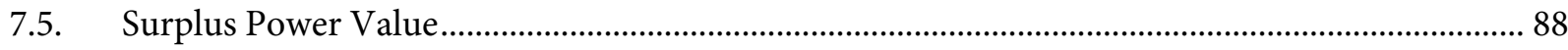

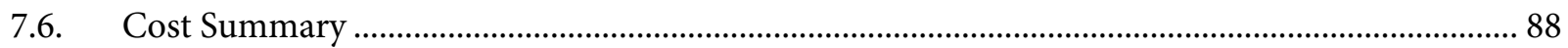

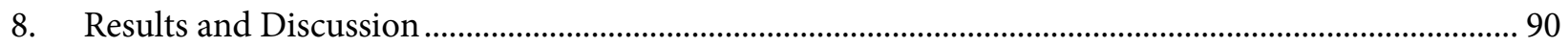

8.1. Grid-integrated: Wind/Photovoltaic with Grid-Purchased Power ................................................ 91

8.2. Stand-alone: Wind and Photovoltaic with On-Site Diesel Power ................................................... 97

8.3. Low-maintenance: Photovoltaic-Battery Configuration ............................................................ 100

8.4. Highest Penetration: Maximizing Renewable Energy for CHARS............................................... 104

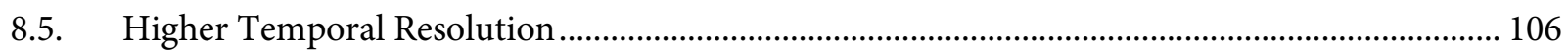

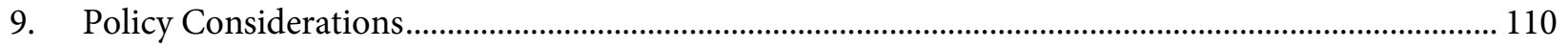

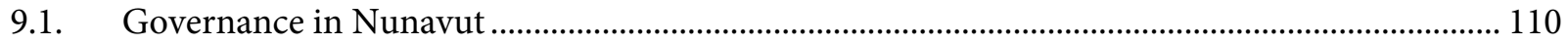

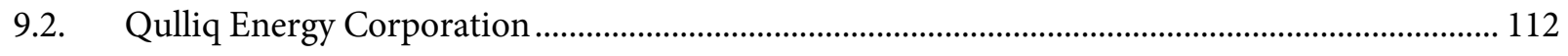

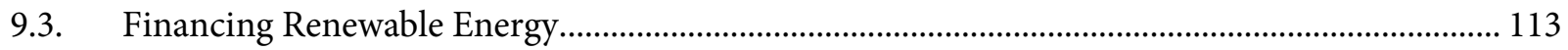

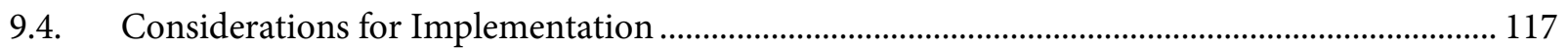

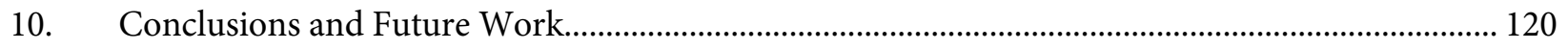

10.1. Recommendations for Future Work ............................................................................... 123

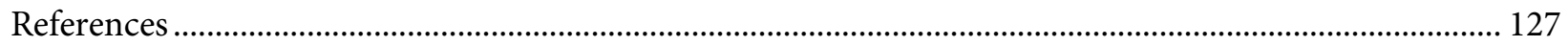

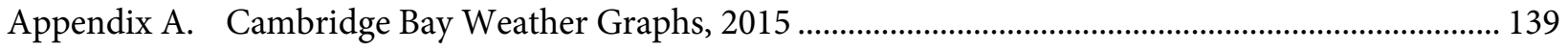

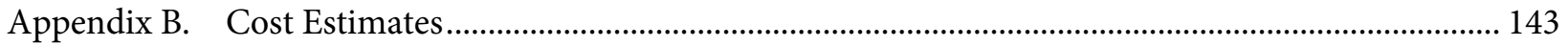

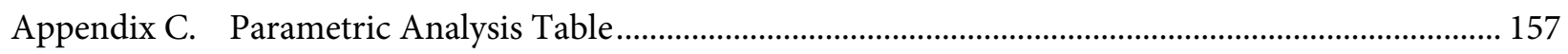




\section{List of Tables}

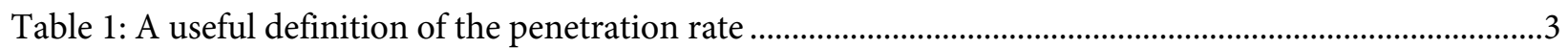

Table 2: Comparison of reference and design buildings ..........................................................................6

Table 3: Comparison of design and reference buildings annual energy consumption and cost .....................6

Table 4: Technological maturity level of various electricity storage concepts................................................ 35

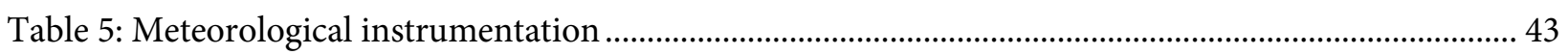

Table 6: Conditions indicative of anemometer freezing events ....................................................................... 44

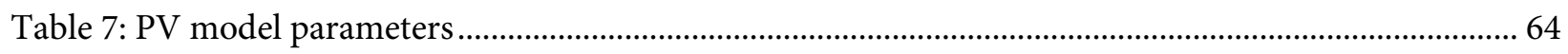

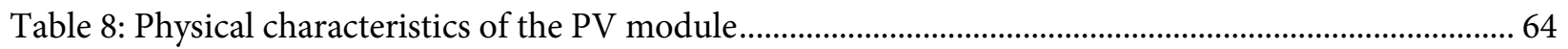

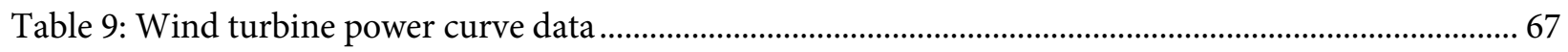

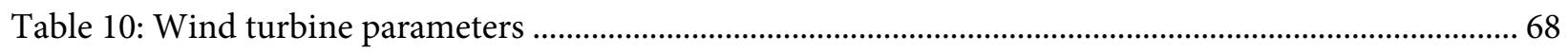

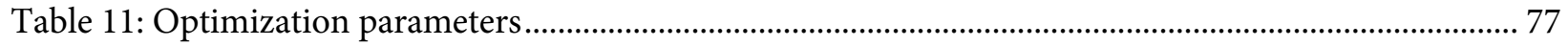

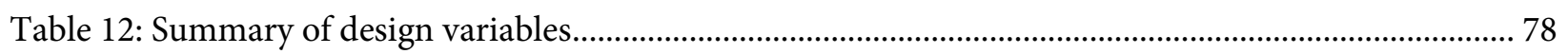

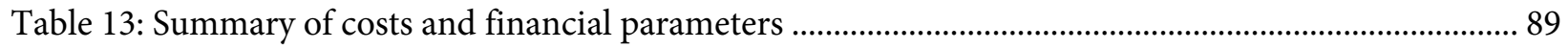

Table 14: Grid-tied configuration capital and net present cost ........................................................................ 92

Table 15: Grid-tied configuration first-year operational cost....................................................................... 93

Table 16: Grid-tied configuration design vector ............................................................................................ 94

Table 17: Grid-tied configuration annual renewable performance ………..................................................... 95

Table 18: Stand-alone configuration capital and net present cost .................................................................. 97

Table 19: Stand-alone configuration first-year operational cost .................................................................. 98

Table 20: Stand-alone configuration design vector .......................................................................................... 99

Table 21: Stand-alone configuration annual renewable performance ........................................................... 99

Table 22: PV-only configuration capital and net present cost...................................................................... 101

Table 23: PV-only configuration first-year operational cost ...................................................................... 101

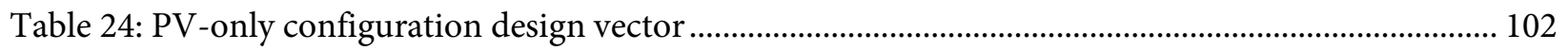

Table 25: Optimal solution annual renewable performance, PV-only configuration.................................. 103

Table 26: Highest penetration configuration design variables ......................................................................... 104

Table 27: Highest penetration configuration capital and net present cost ................................................... 105 
Table 28: Highest penetration configuration design vector.......................................................................... 105

Table 29: Highest penetration configuration first-year operational costs ................................................... 105

Table 30: Highest penetration configuration annual renewable performance.............................................. 105

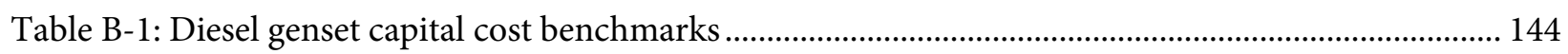

Table B-2: Qulliq Energy Corporation allocation of expenses (\$) .............................................................. 145

Table B-3: Qulliq Energy Corporation allocation of expenses (\%) ................................................................ 146

Table B-4: Qulliq Energy Corporation allocation of expenses ( $\$ / \mathrm{kW}$ installed capacity) ......................... 146

Table B-5: Solar photovoltaic installed system capital cost benchmarks .................................................... 149

Table B-6: Solar photovoltaic equipment capital cost benchmarks ........................................................... 149

Table B-7: Wind turbine capital cost benchmarks............................................................................................ 152

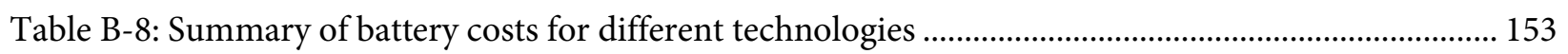

Table B-9: Cost of different Lithium-ion battery chemistries..................................................................... 154 


\section{List of Figures}

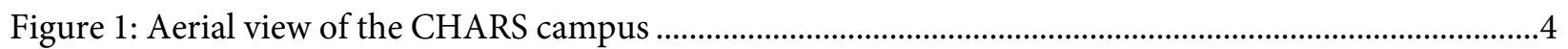

Figure 2: Comparison of reference and design building annual energy cost...................................................6

Figure 3: Local and global minima of an arbitrary objective function ........................................................... 12

Figure 4: An example of a simulated annealing cooling schedule.................................................................. 15

Figure 5: Selection, cross-over, and mutation in the genetic algorithm...................................................... 16

Figure 6: Movement of a particle in a particle swarm optimization across two-dimensional space ............ 17

Figure 7: Electricity production by source in a variety of Arctic jurisdictions ............................................... 18

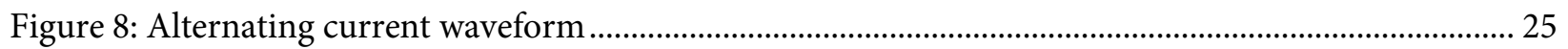

Figure 9: Thermal losses (\%) in a diesel genset.............................................................................................. 27

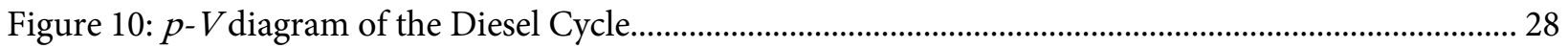

Figure 11: Diesel cycle thermal efficiency as a function of compression ratio ...............................................2 29

Figure 12: Wind turbine generator types....................................................................................................... 31

Figure 13: Silicon lattice structure; pure (left) and doped with phosphorous (right).................................. 32

Figure 14: Diffusion voltage of the p-n junction without external voltage applied (left), and with applied

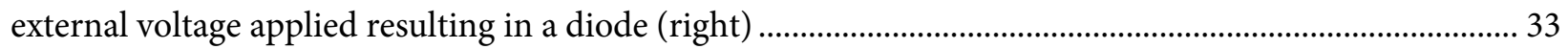

Figure 15: Photovoltaic power-voltage and current-voltage curves ................................................................ 34

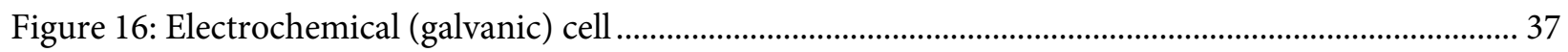

Figure 17: Simulated CHARS annual electricity (top) and heating (bottom) demand ................................. 41

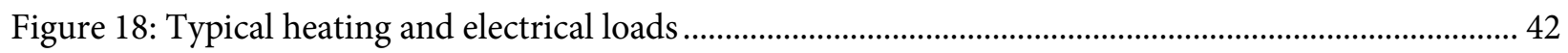

Figure 19: Meteorological mast (left) and solar pyranometers (right) ............................................................ 44

Figure 20: Wind speed variation with height above ground........................................................................ 46

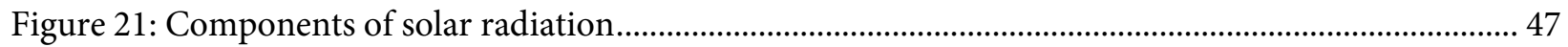

Figure 22: Comparison of measured and modelled tilted surface solar radiation ......................................... 49

Figure 23: Residual plot of measured and modelled solar radiation on a tilted plane ................................... 50

Figure 24: Stand-alone system configuration model in the Simulation Studio.............................................. 53

Figure 25: Entering simulation parameters in Type 90 ................................................................................... 53

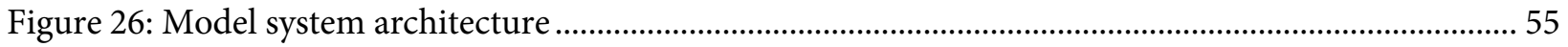




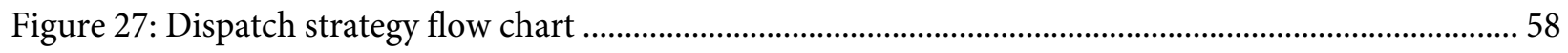

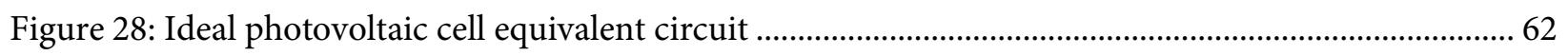

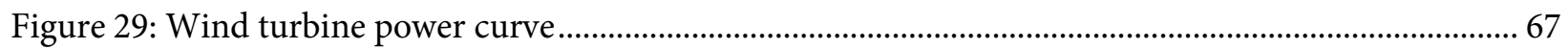

Figure 30: Fuel consumption and efficiency for a $545 \mathrm{~kW}$ prime power diesel genset .................................. 69

Figure 31: Normalized fuel consumption for nine diesel gensets .................................................................... 71

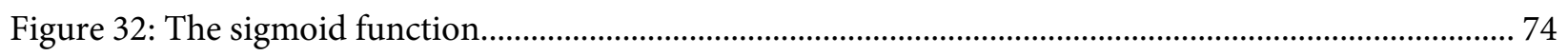

Figure 33: Neighborhood topology options for the particle swarm optimization........................................... 76

Figure 34: Monthly year-over-year change in Industrial Product Price Index and Consumer Price Index 83

Figure 35: Monthly year-over-year change in Energy and Petroleum Price Index ......................................... 84

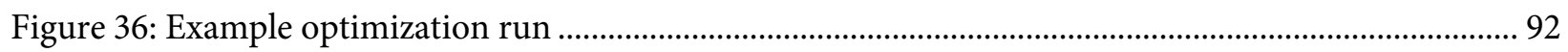

Figure 37: Parametric analysis, grid-tied configuration .................................................................................... 96

Figure 38: Parametric analysis, stand-alone configuration ............................................................................ 100

Figure 39: Parametric analysis, PV-only configuration.................................................................................. 103

Figure 40: Histogram of optimal configuration total surplus power ........................................................... 108

Figure 41: Histogram of optimal configuration solar PV output................................................................. 108

Figure 42: Histogram of optimal configuration wind turbine output ......................................................... 109

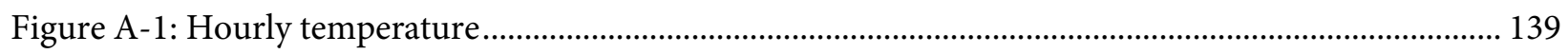

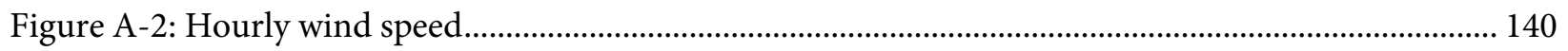

Figure A-3: Hourly global horizontal solar radiation ............................................................................... 140

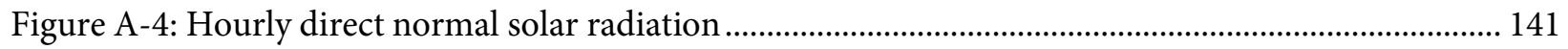

Figure A-5: Hourly diffuse horizontal solar radiation ................................................................................... 141

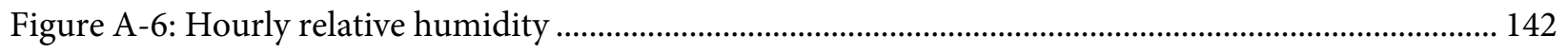

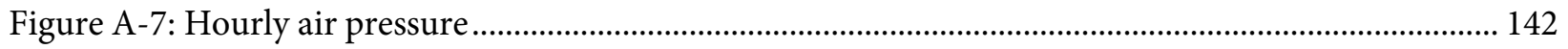

Figure B-1: Levelized cost of electricity of utility-scale solar PV power, contiguous United States ............ 148

Figure B-2: Levelized cost of electricity of utility-scale wind power, contiguous United States.................. 150 


\section{List of Acronyms}

AC: Alternating current

AMY: Actual meteorological year

BSRN: Baseline Solar Radiation Network

CO2,eq: Carbon dioxide equivalent

CHARS: Canadian High Arctic Research Station

CPI: Consumer price index

DC: Direct current

FIT: Feed-in tariff

FMB: Field and Maintenance Building

fSOC: Fractional state-of-charge

GHG: Greenhouse gas

GN: Government of Nunavut

HTO: Hunters and Trappers Association

IBP: Inuit Benefits Plan

INAC: Indigenous and Northern Affairs Canada

IQ: Inuit Qaujimajatuqangit

IPP: Independent power producer

IPPI: Industrial products price index

LCOE: Levelized cost of electricity

MLA: Member of the Legislative Assembly

MRB: Main Research Building

NERC: North American Electric Reliability Corporation

NIRB: Nunavut Impact Review Board

NLCA: Nunavut Land Claims Agreement 
NPC: Net present cost

NPC: Nunavut Planning Commission

NPV: Net present value

NTI: Nunavut Tunngavik Incorporated

NWMB: Nunavut Wildlife Management Board

NWB: Nunavut Water Board

O\&M: Operations and maintenance

PCS: Power conditioning system

PV: Photovoltaic

QEC: Qulliq Energy Corporation

RPS: Renewable portfolio standard

SOC: State-of-charge

SMY: Statistical meteorological year

S\&T: Science and technology

TMY: Typical meteorological year

TRNSYS: Transient System Simulation 


\section{Nomenclature}

\begin{tabular}{|c|c|c|}
\hline Symbol & Description & Units \\
\hline \multicolumn{3}{|c|}{ Optimization } \\
\hline$c_{1}$ & Cognitive acceleration constant & - \\
\hline$c_{2}$ & Social acceleration constant & - \\
\hline$E$ & Energy (objective function value) & - \\
\hline$f(x)$ & Objective function value & - \\
\hline$g_{\mathrm{i}}(x)$ & Inequality constraint(s) & - \\
\hline$h_{\mathrm{j}}(x)$ & Equality constraint(s) & - \\
\hline$k$ & Generation number & - \\
\hline$K_{\mathrm{B}}$ & Boltzmann Constant & $1.3806488 \times 10^{-23}[\mathrm{~J} / \mathrm{K}]$ \\
\hline$K$ & Total number of generations & - \\
\hline$p$ & \# of design variables & - \\
\hline$p_{\mathrm{i}}(k)$ & $i^{\text {th }}$ particle (solution) of the $k^{\text {th }}$ generation & Varies \\
\hline$P$ & Boltzmann probability factor & - \\
\hline$r, r_{1}, r_{2}$ & Uniform random numbers & {$[0,1]$} \\
\hline$s(v)$ & Sigmoid function & - \\
\hline$T$ & Temperature (simulated annealing) & {$[\mathrm{K}]$} \\
\hline$v_{\max }$ & Maximum particle velocity & - \\
\hline$v_{\mathrm{i}}(k)$ & $i^{\text {th }}$ particle's velocity at generation $k$ & Varies \\
\hline$\hat{v}_{\mathrm{i}}^{\mathrm{j}}$ & Particle velocity of binary particle swarm implementation & - \\
\hline$w_{0}$ & Particle inertia weight, first generation & - \\
\hline$w_{1}$ & Particle inertia, last generation & - \\
\hline$x$ & Design vector & - \\
\hline$x(t)$ & Objective function solution at time $t$ & Varies \\
\hline$x(t+1)$ & Objective function solution at time $t+1$ & Varies \\
\hline$\delta_{\mathrm{i}, \mathrm{j}}$ & Random number for each bit $\psi_{\mathrm{i}}^{\mathrm{j}}$ & $(0,1)$ \\
\hline$\pi_{1, \mathrm{i}}(k)$ & Position (solution) of particle's own best solution & Varies \\
\hline$\pi_{\mathrm{g}, \mathrm{i}}(k)$ & Position (solution) of nearby particles' best solution & Varies \\
\hline$\chi$ & Constriction coefficient & - \\
\hline$\psi_{\mathrm{i}}^{\mathrm{j}}$ & Binary representation of design variables with $j$ for $i$ particles & - \\
\hline \multicolumn{3}{|c|}{ Energy Conversion } \\
\hline$f$ & Frequency & {$\left[\mathrm{s}^{-1}\right]$} \\
\hline$I$ & Current & {$[\mathrm{A}]$} \\
\hline$P$ & Real power & {$[\mathrm{W}]$} \\
\hline
\end{tabular}




\begin{tabular}{|c|c|c|}
\hline Symbol & Description & Units \\
\hline$P F$ & Power factor & - \\
\hline$Q$ & Reactive power & {$[\mathrm{VA}]$} \\
\hline$S$ & Apparent power & {$[\mathrm{VA}]$} \\
\hline$t$ & Time & {$[\mathrm{s}]$} \\
\hline$T$ & Mechanical torque & {$[\mathrm{N}-\mathrm{m}]$} \\
\hline V & Voltage & {$[\mathrm{V}]$} \\
\hline$W$ & Work & {$[\mathrm{N}]$} \\
\hline$\omega$ & Angular velocity & {$\left[s^{-1}\right]$} \\
\hline$\theta$ & Phase angle & {$\left[{ }^{\circ}\right]$} \\
\hline \multicolumn{3}{|c|}{ Diesel Generator } \\
\hline$a$ & Fuel consumption coefficient & {$[\mathrm{L} / \mathrm{h}]$} \\
\hline$b$ & Fuel consumption coefficient & {$[\mathrm{L} / \mathrm{h}]$} \\
\hline$C_{\mathrm{p}}$ & Specific heat at constant pressure & {$[\mathrm{kJ} / \mathrm{kg}-\mathrm{K}]$} \\
\hline$C_{\mathrm{v}}$ & Specific heat at constant volume & {$[\mathrm{kJ} / \mathrm{kg}-\mathrm{K}]$} \\
\hline$l h v_{\text {fuel }}$ & Lower heating value of fuel & {$[\mathrm{kJ} / \mathrm{kg}]$} \\
\hline$p$ & Pressure & {$[\mathrm{Pa}]$} \\
\hline$P_{\text {genset }}$ & Generator power output & {$[\mathrm{kW}]$} \\
\hline$P_{\text {genset,rated }}$ & Nominal generator power output & {$[\mathrm{kW}]$} \\
\hline$Q$ & Heat & {$[\mathrm{W}]$} \\
\hline$\dot{Q}_{\text {genset }}$ & Thermal losses from genset & {$[\mathrm{kW}]$} \\
\hline$r$ & Diesel engine compression ratio & - \\
\hline$r_{\mathrm{c}}$ & Diesel engine cutoff ratio & - \\
\hline$U$ & Internal energy & {$[\mathrm{J}]$} \\
\hline V & Specific volume & {$\left[\mathrm{m}^{3} / \mathrm{kg}\right]$} \\
\hline$\dot{V}_{\text {fuel }}$ & Fuel consumption & {$[\mathrm{L} / \mathrm{h}]$} \\
\hline$W_{\mathrm{th}}$ & Theoretically useful work & {$[\mathrm{W}]$} \\
\hline$\gamma$ & Ratio of specific heats & - \\
\hline$\eta$ & Efficiency & [\%] \\
\hline$\eta_{\text {electrical }}$ & Electrical efficiency & {$[\%]$} \\
\hline$\eta_{\text {fuel }}$ & Fuel efficiency & {$[\mathrm{kWh} / \mathrm{L}]$} \\
\hline$\rho_{\text {fuel }}$ & Fuel density & {$\left[\mathrm{kg} / \mathrm{m}^{3}\right]$} \\
\hline \multicolumn{3}{|c|}{ Wind Speed and Turbines } \\
\hline$a$ & Acceleration & {$\left[\mathrm{m} / \mathrm{s}^{2}\right]$} \\
\hline$A$ & Fluid stream cross-sectional area & {$\left[\mathrm{m}^{2}\right]$} \\
\hline$b$ & Interference factor & - \\
\hline$C P$ & Coefficient of performance & - \\
\hline
\end{tabular}




\begin{tabular}{|c|c|c|}
\hline Symbol & Description & Units \\
\hline$F$ & Force & {$[\mathrm{N}]$} \\
\hline$m$ & Mass & {$[\mathrm{kg}]$} \\
\hline$\dot{m}$ & Mass flow rate & {$[\mathrm{kg} / \mathrm{s}]$} \\
\hline$P_{\text {corr }}$ & Power output corrected for air density & {$[\mathrm{kW}]$} \\
\hline$P_{\text {elev }}$ & Pressure at hub height & {$[\mathrm{Pa}]$} \\
\hline$P_{\text {rated }}$ & Wind turbine rated power output & {$[\mathrm{kW}]$} \\
\hline$R$ & Gas constant (dry air) & $287[\mathrm{~J} / \mathrm{kg}-\mathrm{K}]$ \\
\hline$T_{\mathrm{db}}$ & Dry-bulb temperature & {$\left[{ }^{\circ} \mathrm{C}\right]$} \\
\hline$T_{\text {elev }}$ & Temperature at hub height & {$[\mathrm{K}]$} \\
\hline$u$ & Fluid velocity & {$[\mathrm{m} / \mathrm{s}]$} \\
\hline$u_{\mathrm{h}}$ & Wind speed at heated anemometer & {$[\mathrm{m} / \mathrm{s}]$} \\
\hline$u_{\mathrm{un}}$ & Wind speed at unheated anemometer & {$[\mathrm{m} / \mathrm{s}]$} \\
\hline$u_{\text {un,std }}$ & Standard deviation of unheated measurement & {$[\mathrm{m} / \mathrm{s}]$} \\
\hline$z$ & Height of wind speed measurement & {$[\mathrm{m}]$} \\
\hline$\theta$ & Wind shear exponent & - \\
\hline$\rho$ & Fluid density & {$\left[\mathrm{kg} / \mathrm{m}^{3}\right]$} \\
\hline$\rho_{\text {elev }}$ & Air density at hub height & {$\left[\mathrm{kg} / \mathrm{m}^{3}\right]$} \\
\hline$\rho_{\text {std }}$ & Air density used to generate power curve & {$\left[\mathrm{kg} / \mathrm{m}^{3}\right]$} \\
\hline \multicolumn{3}{|c|}{ Solar Radiation and Photovoltaic Panels } \\
\hline$A$ & Module area & {$\left[\mathrm{m}^{2}\right]$} \\
\hline$A_{\mathrm{G}}$ & Anistropy index & - \\
\hline$e$ & Residual & {$\left[\mathrm{W} / \mathrm{m}^{2}\right]$} \\
\hline$E$ & Semiconductor bandgap & {$[\mathrm{eV}]$} \\
\hline$f$ & Horizon brightening modulating factor & - \\
\hline$G$ & Global solar radiation & {$\left[\mathrm{W} / \mathrm{m}^{2}\right]$} \\
\hline$G_{\mathrm{b}}$ & Beam solar radiation & {$\left[\mathrm{W} / \mathrm{m}^{2}\right]$} \\
\hline$G_{\mathrm{d}}$ & Sky diffuse solar radiation & {$\left[\mathrm{W} / \mathrm{m}^{2}\right]$} \\
\hline$G_{\mathrm{NOCT}}$ & Incident solar radiation at nominal operating cell temperature & {$\left[\mathrm{W} / \mathrm{m}^{2}\right]$} \\
\hline$G_{\mathrm{O}}$ & Extraterrestrial horizontal solar radiation & {$\left[\mathrm{W} / \mathrm{m}^{2}\right]$} \\
\hline$G_{\mathrm{r}}$ & Ground-reflected diffuse solar radiation & {$\left[\mathrm{W} / \mathrm{m}^{2}\right]$} \\
\hline$G_{\text {ref }}$ & PV cell reference insolation & {$\left[\mathrm{W} / \mathrm{m}^{2}\right]$} \\
\hline$G_{\mathrm{T}}$ & Total solar radiation on tilted surface & {$\left[\mathrm{W} / \mathrm{m}^{2}\right]$} \\
\hline$I_{\mathrm{D}}$ & Diode current & {$[\mathrm{A}]$} \\
\hline$I_{\mathrm{o}}$ & Diode reverse saturation current & {$[\mathrm{A}]$} \\
\hline$I_{\mathrm{o}, \mathrm{ref}}$ & Diode reverse saturation current at reference conditions & {$[\mathrm{A}]$} \\
\hline$I_{\mathrm{L}}$ & Photocurrent & {$[\mathrm{A}]$} \\
\hline
\end{tabular}




\begin{tabular}{|c|c|c|}
\hline Symbol & Description & Units \\
\hline$I_{\mathrm{L}, \mathrm{ref}}$ & Photocurrent at reference conditions & {$[\mathrm{A}]$} \\
\hline$I_{\mathrm{mp}, \mathrm{ref}}$ & Maximum power point module current at reference conditions & {$[\mathrm{A}]$} \\
\hline$I_{\mathrm{sc}, \mathrm{ref}}$ & Module short-circuit current at reference conditions & {$[\mathrm{A}]$} \\
\hline$K_{\mathrm{B}}$ & Boltzmann Constant & $1.3806488 \times 10^{-23}[\mathrm{~J} / \mathrm{K}]$ \\
\hline$K_{\mathrm{T}}$ & Clearness index & - \\
\hline$M_{\mathrm{PP}}$ & Maximum power point & - \\
\hline$N_{\mathrm{s}}$ & Number of cells in series & - \\
\hline$P_{\max }$ & Power at maximum power point & {$[\mathrm{W}]$} \\
\hline$q$ & Electron charge constant & $\begin{array}{l}\sim 1.602 \times 10^{-19} \\
\text { coulombs }\end{array}$ \\
\hline$R_{\mathrm{S}}$ & PV module series resistance & {$[\Omega]$} \\
\hline$R_{\mathrm{sh}}$ & Shunt resistance & {$[\Omega]$} \\
\hline$T_{\mathrm{a}, \mathrm{NOCT}}$ & Ambient temperature at nominal operating cell temperature & {$[\mathrm{K}]$} \\
\hline$T_{\mathrm{c}, \mathrm{NOCT}}$ & Module temperate at nominal operating cell temperature & {$[\mathrm{K}]$} \\
\hline$T_{\mathrm{c}, \mathrm{ref}}$ & PV cell reference temperature & {$[\mathrm{K}]$} \\
\hline$U_{\mathrm{L}}$ & Thermal loss coefficient & {$\left[\mathrm{W} / \mathrm{m}^{2}-\mathrm{K}\right]$} \\
\hline$V_{\mathrm{D}}$ & Diffusion voltage & {$[\mathrm{V}]$} \\
\hline$V_{\mathrm{OC}}$ & Open-circuit voltage & {$[\mathrm{V}]$} \\
\hline$V_{\mathrm{OC}, \mathrm{ref}}$ & Open-circuit voltage at reference conditions & {$[\mathrm{V}]$} \\
\hline$V_{\mathrm{mp}, \mathrm{ref}}$ & Maximum power point module voltage at reference conditions & {$[\mathrm{V}]$} \\
\hline$y$ & Expected value of solar radiation & {$\left[\mathrm{W} / \mathrm{m}^{2}\right]$} \\
\hline$\hat{y}$ & Predicted (modelled) value of solar radiation & {$\left[\mathrm{W} / \mathrm{m}^{2}\right]$} \\
\hline$\alpha$ & Solar elevation angle & {$\left[{ }^{\circ}\right]$} \\
\hline$\beta$ & Array slope & {$\left[{ }^{\circ}\right]$} \\
\hline$\gamma$ & Diode ideality factor & $1 \leq \gamma \leq 2$ \\
\hline$\gamma$ & PV array surface azimuth & {$\left[{ }^{\circ}\right]$} \\
\hline$\gamma_{S}$ & Solar azimuth & {$\left[{ }^{\circ}\right]$} \\
\hline$\delta$ & Solar declination & {$\left[{ }^{\circ}\right]$} \\
\hline$\eta_{\mathrm{c}}$ & Cell efficiency & [\%] \\
\hline$\theta$ & Angle of incidence of beam radiation & {$\left[{ }^{\circ}\right]$} \\
\hline$\theta_{\mathrm{d}, \mathrm{eff}}$ & Effective incident angle for diffuse solar radiation & {$\left[{ }^{\circ}\right]$} \\
\hline$\theta_{\mathrm{z}}$ & Solar zenith angle & {$\left[{ }^{\circ}\right]$} \\
\hline$\mu_{\mathrm{voc}}$ & $\begin{array}{l}\text { Temperature coefficient of open-circuit voltage at reference } \\
\text { conditions }\end{array}$ & {$[\mathrm{V} / \mathrm{K}]$} \\
\hline$\mu_{\mathrm{sc}}$ & $\begin{array}{l}\text { Temperature coefficient of short-circuit current at reference } \\
\text { conditions }\end{array}$ & {$[\mathrm{A} / \mathrm{K}]$} \\
\hline
\end{tabular}




\begin{tabular}{|c|c|c|}
\hline Symbol & Description & Units \\
\hline$\tau \alpha$ & Transmittance-absorptance produce at normal incidence & - \\
\hline$\varphi$ & Relative humidity & [\%] \\
\hline$\phi$ & Site latitude & {$\left[{ }^{\circ}\right]$} \\
\hline$\omega$ & Hour angle & {$\left[{ }^{\circ}\right]$} \\
\hline \multicolumn{3}{|c|}{ Power Balance } \\
\hline$E_{\text {battery,max }}$ & Maximum capacity of battery bank & {$[\mathrm{kWh}]$} \\
\hline fSOC & Fractional state of charge & {$[0,1]$} \\
\hline$P_{\text {battery }}$ & DC power into (+) or out of (-) the battery bank & {$[\mathrm{kW}]$} \\
\hline$P_{\text {diesel }}$ & AC power output from diesel generator or grid & {$[\mathrm{kW}]$} \\
\hline$P_{\text {load }}$ & CHARS electrical load (demand) & {$[\mathrm{kW}]$} \\
\hline$P_{\mathrm{PCS}}$ & Capacity of the power condition system & {$[\mathrm{kW}]$} \\
\hline$P_{\mathrm{PV}}$ & AC power output from PV array & {$[\mathrm{kW}]$} \\
\hline$P_{\text {renewable }}$ & Total renewable power generated & {$[\mathrm{kW}]$} \\
\hline$P_{\text {surplus }}$ & Surplus power generated in excess of load & {$[\mathrm{kW}]$} \\
\hline$P_{\text {unmet }}$ & Load not met by generators or stored power & {$[\mathrm{kW}]$} \\
\hline$P_{\mathrm{WT}}$ & AC power output from wind turbine(s) & {$[\mathrm{kW}]$} \\
\hline SOC & State-of-charge & {$[\mathrm{kWh}]$} \\
\hline$\Delta t$ & Timestep & e.g., 1 hour \\
\hline$\sigma$ & Self-discharge of battery bank & [kWh/hour] \\
\hline$\eta_{\text {battery }}$ & Efficiency of battery bidirectional inverter & {$[\%]$} \\
\hline$\eta_{\mathrm{PV}}$ & Efficiency of DC-AC PV conversion due to losses & {$[\%]$} \\
\hline$\eta_{\mathrm{WT}}$ & Efficiency of wind turbine due to losses & [\%] \\
\hline \multicolumn{3}{|l|}{ Financial } \\
\hline$C_{\mathrm{b}, \mathrm{C}}$ & Battery capital cost & {$[\$]$} \\
\hline$C_{\mathrm{b}, \mathrm{O} \& \mathrm{M}}$ & Battery O\&M cost & {$[\$]$} \\
\hline$C_{\mathrm{b}, \text { replace }}$ & Battery replacement cost & {$[\$]$} \\
\hline$C_{\mathrm{C}}$ & Total capital cost & {$[\$]$} \\
\hline$C_{\mathrm{d}}$ & Grid-purchased diesel energy cost & {$[\$]$} \\
\hline$C_{\mathrm{d}, \mathrm{C}}$ & Diesel genset capital cost & {$[\$]$} \\
\hline$C_{\mathrm{d}, \mathrm{O} \& \mathrm{Mf}}$ & Fixed non-fuel O\&M diesel cost & {$[\$ / \mathrm{kW}]$} \\
\hline$C_{\mathrm{d}, \mathrm{O} \& \mathrm{Mv}}$ & Variable non-fuel diesel O\&M cost & [\$/kW-hr runtime] \\
\hline$C_{\mathrm{F}}$ & Fuel cost & {$[\$ / L]$} \\
\hline$C_{\mathrm{p}, \mathrm{C}}$ & Balance of project capital costs & {$[\$]$} \\
\hline$C_{\mathrm{PCS}, \mathrm{C}}$ & Power conditioning capital cost & {$[\$]$} \\
\hline$C_{\mathrm{PCS}, \mathrm{O} \& \mathrm{M}}$ & Power conditioning system cost & {$[\$]$} \\
\hline$C_{\mathrm{s}}$ & Surplus power generated & {$[\mathrm{kWh}]$} \\
\hline
\end{tabular}




\begin{tabular}{|c|c|c|}
\hline Symbol & Description & Units \\
\hline$C_{\mathrm{PV}, \mathrm{C}}$ & Solar PV capital cost & {$[\$]$} \\
\hline$C_{\mathrm{PV}, \mathrm{O} \& \mathrm{M}}$ & Solar PV O\&M cost & {$[\$]$} \\
\hline$C_{\mathrm{t}}$ & Net cashflow at time period $t$ & {$[\$]$} \\
\hline$C_{\mathrm{W}, \mathrm{C}}$ & Wind turbine capital cost & {$[\$ / \mathrm{kW}]$} \\
\hline$C_{\mathrm{W}, \mathrm{O} \& \mathrm{M}}$ & Wind turbine O\&M cost & {$[\%]$} \\
\hline$d$ & Periodic (e.g., annual) cost escalation factor & {$[\mathrm{kWh}]$} \\
\hline$D$ & Grid-purchased diesel energy & {$[\mathrm{L}]$} \\
\hline$F$ & Diesel fuel consumed & {$[\%]$} \\
\hline$G$ & Greenhouse gas emission cost & {$[\$ / \mathrm{kWh}]$} \\
\hline$g$ & Growth rate of consumption & {$[\mathrm{years}]$} \\
\hline$S$ & Value of surplus power & {$[\%]$} \\
\hline$T$ & System life span & {$[\%]$} \\
\hline$r$ & Discount rate & - \\
\hline$\delta$ & Time discount rate & {$[\%]$} \\
\hline$\eta$ & Marginal utility of consumption & \\
\hline$\rho$ & Social discount rate & \\
\hline
\end{tabular}




\section{Introduction}

This thesis presents the results of a simulation and optimization exercise for powering the Canadian High Arctic Research Station (CHARS) with renewable wind and solar energy. Construction of CHARS in Cambridge Bay, Nunavut concluded in spring 2018 and the station is now in operation.

Aside from a small (18 $\mathrm{kW})$ building-integrated solar photovoltaic (PV) array for testing and demonstration purposes, the station is entirely powered by the community diesel-electric grid and from diesel-fueled boilers for heat. While there is currently no firm plan for additional renewable power at CHARS, the government and research community has expressed interest in using CHARS as a testbed for sustainable energy systems at various stages of maturity. This thesis explores the potential for proven renewable energy technologies to meet the energy demand of CHARS at lower cost than a diesel-only configuration.

Advantages of renewable energy over diesel include reduction or mitigation of (Baring-Gould and Dabo, 2009):

- Greenhouse gas emissions that contribute to anthropogenic climate change;

- Local environmental issues such as poor air quality contributing to cancer, asthma, and other health impacts, fuel spills, and noise pollution;

- Spending on fuel and the impacts of fuel price volatility; and,

- Fuel storage and transportation challenges.

For this thesis, computer simulation models of wind turbines and a solar photovoltaic (PV) array were created in the simulation program TRNSYS, using measured weather data from 2015 . The TRNSYS models were coupled with an optimization program, GenOpt, to optimize the system configuration with respect to net present cost (NPC) through an implementation of the particle swarm algorithm.

The modelling results suggest that renewable energy can affordably supply a portion of the station's electricity needs, about $65 \%$. However, as the renewable portion increases beyond that point, so does the total per-unit energy cost. This is because of the need to match supply with demand. A diesel generator is 
dispatchable, meaning it can adjust its output to match changes in demand more or less instantaneously. Intermittent sources like wind and solar cannot be controlled as easily. Without electrical storage or secondary loads, renewable power in excess of demand must be spilled, while backup generators must supply any shortfall if the load is to be met at all times.

Typically, capital costs of renewable energy and electrical storage are high compared to fossil-fuel alternatives, which have a higher operational cost due to fuel consumption and higher maintenance demands. The optimal balance of fossil fuel generators, renewable generators, and electrical storage minimizes life-cycle costs, reduces greenhouse gas emissions and other environmental impacts, and meets reliability and firm power dispatch requirements.

A hybrid energy system has more than one type of generator and/or electrical storage (Luna-Rubio et al., 2012). The penetration rate is the metric that expresses the amount of renewable energy in a hybrid system, either as an average over the period of interest (e.g., a year) or as the maximum instantaneous renewable power fraction (Freris and Infield, 2008):

$$
\begin{gathered}
\text { Average penetration }=\frac{\text { Renewable energy generated }(\mathrm{kWh})}{\text { Total energy demand }(\mathrm{kWh})} \\
\text { Instantaneous penetration }=\frac{\text { Renewable power generated }(\mathrm{kW})}{\text { Total power demand }(\mathrm{kW})}
\end{gathered}
$$

There is no standard as to what constitutes a high- or low-penetration hybrid system, but a useful classification scheme, shown in Table 1, was presented by Baring-Gould and Dabo (2009). This thesis is concerned with investigation of high-penetration systems. 
Table 1: A useful definition of the penetration rate

\begin{tabular}{|c|c|c|c|}
\hline \multirow{2}{*}{ Class } & \multicolumn{2}{|c|}{ Percent Renewable } & \multirow{2}{*}{ Characteristics } \\
\hline & Instantaneous & Annual & \\
\hline Low & $<50 \%$ & $<20 \%$ & $\begin{array}{ll}\text { - } & \text { Diesel gensets always on } \\
\text { - } & \text { No supervisory control system } \\
\text { - } & \text { All renewable energy serves primary load } \\
\end{array}$ \\
\hline Medium & $50 \%-100 \%$ & $20 \%-50 \%$ & $\begin{array}{ll}\text { - } & \text { Diesel gensets always on } \\
\text { - } & \text { Relatively simple control system } \\
\text { - } & \text { Renewable energy may serve secondary load } \\
\end{array}$ \\
\hline High & $100-400 \%$ & $50 \%-150 \%$ & $\begin{array}{l}\text { - } \text { Diesel gensets may be shut down for a period } \\
\text { - } \quad \text { Sophisticated control system } \\
\text { - } \quad \text { Auxiliary components regulate voltage and frequency }\end{array}$ \\
\hline
\end{tabular}

\subsection{CHARS Project Context}

In 2007, the Government of Canada announced plans for a new Arctic research facility, intended to be “.. a world-class Arctic research station... on the cutting edge of Arctic issues..." (Government of Canada, 2011b). Following a feasibility stage that included public consultation, policy analysis, project scoping, and determination of the host community, a design firm was retained through a competitive request-for-proposal process. Construction began in summer 2014 and concluded in spring 2018.

CHARS is an interdisciplinary facility of approximately $8000 \mathrm{~m}^{2}$ and features general analytical laboratories, technology development spaces, a high-powered computer lab, and offices and social science areas, as well as more specialized spaces including an animal necropsy laboratory, cold rooms, growth chambers and a genomics lab. The station also has public areas, such as a multi-use space for public gatherings and conferences, a knowledge sharing centre that forms the architectural focus of the Main Research Building (MRB), a commercial kitchen/cafeteria, and a business incubation space.

The campus comprises four buildings: the MRB contains most of the offices and research spaces, the Field and Maintenance Building (FMB) houses maintenance, storage, and workshop facilities, and two triplex housing units provide lodging for visiting researchers, such as graduate students, international scientists, staff from other government departments, and other users. The intent is that significant use of the campus by such visitors will augment the in-house research program. 
A major driver for development of the CHARS initiative was 'community integration', where community members from Cambridge Bay and across the north will make use of the infrastructure. Community integration efforts were also undertaken during the construction phase to mitigate negative impacts on infrastructure services.

An aerial view of the CHARS campus is shown in Figure 1 (@ Government of Canada, 2017). The MRB is in the foreground, with the triplexes to the left and FMB to the right; the construction camp with sea container storage is in the background.

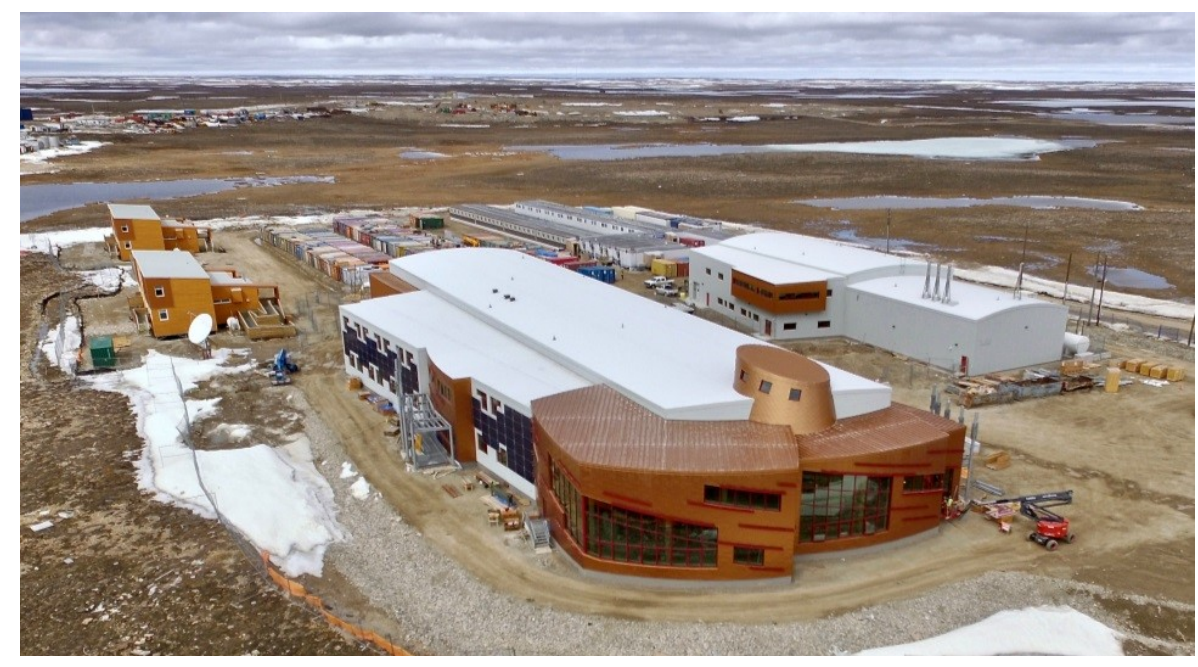

Figure 1: Aerial view of the CHARS campus

\subsection{Community Context}

CHARS is a major facility for a community like Cambridge Bay, which has a population of approximately 1,800. In recognition of the potential strain on local infrastructure services, the Government of Canada made targeted investments during construction (Brown et al., 2018).

One investment was to the local water treatment plant, which was already being upgraded by the Government of Nunavut. The CHARS construction investment supported an upgrade from the planned low-pressure system to a preferred high-pressure system. It also supported extension of piped water services to the CHARS campus, eliminating the need for costly on-site water storage for domestic water 
and fire protection purposes (most buildings in Cambridge Bay and across Nunavut rely on trucked water).

Another investment was made to the territorial power corporation, Qulliq Energy Corporation (QEC), to support upgrades to generation and distribution capacity. As CHARS is a significant electrical load on the community, QEC installed a modular (containerized) 1.1 MW generator to augment the existing generators, for a total capacity of about 4.5 MW. The new generator provides firm power to CHARS and to the growing community.

The upgrades made by QEC have implications for renewable energy planning at CHARS, since the power corporation relies on a regulated rate of return on assets. Should CHARS implement a stand-alone power generation system, it would reduce the rate of return on the existing generation assets in Cambridge Bay, which were planned with the assumption of CHARS as a major consumer of electricity.

Furthermore, it cannot be assumed that surplus renewable energy can simply be sold to the grid, as is common in southern regions with feed-in tariffs, net-metering, and other policy initiatives intended to advance the installation of renewable energy. A high-penetration renewable energy project planned at CHARS or elsewhere in Nunavut therefore needs to engage QEC as a major stakeholder.

\subsection{Sustainable Design of the CHARS Campus}

Sustainability measures for the design, construction and operation of CHARS were discussed by the author in Brown et al. (2018) and are summarized below.

CHARS was designed using common sustainable building and laboratory design frameworks (LEED Canada 2010; I2SL 2010). To quantify the impact of energy-saving measures, the proposed design was compared to a reference building designed to minimum energy standards. Simulation results from the CHARS design consultant indicate estimated reductions in energy use and cost of approximately $70 \%$ and $60 \%$, respectively, compared to the reference building. Key factors contributing to this reduction and the annual energy consumption and cost are summarized in Table 2 and Table 3. Annual energy costs are shown in Figure 2. 
Table 2: Comparison of reference and design buildings

\begin{tabular}{|l|c|c|}
\hline & Reference Buildings & Design Buildings \\
\hline Thermal transmittance (typical) & & \\
\hline Wall & $0.270 \mathrm{~W} / \mathrm{m}^{2 \circ} \mathrm{C}$ & $0.191 \mathrm{~W} / \mathrm{m}^{2 \circ} \mathrm{C}$ \\
\hline Roof & $0.200 \mathrm{~W} / \mathrm{m}^{2 \circ} \mathrm{C}$ & $0.159 \mathrm{~W} / \mathrm{m}^{2 \circ} \mathrm{C}$ \\
\hline Foundation & $0.323 \mathrm{~W} / \mathrm{m}^{2 \circ} \mathrm{C}$ & $0.265 \mathrm{~W} / \mathrm{m}^{2 \circ} \mathrm{C}$ \\
\hline Window & $2.100 \mathrm{~W} / \mathrm{m}^{2 \circ} \mathrm{C}$ & $1.761 \mathrm{~W} / \mathrm{m}^{2 \circ} \mathrm{C}$ \\
\hline Boiler efficiency & $80 \%$ & $88 \%$ \\
\hline Heat recovery efficiency (sensible) & None & $85 \%$ \\
\hline Heat recovery efficiency (latent) & None & $65 \%$ \\
\hline Supply/return fan efficiency & $55 \% / 30 \%$ & $62 \% / 55 \%$ \\
\hline Pump efficiency & $60 \%$ constant speed & $90 \%$ variable speed \\
\hline Humidification system & Electric steam & Adiabatic \\
\hline
\end{tabular}

Table 3: Comparison of design and reference buildings annual energy consumption and cost

\begin{tabular}{|l|c|c|}
\hline & Reference Buildings & Design Buildings \\
\hline Annual Energy & & \\
\hline Building Heating Oil & $12,100 \mathrm{GJ}$ & $3,300 \mathrm{GJ}$ \\
\hline Building Electricity & $20,600 \mathrm{GJ}$ & $5,700 \mathrm{GJ}$ \\
\hline Total Annual Energy & $\mathbf{3 2 , 7 0 0 \mathrm { GJ }}$ & $\mathbf{9 , 0 0 0} \mathrm{GJ}$ \\
\hline Annual Cost & & \\
\hline Building Heating Oil & $\$ 639,000$ & $\$ 202,000$ \\
\hline Building Electricity & $\$ 2,212,000$ & $\$ 923,000$ \\
\hline Total Annual Cost & $\$ 2,851,000$ & $\$ 1,125,000$ \\
\hline
\end{tabular}

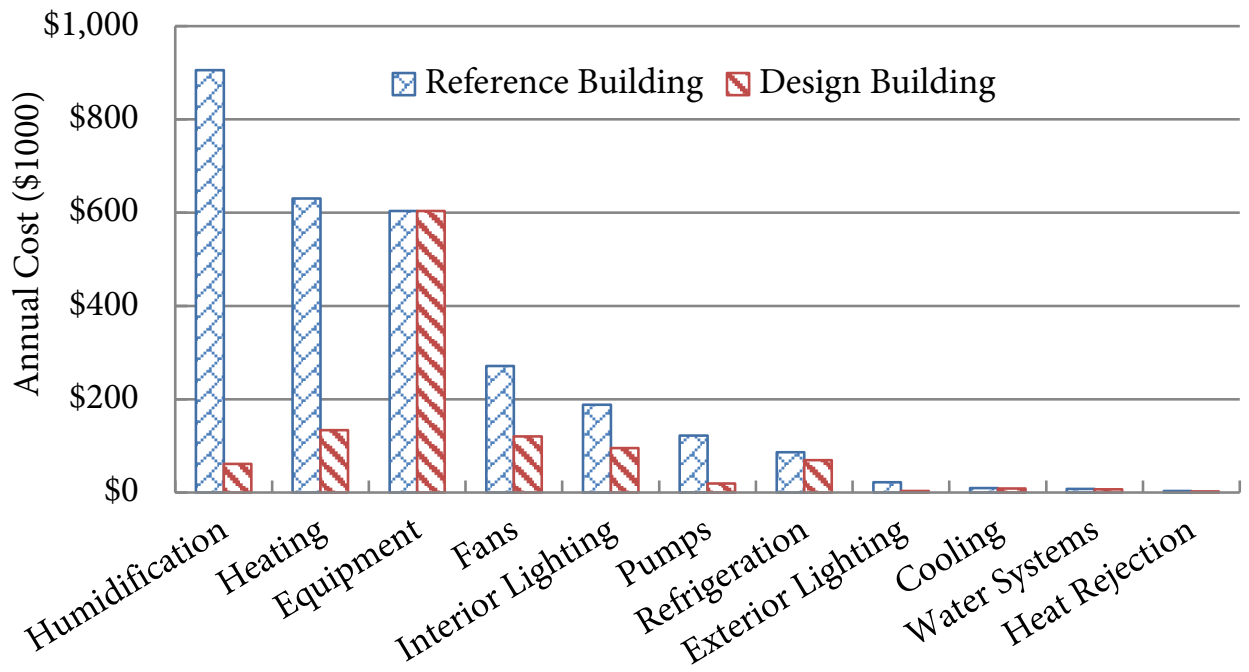

Figure 2: Comparison of reference and design building annual energy cost 
The building design framework requires that the equipment load be equal for both the design and reference building, since the emphasis is on building design and not the activities that are conducted within. The design consultant used typical building equipment densities for office and laboratory spaces. However, the equipment energy consumption is dependent on the occupant load and the type of research conducted at CHARS. If the program evolves to emphasize technology development, the energy profile could look very different than a program more focused on field research and social science.

For this thesis, the simulated building loads were used as the station was not yet in operation and measured data were not available. As noted in Brown et al. (2018), a comprehensive energy monitoring system was installed at CHARS. Once the monitoring system has collected sufficient operational data, the building simulation model and the results of this thesis can be updated to more realistically represent actual energy demands. More information is provided in Section 4.

\subsection{Research Objectives}

The objective of this thesis was to demonstrate how simulation and optimization techniques can be used to find optimal hybrid energy system configurations in a diesel-electric grid. While these techniques were applied to the problem of meeting the CHARS electrical demand, the approach could be adapted for use at other facilities or extended to community-wide renewable energy planning.

Specifically, two objectives were explored:

- Meeting the electricity needs of the station in the most cost-effective manner; and,

- Maximizing the renewable portion of the electricity supply.

These objectives can be in conflict, since as the penetration rate increases, so does the difficulty of integrating surplus renewable power. Effective management of the surplus is critical for economic system operation. 


\subsection{Research Contribution}

In this thesis, five system configurations were investigated:

1. A grid-connected hybrid system modelled using hourly timesteps and incorporating $100-\mathrm{kW}$, Arctic-rated wind turbines, crystalline solar PV, and lithium-ion battery storage, where any renewable power shortfall was supplied from the local diesel grid;

2. A stand-alone hybrid system identical to Configuration 1, except that power from the community power plant was replaced with an on-site diesel generator;

3. A low-maintenance hybrid system identical to Configuration 1, except without wind turbines; the intent was to explore the potential for lower-maintenance PV systems;

4. A highest-renewable system identical to Configuration 1 except with a large penalty cost applied to fossil-fuel power; and,

5. A grid-connected system identical to Configuration 1 but modelled with 10-min instead of hourly timesteps; the intent was to explore the impact of temporal resolution on the solution.

This work is aligned with the station's inaugural five-year science and technology (S\&T) research program, which includes renewable energy as a priority research area (Government of Canada, 2013):

“[CHARS] will support long-term capital planning for industry and governments by mapping renewable energy sources at scales appropriate to investment. It will accelerate the uptake of existing technologies by providing a platform and funding for testing and refining renewable energy technologies used south of 60 degrees to work under Northern conditions. It will address the fundamental need for safety and security through consistent and reliable power sources by fostering research into renewable/diesel integration systems and storage from variable renewable sources such as wind."

While optimization techniques have been used to plan high-penetration hybrid renewable energy systems in other regions of the world, published literature contains few applications in Arctic regions and almost none in northern Canada (some exceptions are noted in Section 2.3). The few optimization studies in the 
literature have tended to use brute-force techniques, an approach that limits the size of the design space. Recognizing this gap, this thesis applies existing techniques called metaheuristics that can quickly search a large design space to find the optimal or near-optimal system design. The approach is specifically geared towards diesel-electric communities in Canada's north and in other Arctic locations.

There are many diesel-electric powered communities in the Arctic and nearby regions - approximately 260 across Canada (Government of Canada, 2011a), 70 in Greenland (Nukissiorfiit, 2014), and 180 in Alaska (Avadhanula, 2015). In addition, remote research stations, resource extraction sites such as mines and fisheries, military bases, telecommunications and weather stations, and other off-grid applications in the Arctic frequently use diesel gensets to meet electricity needs. The installed generation capacity for permanent habitations is typically on the order of hundreds of $\mathrm{kW}$ to tens of MW.

More broadly, the approaches demonstrated in this thesis have applications world-wide. An estimated 1.2 billion people do not have access to electricity today, most of whom live in poverty and who are mainly located in rural regions. Electrification of these communities is typically achieved via extension of the

central grid, which usually implies connection to fossil-fuel generators. Wind and solar energy could potentially meet the needs of these communities at lower cost and with fewer impacts to the environment (Zomers, 2014).

\subsection{Thesis Outline}

The structure of this thesis is as follows:

- Chapter 2 presents a literature review on energy simulation approaches, hybrid system optimization, and wind and solar energy in Arctic regions;

- Chapter 3 provides background on the physics of the relevant energy conversion devices;

- Chapter 4 describes the load (demand) and resource (weather) data used in this study;

- Chapters 5 outlines the TRNSYS modelling approach;

- Chapter 6 explains the optimization approach; 
- Chapter 7 details the financial model used in the optimization;

- Chapter 8 presents and discusses the optimization results for each scenario;

- Chapter 9 summarizes the policy environment in Nunavut and identifies some policy considerations for implementation of renewable energy; and,

- Chapter 10 concludes this thesis and provides recommendations for future work. 


\section{Literature Review}

This section introduces simulation and optimization of hybrid renewable energy systems and summarizes historical and contemporary uses of wind and solar PV energy in the Arctic.

\subsection{Simulation of Hybrid Renewable Energy Systems}

Computer simulation is used to determine the performance of energy generators over a specified time period, typically a year. Energy simulations can be classified as either time series (deterministic), probabilistic (stochastic), or hybrid (Hoevenaars, 2012; Bailey, 2012). Time series energy models chronologically calculate power output at each timestep based on weather data and system parameters; steady-state behavior is typically assumed within the timestep. Time series analyses are intuitive, account for seasonal and diurnal variations, and allow for the calculation of the state-of-charge (SOC) of any energy storage components. However, they require significant input data and have long computation times compared to probabilistic methods. For 'one-off simulations, computation time is rarely an issue with modern computers, but can become prohibitive when attempting to optimize a system with many possible configurations or when simulating in near real-time.

Probabilistic methods use statistical techniques to analyze whether system reliability metrics are met. While they are less computationally intensive and do not require long-term datasets, they are less capable of modelling seasonal and diurnal variations and typically do not allow the SOC to be tracked directly (Hoevenaars, 2012). Phrased differently, probabilistic approaches "[do] not provide information on the temporal behavior of the power system and therefore [do] not give any insight into system dynamics at a specific point in time”(Gassner, 2010).

There are many software tools available for hybrid renewable energy simulation, with varying degrees of modelling complexity. Comprehensive reviews of software tools include Connolly et al. (2010) and Sinha and Chandel (2014). Only a few tools are capable of simulation and optimization of a $100 \%$ renewable energy system, including H2RES (H2RES, 2009), which is not publicly available, HOMER (HOMER Energy LLC, 2018), and TRNSYS (Klein et al., 2014). The latter two are commonly featured in the 
literature. TRNSYS has no built-in optimization function but can be coupled with an external engine, such as MATLAB (Mathworks, 2018) or GenOpt (LBNL, 2016). For this thesis, TRNSYS coupled to GenOpt was used; more details are provided in Section 5.

\subsection{Optimization}

Computer energy simulation is the process by which the performance of a system is evaluated or estimated. Optimization is concerned with finding the best system configuration defined by an objective function. The objective function $f(x)$, also called the cost or fitness function, is a function of the design vector $x$, which is composed of $p$ design or decision variables (Wetter, 2011):

$$
x=\left(x^{1}, x^{2}, \ldots, x^{\mathrm{p}}\right)
$$

The objective function is a quantitative measure of the 'goodness' or 'fitness' of the design. The values of the design variables are adjusted through a specified process to find the minimum (or, equivalently, maximum) of the objective function. This minimum may be local, in which case there exists another solution with a lower value of $f(x)$, or it may be global. An example is shown in Figure 3; optimization techniques are typically generalizable to $p$-dimensional space and the $\mathrm{x}$-axis in Figure 3 represents a vector rather than a single variable.

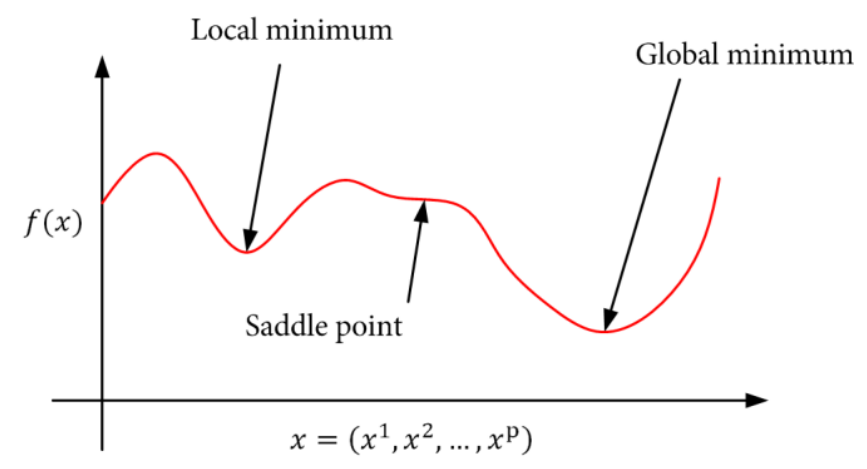

Figure 3: Local and global minima of an arbitrary objective function

The objective function may be subject to $m$ inequality constraints, which constrain the design space to what are considered feasible solutions:

$$
g_{\mathrm{i}}(x) \leq 0
$$


for $i=1,2, \ldots, m$ and $n$ equality constraints:

$$
h_{\mathrm{j}}(x)=0
$$

for $j=1,2, \ldots, n$.

There are many different types of optimization algorithms and no single algorithm is appropriate for solving all problems. Sörensen (2012) divided algorithms into two types: exact algorithms, which are guaranteed to find the optimal solution in a finite amount of time, and heuristics, which cannot guarantee finding a global optimum (i.e., it may become 'stuck' in a local optima as shown in Figure 3 and not minimize the objective function as fully as possible) but generally require far less computational effort. One example of an exact algorithm is a brute-force or enumerative approach that involves testing all possible combinations of the design variables. While this guarantees that a global minimum is found, the time required can be prohibitive. When order does not matter, the number of possible iterations $N$ is:

$$
N=\prod_{i=1}^{p} n_{\mathrm{i}}
$$

where $n_{\mathrm{i}}$ is the number of possible values for design variable $i$. If $n$ is constant for all $i$, this is equivalent to:

$$
N=n^{\mathrm{p}}
$$

This can quickly become intractable. For example, when optimizing a hybrid renewable energy system including hydrogen storage, Kyriakarakos et al. (2011) noted approximately 70,000,000 realistic system configurations. At a rate of one simulation per second, evaluating every possible configuration would take 2.2 years. Improved computational speed is helpful but is not in itself necessarily a solution, since for an arbitrary increase in computing power an optimization problem of arbitrary greater complexity can be defined.

Heuristic algorithms have been developed that can find optimal or near-optimal solutions with significantly lower computational requirements. The term 'metaheuristic' has been used to refer to both “general problem-independent algorithmic framework [s]” and "problem-specific implementation[s] of ... heuristic optimization algorithm[sP’, a somewhat contradictory definition (Sörensen, 2012). Luke (2015) 
refers to metaheuristics as the primary subfield of stochastic optimization, a class of optimization algorithms that use an element of randomness to find optimal solutions.

There are many metaheuristics, often based on analogy to physical phenomena, although Sörensen (2012) cautioned against over-use of analogy and metaphor. Erdinc and Uzunoglu (2012) noted several methods commonly used for the design of hybrid renewable energy systems, including simulated annealing, genetic algorithms, and particle swarm optimization. The basic approach of each of these three techniques is outlined in the following.

Simulated annealing (Kirkpatrick et al., 1983) drew inspiration from annealing of metals, where molten metals are slowly cooled at specific rates in order to obtain a low-defect crystal structure and the resultant desired mechanical properties. In statistical mechanics, the probability of a collection of atoms (such as that of a cooling metal) being in a certain configuration (state) is weighted by the Boltzmann probability factor:

$$
P=e^{-E / K_{\mathrm{B}} T}
$$

where,

$$
\begin{aligned}
& P=\text { probability distribution; } \\
& E=\text { the energy of the system }[\mathrm{J}] \text { (analogous to the objective function); } \\
& K_{\mathrm{B}}=\text { Boltzmann Constant }\left[1.3806488 \times 10^{-23} \mathrm{~J} / \mathrm{K}\right] \text {; and, } \\
& T=\text { temperature }[\mathrm{K}] \text {, which typically starts high and decreases throughout the optimization } \\
& \text { process. }
\end{aligned}
$$

Note that the units of measurement are metaphorical, and the objective function can have any units, e.g., cost, greenhouse gas emissions, etc.

Simulated annealing uses an iterative approach. At each iteration, the design vector is modified and the resulting objective function calculated. The new candidate solution for the design vector will be accepted if $\Delta E<0$, i.e., the objective function value is lower (better) than the previous candidate solution. 
Crucially, there is also a probability that a worse solution will be accepted, allowing the algorithm to 'escape' from a local optimum (Askarzadeh et al., 2016):

$$
\text { if } \Delta E>0, \quad x(t+1)= \begin{cases}x_{\mathrm{p}} & \text { if } e^{-\Delta E} / T>r \\ x(t) & \text { otherwise }\end{cases}
$$

where,

$$
\begin{aligned}
& x(t) \text { and } x(t+1)=\text { solutions at time } t \text { and } t+1 \text { respectively; } \\
& x_{\mathrm{p}}=\text { random solution with a worse objective function value near } x(t) ; \text { and, } \\
& r=\text { uniform random number } r \in[0,1]
\end{aligned}
$$

The probability of accepting a worse solution is higher at high values of $T$, since $e^{-\Delta E / T} \rightarrow 1$ as $T \rightarrow \infty$. The 'cooling schedule' is at the discretion of the user; as an example, Askarzadeh et al. used (shown in Figure 4):

$$
T(t)=\frac{T_{0}}{\ln (1+t)}, \quad t>0
$$

where $T_{0}$ is the initial temperature.

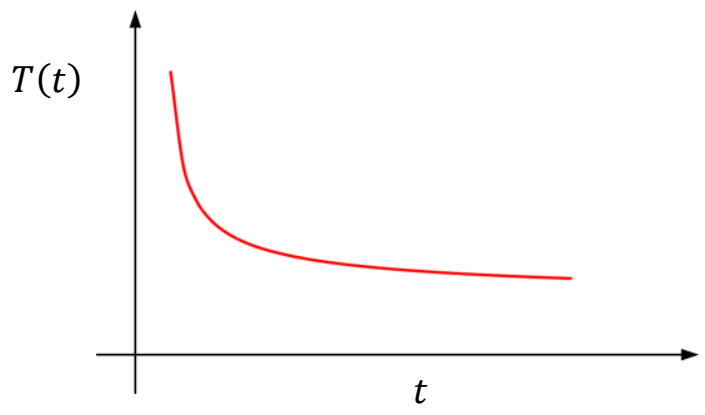

Figure 4: An example of a simulated annealing cooling schedule

The initial formulation of simulated annealing involved one function evaluation at a time, though Askarzadeh et al. (2016) expanded the concept to include multiple concurrent function evaluations. Utilizing a population of solutions is also one of the fundamental principles behind genetic algorithms.

Genetic algorithms are an evolutionary process that was introduced in a seminal text by Holland (1975). An initially-randomized population of solutions, called individuals or chromosomes, is encoded using a 
binary representation of the design vector $x=\left(x^{1}, x^{2}, \ldots, x^{\mathrm{p}}\right)$. At each iteration, called a generation, some percentage of low-fitness (worse objective function value) individuals are eliminated according to a selection rule. This can be done stochastically, like simulated annealing, to preserve some less-fit individuals for the next generation. Then, 'child' solutions will be created according to a crossover rule that exchanges bits between two 'parent' solutions (Eberhart et al., 2001).

In addition, at each generation a mutation operator can randomly alter the population (surviving parents and children) by stochastically flipping a bit, helping to prevent getting stuck in a local optimum. The mutation rate is typically low however; it is cross-over that provides the greatest benefit and which is at the core of genetic algorithms (Eberhart et al., 2001). The process is shown in a simple schematic in Figure 5 (original figure based on Holland, 1975), using shaded and unshaded blocks in place of binary code.

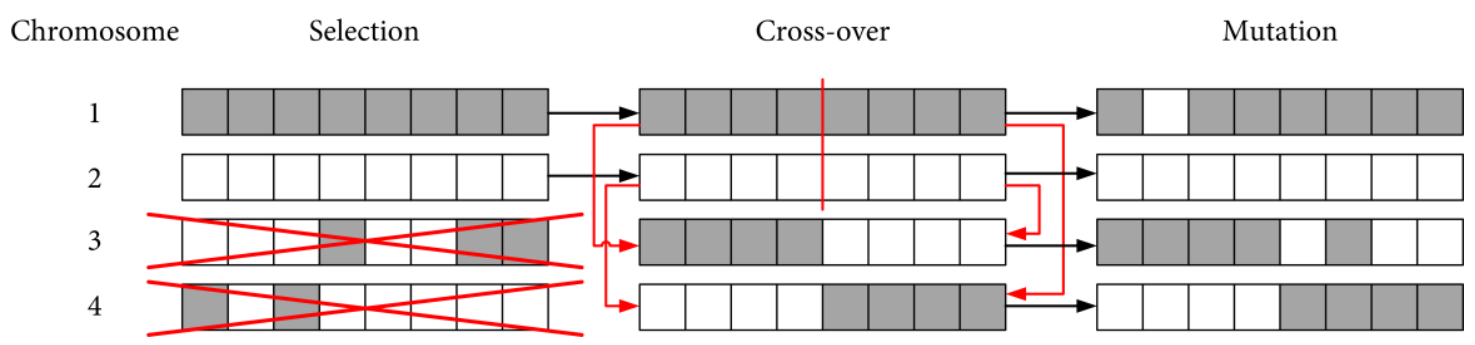

Figure 5: Selection, cross-over, and mutation in the genetic algorithm

Particle swarm optimization is a relatively simple evolutionary-like algorithm with a basis in simulations of flocking behavior of birds (Kennedy and Eberhart, 1995). Like genetic algorithms, particle swarm optimizations feature a population of candidate solutions (particles) that iterate; by contrast, the population is fixed and there is no selection process that discards less fit individuals (Luke, 2015).

Instead, each particle updates its solution, also called its position, from one generation to the next. The new position is the sum of the particle's velocity and its own best solution and the best solution of its neighbours across all generations. This 'memory effect' is the primary feature of the particle swarm optimization.

The update equation from one generation to the next is (Wetter, 2011):

$$
p_{\mathrm{i}}(k+1)=p_{\mathrm{i}}(k)+v_{\mathrm{i}}(k+1)
$$


where,

$$
\begin{aligned}
& k=\text { generation number; } \\
& p_{\mathrm{i}}(k)=i^{\text {th }} \text { particle of the } k^{\text {th }} \text { generation; and, } \\
& v_{\mathrm{i}}(k)=i^{t h} \text { particle's velocity at generation } k .
\end{aligned}
$$

The velocity term is:

$$
v_{\mathrm{i}}(k+1)=v_{\mathrm{i}}(k)+c_{1} r_{1}(k)\left(\pi_{\mathrm{l}, \mathrm{i}}(k)-p_{\mathrm{i}}(k)\right)+c_{2} r_{2}(k)\left(\pi_{\mathrm{g}, \mathrm{i}}(k)-p_{\mathrm{i}}(k)\right)
$$

where,

$c_{1}$ and $c_{2}=$ cognitive and social acceleration constants, respectively;

$r_{1}(k)$ and $r_{2}(k)=$ uniformly distributed random numbers $r_{1}, r_{2} \in[0,1]$; and,

$\pi_{\mathrm{l}, \mathrm{i}}(k)$ and $\pi_{\mathrm{g}, \mathrm{i}}(k)=$ the position (solution) of the particle's own best solution and the best solution of nearby particles, respectively, across all generations.

This 'memory effect' or 'experience' is the primary feature of particles swarm optimization. By adjusting the constants $c_{1}$ and $c_{2}$, the algorithm can be weighted more or less towards its own experience or the experience of its neighbours.

Figure 6 shows Eq. (3) schematically for an optimization with two design variables; of course, the procedure is generalizable across $\mathrm{p}$-dimensional space for $x=\left(x^{1}, x^{2}, \ldots, x^{\mathrm{p}}\right)$.

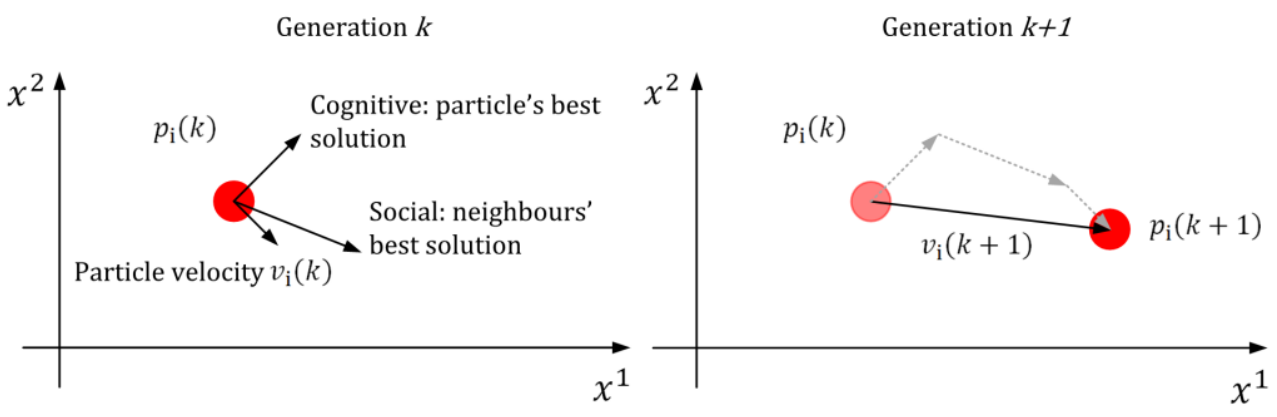

Figure 6: Movement of a particle in a particle swarm optimization across two-dimensional space 
The previous examples emphasized single-objective optimization. Multi-objective optimization allows for the evaluation of multiple objective functions. For example, Dufó-Lopez and Bernal-Agustín (2008) simultaneously minimized cost, pollutant emissions, and unmet load by generating a Pareto front of potential solutions. However, multi-objective optimization is more complex, and not all optimization tools have the capability.

\subsection{Wind and Solar Energy in Diesel-Electric Grids in the Arctic}

Wind and solar energy have been used for decades in the Arctic but do not contribute a significant share of the energy mix. Figure 7 shows electricity production across Arctic jurisdictions. Norway and Iceland are primarily powered by renewable energy (hydro and geothermal electricity), while fossil fuels such as coal, diesel, and natural gas provide a significant or majority portion of electricity in Alaska, northern Canada, Greenland, the Faroe Islands, Finland, and northern Russia.

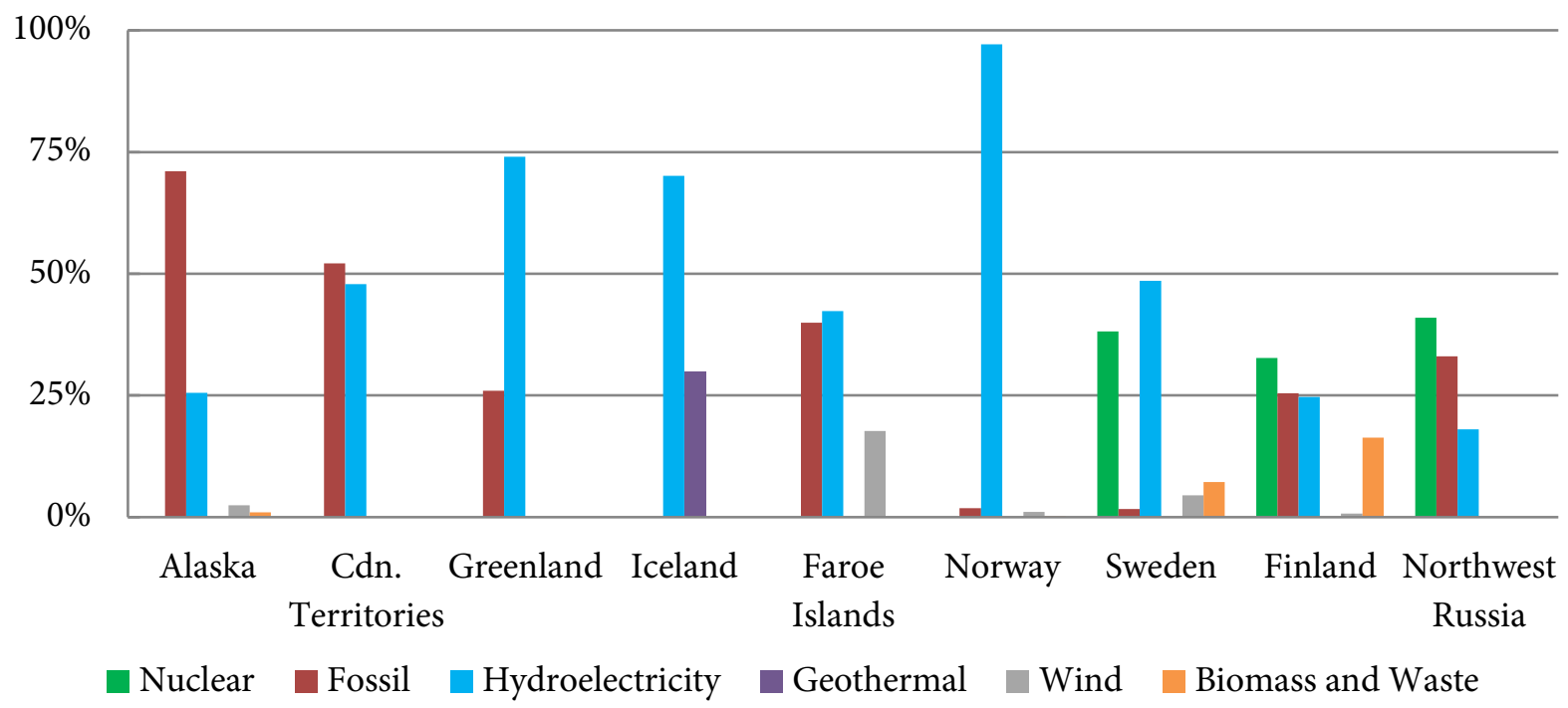

Figure 7: Electricity production by source in a variety of Arctic jurisdictions

(Figure sources: Canada - Statistics Canada, 2014; Alaska, Iceland, Norway, Sweden, Finland - U.S. Energy Information Agency, 2015; Greenland - Nukissiorfiit, 2014; Faroe Islands - Statistics Faroe Islands, 2016; Northwest power grid of Russia - Korppoo et al., 2008; Northwest Russia included 8\% 'other' which was not defined and which is omitted here.) 


\subsubsection{Wind and Solar Energy in the North American Arctic}

Early uses of solar PV in the Arctic were primarily niche, remote applications such as telecommunications repeater stations and navigation (Ikkala and Nieminen, 1990). This is not surprising considering the cost of flying diesel fuel in by helicopter. A PV-battery system was tested at Canadian Forces Station Alert in 1984 to power ground transmissions from Alert to Eureka, necessary for communications since Alert is too far north to be visible to geostationary satellites. At the time, there were already several thousand such systems in use by the Canadian Coastguard at remote sites (Gardner, 1989). Usher et al. (1994) described early examples of PV applications in northern Canadian settings, including telecommunications, water pumping, and remote lodges. The technical feasibility of building-integrated PV was demonstrated by an array installed in Iqaluit, Canada, in the mid-1990s and monitored for nine years. The best output was achieved between March and May due to low temperatures and good solar insolation (presumably including high albedo), while efficiency typically peaked in March (Thevenard et al., 2000; Poissant et al., 2004). The system including the inverter was still operational almost twenty years later, although efficiency had degraded and two consecutive monitoring systems were no longer operational (Chen, 2012). More recently, Venables (2014) described a solar project in northwest Alaska, noting that, despite shipping all materials by air at great expense, project payback was approximately 12.5 years - well below the lifespan of the PV panels. In the Northwest Territories, Canada, a high-penetration PV-battery-diesel system was installed as part of a project to replace an aged diesel plant; it was expected that enough power will be generated by the PV array in the summer to shut down the diesel gensets for periods of time (Byrne and Flood, 2015).

Similarly, Arctic countries have demonstrated interest in wind power for decades. Canada, Norway, Sweden, Finland, Denmark and the United States are all members of a wind research initiative that began in 1977. Early progress included a wind/diesel system in Quebec, Canada, installation of a wind turbine in Yukon, Canada, and Arctic wind technology in Finland (NREL, 1995). Aarnio and Partonen (2000) detailed the operation of an early Arctic wind farm, constructed in 1996 in northern Finland. Output lagged in early years compared to predictions, but after a few years came close to the target. Losses in availability were due to issues with hydraulics, anemometers, and blade heating control systems. Another early project was the installation of a $600 \mathrm{~kW}$ turbine in Suorva in the north of Sweden (Norling, 1999). 
Alaska is a leader in wind-diesel hybrid systems in the Arctic. The first systems were installed in the 1980s; since 2008, an active approach by government has dramatically increased the number of systems in the state (Konkel, 2013), with 26 wind-diesel projects operational or under construction as of 2014 (Hirsch). Baring-Gould and Dabo (2009) and Fay et al. (2010) reported on the state of technology, research, and system performance of wind-diesel systems in Alaska. Older demonstration projects achieved only 30$40 \%$ of the expected output, due to problems with older turbine models, inexperienced developers, and lack of electronic controls. These problems have largely been addressed in newer systems, which achieve 70-110\% of expected output. Some projects can be considered medium-penetration systems - around 22$24 \%$ of energy from wind in the case of Kasigluk and Toksook Bay. Kotzebue reached an instantaneous penetration rate of $35 \%$ some times of the year (Zucchi, 2007). Generally, Alaska hybrid systems do not use electricity storage - excess wind energy is used to power electric boilers to meet village thermal loads. Saint Paul Island is a high-penetration system, with a 55\% average wind penetration rate. Secondary heating loads and a synchronous condenser support productive use of surplus renewable power and power quality management.

To a lesser extent, wind power has been deployed in the Canadian Arctic. For example, Maissan (2001) described the installation of two wind turbines near Whitehorse, Yukon. Icing of the blades was a major problem and was addressed through leading-edge blade heaters that were left on during the winter. Annual losses due to icing were estimated at about $20 \%$ of the production target. Later, a black hydrophobic coating was added to the blades, resulting in a significant performance improvement. Other important considerations include low-temperature steels and synthetic lubricants, electric heaters in sensitive areas such as the gearbox, generator, and computer controls, and burying power cables to avoid ice build-up. More recently, two mines in northern Canada - Diavik Diamond Mine in the Northwest Territories and Raglan Nickel Mine in Nunavik - installed MW-scale wind turbines to reduce diesel costs and emissions (Choi and Song, 2017). At Raglan, the turbine was coupled to an energy storage system including hydrogen, batteries, and flywheels.

\subsubsection{Cold-Climate Wind Energy Research}

Research on wind power in cold climates has typically focused more on turbine performance than highpenetration integration. Lacroix and Manwell (2000) identified three main issues with wind turbines in 
cold climates - material performance at low temperature, snow, and icing. Modelling of turbine blade fatigue in Arctic climates is still an ongoing area of research, since modelling an entire blade is challenging and material properties of composites at cold temperatures are not well-understood (Gallardo, 2011). Rindeskar (2010) compared measured and modelled icing and found that a statistical approach was not suitable; a physical model showed better results but there was still significant error. Homola et al. (2011) also compared measured and modelled icing and found that modelled results underestimated icing losses. This was attributed to a longer duration for icing events in practice. Overall power production was reduced by $27 \%$ for wind speeds between 8 and $10 \mathrm{~m} / \mathrm{s}$. Analyzing ten wind parks in Sweden, Malmsten (2011) estimated losses of $10-20 \%$ in the winter due to icing.

To mitigate icing events, Fortin et al. (2011) experimented with glaze and rime icing on airfoils, using both hydrophobic (passive) coatings and thermoelectric (active) de-icing mechanisms. Parent and Illinca (2010) summarized the advantages and disadvantages of various anti- and de-icing techniques. Fay et al. (2010) noted that hydrophobic coatings were more common in Alaska, and that active techniques such as blade heating were not common as they had not been proven to be economical on smaller-scale projects typical in the region.

Cattin (2012) summarized trends in wind turbine icing technology and assessed future research needs, including better measurement and simulation, a validated ballistics model of ice throw, and bridging the gap between meteorological researchers and industry engineers. Other recent publications on cold climate wind turbine performance include a state-of-the-art report (Ronsten et al., 2012), an expert group study on recommended practices (Baring-Gould et al., 2012), and assessment of available technologies (Krenn et al., 2016).

\subsubsection{Hybrid Systems Modelling in the Arctic}

Several authors have modelled hypothetical or real hybrid wind energy systems in Arctic regions. Ibrahim et al. (2015) extrapolated performance data from an experimental wind-diesel-adiabatic compressed air energy storage system to model a system for Tuktoyaktuk, Northwest Territories. Krizan et al. (2011) evaluated renewable energy resources for Nunavut, including scenario modelling for three communities in the territory. Strommen (2006) explored the use of domestic hot water tanks and space heating to capture excess electrical energy from a wind-diesel system in the Faroe Islands. In a wind-diesel-only 
system, large $(\sim 50 \%)$ reductions in diesel output required about $50 \%$ of the renewable energy to be spilled, indicating a significant mismatch between supply and demand. Using electric heating to capture the otherwise wasted energy significantly improved project economics. The application of this planning was described by Thomsen et al. (2014), utilizing an older, refurbished $220 \mathrm{~kW}$ wind turbine in Nolsoy, Faroe Islands. In addition to providing a means of energy storage at lower cost than electricity storage, the hot water tanks with electric heaters also provided frequency regulation by adjusting the load to match the supply. Reactive power (and hence voltage regulation) was provided by a capacitor bank. Enevoldsen and Sovacool (2016) modelled a 100\% renewable energy system in the Faroe Islands that utilized $22 \mathrm{~kW}$ cold climate-resistant wind turbines and hydrogen storage. Ulleberg and Morkved (2008) monitored wind speeds in southern Nolsoy in the Faroe Islands, and evaluated the feasibility of wind power with various secondary loads, such as hydrogen electrolysis and storage, domestic hot water heaters, and groundsource heat pumps. A wind-hydrogen system in Utsira, Norway, operational since 2004, was described by Korpas and Greiner (2008) and Ulleberg et al. (2010), including details on system performance and modelling.

The preceding studies typically used some form of energy simulation; however, no system optimization was articulated. A few studies have demonstrated optimization techniques, usually a brute-force (enumerative) approach which limits the size of the design space. Das and Canizares (2016) evaluated thirteen communities in Nunavut for optimal penetration rate and cost savings. Guo et al. (2016) optimized a potential wind-diesel-battery system in Whapmagoostui, Nunavik, Canada; objectives of minimum cost, life cycle pollutant emissions, and system reliability were converted to a single-objective optimization problem through weighting coefficients. Interestingly, the optimization incorporated loadshedding, a demand-side management approach in which certain loads are turned off for a period to improve overall performance. Romero et al. (2016) conducted an optimization exercise for energy supply and operation of the Diavik Diamond Mine in Northwest Territories, Canada, and validated the results with operational data. Chade et al. (2015) modelled a wind-diesel-hydrogen system for the Icelandic island of Grimsey, which unlike most of Iceland relies on diesel power. A four-year payback period was estimated. Isherwood et al. (2000) developed a fictional Alaskan village served by diesel power and optimized a variety of systems, including wind, diesel, fuel cells, and hydrogen storage, with respect to 
cost. Using load and resource data from Unalakleet, Alaska, Simpkins et al. (2015) concluded that a 75\% reduction in fuel use for heating and electricity was technically but not economically feasible; however, a more modest renewable system that reduced fuel use by $54 \%$ also reduced energy costs by $21 \%$. This result implies that increasing the renewable penetration rate beyond a certain point will result in negative returns.

As demonstrated in this review, significant efforts have been applied over the years to integrating wind and solar energy into Arctic diesel grids. Efforts have focused on technical feasibility in the harsh climate and, in Alaska, on integrating significant levels of wind power into the diesel grid. Few studies however have demonstrated optimization of hybrid renewable energy systems. 


\section{Energy Conversion for Electric Power Generation}

With the invention of the dynamo to produce direct current and the alternator to produce alternating current in the mid-to-late 1800s, rotating machinery could be used to produce an electric current. The first electric power plants ran off coal-fired steam or moving water (hydro), power sources that were already being used in industrial applications. Until the invention of nuclear power for electricity production in the 1950s and 60s, they were the main sources of electricity, although spark-ignition and diesel internal combustion engines were also sometimes used. This is still true today - the vast majority of electricity production worldwide is from fossil-fuel steam plants, hydro, and nuclear sources, with natural gas-powered turbines become increasingly important (Breeze, 2014).

Almost all electricity is produced through electromagnetic generators, where mechanical energy is used to rotate a magnetic core inside a permanent magnet. The rotation results in a changing magnetic polarity that induces an electric current. Electrical and mechanical energy are related by (Sarma, 2001):

$$
V I=T \omega
$$

where,

$$
\begin{aligned}
& V=\text { voltage }[\mathrm{V}] ; \\
& I=\text { current }[\mathrm{A}] ; \\
& T=\text { mechanical torque }[\mathrm{N}-\mathrm{m}] ; \text { and, } \\
& \omega=\text { angular velocity }\left[\mathrm{s}^{-1}\right] .
\end{aligned}
$$

The lossless power from direct current is given by:

$$
P=V I
$$

where the work $W$ is the integral of power:

$$
W=\int_{0}^{t} P d t
$$


Most electrical energy is generated and transmitted as alternating current, where the voltage and hence the current changes direction at a frequency of $60 \mathrm{~Hz}$ in North America and $50 \mathrm{~Hz}$ in most of the rest of the world. This is represented by a sine wave with radian frequency $\omega=2 \pi f$, where $f=\frac{1}{T}$ and $T$ is the period, shown in Figure 8 (adapted from Sarma, 2001).

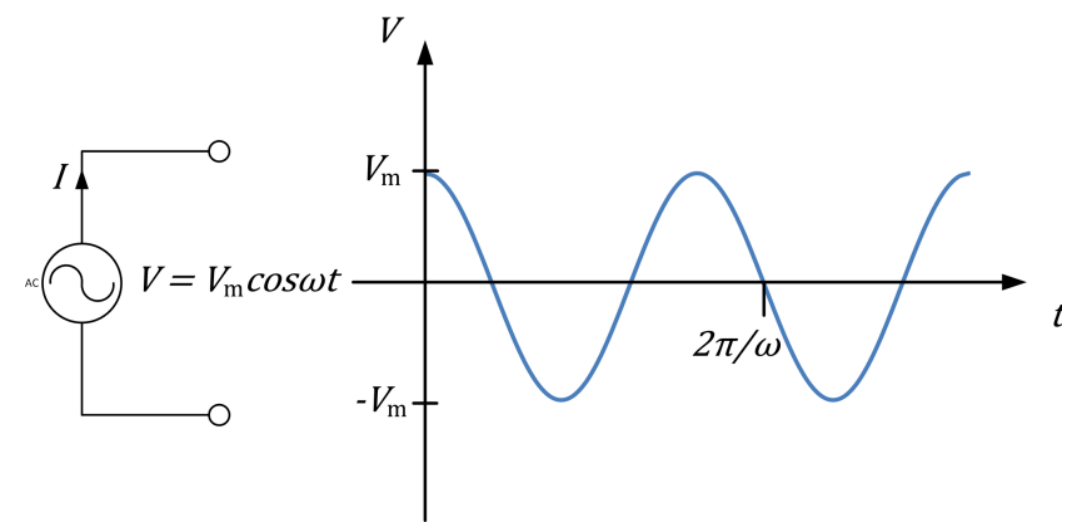

Figure 8: Alternating current waveform

For an ideal circuit without capacitance or inductance, the current is in phase with the voltage. For real circuits however, in addition to the real power that is transferred to the load there is a reactive power component. Reactive power does no useful work but rather is transferred between the electric field (driven by the sinusoidal voltage) and the magnetic field (driven by the sinusoidal current). The apparent power $S$ is the vector sum of real power $P$ and reactive power $Q$ :

$$
S=\sqrt{P^{2}+Q^{2}}
$$

The power factor describes the ratio of real power in $\mathrm{W}$ to apparent power in volt-amps (VA):

$$
P F=\frac{P}{S}=\cos \theta
$$

where $\theta$ is the phase angle between the real and apparent power components. It is important to maintain a high power factor, since generating and transmission equipment is sized for the apparent power in VA as opposed to the real power in $\mathrm{W}$.

Voltage and frequency fluctuations need to be minimized. In a power grid, system frequency is regulated by maintaining a real power balance (matching of supply and demand), while voltage is regulated by 
maintaining a reactive power balance (Drouilhet, 2001). Excessive frequency or voltage deviation can cause equipment damage, tripping (deactivation) of generators, excess heat, and unintended loadshedding (Kirby, 2002; Seymour, 2010). These deviations have several causes, such as starting of large motors or the intermittent output of wind and solar PV generators, and can have significant implications for the safe integration of renewable energy in a conventional power grid.

\subsection{Diesel Generator}

Interest in diesel engines stems from the early 20th century, when they were applied in a 'prime moving' capacity to combat rising coal prices. Early applications included 'central station' electricity generation, pumping oil in pipelines, and industry. One advantage was that diesel engines are more modular than steam plants and hence more flexible (Morrison, 1923).

A diesel engine works by compressing air in a piston and cylinder above the auto-ignition point of the fuel. Fuel is then injected, auto-igniting and causing a rapid increase in temperature and pressure, which provides motive force to the piston. The pistons in turn are coupled to a rotating shaft that drives an electric generator.

Typically, about $2 / 3$ of the energy content in the fuel is lost as heat, as shown in Figure 9 for a typical $910 \mathrm{~kW}$ genset equipped with a turbocharger and aftercooler (Caterpillar, 2016). The figure was made with a free online utility (Sankeymatic, 2017). Some of this lost or residual heat is typically used for 'station service' of the diesel plant, to keep the facility and any off-line engines warm - an important consideration in a high-penetration renewable system where the generators may be deactivated for extended periods of time, requiring an alternative source of heat such as an oil boiler. 
Water jacket cooling: $13 \%$

Fuel energy content: $100 \%$

Exhaust: $35 \%$

Aftercooler: 8\%

To atmosphere from engine: $5 \%$

To atmosphere from generator: $2 \%$ :

Figure 9: Thermal losses (\%) in a diesel genset

A diesel genset is a synchronous generator - it has a rotational speed proportional to the frequency of the generated voltage, e.g., $1200 \mathrm{rpm}$ at $60 \mathrm{~Hz}$. When electrical demand increases, the initial demand (electrical load torque) is met by a slowing of the generator, which decreases system frequency. The engine's governor senses the decrease and responds by injecting more fuel, causing the engine and generator to increase speed until the frequency is within acceptable limits (Freris and Infield, 2008). Thus, a diesel genset is typically able to provide good frequency and voltage regulation, although the inertia of a reciprocating engine is lower compared to gas and steam turbines and as such a diesel grid can still experience issues with grid stability, even in the absence of intermittent generators (Tian and Crous, 2013).

Figure 10 shows a $p-V$ diagram of the ideal Diesel Cycle (adapted from Moran and Shapiro, 2004), where $V$ is the specific volume in $\mathrm{m}^{3} / \mathrm{kg}, p$ is the pressure in $\mathrm{Pa}$, and $W$ and $Q$ represent work and heat, respectively, into or out of the control volume in $\mathrm{J} / \mathrm{kg}$. 


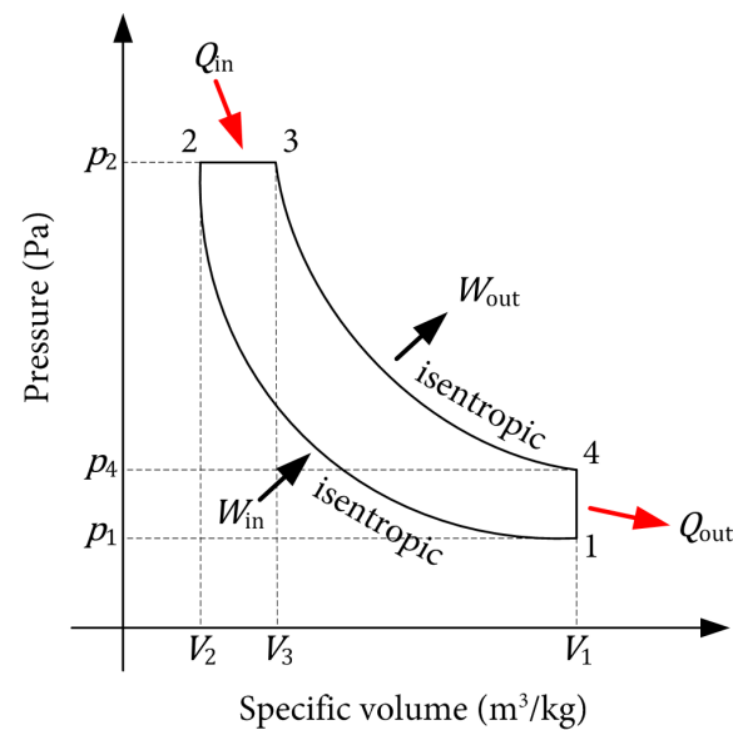

Figure 10: $p$-V diagram of the Diesel Cycle

Point 1-2 represents an adiabatic, isentropic compression of the air in the cylinder by the piston. At point 2-3, fuel is injected and combusted at constant pressure. Point 3-4 is an adiabatic, isentropic expansion of the piston - the power stroke. Finally, point 4-1 is heat rejection at constant volume.

The theoretical efficiency of the diesel cycle is a function of the compression and cutoff ratios:

$$
\eta_{\text {diesel }}=1+\frac{1}{\gamma}\left(\frac{1}{r^{\gamma-1}}\right)\left(\frac{r_{\mathrm{c}}^{\gamma}-1}{r_{\mathrm{c}}-1}\right)
$$

where,

$$
\begin{aligned}
& \gamma=\frac{C_{\mathrm{p}}}{C_{\mathrm{v}}} ; \\
& C_{\mathrm{p}}=\text { specific heat at constant pressure }[\mathrm{kJ} / \mathrm{kg}-\mathrm{K}] ; \\
& C_{\mathrm{v}}=\text { specific heat at constant volume }[\mathrm{kJ} / \mathrm{kg}-\mathrm{K}] ; \\
& r_{\mathrm{c}}=\text { cutoff ratio, volumetric ratio of the combustion process, }\left[\frac{V_{3}}{V_{2}}\right] ; \text { and, } \\
& r=\text { compression ratio, }\left[\frac{V_{1}}{V_{2}}\right] .
\end{aligned}
$$


Eq. (4) is shown in Figure 11. A real diesel engine deviates from these ideal conditions. For example, the working gas is real, not ideal, and $\gamma$ is in fact not constant; the compression and expansion phases involve heat losses; combustion occurs instead of an ideal input of heat; and, the exchange of gases results in irreversibilities (Mollenhauer and Schreiner, 2010).

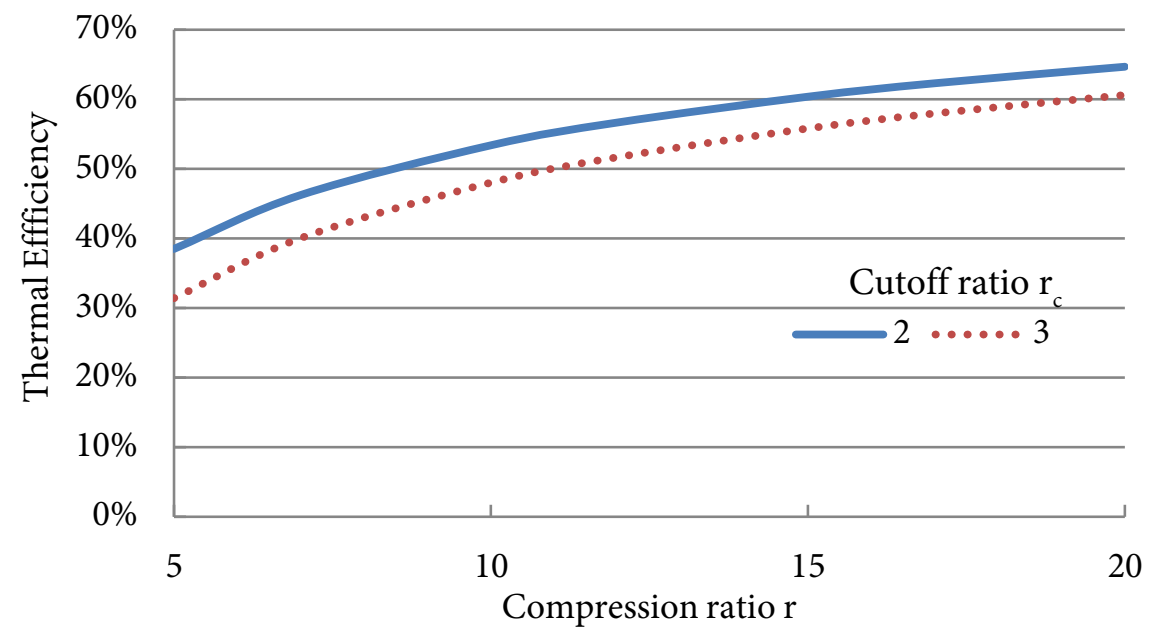

Figure 11: Diesel cycle thermal efficiency as a function of compression ratio

Since auto-ignition at high pressure and temperature is highly undesirable for a spark-ignition engine but required for a diesel, greater compression ratios and hence higher efficiency can be obtained by a diesel. Diesel engines typically operate at compression ratios up to about 20 , significantly higher than sparkignition engines. Other potential advantages over spark-ignition engines include lower volatility of diesel fuel compared to gasoline and relative ease of maintenance due to the lack of air throttling and spark plugs (Bacha et al., 2007).

\subsection{Wind Turbine}

Like a diesel genset, wind turbines generate electric power by an electromagnetic generator, with the motive force supplied by wind instead of diesel fuel combustion. The power $P$ of an incompressible fluid moving with uniform axial flow is:

$$
P=0.5 \rho A u^{3}
$$

where, 


$$
\begin{aligned}
& \rho=\text { fluid density }\left[\mathrm{kg} / \mathrm{m}^{3}\right] ; \\
& A=\text { cross-sectional area }\left[\mathrm{m}^{2}\right] ; \text { and, } \\
& u=\text { velocity of the fluid flow }[\mathrm{m} / \mathrm{s}] .
\end{aligned}
$$

The theoretical limit to extractable power (maximum coefficient of performance) from a wind stream, $59.259 \%$, is called Betz' Limit, and is analogous to Carnot Cycle efficiency for a heat engine. Nonidealities, including the rotor, drag resistance from the turbine blades, finite wing size, whirlpool losses resulting from non-axial flow, and turbine design losses, reduce the maximum coefficient of performance to about $40 \%$. In addition, the coefficient of performance is not constant across the entire operating range of the wind turbine (Ragheb and Ragheb, 2011).

Most wind turbines use induction (asynchronous) generators, which consume reactive power and which therefore require additional power electronics to maintain the proper voltage. The North American Electric Reliability Corporation identifies four types based on the level of control and performance capability (NERC, 2009). Type 1, a basic induction generator, and Type 2, a variable-slip induction generator, have limited voltage and frequency control. Type 3 is a double-fed induction generator and supports adjustment of frequency and voltage to compensate for changes in wind speed, which dramatically reduces grid integration issues. Finally, Type 4 turbines utilize full AC-DC-AC conversion for all generator output. Typically, all four types utilize a gearbox to step up the slow rotational speed of the turbine rotor to a multiple of the grid frequency (e.g., $1200 \mathrm{rpm}$ for $60 \mathrm{~Hz}$ grids).

He et al. (2015) analyzed the effect of different turbine types on power system stability using a slightly different classification. Three approaches were investigated: a basis induction generator, a double-fed induction generator, and a direct-drive permanent magnet synchronous generator utilizing full AC-DCAC conversion, shown in Figure 12 (adapted from He et al., 2015). The first is similar to Types 1 and 2 defined by NERC, the double-fed generator is Type 3, and the last is Type 4 with a permanent magnet synchronous generator. 


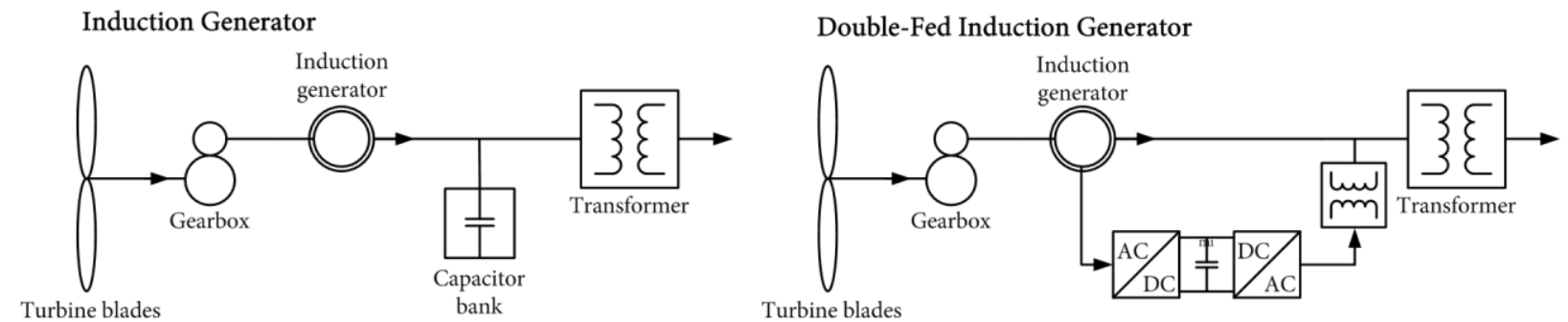

Direct-Drive Generator

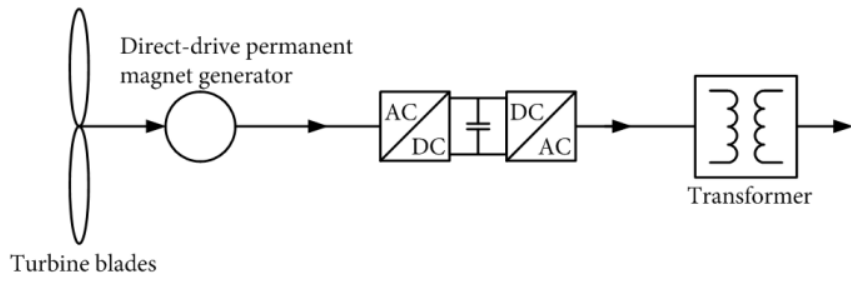

Figure 12: Wind turbine generator types

Direct-drive permanent magnet generators have been recommended for use in Antarctic wind-diesel systems (Stander, 2008); while these turbines are heavier and more expensive, they reduce frequency regulation issues and may simplify maintenance by eliminating moving parts such as the gearbox (Fry, 2006). These factors are particularly important in small diesel grids, which may already face power quality issues and difficulty sourcing maintenance.

Finally, control of the turbine blade angle of attack can help control power output. Most modern turbines, particularly of the MW scale, use active pitch control where each turbine blade rotates about its longitudinal axis. This optimizes power output at different wind speeds, curtails rotational speed at very high wind speeds (above the nominal capacity) to avoid damage, and helps control the aggregate output from a wind farm. Stall-controlled turbines have the blades fixed to the rotor. The shape of the blade induces turbulence on its leeward side at wind speeds higher than the design rating, stalling the blade and preventing damage from overly-high forces on the rotor (NERC, 2009).

\subsection{Solar PV}

Unlike wind turbines, diesel generators, and other forms of electricity generation, solar photovoltaic cells do not rely on the transfer of kinetic energy to electrical energy using an electromagnetic generator. In fact, there are no moving parts at all. Instead, electricity is generated through the photoelectric effect, in 
which energized photons strike a semiconductor and cause electrons to be liberated from the valence band and lifted into the conduction band, where they are free to conduct electricity (Haberlin, 2012). The amount of energy required to liberate a photon is called the bandgap energy.

Silicon, a common semiconductor material, is typically arranged in a crystal lattice structure as shown in Figure 13 (adapted from Haberlin, 2012). Since silicon has four valence electrons, each atom can form a covalent bond with four other silicon atoms, an extremely stable arrangement with low electrical conductivity. To increase conductivity, silicon semiconductors are doped by adding other elements in extremely low concentrations (e.g., one doping atom per $10^{9}$ or $10^{10}$ silicon atoms).

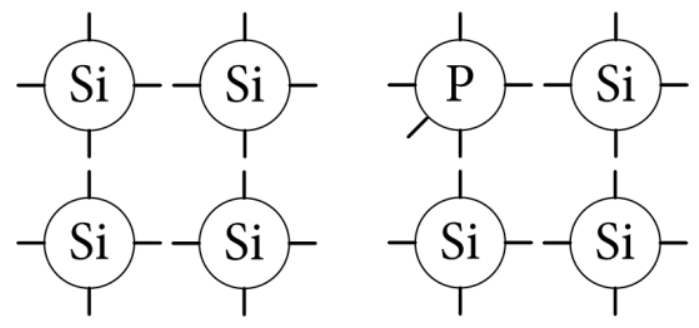

Figure 13: Silicon lattice structure; pure (left) and doped with phosphorous (right)

The doping atoms typically have five or three valence electrons. In the former, the fifth electron does not form a covalent bond and hence the energy required to liberate the free valence electron into the conduction band is significantly lower. This type of semiconductor functions by 'donating' electrons or negative charges, resulting in a local positive charge, and is called n-conductive. A doping atom with three electrons has a 'hole' in the covalent bonding and can readily accept an electron, resulting in a local negative charge. This is called $\mathrm{p}$-conductive.

Solar cells function through the interface of p-conductive and n-conductive materials, also called the p-n junction, shown in Figure 14 (adapted from Haberlin, 2012) with diffusion voltage $V_{\mathrm{D}}$. This junction contains the depletion region, in which there are no excess electrons or electron holes and hence no available charge carriers. The diffusion voltage results from positively charged electron-donor atoms in the n-zone and negatively charged electron-receptor atoms in the p-zone. This ionization results in an internal electric field (and the creation of the depletion region), which resists further electron diffusion. 

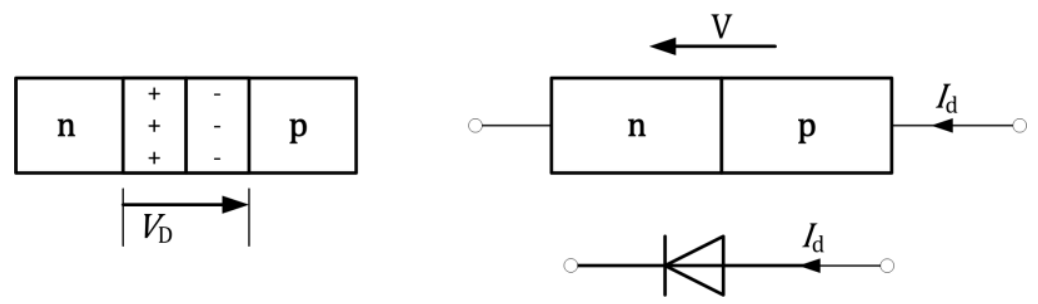

Figure 14: Diffusion voltage of the p-n junction without external voltage applied (left), and with applied external voltage applied resulting in a diode (right)

If a positive voltage is applied (from the p-zone to the n-zone), the potential difference between the nzone and p-zone, $V_{\mathrm{D}}$, disappears. However, if a negative voltage is applied, the potential difference will increase, resisting further diffusion of charge carriers. This is the principle of a diode, a semiconductor that permits current flow in only one direction. The diode current $I_{\mathrm{D}}$ is described by the Shockley Equation:

$$
I_{\mathrm{D}}=I_{\mathrm{o}}\left[e^{\left(\frac{q V}{\gamma K T}\right)}-1\right]
$$

where,

$$
\begin{aligned}
& I_{\mathrm{O}}=\text { diode reverse saturation current }[\mathrm{A}] \\
& q=\text { electron charge constant }\left[\sim 1.602 \times 10^{-19}\right. \text { coulombs]; } \\
& K_{\mathrm{B}}=\text { Boltzmann Constant }\left[1.3806488 \times 10^{-23} \mathrm{~J} / \mathrm{K}\right] \\
& T=\text { temperature }[\mathrm{K}] \\
& V=\text { applied voltage }[\mathrm{V}] ; \text { and, } \\
& \gamma=\text { diode ideality factor, where } 1 \leq \gamma \leq 2 \text { and } \gamma=1 \text { represents an ideal diode. }
\end{aligned}
$$

As there are no moving parts or rotating masses in a PV system, there is zero system inertia. In addition, unlike diesel and wind turbine generators, direct current (DC) power is produced and an inverter is required to transform the DC current into an AC waveform. This is similar in function to the Type 4 wind turbine noted in Figure 12 as the inverter can provide some level of voltage and frequency control. However, given the lack of inertia, PV output can fluctuate very rapidly - on the order of $+/-50 \%$ in about 
a minute time frame, depending on weather (NERC, 2009). Thus, while PV output generally is more predictable than wind on a diurnal and seasonal basis, a system with a high PV penetration rate must accommodate high ramp rates.

The current, voltage, and power output from a PV panel is defined by the current-voltage or I-V curve. An example generated with TRNSYS is shown in Figure 15, where $I_{s c}$ is the short-circuit current in A and $V_{\mathrm{OC}}$ is the open-circuit voltage in $\mathrm{V}$.

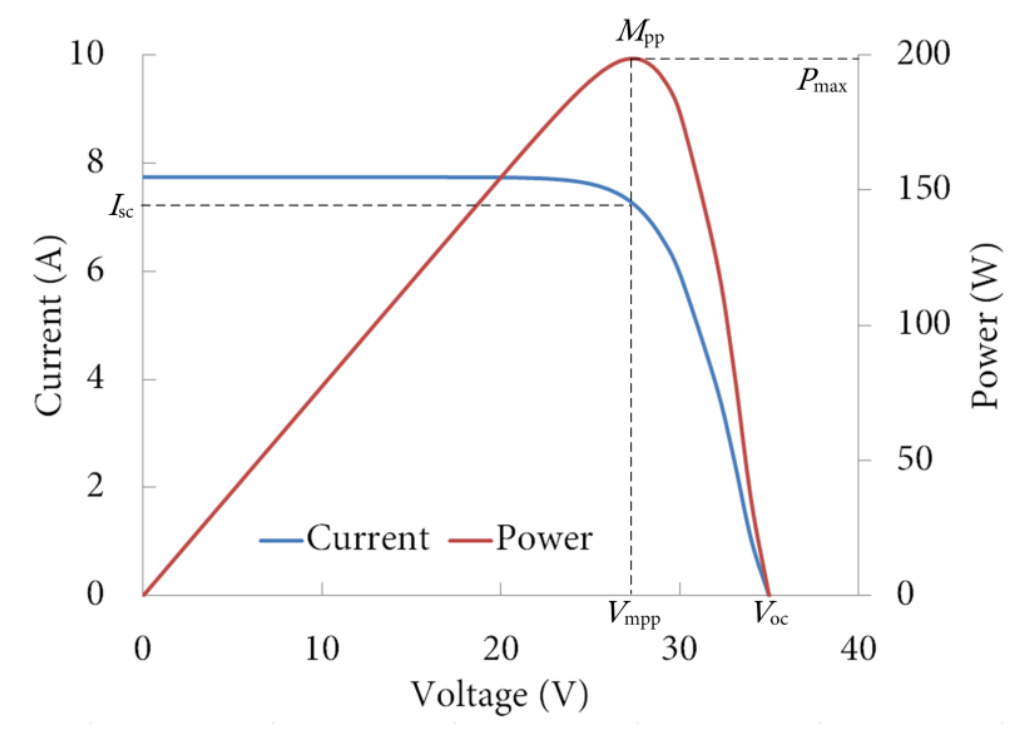

Figure 15: Photovoltaic power-voltage and current-voltage curves

The curve is not constant; the specific values of power, current, and voltage depend on cell temperature, incident radiation, and cell degradation and soiling. There is a specific point on the I-V curve, the maximum power point $\left(M_{\mathrm{PP}}\right)$ where power output is at a maximum $\left(P_{\max }\right)$. The current and voltage at this location are denoted by the subscript mpp in Figure 15. PV modules utilize a maximum power point tracker to constrain the PV voltage to the point of maximum power for a given solar insolation and cell temperature; generally, all grid-connected PV systems utilize maximum power point tracking (Klein et al., 2010).

\subsection{Electrical Storage}

To achieve high intermittent penetration levels in a small grid like Cambridge Bay usually requires some form of electrical storage. Storage can be useful on the scale of seconds to minutes to smooth out rapid 
fluctuations (ramping) in intermittent output, or on the scale of minutes to hours to days for supply shifting - storing energy when intermittent output is higher than demand for use when output is lower than demand. Other applications include improvements to system efficiency, emissions control, peak shaving, deferral of capital expenditures, reduced maintenance through decreased run-time of the diesel engine, and power conditioning/ancillary services such as voltage and frequency regulation (IEA, 2014).

Storage can be divided into several categories at varying levels of technical maturity (IEC, 2011), as shown in Table 4.

Table 4: Technological maturity level of various electricity storage concepts

\begin{tabular}{|l|l|l|}
\hline \multicolumn{1}{|c|}{ Category } & \multicolumn{1}{|c|}{ Technology } & \multicolumn{1}{c|}{ Maturity level } \\
\hline \multirow{4}{*}{ Mechanical } & Pumped hydro & Mature \\
\cline { 2 - 3 } & Diabatic compressed air & Mature / near-mature \\
\cline { 2 - 3 } & Adiabatic compressed air & Under development \\
\cline { 2 - 3 } Electrochemical & Flywheel & Mature / near-mature \\
\cline { 2 - 3 } & Rechargeable batteries & Mature / near-mature / experimental \\
\hline \multirow{3}{*}{ Chemical } & Flow batteries & Under development \\
\hline \multirow{3}{*}{ Electrical } & Hydrogen fuel cells & Under development \\
\cline { 2 - 3 } & Synthetic natural gas & Experimental \\
\hline Thermal & Capacitors & Mature \\
\cline { 2 - 3 } & Supercapacitors & Mature \\
\cline { 2 - 3 } & Magnetic storage & Experimental \\
\hline
\end{tabular}

Mechanical storage includes pumped hydro, compressed air, and flywheels. Pumped hydro and 'traditional' large-scale diabatic compressed air both require specific geographical formations and large volumes (Kim et al., 2012; Luo et al., 2014). A newer approach still under development is advanced adiabatic compressed air energy storage with above-ground storage tanks. In this approach, the heat of compression is stored and used to re-heat the air in the expansion phase. If the compression cycle is powered by renewable sources, fossil fuel use is minimized or eliminated. While efficiency is high, hightemperature $\left(\sim 600^{\circ} \mathrm{C}\right)$ thermal storage is required (Kim et al., 2012).

Flywheels store energy in a spinning mass and have a very long life, high round-trip efficiency, and very fast response time. Self-discharge is high however, on the order of $55-100 \%$ per day, and as such they are 
mainly used for emergency power and power conditioning. They can also help mitigate the impacts of fast ramping in intermittent generation caused by rapidly changing cloud cover or wind speed (Beaudin et al., 2010).

Chemical storage includes hydrogen and synthetic natural gas. Worldwide, most hydrogen is produced directly from fossil fuels. Alternatively, electricity can be used to electrolyze water, separating it into oxygen and hydrogen. The hydrogen can be stored and later passed through a fuel cell or combusted in an internal combustion engine to generate electricity (Beaudin et al., 2010). While hydrogen as an energy carrier faces many challenges, such as storage, round-trip efficiency, and cost, it may be a promising technology for stationary power applications and has been demonstrated in northern and remote regions such as Utsira, Norway (Ulleberg et al., 2010), Ramea, Canada (Islam, 2011), and the Raglan Nickel Mine in Nunavik, Canada (Choi and Song, 2016).

Batteries, also called electrochemical or galvanic cells, store and release electrical energy through chemical reactions. There are three types: primary (non-rechargeable), secondary (rechargeable) and flow. Secondary batteries feature a closed structure containing a rechargeable electrolyte, and include lead-acid, nickel-cadmium, lithium-ion, sodium-sulphur, and others, while in flow batteries, the charged electrolyte moves through the electrochemical cell, rather than being confined in a closed structure (Beaudin et al., 2010).

In a battery, energy is transferred by the transport of ions through an electrolyte in the presence of an external electric load. Solid electrodes either donate or accept electrons to the electrolyte through reversible chemical oxidation-reduction (redox) reactions at the interface of the electrode and electrolyte (Krischer and Schonleber, 2015). A redox reaction is a chemical reaction that involves the transfer of electrons between chemical species.

An electrode that donates electrons is called the cathode, while the electrode that accepts electrons is called the anode. The transfer is driven by the chemical potential difference between the anode and cathode. Since electrons diffuse to and from the electrolyte, the electrolyte becomes negatively charged in a cathodic reaction and positively charged in an anodic reaction:

$$
\text { Cathodic Reaction: } \mathrm{A}+\mathrm{e}^{-} \rightarrow \mathrm{A}^{-} \quad \text { Anodic Reaction: } \mathrm{A} \rightarrow \mathrm{e}^{-}+\mathrm{A}^{+}
$$


where $A$ is the chemical species in the electrolyte. As the process is reversible, the cathode under charging conditions becomes the anode under discharging conditions and vice versa. A schematic of an electrochemical cell is shown in Figure 16 (adapted from Krischer and Schlonleber, 2015).

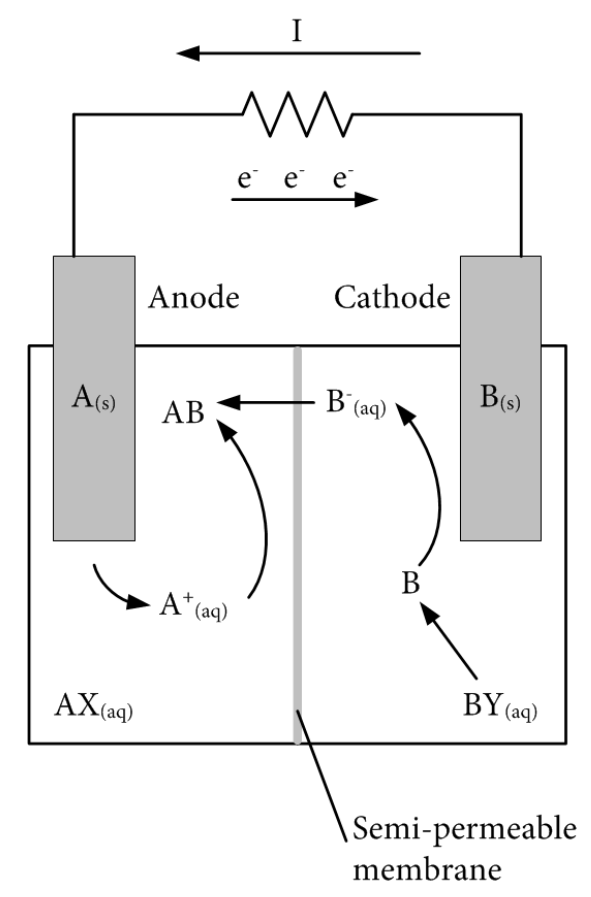

Figure 16: Electrochemical (galvanic) cell

The cell contains solid electrodes composed of species A and B, each suspended in an aqueous solution represented by $\mathrm{AX}_{\mathrm{aq}}$ and $\mathrm{BY}_{\mathrm{aq}}$. A conductor connecting the two electrodes permits current flow across a resistor, leaving electron holes (positive charges) in the anode and additional electrons (negative charges) in the cathode. This results in positively charged ions of species A and negatively charged ion of species B. If the two electrolyte solutions were separated, the reaction would end; however, if at least one of the ion species can cross a semi-permeable membrane, a complete circuit forms and the reaction continues until the chemical potential difference has decreased to a point where the external electric load cannot be met (Saldanha, 2010).

There are several battery chemistries commonly used in renewable energy applications. Sodium-sulphur batteries have significant market share for renewable energy applications, although the market is moving towards lithium-ion and advanced lead-acid batteries (Kempener and Borden, 2015). This thesis bases the financial evaluation on the cost and performance of lithium-ion batteries, although detailed battery 
chemistry is not modelled; see Sections 5.2 for more information. There are a wide variety of lithium battery chemistries available, typically utilizing electrodes comprising a lithium metal oxide and lithiated carbide (Rahn and Wang, 2013). For example, the chemical reaction occurring for a lithium cobalt oxide electrode, with charging occurring from left to right, is (Saldanha, 2010):

$$
\mathrm{LiCoO}_{2} \rightleftharpoons \mathrm{Li}_{0.55} \mathrm{CoO}_{2}+0.45 \mathrm{Li}^{+}+0.45 \mathrm{e}^{-}
$$

and for the lithiated carbide electrode:

$$
6 \mathrm{C}+0.45 \mathrm{Li}^{+}+0.45 \mathrm{e}^{-} \rightleftharpoons \mathrm{Li}_{0.45} \mathrm{C}_{6}
$$

Because lithium is highly reactive in the presence of water, lithium-ion batteries do not use an aqueous electrolyte as indicated in Figure 16. Instead non-aqueous compounds or solid polymers are used (Saldanha, 2010).

The performance of a lithium ion battery is affected by discharge rate, temperature, and cycling. A higher discharge rate (i.e., higher current) will effectively reduce the available battery capacity. The voltage delivered to the load also decreases with increasing current. Low temperatures similarly decrease the maximum voltage for a given current. Batteries lose capacity over time (both power and energy) as they cycle (repeated charging and discharging). Battery degradation is complex and depends on the battery chemistry, the depth and rate of discharge and charge, and the battery temperature. Typically, a battery is considered to have reached end-of-life when energy capacity has been reduced to $80 \%$ of the original. Beyond this point, the rate of degradation tends to rapidly increase (Saldanha, 2010). 


\section{Demand and Resource Analysis}

To plan a hybrid energy system, measurements or estimates of the electrical and/or heating load (demand) and relevant weather data (resource) are required. This section first outlines some relevant considerations, followed by details of the demand and resource data used in this thesis.

For a building or campus, the most comprehensive data is high-resolution (hourly or sub-hourly) data separated by end-use, for example lighting or equipment. Often however, data are measured at the utility interconnection, i.e., the total electrical or natural gas demand for the building or campus. Sometimes, only monthly data from utility bills are available. For this thesis, hourly data from a building simulation model were used as no operational data were available.

At the community level, demand is recorded in some fashion at the utility level. In the Arctic, not all community power plants measure demand at high resolution, instead reporting higher-level metrics such as peak demand and annual fuel consumption. One effort in Alaska to address this issue involved developing a typical village load profile and then adapting it based on characteristics of specific communities, such as population, median household income, and number and type of buildings (Devine, 2005).

Community electrical demand can be separated into component parts: base, weather-dependent, and residual (Soliman and Al-Kandari, 2010). The base load comprises most of the total demand and has four distinct sub-components: seasonal, weekly, and daily load cycles, and a long-term sub-component that reflects economic change. Weather-dependent load is primarily driven by dry bulb temperature, wind speed, and humidity. The residual load results from abnormal consumer behavior, including storms, responses to daylight savings time, and natural disasters; while this behavior can be frequent, it is typically a small percentage of the total load and is often excluded from load modelling.

Angelis-Dimakis et al. (2011) discussed different methods to estimate wind and solar resource data. For solar energy this includes ground-based measurements, satellite-derived values, or a combination of both. Sometimes, proxies such as sunshine duration or cloud cover are used. Ground measurements provide high temporal resolution (on the order of minutes), but at low spatial coverage - a single point. On the other hand, satellite measurements cover large areas but at a coarser spatial and temporal resolution (Niu and 
Pinker, 2011). Geostationary-orbiting weather satellites have a limited view of high latitudes, making satellite measurements in these regions difficult. The geometry of Earth-satellite observations therefore introduces further uncertainty into high-latitude satellite measurements (Vignola et al., 2012).

Beyond about $50 \mathrm{~km}$ from ground stations, measurement uncertainty increases and it can be better to use an interpolation model. This is the approach used by the Meteonorm weather database (Meteonorm, 2013). The density of ground measurements in Arctic is very sparse compared to southern North America, reducing the accuracy of interpolation models.

To determine available wind energy, in-situ measurements, statistical analysis, forecasting, flow modelling, and mesoscale modelling can be used (Angelis-Dimakis et al., 2011). In-situ measurements are best, ideally for multiple years. This is usually accomplished by erecting a meteorological mast with anemometers at several heights, or with lasers (Light Detection and Ranging or LiDAR).

Pyranometers measure total (global) radiation and are typically oriented horizontally or in the plane of a PV array. More sophisticated approaches include measurement of beam (direct) and diffuse radiation with solar tracker-mounted pyrheliometers and shaded pyranometers, respectively, reflected solar radiation, and upand down-welling infrared radiation (McArthur, 2005).

\subsection{CHARS Campus Energy Demand}

Because the building not yet operational and no measured data were available, the building energy demand was obtained from simulation models developed by the CHARS design consultant. As noted in Section 1.3, measures were implemented to improve the energy performance compared to a reference model design. Hourly electrical and space heating demand were produced from the simulation model; these data are shown in Figure 17. 

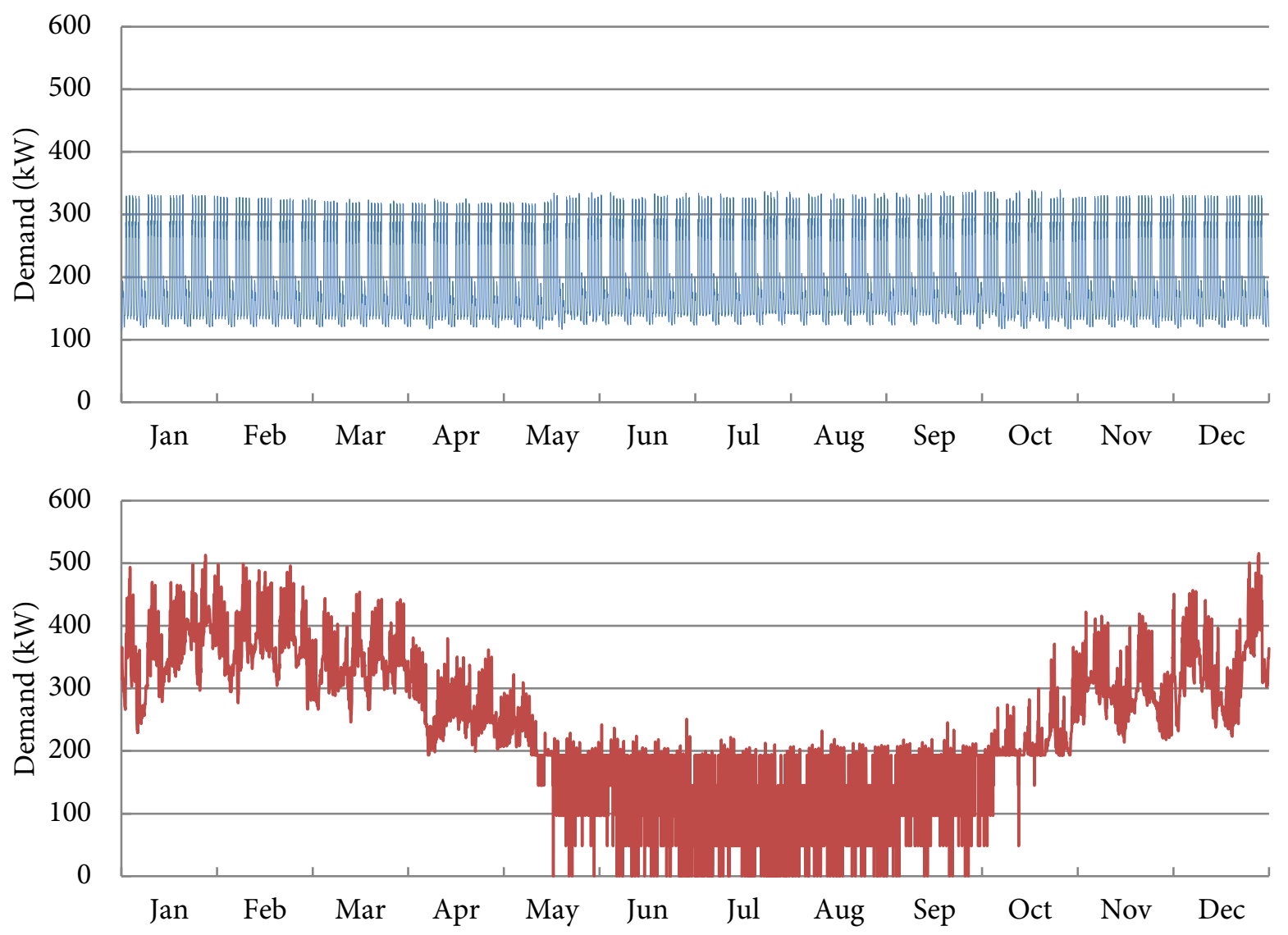

Figure 17: Simulated CHARS annual electricity (top) and heating (bottom) demand

Since the intent of the building energy modelling was to compare the impact of different energy efficiency options, and as such, simulated loads were based on an assumed occupant profile and equipment load density that was constant throughout the year. While this may suffice for an annual estimate of building energy consumption, it is less realistic for hybrid energy systems planning, where time-of-use is extremely important. During operations, both the occupant load and the equipment usage profiles will likely vary substantially from the modelled loads throughout the year, based on peak research times and the nature of the research program (e.g., relative emphasis of field work, technology development, bench-top science, etc.).

Nevertheless, the modelled demand was taken at face value. In the future, both the building simulation model and the results of this thesis can be refined with data from the comprehensive building energy monitoring system (Brown et al., 2018).

Figure 18 shows typical building model heating and electrical loads near the solstice for both weekends and weekdays. Of note are the relatively consistent electrical load, and the heat load in summer. 

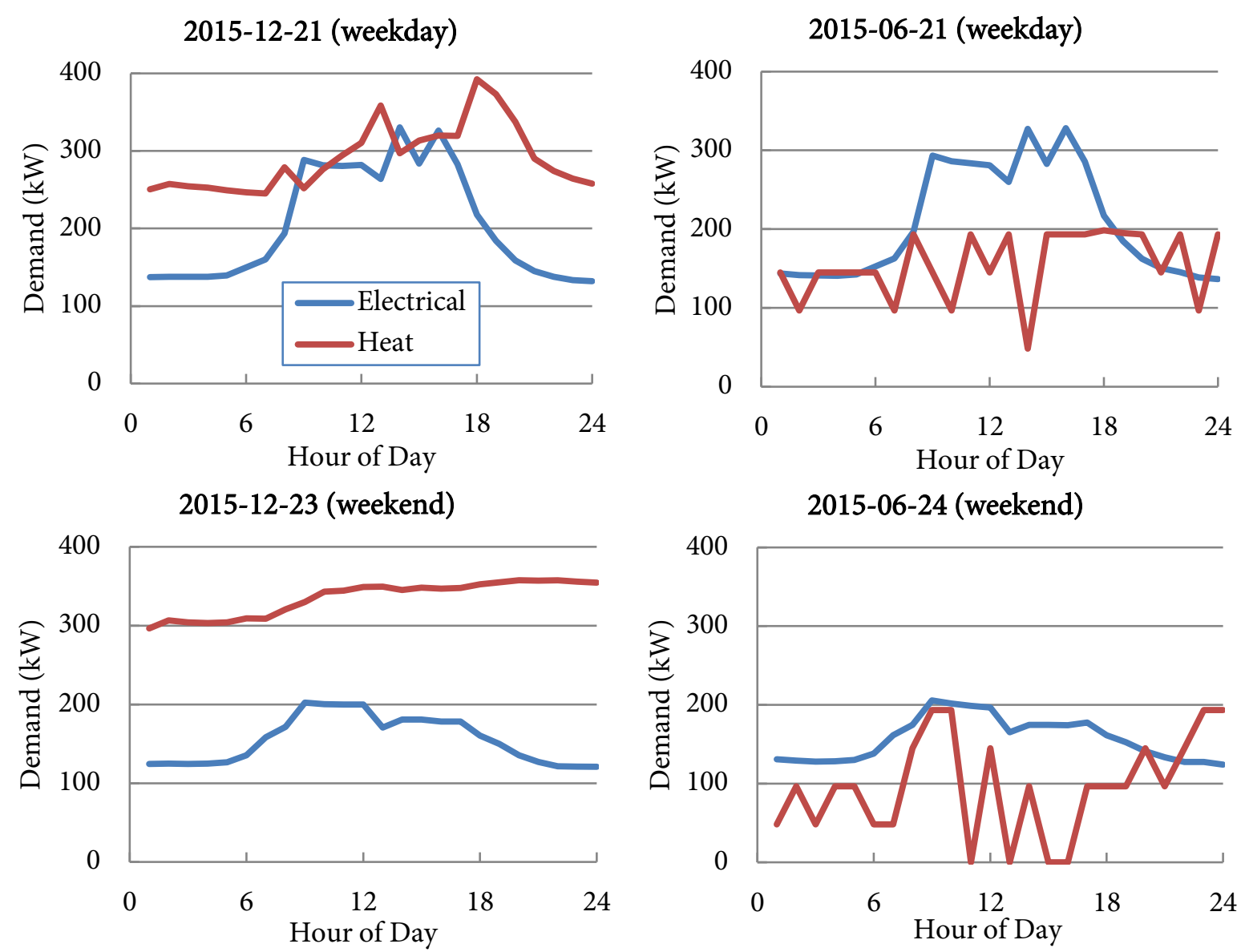

Figure 18: Typical heating and electrical loads

\subsection{Statistical and Actual Meteorological Year Weather Files}

Weather files for time-series simulation come in two main formats: statistical and actual. Statistical meteorological year (SMY) weather files use measured or synthetic data to generate a file format indicative of long-term averages. These include the Meteonorm files mentioned in Section 4.0 and the Typical Meteorological Year (TMY) file format. For the TMY format, long-term (e.g., 30 years) weather data is examined month-by-month. The most typical or average of each month out of the dataset is then selected and concatenated into a single, 12-month weather file. These files usually do not contain extreme weather scenarios that significantly deviate from typical conditions, and as such are not appropriate for some purposes such as sizing building heating and cooling systems that need to meet the energy demand under extreme conditions. They are also usually not recommended for modelling wind energy generator performance as the weighting is primarily based on solar radiation and dry bulb temperature (Wilcox and 
Marion, 2008). On the other hand, they are useful for examining the expected long-term performance of a building or solar PV installation.

An Actual Meteorological Year (AMY) file uses measured data from ground stations and/or satellites for the time period of interest. They are particularly useful for calibrating or validating energy models against actual performance. A drawback is that they may not represent average conditions; for example, an unusually windy year would lead to over-prediction of long-term wind farm production.

An SMY weather file was available for Cambridge Bay and was used by the CHARS design consultant for the building simulation modelling. This weather file was not, however, used in the renewable energy simulation in this thesis, since the source and accuracy of the solar radiation and wind speed data were unclear. More robust wind and solar data were desired for the hybrid renewable system analysis, and as such, monitoring instrumentation was installed in Cambridge Bay.

\subsection{Cambridge Bay Weather Monitoring and Data}

In 2014, a meteorological mast for wind monitoring and a tripod with pyranometers for solar monitoring were installed just north of the community. Details of the instrumentation are provided in Table 5. The first full year of data, 2015, was used in this thesis; graphs of relevant variables are shown in Appendix A.

Table 5: Meteorological instrumentation

\begin{tabular}{|c|c|c|c|c|}
\hline Description & Qty. & Model \# & Units & Height or Angle \\
\hline Heated anemometer & 2 & NRG \#3447 & $\mathrm{m} / \mathrm{s}$ & $19 \mathrm{~m} / 33 \mathrm{~m}$ \\
\hline Unheated anemometer & 2 & NRG \#40C & $\mathrm{m} / \mathrm{s}$ & $20 \mathrm{~m} / 34 \mathrm{~m}$ \\
\hline Temperature sensor & 1 & NRG 110S & ${ }^{\circ} \mathrm{C}$ & $4 \mathrm{~m}$ \\
\hline Wind directional vane & 2 & NRG 200P & ${ }^{\circ} \mathrm{CW}$ from north & $20 \mathrm{~m} / 34 \mathrm{~m}$ \\
\hline Pyranometer & 2 & CM-22 & $\mathrm{W} / \mathrm{m}^{2}$ & $90^{\circ}$ and $69^{\circ}$ \\
\hline
\end{tabular}

Photographs of the meteorological mast and the pyranometer tripod are shown in Figure 19. Fans integrated into the housing help keep the pyranometer sensor domes frost-free. 

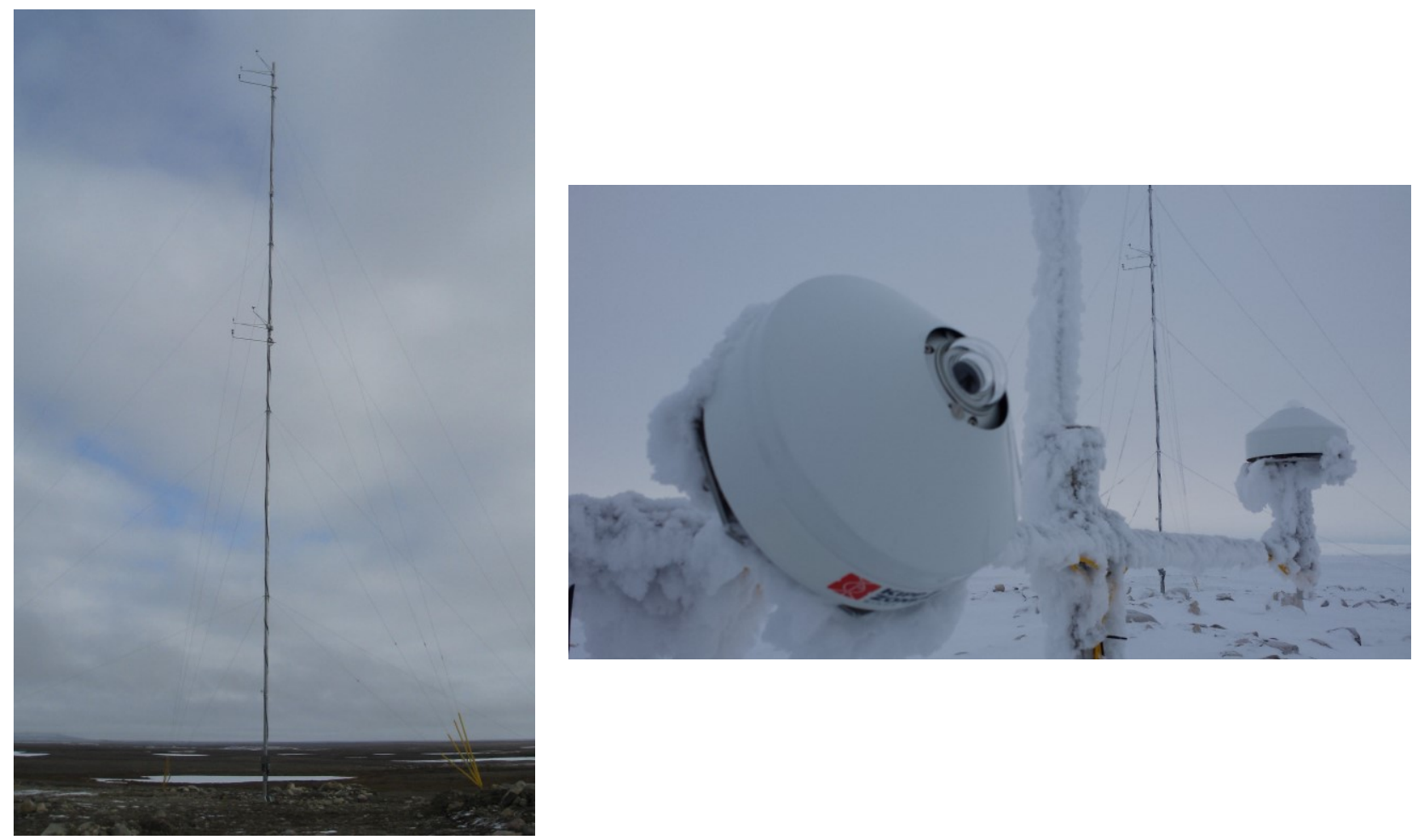

Figure 19: Meteorological mast (left) and solar pyranometers (right)

Measurements included wind speed and direction, dry bulb temperature, and horizontal and tilted global (total) radiation. Atmospheric pressure measurements, available online, were taken from instrumentation at the nearby airport (Environment Canada, 2015).

Wind speed was measured at a height of $19 \mathrm{~m}$ and $33 \mathrm{~m}$ using heated anemometers and $20 \mathrm{~m}$ and $34 \mathrm{~m}$ using unheated anemometers. The sampling rate was $1 \mathrm{~Hz}$, averaged over 10-min timesteps. The heated instrumentation was uncalibrated and hence potentially less accurate than the unheated instrumentation; as such, the heated instrument data were only used if the unheated instruments show signs of icing. Two checks were used to determine if an icing event was likely:

Table 6: Conditions indicative of anemometer freezing events

\begin{tabular}{|c|c|}
\hline Condition 1: & If $T_{\mathrm{db}}<5^{\circ} C$ and $u_{\mathrm{un}}<0.5 \mathrm{~m} / \mathrm{s}$ and $u_{\mathrm{un}, \mathrm{std}}=0$ \\
\hline Condition 2: & If $u_{\mathrm{un}}<0.5 u_{\mathrm{h}}$ \\
\hline
\end{tabular}

where, 
$T_{\mathrm{db}}=$ dry bulb temperature $\left[{ }^{\circ} \mathrm{C}\right]$;

$u_{\mathrm{un}}, u_{\mathrm{h}}=$ the unheated and corresponding heated wind speed measurement $[\mathrm{m} / \mathrm{s}]$; and,

$u_{\mathrm{un}, \mathrm{std}}=$ standard deviation of the unheated wind measurement over the timestep $[\mathrm{m} / \mathrm{s}]$.

Condition 1 indicates that the unheated anemometer has frozen. Condition 2 indicates that the unheated anemometer is probably being slowed by ice accretion; the somewhat arbitrary factor of 0.5 was believed to be sufficient to indicate icing conditions while preventing false positives. For the ten-minute data, Condition 1 was observed in 2,619 or $5 \%$ of entries for the $19 \mathrm{~m} / 20 \mathrm{~m}$ instrumentation and 4,604 or $9 \%$ of entries for the $33 \mathrm{~m} / 34 \mathrm{~m}$ instrumentation. Condition 2 always evaluated to true if the first condition evaluated to true, and was observed in 6,416 or $12 \%$ of $19 \mathrm{~m} / 20 \mathrm{~m}$ entries 10,299 or $19 \%$ of entries at $33 \mathrm{~m} / 34$ $\mathrm{m}$.

There are two reasons to account for anemometer icing. First, wind speed can be under-predicted, sometimes significantly so, which would decrease modelled wind turbine production (as noted in Section 2.3 however, wind turbines can also experience icing). Second, calculation of the wind shear exponent would otherwise be erroneous, as explained in the following.

The wind shear exponent describes the change in wind speed with height. Except for inversions, speed typically increases with height above ground level in the height considered for wind turbines. There are two methods commonly used to extrapolate wind speed at height: the logarithmic law ('log law') and the power law.

The log law uses the concept of surface roughness, which is the known or assumed height above ground where wind speed is theoretically zero. The power law, on the other hand, is an empirically derived relationship that does not rely upon assumptions of surface roughness:

$$
\frac{u_{1}}{u_{2}}=\left(\frac{z_{1}}{z_{2}}\right)^{\theta}
$$

where,

$$
u_{1}, u_{2}=\text { wind speed at heights } 1 \text { and } 2[\mathrm{~m} / \mathrm{s}] \text {; }
$$




$$
\begin{aligned}
& z_{1}, z_{2}=\text { elevation of heights } 1 \text { and } 2[\mathrm{~m}] \text {; and, } \\
& \theta=\text { wind shear exponent. }
\end{aligned}
$$

For flat terrain, a value of $1 / 7(0.142)$ is often used; an appropriate value for open water might be 0.10 , wooded areas and suburbs 0.3 , and 0.4 for urban regions (Ray et al, 2006). A typical wind speed curve for $\theta=0.142$ is shown in Figure 20.

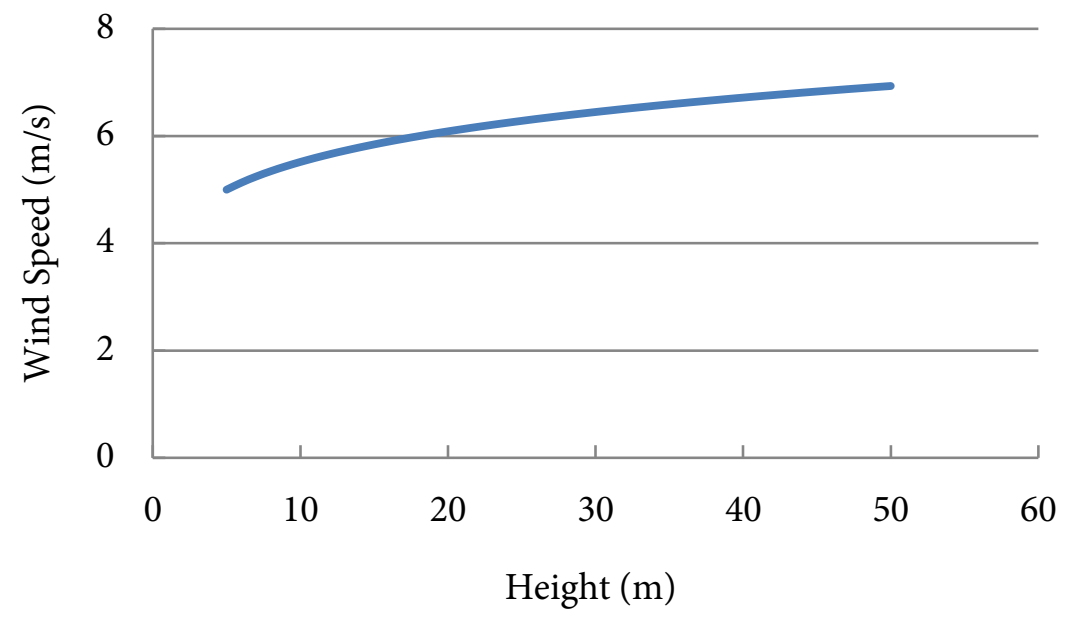

Figure 20: Wind speed variation with height above ground

In reality, the wind shear exponent is variable with time, since the wind direction and surface conditions are not constant (Quinlan, 1995). Given measurements of wind speed at two heights, the wind shear exponent can be calculated as follows:

$$
\theta=\frac{\ln u_{2}-\ln u_{1}}{\ln z_{2}-\ln z_{1}}
$$

To extrapolate measured wind speed to the turbine hub height, the wind shear exponent was calculated at each timestep. When freezing conditions were suspected as per Table 6, the heated anemometer measurement was used in the calculation.

Notwithstanding the advice of Ray et al., the limits of the wind shear exponent in TRNSYS are -0.06 to 0.30 . Even after correcting for freezing conditions, about $24 \%$ of timesteps were outside this limit. A suspected cause is freezing of one, but not both, of the heated anemometers when the unheated anemometers were also frozen. Another suspected cause is variation at low wind speeds, where the absolute difference is not large 
but the percentage difference is; this can result in a high value for wind shear outside the TRNSYS limits. To correct this issue, when the wind shear was out of the TRNSYS bounds it was replaced with the average of the entire dataset, 0.102 (out-of-bounds values were omitted when calculating this average). Since the wind mast was in an open field with few obstructions that is covered with snow for most of the year, this average is deemed reasonable when compared to the advice of Ray et al.

Global (total) radiation on horizontal and tilted planes were measured at a rate of $0.2 \mathrm{~Hz}$ and averaged over a minute. However, solar PV simulations in TRNSYS require the radiation in its constituent components:

$$
G=G_{\mathrm{b}}+G_{\mathrm{r}}+G_{\mathrm{d}}
$$

where,

$$
\begin{aligned}
& G=\text { global solar radiation }\left[\mathrm{W} / \mathrm{m}^{2}\right] \\
& G_{\mathrm{b}}=\text { beam solar radiation }\left[\mathrm{W} / \mathrm{m}^{2}\right] \\
& G_{\mathrm{r}}=\text { ground-reflected diffuse solar radiation }\left[\mathrm{W} / \mathrm{m}^{2}\right] ; \text { and, } \\
& G_{\mathrm{d}}=\text { sky diffuse solar radiation }\left[\mathrm{W} / \mathrm{m}^{2}\right]
\end{aligned}
$$

The constituent components are shown in Figure 21. For a horizontally-mounted upwards-facing pyranometer, $G_{\mathrm{r}}=0$.

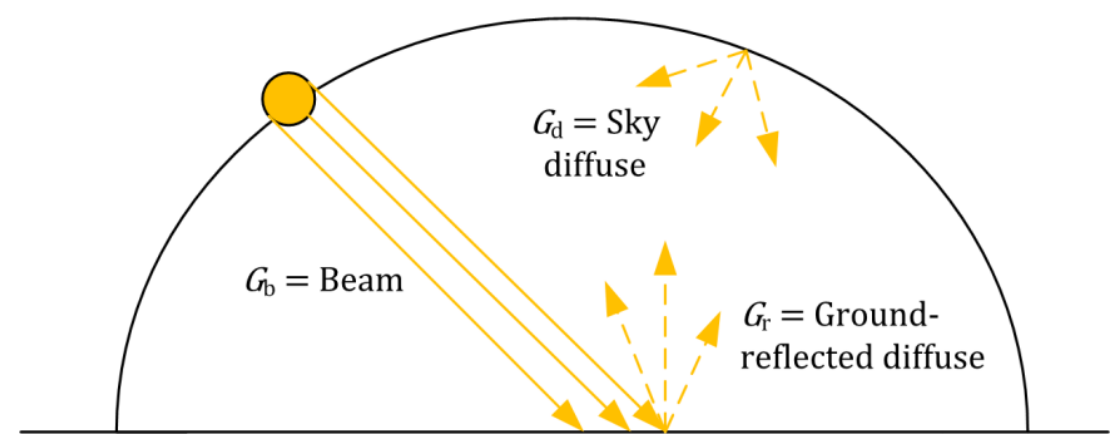

Figure 21: Components of solar radiation

When measurements of beam and diffuse radiation are unavailable, they must be calculated based on available data. The TRNSYS radiation processor subroutine includes several methods to do so; the Reindl Model was chosen since only horizontal radiation data were available. This model (Reindl et al., 1990a) uses the concept of a clearness index $K_{\mathrm{T}}$ to calculate the beam and diffuse components on a horizontal plane: 


$$
K_{T}=\frac{G}{G_{\mathrm{o}}}
$$

where $G_{\mathrm{o}}$ is the extraterrestrial solar radiation on a horizontal plane, a function of position (latitude), time of day (hour angle), and time of year (declination). Piecewise empirical relationships are then used to express the diffuse fraction, $\frac{G_{\mathrm{d}}}{G}$ as a function of the most relevant parameters: clearness index $K_{\mathrm{T}}$, solar elevation angle $\alpha$ in ${ }^{\circ}$ from the horizontal, ambient dry-bulb temperate $T_{\mathrm{db}}$ in ${ }^{\circ} \mathrm{C}$, and the relative humidity $\varphi$ in $\%$.

The beam component is total radiation minus diffuse radiation:

$$
G_{\mathrm{b}}=G-G_{\mathrm{d}}
$$

Once the constituent components have been calculated, they must then be transposed onto the plane of the PV array. Reindl e al. (1990b) also developed a model for this purpose. It accounts for ground-reflected radiation and diffuse circumsolar and horizon brightening and is more accurate than a simple isotropic sky model.

Total insolation on the tilted surface is the sum of beam, diffuse, and ground-reflected radiation:

$$
G_{\mathrm{T}}=G_{\mathrm{b}, \mathrm{T}}+G_{\mathrm{d}, \mathrm{T}}+G_{\mathrm{r}, \mathrm{T}}
$$

Ground-reflected radiation is diffuse and isotropic; therefore, it is assumed that the view to the horizon is unobstructed (Reindl et al., 1990b):

$$
G_{\mathrm{r}, \mathrm{T}}=G \rho_{\mathrm{r}}(1-\cos \beta) / 2
$$

where $\rho_{\mathrm{r}}$ is the surface albedo or reflectivity. The term $(1-\cos \beta) / 2$ in Eq. (6) accounts for the amount of ground the surface can 'see' and is equal to 0 for a horizontal surface and $1 / 2$ for a vertical tilt ( $90^{\circ}$ slope). Albedo in TRNSYS is typically based only on the presence of snow; in reality, the surface albedo is complex and depends on a number of factors, such as the time since last snowfall (personal communication, Alexandre Langlois, University of Sherbrooke, March 10, 2018). Default figures in TRNSYS are 0.2 and 0.7 for no-snow and snow cover conditions, respectively. Those figures were used in this thesis based on snow cover in Cambridge Bay: between January 1 and June 5, and October 1 and December 31, snow cover was present and the albedo was set to 0.7 . 
The tilted pyranometer allowed for comparison of measured and modelled tilted solar radiation. The measured horizontal radiation, dry-bulb temperature, and relative humidity data were input to the TRNSYS radiation processor with the slope set to $69^{\circ}$, the same as the tilted pyranometer and Cambridge Bay's latitude. The measured data were averaged over an hour. The result is shown in Figure 22.

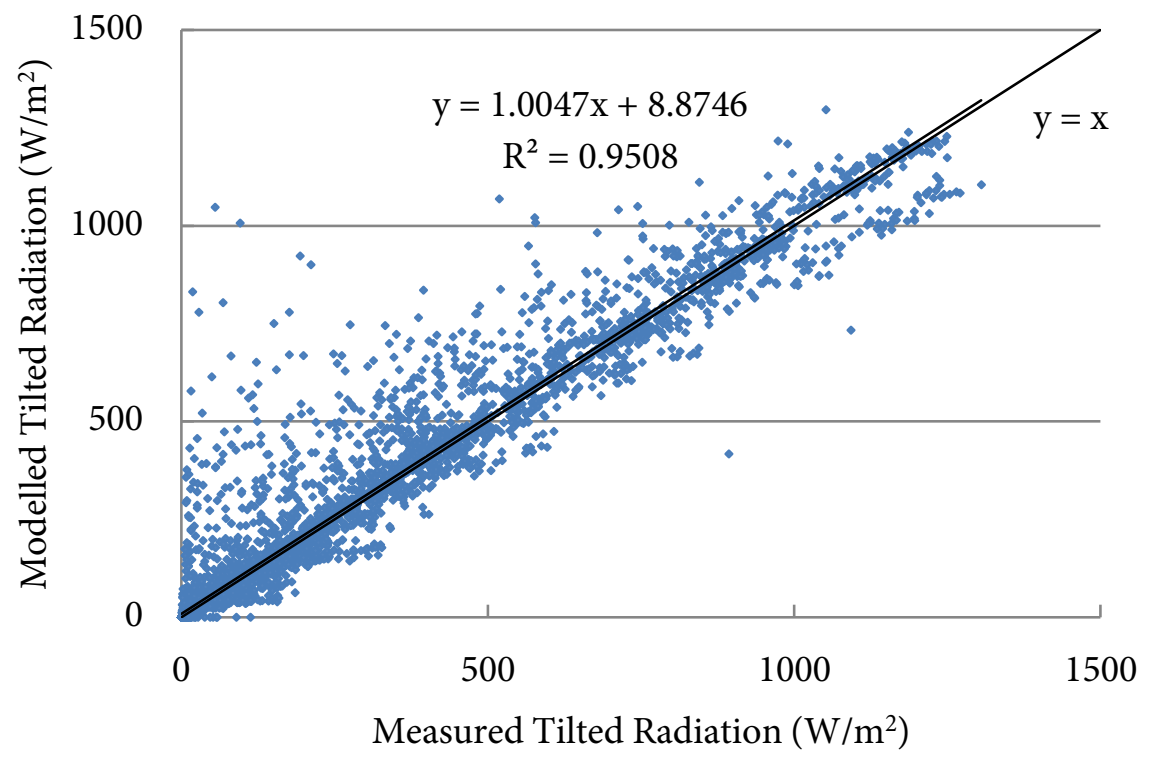

Figure 22: Comparison of measured and modelled tilted surface solar radiation

The $\mathrm{R}^{2}$ of 0.95 indicates a high goodness-of-fit of the model; however, significant scatter was observed at low levels of insolation. A residual plot was used to help determine whether a linear regression is a valid fit for the model. The residual is the difference between predicted and expected values, in this case the measured and modelled values of tilted global radiation:

$$
e=y-\hat{y}
$$

where,

$$
\begin{aligned}
& e=\text { the residual; } \\
& y=\text { the expected value (measured radiation); and, } \\
& \hat{y}=\text { the predicted value (modelled radiation). }
\end{aligned}
$$

Figure 23 shows a residual plot for the tilted global radiation. 


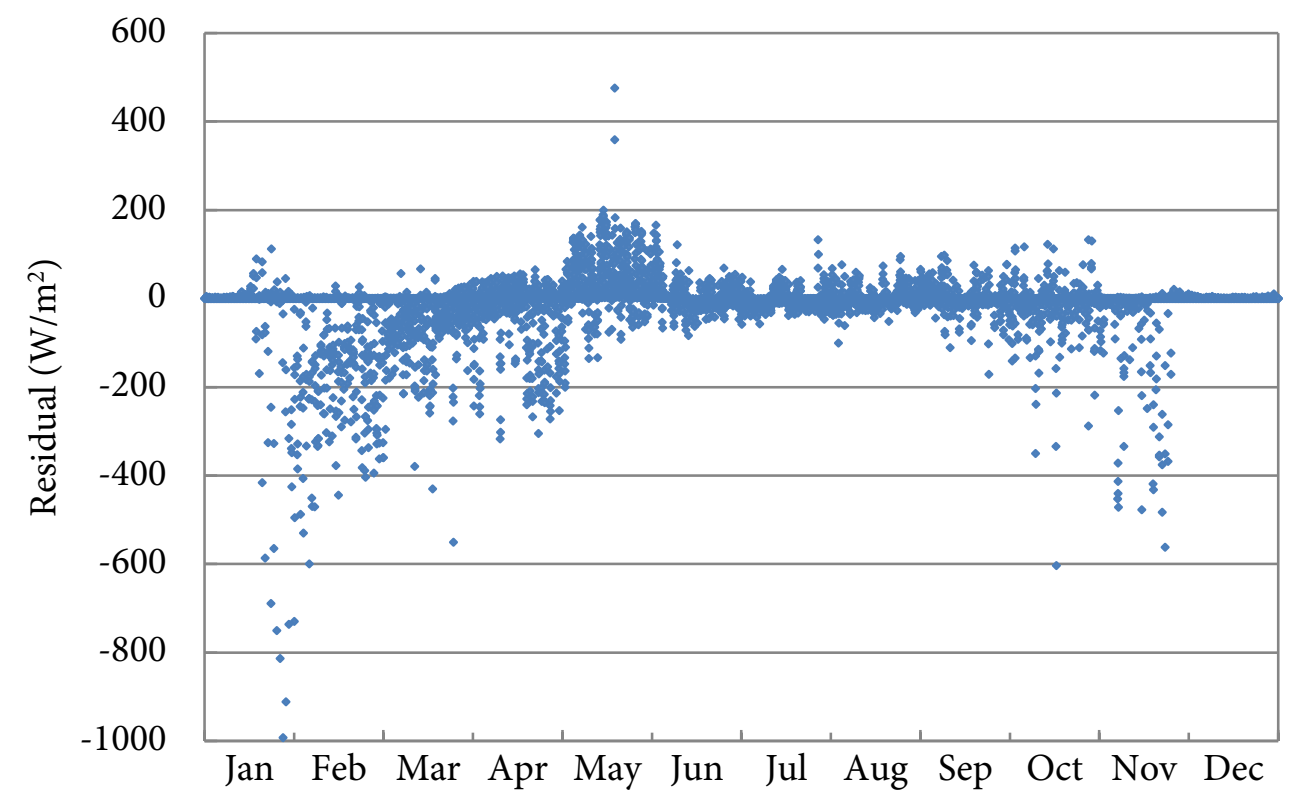

Figure 23: Residual plot of measured and modelled solar radiation on a tilted plane

The over-prediction of modelled solar radiation (negative values in Figure 23) were clustered at the beginning and end of the year; note that there is no scatter in December and early January because the sun does not rise above the horizon during this time. One possible explanation of this result is the low solar elevation angles (high zenith angle). Transposing beam radiation onto a tilted plane includes a division by cosine term:

$$
G_{\mathrm{b}, \mathrm{T}}=G_{\mathrm{b}} \frac{\cos \theta}{\cos \theta_{\mathrm{z}}}
$$

where,

$$
\begin{aligned}
& G_{\mathrm{b}}=\text { beam radiation on a horizontal plane }[\mathrm{W}] ; \\
& G_{\mathrm{b}, \mathrm{T}}=\text { beam radiation on tilted plane }[\mathrm{W}] ; \\
& \theta=\text { angle of incidence of beam radiation }\left[^{\circ}\right] ; \text { and, } \\
& \theta_{\mathrm{z}}=\text { zenith angle }\left[^{\circ}\right] .
\end{aligned}
$$

Division by the cosine term can cause problems at low solar elevation angles, since as $\theta_{\mathrm{z}} \rightarrow 90^{\circ}, \cos \theta_{\mathrm{z}} \rightarrow 0$ and hence $G_{\mathrm{b}, \mathrm{T}} \rightarrow \infty$. This could result in erroneously high values of incident radiation. In addition, the Reindl Model for determining beam and diffuse radiation is an empirical relationship with the coefficients 
extracted from datasets in the continental United States. Appropriate coefficients could differ in a northern location like Cambridge Bay, where solar radiation occurs at lower elevation angles and hence higher air mass. The transposition also requires assumptions of surface albedo, which may introduce further error.

Hoevenaars and Crawford (2011) noted that significant scatter is common in solar transposition exercises, but that the results tend to cancel out over the year, leading to differences in measured and modelled radiation of about $1-2 \%$. For this exercise, modelled radiation was $6 \%$ higher than measured on an annual basis. Measurements of diffuse and beam radiation and surface albedo could help further evaluate the accuracy of the Reindl Models as applied in Cambridge Bay and perhaps improve the algorithm. Efforts were made during this thesis to acquire and commission a solar tracker that would provide the necessary measurements; ultimately these efforts were unsuccessful and hence this analysis was beyond the scope of this thesis. It is noted however as a potential avenue for future work. 


\section{Simulation Model}

The simulation models used in this thesis were constructed in TRNSYS v.17.02 (Klein et al., 2014), a program for dynamic simulation of transient energy systems. It uses a quasi-steady-state iterative solver to reach convergence at each timestep, and it can solve differential equations using analytical or numerical approaches. TRNSYS has a modular approach to simulation, where physical phenomena are represented by individual subroutines called 'Types' (the term 'component' is used synonymously). Each Type includes:

- User-specified parameters, which do not change with time during the simulation;

- Inputs, which may vary at each timestep; and,

- Outputs, which are the result of the internal calculations of each Type based on the inputs and parameters. Outputs of one Type are often inputs to another Type.

TRNSYS has many advantages compared to other common renewable energy simulation programs. In addition to a library of standard Types, representing components such as solar PV panels, hot water tanks, weather file readers, and many others, users can write their own custom Types using a standard template. It supports parametric analyses and can be coupled with external programs, such as Excel, MatLab, and GenOpt, and allows the use of an arbitrary time period and timestep, down to one second. TRNSYS has the flexibility of both a graphical user interface and an ancillary program, TRNEDIT, to directly edit the simulation model code. Finally, the code of both the simulation kernel and the standard library of Types is open-source, allowing the user to gain a deeper understanding of the modelling logic and to easily adapt existing Types or create new Types as required.

Figure 24 shows the graphical representation of the stand-alone system configuration used in this thesis. Types are represented by icons. Where the outputs of one Type form the inputs of another Type, they are connected with a line, with the direction of the arrows indicating the flow of information (outputs to inputs). Parameters, such as the number of wind turbines, the slope of the PV array, or the location of any required external data files, are entered by double-clicking on each Type and entering the data in a pop-up window. An example is shown in Figure 25. 


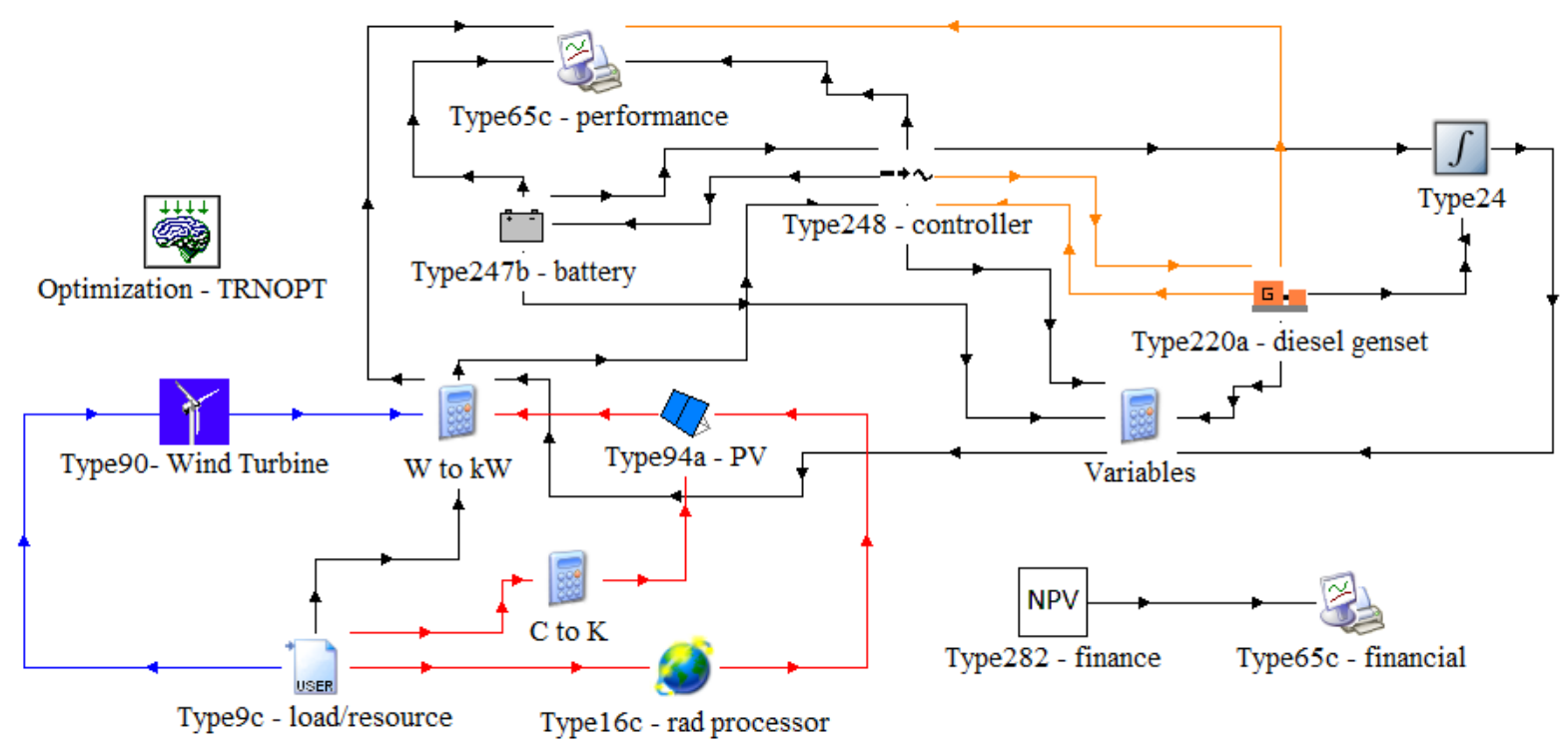

Figure 24: Stand-alone system configuration model in the Simulation Studio

\begin{tabular}{|c|c|c|c|c|c|c|c|c|}
\hline \multicolumn{8}{|c|}{ (01-gridtied.tpf) Type90- Wind Turbine } & \multirow[t]{2}{*}{$\square$} \\
\hline \multicolumn{2}{|c|}{ Parameter } & Input & it Output & \begin{tabular}{|l|l} 
Derivative & Special Cards \\
\end{tabular} & External Files & Comment & \multirow[b]{2}{*}{ More } & \\
\hline \multicolumn{2}{|l|}{ (8) } & \multicolumn{3}{|r|}{ Name } & Value & Unit & & Macro \\
\hline \multirow{6}{*}{ 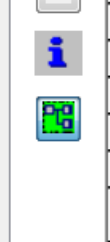 } & 1 & \multicolumn{3}{|c|}{ Site elevation } & 20 & $\mathrm{~m}$ & More... & $\nabla$ \\
\hline & 2 & (0) & \multicolumn{2}{|c|}{ Data collection Height } & 34 & $\mathrm{~m}$ & More... & $\nabla$ \\
\hline & 3 & - & \multicolumn{2}{|l|}{ Hub height } & 37 & $\mathrm{~m}$ & More... & $\nabla$ \\
\hline & 4 & बी & \multicolumn{2}{|c|}{ Turbine power loss } & effWT & string & More... & $\nabla$ \\
\hline & 5 & 圀 & \multicolumn{2}{|c|}{ Number of turbines } & NumWT & string & More... & 8 \\
\hline & $\begin{array}{ll}6 \\
\end{array}$ & (1) & \multicolumn{2}{|c|}{$\begin{array}{l}\text { Logical unit of file containing power } \\
\text { curve data }\end{array}$} & 36 & - & More... & $\nabla$ \\
\hline
\end{tabular}

Figure 25: Entering simulation parameters in Type 90

The following is a brief description of each of the Types used in this thesis. Some components were taken from the TRNSYS library. For others, the TRNSYS library did not contain a suitable Type, in which case a Type was custom-written for the purposes of this thesis; by convention, custom components are numbered 2xx.

Standard components from the TRNSYS library include:

- Type 9c: a data file reader that reads in the load (demand) and resource (weather) data;

- Type 16c: a radiation processor that extracts from global horizontal radiation data the constituent components and transposes onto the plane of the PV array; 
- $\quad$ Type 90: $100 \mathrm{~kW}$, Arctic-rated wind turbine(s);

- Type 94a: a monocrystalline solar PV array;

- Type 65: a printer used several times, this Type prints user-selected outputs from the simulation to an external data file. It can also be used to graphically display the outputs as the simulation progresses;

- Type 24: an integrator, used to integrate an output over the course of the simulation (e.g., cost of fuel at each timestep the obtain annual fuel cost);

- TRNOPT: this Type calls GenOpt, the external optimization program; and,

- Calculators: these are used to change units when required, or to store the value of some simulation parameters as a string. For example, the number of wind turbines is not entered directly in Type 90; instead, as per Figure 25, it is entered as string called 'NumWT'. NumWT is stored in the Calculator titled 'Variables'.

There are at least three reasons to store parameters as strings in a Calculator. First, doing so makes it easier to change them as required during the design process and to see all other parameters at the same time. Second, some variables are functions of other variables - for example, the total capital cost depends on the number of wind turbines, solar panels, battery size, etc. To calculate these variables, they need to be defined in a Calculator instead of within a Type. Finally, GenOpt works with text files and therefore requires design vector variables to be defined as a string in order to modify them during the optimization process.

Custom components written for this thesis include:

- Type 247: an energy storage (lithium ion battery) model. There are two options, 247a and $247 \mathrm{~b}$, corresponding to different approaches to handling the battery cycling count;

- Type 248: a controller meant to be used in conjunction with Type 247. Type 248 evaluates the energy balance (supply and demand) and will either draw power from or supply power to the battery as appropriate; 
- Type 220: a diesel generator. It has two options, Type 220a, which uses built-in fuel consumption coefficients, and Type 220b, where the user can supply the coefficients. For grid-connected scenarios, where any shortfall in demand is met through grid-purchased power, Type 220 was not used; and,

- Type 282: a financial calculator that computes the system net present cost (NPC). The purpose of the optimization is to minimize the output of this Type.

Figure 26 shows the system architecture. Energy generators and the lithium-ion battery bank were connected to an AC bus, which serves the primary load (CHARS electrical demand) and secondary load (CHARS heating demand or community electrical grid). Heating demand could be met through glycol storage tanks with electric resistance heaters, with thermal storage supporting load-shifting. Where a secondary load was present, it was assumed that all surplus power could be used. Any shortfall in demand was met through either an on-site diesel generator in the stand-alone configuration, or from the Cambridge Bay grid in the grid-tied configuration. While typically multiple diesel gensets would be used in a stand-alone configuration in order to provide redundancy and potentially more efficient operation, this was omitted in favour of the simplicity of a single generator.

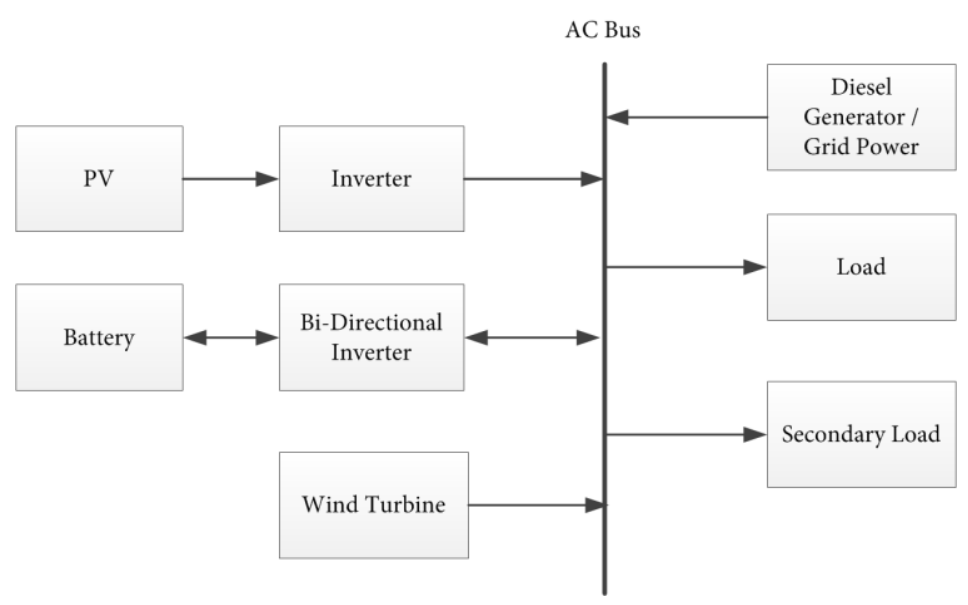

Figure 26: Model system architecture

The PV inverter converts DC output into an AC waveform. The battery, which is charged and discharged with DC current, is coupled to a bi-directional inverter. While it is possible to connect both the battery and PV to a DC bus, this is not typically done in larger systems. Since a direct connection can result in battery over-voltage and fire or explosion hazards, separate DC/DC converters must be used for the PV 
and battery. This approach results in higher losses compared to a DC/AC inverter coupled to an AC bus. Further, coupling through an AC bus improves system modularity (Thompson, 2016).

Omitted from Figure 26 is a dump load, required for when the batteries or secondary load are not capable of absorbing the entire surplus power. Without a dump load, damage could be caused to both batteries and secondary loads (e.g. overcharging of thermal storage tanks). Typically, a dump load is included with inverters or charge regulators and takes the form of thermal resistors and a controller (Ismail et al., 2015). While details of the dump load were abstracted from this study and are assumed to be included in the cost of other components (e.g. the solar PV array), in practice the dump load can be a significant component and may have to be sized for the peak capacity of the renewable generators.

As modelled in TRNSYS, the system computes an energy balance at each timestep, where the power in $\mathrm{kW}$ into or out of each component is constant over the timestep:

$$
\begin{gathered}
P_{\text {net }}=0=P_{\text {load }}+P_{\text {surplus }}-P_{\text {unmet }}-\left(\eta_{\mathrm{PV}} * P_{\mathrm{PV}}\right)-\left(\eta_{\mathrm{WT}} * P_{\mathrm{WT}}\right)+\left(\eta_{\text {battery }} * P_{\text {battery }}\right) \\
-P_{\text {diesel }}
\end{gathered}
$$

where,

$P_{\text {load }}=$ CHARS electrical demand $[\mathrm{W}]$;

$P_{\text {surplus }}=$ any surplus generated power that cannot feed the battery due to battery capacity or power limitations;

$P_{\text {unmet }}=$ any shortfall in meeting $P_{\text {load }}$; since in this thesis all system configurations have a firm source of power (either an on-site diesel generator or grid-purchased power), $P_{\text {unmet }}$ is typically very low or zero;

$P_{\mathrm{PV}}=$ power from the $\mathrm{PV}$ array;

$\eta_{\mathrm{PV}}=$ efficiency term that accounts for losses from the PV array, including dirt and soiling, the inverter, voltage mismatch, shading, and electrical transmission [\%];

$P_{\mathrm{WT}}=$ wind turbine power; 
$\eta_{\mathrm{WT}}=$ efficiency term that accounts for losses from the wind turbine(s), including blade soiling, icing, power conditioning, and electrical transmission [\%];

$P_{\text {battery }}=$ power to (+) or from (-) the battery;

$\eta_{\text {battery }}=$ efficiency term that accounts for losses in the battery from the inverter, temperature impacts, and other electrical losses [\%]; and,

$P_{\text {diesel }}=$ power from the on-site diesel generator or the grid, depending on the scenario

Details on $\eta_{\mathrm{PV}}, \eta_{\mathrm{WT}}$, and $\eta_{\text {battery }}$ are explained in the respective following sections. $P_{\text {diesel }}$ does not have an efficiency term since it represents the power delivered to the AC bus; to determine fuel consumption, the efficiency of the diesel plant is calculated internally by Type 220 or by assumptions of the power corporation's plant efficiency. Transmission losses are assumed negligible in the case of on-site generation or are assumed to be included in the power corporation's plant efficiency.

Each component, including parameters and design variables, is described in the following.

\subsection{Controller Model \& Dispatch Strategy}

Type 248 is a controller model meant to operate in conjunction with Type 247, the battery model developed for this thesis. Type 248 directs the flow of power from renewable and diesel generators, to or from the battery, and to the load according to an implicit dispatch strategy.

The dispatch strategy refers to the control of energy flows among energy generators, load, and storage. Barley and Winn (1996) outlined a variety of strategies and compared them to an ideal predictive strategy using historical data. These strategies include:

- Load-following, where the diesel never charges the batteries except when necessary to keep diesel power output above the minimum set-point;

- State-of-charge set-point, where the diesel will run until the battery is charged to a prescribed SOC; and, 
- Full power/minimum run-time, where the diesel operates at maximum (or most efficient) power output for a minimum run time.

Barley et al. (1995) noted that full charging of batteries with diesel energy is unlikely to be cost effective. Given that the cost of battery storage has declined significantly since then, and the cost of diesel fuel has increased, it is unlikely to be an effective strategy today. Therefore Type 248 uses the load-following dispatch strategy, described in Figure 27. The objective of the strategy is to draw as little diesel power as possible.

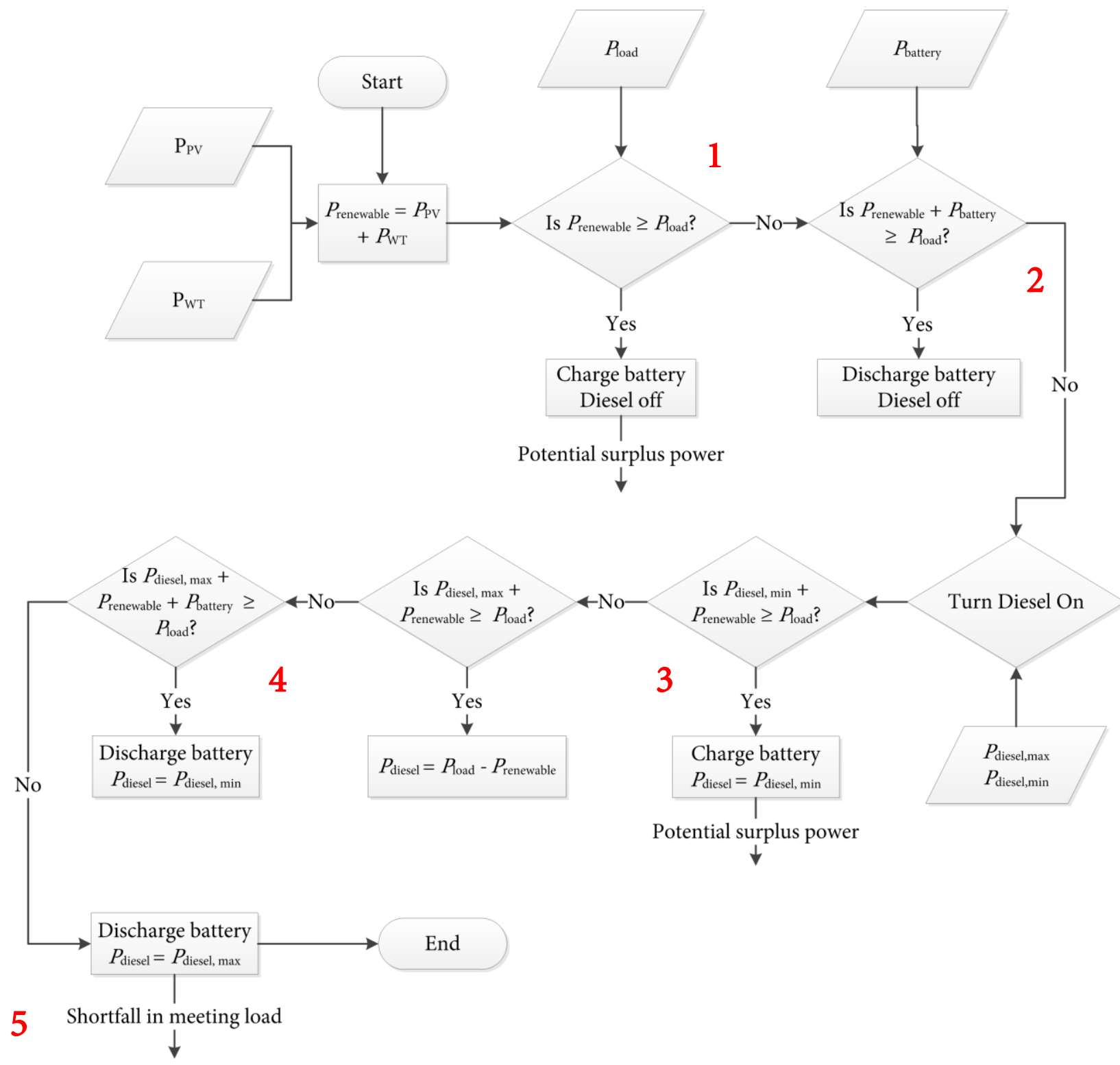

Figure 27: Dispatch strategy flow chart 
Power into or out of the battery was constrained by the size of the power conditioning system, $P_{\mathrm{PCS}}$, and the maximum possible stored energy, $E_{\text {battery,max }}$ for example, when $P_{\text {renewable }}>P_{\text {load }}$ and the battery was charging, $P_{\text {battery }}>0$ :

$$
P_{\text {battery }}=\min \left[P_{\text {renewable }}-P_{\text {load }}, P_{\mathrm{PCS}}, \frac{(1-f S O C) \cdot E_{\text {battery,max }}}{\Delta t}\right]
$$

When $P_{\text {battery }}<0$ and the battery was discharging,

$$
P_{\text {battery }}=\min \left[P_{\text {renewable }}-P_{\text {load }},-P_{\mathrm{PCS}},-\frac{(1-f S O C) \cdot E_{\text {battery,max }}}{\Delta t}\right]
$$

Surplus power occurred when the battery could not accept all generated power in excess of the load, either due to limitations from the PCS or the available storage space in the battery:

$$
P_{\text {surplus }}=\max \left[P_{\text {renewable }}+P_{\text {diesel }}-P_{\text {load }}-P_{\text {battery }}, 0\right]
$$

In this case, the surplus power was either spilled (dumped) or used to power a secondary load.

At Point 1 in Figure 27, the total available renewable power was compared to the load. If $P_{\text {renewable }}>$ $P_{\text {load }}$, the extra power was used to charge the battery if possible.

At Point 2, the generated renewable power was not sufficient to meet the load. In this condition, the system drew power from the battery, subject to the conditions noted above. If available battery power was sufficient to meet the load, no diesel power was drawn.

At Point 3, power was drawn from either the grid or the on-site diesel generator, depending on the configuration. In the former, the grid was assumed to meet the load deficit at all times and no surplus power was generated. In the stand-alone configuration, available diesel power was subject to minimum and maximum loading, $P_{\text {diesel,min }}$ and $P_{\text {diesel,max }}$. This was set to $30 \%$ and $100 \%$ of the rated power, respectively, and could result in either battery charging and/or surplus power due to minimum loading, or not meeting the load due to the maximum loading restriction. 
At Point 4, diesel and renewable power alone were not sufficient to meet the demand, and power was drawn from the battery. Finally at Point 5, the available power from all sources was not sufficient to meet the demand. This did not occur in practice due to the reliability constraint on the model; see Section 6.3 for more details.

Type 248 has two parameters, the efficiency of the battery's bi-directional inverter $\eta_{\text {battery, and the }}$ inverter/power conditioning system capacity $P_{\mathrm{PCS}}[\mathrm{kW}]$. The latter was a design variable in this thesis, while $\eta_{\text {battery }}=0.95$, resulting in a round-trip efficiency of approximately $90 \%$ which is typical of lithium-ion batteries (Zakeri and Syri, 2015).

Outputs from Type 248 include power to or from the battery, surplus power, power to load, unmet load, and losses due to the battery inverter. It also outputs the residual demand after other generators are considered; this output is used to control the diesel generator output or grid power draw.

\subsection{Electrical Storage Model}

Type 247 is a generic electrical storage model that maintains a power balance between the storage and the controller. The state-of-charge (SOC) is the amount of energy stored in kWh and is given at time $\mathrm{t}+1$ by (Luna-Rubio et al., 2012):

$$
\operatorname{SOC}(t+1)=S O C(t) \cdot \sigma+P_{\text {battery }}(t) \cdot \Delta t \cdot \eta_{\text {battery }}
$$

where,

$$
\begin{aligned}
& \sigma=\text { self-discharge rate of the storage [kWh/hour]; } \\
& P_{\text {battery }}(t)=\text { power into }(+) \text { or out of }(-) \text { the storage }[\mathrm{kW}] \\
& \Delta t=\text { timestep (e.g., an hour); and. } \\
& \eta_{\text {battery }}=\text { charging or discharging efficiency [\%]. }
\end{aligned}
$$

In this model, self-discharge is neglected. This is a reasonable assumption for a lithium-ion battery, where self-discharge is on the order of $0.1-0.3 \%$ per day, but is not valid for other battery chemistries such as 
sodium-sulphur or mechanical storage such as flywheels, where self-discharge could be on the order of $20 \%$ and $100 \%$ per day, respectively (Zakeri and Syri, 2015). Another consideration is the battery's discharge rate - as the discharge rate of a lithium-ion battery increases, the effective electrical capacity declines. Effective capacity also declines at lower temperature (Traub, 2016). These details were abstract from the model in the interest of simplicity with the understanding that they are not trivial considerations for hybrid system design. Furthermore, coupled with the PCS, the system was assumed to be able to maintain grid stability (e.g. voltage and current); a detailed electrical design would be required for a real system.

Parameters of Type 247 include $E_{\text {battery,max }}$, the battery capacity [kWh]; the minimum and maximum fractional state-of-charge, $f S O C \in[0,1]$; and initial $f S O C$ (at the beginning of the simulation).

The maximum charging and discharging capacity, $P_{\mathrm{PCS}}[\mathrm{kW}]$ (for 'power conditioning system'), and the efficiency $\eta_{\text {battery }}$ is handled by Type 248 , the controller. Types 247 and 248 are meant to be used in conjunction.

Finally, Type 247 includes two methods to count the number of battery cycles. Saldanha (2010) measured the number of cycles of a lithium-ion battery by summing the absolute change in depth-of-discharge. Once the sum equaled the battery capacity, it was treated as a single cycle. On the other hand, Duggal and Venkatesh (2015) treated every switch from discharge to charge as a new cycle. In reality, battery cycling is complex and depends on the depth-of-discharge, the frequency of switching, battery temperature, and other factors. For example, Rahn and Wang (2013) noted that the life-cycle of typical lithium-ion batteries can range from 3000 cycles at $100 \%$ depth-of-discharge to 20,000 at $20-40 \%$ depth-of-discharge. The approaches of Saldanha as well as Duggal and Venkatesh are reasonable upper and lower bounds, respectively, for cycle-counting. Type 247 allows the user to choose their approach.

In this thesis, $E_{\text {battery,max }}$ was a design variable. Minimum and maximum $f S O C$ were 0.1 and 1.0, respectively, to prevent under- and over-charging. Initial $f S O C$ was set to 0.5 . Saldanha's approach to counting cycles was used, where an absolute energy change equal to battery capacity was treated as one cycle. 


\subsection{Photovoltaic Model}

Type 94 is a silicon PV model included in the standard TRNSYS model libraries. It is based on the PV current-voltage (I-V) curve described in Section 3.3 and was modelled by Townsend (1989) and implemented in TRNSYS by Eckstein (1990). The model defines an equivalent circuit consisting of a single current source in series with a resistance and in parallel with a diode, shown in Figure 28 (adapted from Townsend):

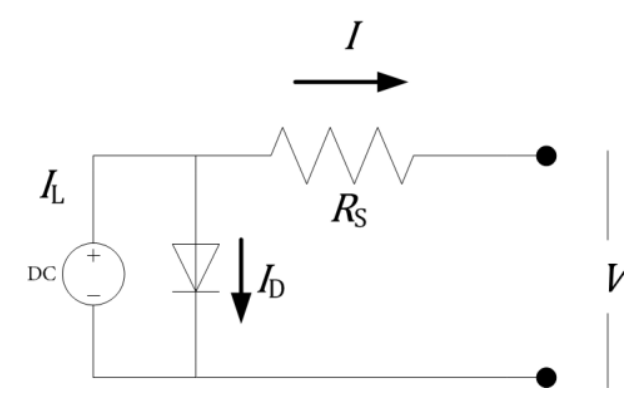

Figure 28: Ideal photovoltaic cell equivalent circuit

where,

$$
\begin{aligned}
& I=\text { output current }[\mathrm{A}] \\
& V=\text { output voltage }[\mathrm{V}] \\
& R_{\mathrm{S}}=\mathrm{PV} \text { module series resistance }[\Omega] ; \\
& I_{\mathrm{L}}=\text { light-generated current from the PV module }[\mathrm{A}] \text {; and, } \\
& I_{\mathrm{D}}=\text { diode current }[\mathrm{A}]
\end{aligned}
$$

This model, the 'four-parameter model', applies to crystalline PV cells where the shunt resistance is assumed to be infinite. The four parameters are:

- $\quad I_{\mathrm{L}, \mathrm{ref}}$ - module photocurrent at reference conditions (typically $1000 \mathrm{~W} / \mathrm{m}^{2}$ and $298 \mathrm{~K}$ ) [A];

- $I_{\mathrm{O}, \mathrm{ref}}$ - diode reverse saturation current at reference conditions [A];

- $\quad \gamma$ - diode ideality factor as noted in Eq. (5); and,

- $\quad R_{\mathrm{S}}-\mathrm{PV}$ module series resistance $[\Omega]$. 
The four parameters cannot be measured directly, but they can be computed using test data commonly found on PV manufacturers' data sheets. This is the great strength of the four-parameter model: it is more accurate than a simple efficiency model but does not require special testing or esoteric knowledge in order to compute the power output of a PV array. Eckstein (1990) noted that the model had reasonable computation time and was a good match for experimental data.

The four-parameter model accounts for the variation in power output with incident radiation and decreasing efficiency with rising cell temperature. The TRNSYS implementation also accounts for the dependence of panel reflectivity on the incident angle of beam radiation; this has the effect of reducing power output at high incident angles. Finally, the model incorporates maximum power point tracking if desired by the user. These trackers are used in grid-connected systems and fix the output voltage at the point of maximum power, as shown in Figure 15.

The four-parameter model strikes a good balance between accuracy and modelling complexity. More recent efforts have evaluated the deviation of datasheet parameters at ambient conditions different from reference conditions (e.g., Zhou et al., 2007, and Khezzar et al., 2014); however this approach requires additional specialized testing of the specific PV module under consideration and negates the advantage of only requiring typical datasheet information. Therefore the original four-parameter model as coded in Type 94 was used in this thesis.

A typical 250 W crystalline PV panel (Resun Solar, 2015) was chosen as indicative of current technology a review of front-page products on a typical vendor website (ENF Solar, 2017) indicates an average panel size of $240 \mathrm{~W}$ and an average efficiency of about 17\%, similar to the characteristics of the chosen panel. Although PV efficiency typically slowly degrades as time progresses, this was omitted from the model as the life-cycle costs were based on a single annual simulation. Instead, the cost escalation of fuel/grid electricity costs served as a proxy for degrading PV output.

One- and two-axis tracking mechanisms could potentially have significantly boosted power output, particularly during the 'midnight sun' in June and July, when the sun does not set. However, considering the permafrost soil conditions and harsh ambient conditions, inclusion of a tracker would increase O\&M 
and the risk of system failure and hence was omitted. Further study should be conducted to quantify the potential output increase and to identify foundation design and system maintenance issues.

Slope, azimuth, and number of panels were design variables. Losses $-\eta_{\mathrm{PV}}$ in Eq. (7) - were set at $10 \%$. This is considered typical for a modern, well-maintained system (e.g., Santiago et al., 2017). Model parameters are summarized in Table 7; Table 8 contains other physical characteristics of interest.

Table 7: PV model parameters

\begin{tabular}{|c|c|c|}
\hline Parameter & Symbol & Value \\
\hline Reference temperature & $T_{\mathrm{c}, \mathrm{ref}}$ & $298 \mathrm{~K}$ \\
\hline Reference Insolation & $G_{\mathrm{ref}}$ & $1000 \mathrm{~W} / \mathrm{m}^{2}$ \\
\hline Module short-circuit current, reference conditions & $I_{\mathrm{sc}, \mathrm{ref}}$ & $8.52 \mathrm{~A}$ \\
\hline $\begin{array}{c}\text { Temperature coefficient of short-circuit current, reference } \\
\text { conditions }\end{array}$ & $\mu_{\mathrm{sc}}$ & $0.003834 \mathrm{~A} / \mathrm{K}$ \\
\hline Module open-circuit voltage, reference conditions & $V_{\mathrm{oc}, \mathrm{ref}}$ & $37.2 \mathrm{~V}$ \\
\hline Temperature coefficient of open-circuit voltage, reference \\
conditions & $\mu_{\mathrm{voc}}$ & $-0.1562 \mathrm{~V} / \mathrm{K}$ \\
\hline Module voltage at max power point, reference conditions & $V_{\mathrm{mp}, \mathrm{ref}}$ & $30.8 \mathrm{~V}$ \\
\hline Module current at max power point, reference conditions & $I_{\mathrm{mp}, \mathrm{ref}}$ & $7.86 \mathrm{~A}$ \\
\hline \# of cells wired in series & - & 60 \\
\hline Module temperature, nominal operating cell temperature & $T_{\mathrm{c}, \mathrm{NOCT}}$ & $318 \mathrm{~K}$ \\
\hline Ambient temperature, nominal operating cell temperature & $T_{\mathrm{a}, \mathrm{NOCT}}$ & $293 \mathrm{~K}$ \\
\hline Module area & $A$ & $1.62 \mathrm{~m}{ }^{2}$ \\
\hline Reflectivity-absorptance (tau-alpha) product for normal incidence & $\tau \alpha$ & 0.9 \\
\hline Incident angle modifier used? & - & Yes \\
\hline Semiconductor bandgap & $E$ & $1.12 \mathrm{eV}$ \\
\hline Slope of IV curve at short-circuit current & $\left(\frac{d I}{d V}\right)_{\mathrm{V}=0}$ & 0 \\
\hline Miscellaneous losses & - & $10 \%$ \\
\hline
\end{tabular}

Table 8: Physical characteristics of the PV module

\begin{tabular}{|c|c|}
\hline Parameter & Value \\
\hline Nominal maximum power & $250 \mathrm{~W}$ \\
\hline Operating temperature & $-40^{\circ} \mathrm{C}-+85^{\circ} \mathrm{C}$ \\
\hline Dimensions & $1.640 \mathrm{~m} \mathrm{x} 0.992 \mathrm{~m} \mathrm{x} 0.040 \mathrm{~m}$ \\
\hline Mass & $18 \mathrm{~kg}$ \\
\hline Modules per pallet & 26 \\
\hline Efficiency at reference conditions & $18.0 \%$ \\
\hline Power tolerance & $0-+5 \mathrm{~W}$ \\
\hline
\end{tabular}




\subsection{Wind Turbine Model}

Unlike the solar PV model, the wind turbine model Type 90 does not directly simulate system performance based on physical characteristics. Instead, it reads a data file that contains the power curve data - the power output of the wind turbine as a function of wind speed. These data are typically provided by manufacturers on their datasheets. The model interpolates wind speed as required and adjusts the power output based on air density. It can also extrapolate wind speed data to an arbitrary hub height (Quinlan, 1996).

Power curves are generated by manufacturers based on International Standard IEC 61400-12-1 (Lydia, 2014). Approaches to power curve generation have known issues that affect accuracy. For example, it can be difficult to make wind speed measurements without impacting the turbine and vice versa. Another problem is that an anemometer provides a point-source measurement, while variable wind speeds may be exhibited across the face of the turbine. Inertial effects can also contribute to scatter in a power/wind speed plot.

These issues are typically addressed by dividing normalized wind speed and power measurements into bins containing ten-minute averaged data (Quinlan, 1996). The resulting power curves therefore do not provide information about dynamic effects at sub-ten-minute time periods. Nevertheless, power curves are easily available and support a simulation approach that does not require detailed knowledge of turbine dynamic behavior or fluid flow. For these reasons, Type 90 was used in this thesis.

Power curves are typically provided at an air density of $1.225 \mathrm{~kg} / \mathrm{m}^{3}$; Type 90 adjusts the power output according to actual air density based on a linear relationship:

$$
P_{\text {corr }}=P_{\text {rated }} \times \frac{\rho_{\text {elev }}}{\rho_{\text {std }}}
$$

where,

$$
\begin{aligned}
& P_{\text {corr }}=\text { power output corrected for air density }[\mathrm{kW}] \\
& P_{\text {rated }}=\text { rated power output as per the power curve }[\mathrm{kW}] \\
& \rho_{\text {elev }}=\text { density at hub height }\left[\mathrm{kg} / \mathrm{m}^{3}\right] ; \text { and, }
\end{aligned}
$$




$$
\rho_{\text {std }}=\text { air density used to generate power curve (typically } 1.225 \mathrm{~kg} / \mathrm{m}^{3} \text { ). }
$$

Air density is calculated from pressure and temperature using the ideal gas law:

$$
\rho_{\mathrm{elev}}=\frac{P_{\mathrm{elev}}}{R T_{\mathrm{elev}}}
$$

where,

$$
\begin{aligned}
& P_{\text {elev }}=\text { pressure at hub height }[\mathrm{Pa}] \\
& R=\text { gas constant }(287 \mathrm{~J} / \mathrm{kg}-\mathrm{K} \text { for dry air }) ; \text { and, } \\
& T_{\text {elev }}=\text { temperature at hub height }[\mathrm{K}]
\end{aligned}
$$

For this thesis, temperature measurements at the base of the meteorological mast and atmospheric pressure measurements from the nearby airport were used and were assumed constant up to the hub height. Type 90 can also account for wind shear. As noted in Section 4.3, the power law was used to calculate wind shear at each timestep based on measured data. This was an input to Type 90, which then extrapolated the wind speed to hub height.

The chosen wind turbine has a nominal power output of $100 \mathrm{~kW}$. This is smaller than typical utility-scale wind turbines in lower-latitude locations, which tend to be MW-scale and are much too large for CHARS. The specific model selected for this thesis is adapted for cold-climate operation. It is rated to $-40^{\circ} \mathrm{C}$, uses a permanent magnet direct-drive system that eliminates gearbox maintenance issues, and features a hydrophobic coating on the blades to reduce icing (Northern Power Systems, 2014).

The power curve for the turbine is shown in Figure 29, with the associated data in Table 9. Turbine parameters are summarized in Table 10 . Losses $-\eta_{\mathrm{WT}}$ in Eq. $(7)-$ were set at $10 \%$. One report (Clifton, 2016) estimated that losses are typically in the range of 7\%-31\%; however, the largest potential loss (10\%) came from wake effects due to the presence of multiple turbines. Since the number of turbines considered in this thesis is relatively low, wake effects were neglected. Curtailment due to power purchase agreements contributed an additional 4\% (maximum) loss and is not applicable in this thesis, since surplus power is explicitly addressed in the financial model. Hence, $10 \%$ was deemed reasonable for this thesis, with the 
caveat that wind turbine production losses are site-specific and, in particular, icing impacts may be underestimated.

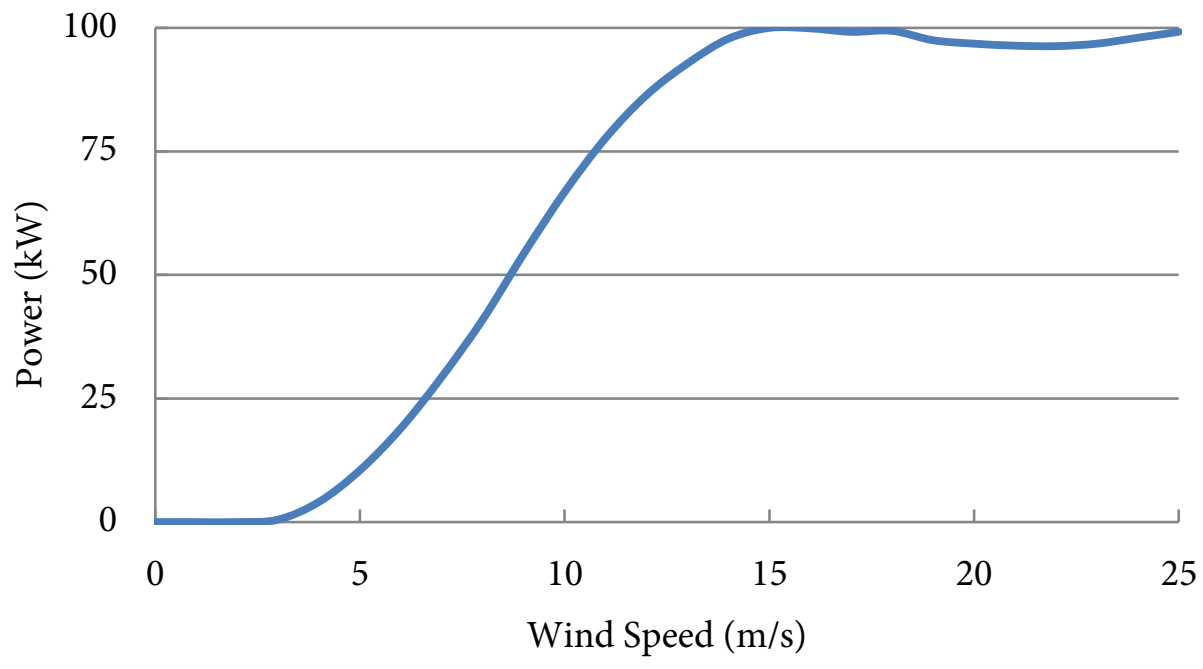

Figure 29: Wind turbine power curve

Table 9: Wind turbine power curve data

\begin{tabular}{|c|c|c|c|}
\hline Wind Speed $(\mathrm{m} / \mathbf{s})$ & Power $(\mathrm{kW})$ & Wind Speed $(\mathrm{m} / \mathbf{s})$ & Power $(\mathrm{kW})$ \\
\hline 0 & 0 & 13 & 92.8 \\
\hline 1 & 0 & 14 & 97.8 \\
\hline 2 & 0 & 15 & 100 \\
\hline 3 & 0.5 & 16 & 99.9 \\
\hline 4 & 4.1 & 17 & 99.2 \\
\hline 5 & 10.5 & 18 & 99.4 \\
\hline 6 & 19 & 19 & 97.5 \\
\hline 7 & 29.4 & 20 & 96.8 \\
\hline 8 & 41 & 21 & 96.4 \\
\hline 9 & 54.3 & 22 & 96.3 \\
\hline 10 & 66.8 & 23 & 96.8 \\
\hline 11 & 77.7 & 24 & 98 \\
\hline 12 & 86.4 & 25 & 99.2 \\
\hline
\end{tabular}


Table 10: Wind turbine parameters

\begin{tabular}{|c|c|}
\hline Parameter & Value \\
\hline Design class & IEC IIA \\
\hline Control mode & Stall \\
\hline Rotor height & $37 \mathrm{~m}$ \\
\hline Rotor diameter & $21 \mathrm{~m}$ \\
\hline Shear exponent & Variable \\
\hline Turbulence intensity & 0.07 \\
\hline Standard air density & $1.255 \mathrm{~kg} / \mathrm{m}^{3}$ \\
\hline Rated power & $100 \mathrm{kw}$ \\
\hline Rated speed & $14.5 \mathrm{~m} / \mathrm{s}$ \\
\hline Operating temperature & $-40^{\circ} \mathrm{C}-+50^{\circ} \mathrm{C}$ \\
\hline Tower type & Monopole \\
\hline Miscellaneous losses & $10 \%$ \\
\hline
\end{tabular}

\subsection{Diesel Generator Model}

The diesel generator model, Type 220, was custom-written based on the standard component Type 120, adapted to include a run-time counter that measures hours of operation. The counter helps to capture the economic benefit of shutting off the diesel engines during times of high renewable output, which in addition to saving fuel also reduces wear-and-tear on the generator and the associated maintenance costs.

Parameters of Type 220 include the nominal power rating of the diesel, the maximum power output as a fraction of nominal power (since diesel engines can typically run above rated power for limited periods of time), the minimum power output as a fraction of nominal power, and the minimum run-time. The minimum run-time prevents too-frequent switching of the diesel, which can result in increased maintenance issues. Outputs include power, fuel and electrical efficiency, volume of fuel consumed, waste heat, total run-time and current run-time (the run-time since the last switching event).

Figure 30 shows the fuel consumption and efficiency curves for a typical $545 \mathrm{~kW}$ prime power diesel genset (Cummings, 2016). Fuel consumption in litres/h is approximately linear, while the efficiency in $\mathrm{kWh} / \mathrm{L}$ usually peaks at about $80-85 \%$ of the nominal (rated) power, declining sharply below about $50 \%$. Manufacturers do not usually include fuel consumption data below 25\% of rated power, as operation below this power level is not recommended. 


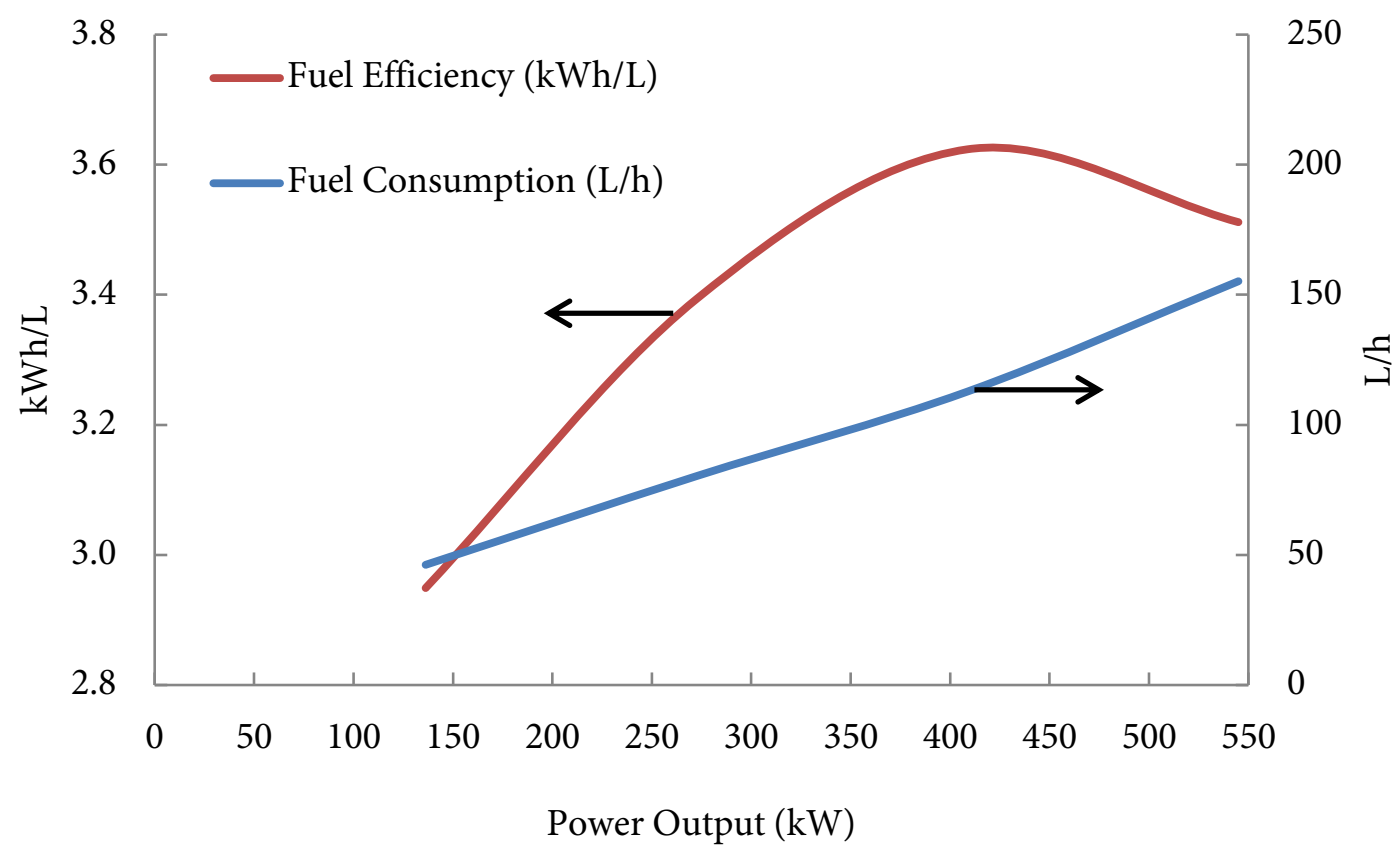

Figure 30: Fuel consumption and efficiency for a $545 \mathrm{~kW}$ prime power diesel genset

Assuming linear fuel consumption in the form $y=a x+b$ :

$$
\begin{gathered}
y=\dot{V}_{\text {fuel }} \\
x=\frac{P_{\text {genset }}}{P_{\text {genset,rated }}} \\
\dot{V}_{\text {fuel }}=a \frac{P_{\text {genset }}}{P_{\text {genset,rated }}}+b
\end{gathered}
$$

where,

$$
\begin{aligned}
& \dot{V}_{\text {fuel }}=\text { volumetric fuel consumption }[\mathrm{L} / \mathrm{h}] \\
& P_{\text {genset }}=\text { electric power output from the generator }[\mathrm{kW}] \\
& P_{\text {genset,rated }}=\text { rated or nominal electric power output }[\mathrm{kW}] \text {; and, } \\
& a \text { and } b=\text { fuel consumption curve coefficients }[\mathrm{L} / \mathrm{h}]
\end{aligned}
$$

Fuel efficiency in $\mathrm{kWh} / \mathrm{L}$ is: 


$$
\eta_{\text {fuel }}=\frac{P_{\text {genset }}}{\dot{V}_{\text {fuel }}}
$$

and electrical efficiency in \% is:

$$
\eta_{\text {electrical }}=\frac{P_{\text {genset }}}{\rho_{\text {fuel }} \times \dot{V}_{\text {fuel }} \times l h v_{\text {fuel }}} \times 3600 \frac{\text { seconds }}{\text { hour }}
$$

where,

$$
\begin{aligned}
& \rho_{\text {fuel }}=\text { fuel density }\left[\mathrm{kg} / \mathrm{m}^{3}\right] \text {; and, } \\
& l h v_{\text {fuel }}=\text { fuel lower heating value }[\mathrm{kJ} / \mathrm{kg}] .
\end{aligned}
$$

The lower heating was used since, unlike a condensing boiler, a diesel engine does not condense the water vapour in the combustion products (Bacha et al., 2007).

The electrical efficiency describes how much energy in the fuel is converted to electricity. The rest is converted to heat, and thermal energy losses are calculated by:

$$
\dot{Q}_{\text {genset }}=P_{\text {genset }} \times \frac{\left(1-\eta_{\text {electric }}\right)}{\eta_{\text {electric }}}
$$

where $\dot{Q}_{\text {genset }}$ is the rate of heat production $[\mathrm{kW}]$. As shown in Figure 9, heat is dissipated in the exhaust, through the water jacket cooling system, and directly from the engine and generator to the surrounding environment.

Values for diesel fuel provided in Type 120 are $l h v_{\text {fuel }}=42,500 \mathrm{~kJ} / \mathrm{kg}$ and $\rho_{\text {fuel }}=0.835 \mathrm{~kg} / \mathrm{L}$. This is very close to values given in other publications (e.g., Bacha et al., 2007), so these values were retained for Type 220. The user can enter the coefficients $a$ and $b$ directly as TRNSYS parameters. They can be extracted by plotting the fuel consumption values in $\mathrm{L} / \mathrm{h}$ that are often, but not always, provided in manufacturers' datasheets.

However, this approach poses a problem when running an optimization where the diesel engine size is a design variable, since the fuel consumption coefficients are unique to each diesel generator and it is complicated to adjust them in GenOpt based on diesel engine size. Therefore Type 220 was written to allow the user to specify a generic model of diesel engine with the coefficients built-in. The built-in 
coefficients are normalized to the nominal power rating, so the units are $\mathrm{L} / \mathrm{h}-\mathrm{kW}$-rated instead of $\mathrm{L} / \mathrm{h}$, where the term ' $\mathrm{kW}$-rated' refers to the nominal power rating of the genset.

The datasheets for nine Cummings and Caterpillar gensets, with a nominal power ranging from $90 \mathrm{~kW}$ to $1,120 \mathrm{~kW}$, were consulted to extract the generic fuel coefficients. Power on the $\mathrm{x}$-axis and fuel consumption on the $y$-axis was normalized to the rated power of the genset. The results are shown in Figure 31. Generally, fuel consumption per kWh of electricity produced decreases as the size of the genset increase, but reasonably close clustering of values is observed except for the smallest genset $(90 \mathrm{~kW})$.

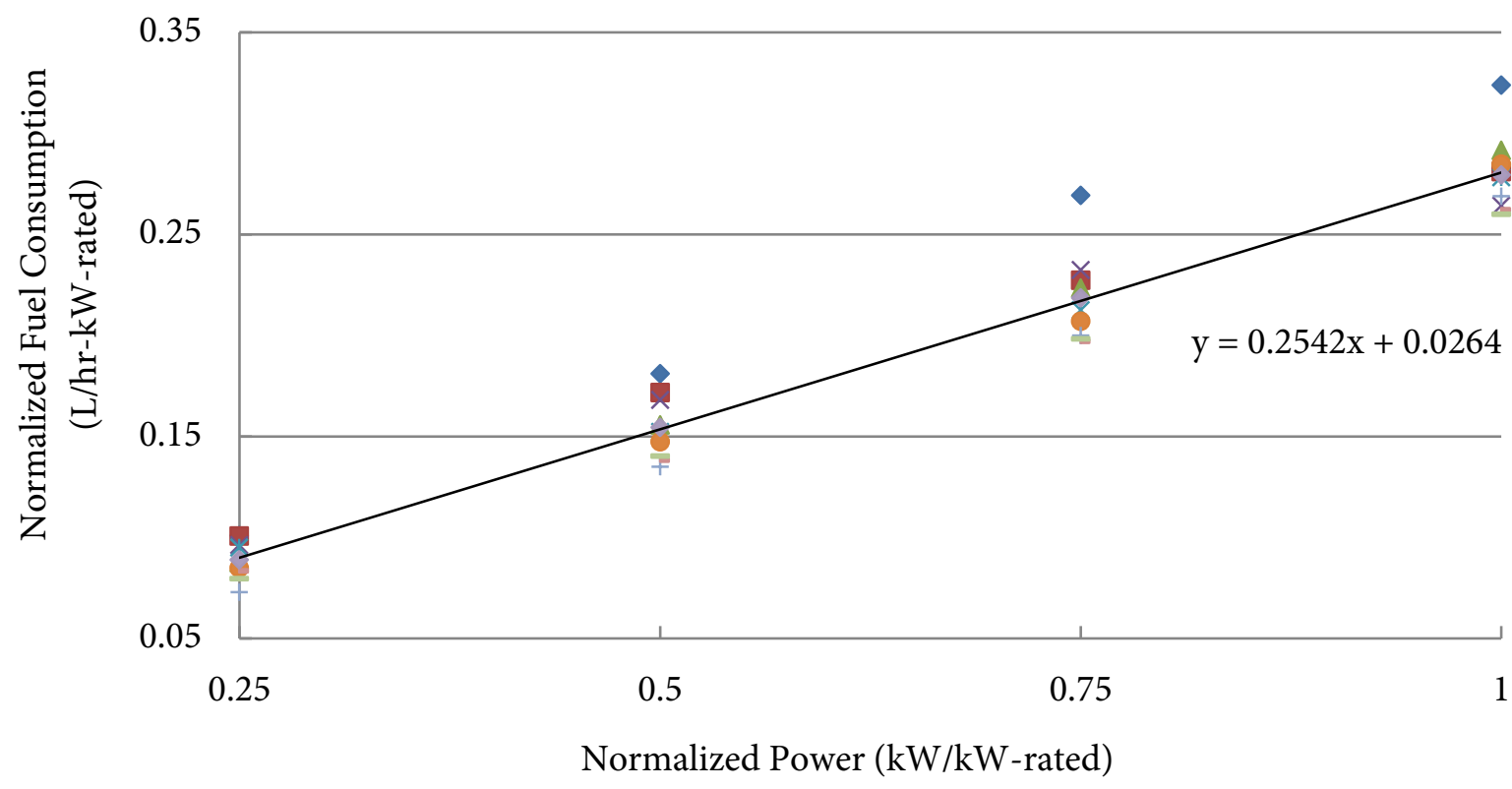
- $90 \mathrm{~kW}$
- $180 \mathrm{~kW}$
$\Delta 270 \mathrm{~kW}$
$\times 365 \mathrm{~kW}$
* $455 \mathrm{~kW}$
- $545 \mathrm{~kW}$
$+900 \mathrm{~kW}$
- $910 \mathrm{~kW}$
- $1120 \mathrm{~kW}$
- Average
_ Linear (Average)

Figure 31: Normalized fuel consumption for nine diesel gensets

The fuel consumption coefficients were extracted from the best-fit line. These are hard-coded into Type 220 should the user wish to use the generic model: $a=0.2542$ and $b=0.0264$. This approach was used in this thesis to ease the optimization of diesel generator size. 
The diesel size in $\mathrm{kW}$ was a design variable. Minimum loading was $30 \%$ of nominal power, a typicallyrecommended value to prevent premature wear-and-tear on the diesel (Tufte, 2014). The maximum power output was $100 \%$ of the nominal power, and minimum run-time was 1 hour.

\subsection{Financial Calculator}

Type 282 is the financial calculator and outputs the net present cost based on cost data inputs. Parameters include the discount rate and the number of periods (e.g., years) for the system to analyze. Inputs include the capital cost and a user-specified number of periodic costs, for example fuel or operations and maintenance $(\mathrm{O} \& \mathrm{M})$ costs. Each cost item can include an escalator, which is the percentage escalation (or de-escalation in the case of negative values) the cost item experiences each period.

In this thesis, the net present cost output from Type 282 is the objective function. The optimization seeks to minimize this output. More details on the financial model are provided in Section 7. 


\section{Optimization Approach}

As noted in Section 2, the literature contains few examples of metaheuristics for design of hybrid renewable energy systems in the Arctic. In this thesis, an existing optimization method was used that achieved significant improvement (in terms of computation time and accuracy of solution) over manual selection of design variables, which is unlikely to yield even a local optimum, and the brute-force (enumerative) approach, which is not capable of finding a solution in a reasonable amount of time.

The particle swarm optimization was chosen for this thesis. Advantages of this metaheuristic include:

- Several particle swarm algorithms are available in the GenOpt extension for TRNSYS, TRNOPT, requiring no new coding or one-off scripting;

- The algorithm is conceptually easy to understand, has few parameters, and is written in just a few lines of code;

- The algorithm can be implemented with continuous or discrete design variables, or both; and,

- The algorithm has a history of use for hybrid energy system optimization (see e.g., Kornelakis, 2010; Kyriakarakos et al., 2011).

\subsection{Particle Swarm Optimization with Discrete Variables}

The design variables in this thesis were all discrete. The discrete particle swarm optimization differs from the implementation noted in Section 2.2 as follows (Wetter, 2011).

The design vector $x=\left(x^{1}, x^{2}, \ldots, x^{\mathrm{p}}\right)$ of each particle is encoded using binary rather than decimal numbers. The velocity of the particle, rather than representing the particle's movement along a real number line for each design variable, represents the probability that a bit will change state from a ' 0 ' to a ' 1 ' or vice versa. Recall from Section 2.2, the particle swarm position $p_{\mathrm{i}}$ at generation $k+1$ is given by:

$$
p_{\mathrm{i}}(k+1)=p_{\mathrm{i}}(k)+v_{\mathrm{i}}(k+1)
$$

with the velocity term given as: 


$$
v_{\mathrm{i}}(k+1)=v_{\mathrm{i}}(k)+c_{1} r_{1}(k)\left(\pi_{\mathrm{l}, \mathrm{i}}(k)-p_{\mathrm{i}}(k)\right)+c_{2} r_{2}(k)\left(\pi_{\mathrm{g}, \mathrm{i}}(k)-p_{\mathrm{i}}(k)\right)
$$

where the first term on the right-hand side is the velocity, the second term is the particle's own best solution (cognitive), and the third term is the best solution of neighboring particles (social).

For $i$ particles, $\psi_{\mathrm{i}}$ is the binary representation of its design variables with $j$ bits, denoted $\psi_{\mathrm{i}}^{\mathrm{j}}$. The velocity term is computed in two steps, where $\hat{v}_{\mathrm{i}}^{\mathrm{j}}(k+1)$ is an intermediate step:

$$
\hat{v}_{\mathrm{i}}^{\mathrm{j}}(k+1)=v_{\mathrm{i}}^{\mathrm{j}}(k)+c_{1} r_{1}(k)\left(\pi_{\mathrm{l}, \mathrm{i}}^{\mathrm{j}}(k)-\psi_{\mathrm{i}}^{\mathrm{j}}(k)\right)+c_{2} r_{2}(k)\left(\pi_{\mathrm{g}, \mathrm{i}}^{\mathrm{j}}(k)-\psi_{\mathrm{i}}^{\mathrm{j}}(k)\right)
$$

The actual velocity is limited by a maximum, $v_{\max }$, to prevent a 'runaway' effect:

$$
v_{\mathrm{i}}^{\mathrm{j}}(k+1)=\operatorname{sign}\left(\hat{v}_{\mathrm{i}}^{\mathrm{j}}(k+1)\right) * \min \left\{\left|\hat{v}_{\mathrm{i}}^{\mathrm{j}}(k+1)\right|, v_{\max }\right\}
$$

To determine the value of each bit in generation $k+1$, the sigmoid function $s(v)$, shown graphically in Figure 32, is first evaluated:

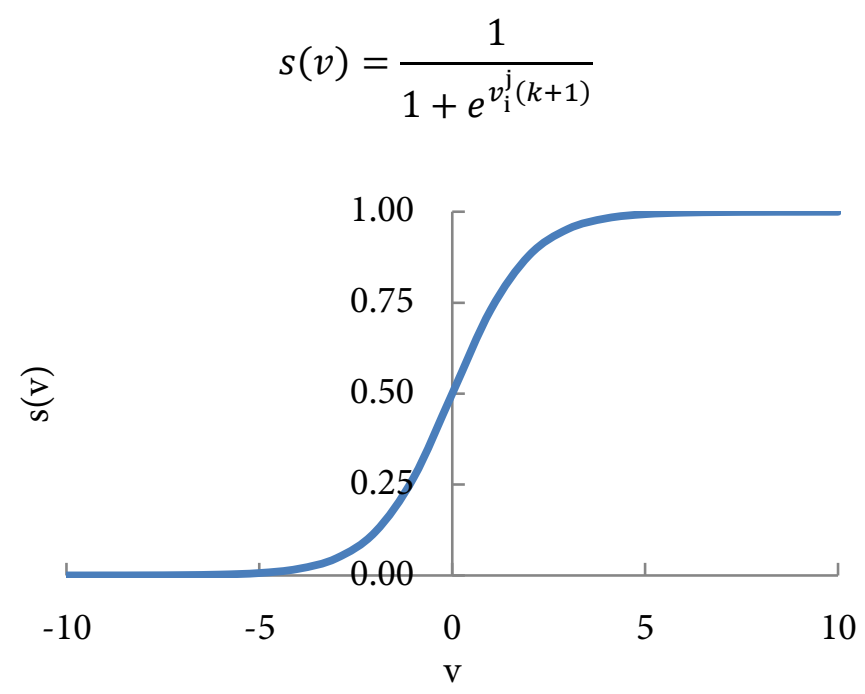

Figure 32: The sigmoid function

Finally, a random number $\delta_{\mathrm{i}, \mathrm{j}}(k) \in(0,1)$ is generated for each bit $\psi_{\mathrm{i}}^{\mathrm{j}}$ and compared to the value of the sigmoid function:

$$
\psi_{\mathrm{i}}^{\mathrm{j}}(k+1)=\left\{\begin{array}{cc}
0 & \text { if } \delta_{\mathrm{i}, \mathrm{j}}(k) \geq s\left(v_{\mathrm{i}}^{\mathrm{j}}(k+1)\right) \\
1 & \text { otherwise }
\end{array}\right.
$$


To summarize, the velocity equation limited by $v_{\max }$ represents the probability that a bit will change state and is influenced by the velocity at the previous generation, the particle's own best value, and the best value of neighboring particles. The probability determined by the sigmoid function allows the particle to move out of a local optimum by selecting, temporarily, a position with a worse objective function value.

The choice of $c_{1}$ and $c_{2}$ is somewhat arbitrary but is typically set to $c_{1}+c_{2}=4$ (Eberhart et al., 2001). Maximum velocity $v_{\max }$ is often set to 4 ; the value of the sigmoid function at $v=4$ is 0.018 , ensuring there is always at least a small chance that a bit will change state. Note that a smaller $v_{\text {max }}$ encourages a large search of the space, since as $v \rightarrow 0, s(v) \rightarrow 0.5$ which gives an equal probability of a bit changing or remaining in its current state.

The maximum velocity $v_{\max }$ is one variation on the initial formulation of the particle swarm that facilitates convergence. Other variations include inertia weight and a constriction coefficient. The inertia weight adjusts the velocity term in Eq. (8) and decreases linearly from the beginning of the optimization to the end:

$$
\begin{gathered}
\hat{v}_{\mathrm{i}}^{\mathrm{j}}(k+1)=w(k) v_{\mathrm{i}}^{\mathrm{j}}(k)+c_{1} r_{1}(k)\left(\pi_{1, \mathrm{i}}^{\mathrm{j}}(k)-\psi_{\mathrm{i}}^{\mathrm{j}}(k)\right)+c_{2} r_{2}(k)\left(\pi_{\mathrm{g}, \mathrm{i}}^{\mathrm{j}}(k)-\psi_{\mathrm{i}}^{\mathrm{j}}(k)\right) \\
w(k)=w_{0}-\frac{k}{K}\left(w_{0}-w_{1}\right)
\end{gathered}
$$

where $w_{0}$ and $w_{1}$ are the inertia weights for the first and last generation, $k$ is the generation number, and $K$ is the total number of generations. The inertia weight causes a shift from an exploratory mode in the beginning to an exploitative mode towards the end of the optimization run. Values in the literature for $w_{0}$ and $w_{1}$ include 0.9 and 0.4 (Eberhart et al., 2001) and 1.2 and 0 (Wetter, 2011).

The constriction coefficient approach applies a coefficient, $\chi$, to the entire right-hand side:

$$
\begin{gathered}
\hat{v}_{\mathrm{i}}^{\mathrm{j}}(k+1)=\chi(\kappa, \varphi)\left[v_{\mathrm{i}}^{\mathrm{j}}(k)+c_{1} r_{1}(k)\left(\pi_{\mathrm{l}, \mathrm{i}}^{\mathrm{j}}(k)-\psi_{\mathrm{i}}^{\mathrm{j}}(k)\right)+c_{2} r_{2}(k)\left(\pi_{\mathrm{g}, \mathrm{i}}^{\mathrm{j}}(k)-\psi_{\mathrm{i}}^{\mathrm{j}}(k)\right)\right] \\
\chi(\kappa, \varphi)=\left\{\begin{array}{cc}
\frac{2 \kappa}{\left|2-\varphi-\sqrt{\varphi^{2}-4 \varphi}\right|} & \text { if } \varphi>4 \\
\kappa & \text { otherwise }
\end{array}\right.
\end{gathered}
$$


where $\varphi=c_{1}+c_{2}$ and $\kappa \in(0,1]$. Where $c_{1}+c_{2}=4$ and $\kappa=1$, Eq. (10) collapses to Eq. (8). Where $\chi(\kappa, \varphi)<1$, the velocity will be reduced ('constricted') and achieve convergence faster, at the potential expense of not searching the design space as thoroughly.

Eberhart et al. (2001) compared the inertia weight and constriction coefficient methods on five test functions, noting that the constriction approach converged faster but had a greater tendency to get stuck in local optima compared to the inertia weight method. Performance on test functions does not necessarily mean that the same relative performance will be achieved on the optimization problem of this thesis.

\subsection{Neighborhood Topology}

The neighborhood topology defines what portion of the population influences a particle's velocity. The GenOpt implementation includes three topologies: local best (lbest), in which only nearby particles (defined by index, not by position) are influencers, global best (gbest), in which the entire population are influencers, and von Neumann, which is like lbest except on a square lattice (Wetter, 2011). These are shown graphically in Figure 33 (original figure based on Wetter, 2011) with the particle in question shaded in black and particles in its neighborhood shaded in gray. Note that the particle index wraps so that, for example, all particles in an lbest topology with a neighborhood size of 1 will have 2 neighbors, even the particles on the 'ends'.

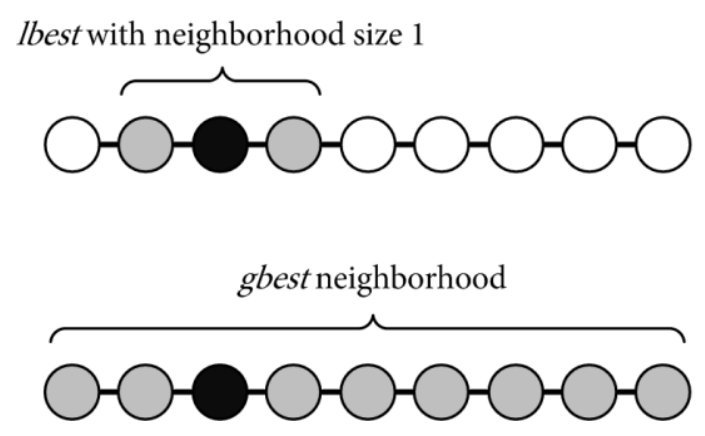

Von Neumann with neighborhood size 1

Figure 33: Neighborhood topology options for the particle swarm optimization 
A larger neighborhood tends to speed convergence but is more likely to get trapped in a local optimum. Wetter (2011) noted that the von Neumann topology tends to produce better results than both lbest and gbest.

\subsection{Optimization Parameters}

Sample optimization runs were conducted to explore the impact of changing the optimization parameters. Adjusting the inertia weights or the constriction gain was found to have little to no impact on the results for this problem. Therefore, the constriction gain coefficient was used with $\chi(\kappa, \varphi)=1$, which collapses the algorithm to the 'basic' particle swarm. Other parameters were chosen based on recommendations in the literature and are summarized in Table 11.

Table 11: Optimization parameters

\begin{tabular}{|l|c|}
\hline \multicolumn{1}{|c|}{ Parameter } & Value \\
\hline Population size, $n_{\mathrm{p}}$ & 8 \\
\hline Number of generations, $K$ & 200 \\
\hline Neighborhood topology & Von Neumann \\
\hline Neighborhood size & 1 \\
\hline Cognitive acceleration constant, $c_{1}$ & 2 \\
\hline Social acceleration constant, $c_{2}$ & 2 \\
\hline Maximum velocity, $v_{\max }$ & 4 \\
\hline Constriction gain, $\kappa$ & 1 \\
\hline
\end{tabular}

The objective function to be minimized was the time-discounted net present cost (NPC):

$$
\min f(x)=\sum_{t=1}^{T} \frac{C_{\mathrm{t}}}{(1+r)^{\mathrm{t}}}-C_{\mathrm{C}}
$$

where,

$$
\begin{aligned}
& C_{\mathrm{t}}=\text { net cashflow at time period } t[\$] ; \\
& C_{\mathrm{C}}=\text { capital cost incurred at time } \mathrm{t}=0[\$] ; \\
& T=\text { life span of the system [years]; and, }
\end{aligned}
$$




$$
r=\text { discount rate }[\%]
$$

The objective function was subject to a constraint of meeting the electrical demand $P_{\text {load }}$ at all timesteps:

$$
\Delta P=P_{\text {load }}-P_{\text {generation }} \leq 0
$$

where $P_{\text {generation }}$ is the power $[\mathrm{kW}]$ generated by all sources (diesel genset, wind turbine(s), solar PV, and batteries).

In GenOpt, constraints are typically implemented by barrier and penalty functions, which increase the objective function value as the dependent variable gets close to or surpasses the limit, respectively (Wetter, 2011). In this thesis, a penalty function was implemented directly in TRNSYS by attaching a dollar value to any shortfall in meeting the load. By trial-and-error, $\$ 100 / \mathrm{kWh}$ appeared to be a reasonable value that eliminated infeasible solutions without overly penalizing solutions with a small shortfall, for example several tens of kWh per year.

The design variables are summarized in Table 12. The minimum battery and PCS sizes were set to $100 \mathrm{kWh} / \mathrm{kW}$, in recognition of the need for power conditioning equipment to manage the intermittent output from renewable generators.

Table 12: Summary of design variables

\begin{tabular}{|l|c|c|c|}
\hline \multicolumn{1}{|c|}{ Variable } & Minimum & Maximum & Step \\
\hline Diesel genset size $(\mathrm{kW})^{\star}$ & 0 & 500 & 100 \\
\hline Number of wind turbines $(\mathrm{kW})$ & 0 & 6 & 1 \\
\hline Size of PV array $(\mathrm{kW})$ & 0 & 1000 & 20 \\
\hline PV array slope (from horizontal) & $0^{\circ}$ & $90^{\circ}$ & $10^{\circ}$ \\
\hline PV array azimuth & $-90^{\circ}$ (east) & $+90^{\circ}($ west $)$ & $10^{\circ}$ \\
\hline Battery size $(\mathrm{kWh)}$ & 100 & 1000 & 20 \\
\hline Power conditioning system size $(\mathrm{kW})$ & 100 & 1000 & 20 \\
\hline
\end{tabular}

${ }^{\star}$ For the stand-alone system configuration only

The number of possible combinations is approximately 800 million. The computer used for this thesis conducted one simulation approximately once per second, a rate that would require more than thirty years to evaluate every combination. While the above system could be reduced in size with a smaller range of PV slope and azimuth or a larger step size, and solved with enumerative (brute-force) methods, the intent was to show how a large design space could be solved with metaheuristic techniques. Additional 
design variables - such as different models of wind turbines PV panels, multiple PV arrays with different orientations, more than one storage technology or dispatch strategy, etc. - would render the problem intractable to a brute-force search. 


\section{Financial Model}

Power generation options for Cambridge Bay were analyzed using a parsimonious financial framework that incorporates capital and operations and maintenance (O\&M) costs, which account for most of the life-cycle cost difference between renewable and traditional fossil fuel power sources. Cost estimates were developed from multiple sources, including benchmarks of related projects, high-level cost trends, and estimates by other authors on planned and hypothetical projects in the Canadian Arctic and Alaska. Details are provided in Appendix B.

The financial viability of a power generation project proposal, including hybrid renewable energy systems, may depend on other factors including system performance and degradation over time, risk, financing, decommissioning expenses and salvage value, externalities such as health impacts and climate change, load growth, and subsidies and rebates. Assessing project viability therefore likely requires intimate knowledge of equipment and labour costs, construction methods, logistics, and the policy environment in which the project is to be undertaken. Many of these considerations are abstracted from this thesis, since the intent is to address the viability of a hybrid energy system at a conceptual level and not to develop a detailed assessment for the purposes of bidding on a tender or obtaining financing.

Cost escalation of O\&M, fuel, and grid-purchased electricity were modelled explicitly; system performance degradation and load growth were not. Instead, these factors were implicit in the fuel price escalation. In addition, load growth at CHARS is highly dependent on the specifics of the research program, an analysis of which was out of scope for this thesis. Finally, both capital and O\&M costs increase linearly based on the installed capacity $(\mathrm{kW})$ or generated energy $(\mathrm{kWh})$. In reality, declining per-unit costs would be expected as the size of the system increases, since many cost elements such as engineering design, project management, and mobilization/demobilization do not scale linearly with the system. Again, this is highly dependent on project specifics and was therefore neglected in this thesis. 


\subsection{Net Present Cost}

The life-cycle cost of each system configuration was evaluated using net present cost (NPC), also called net present value. NPC is the favoured approach for many financial analyses and is used as the basic criterion for project acceptability by international funding agencies (World Bank, 2010). The term NPC is the time-discounted summation of cash flow over the life of the project (Luna-Rubio et al., 2012):

$$
N P C=\sum_{t=1}^{T} \frac{C_{\mathrm{t}}}{(1+r)^{t}}+C_{\mathrm{C}}
$$

where,

$$
\begin{aligned}
& C_{\mathrm{t}}=\text { net cash flow in each time period } t[\$] ; \\
& C_{\mathrm{C}}=\text { initial capital cost }[\$] ; \\
& T=\text { number of periods; and, } \\
& r=\text { discount rate }[\%] .
\end{aligned}
$$

Cash outflows are positive and cash inflows are negative; in this thesis, the only negative term in Eq. (11) is income due to the financial value of surplus generated power.

The total capital cost is the sum of individual capital components:

$$
C_{\mathrm{C}}=C_{\mathrm{w}, \mathrm{C}}+C_{\mathrm{PV}, \mathrm{C}}+C_{\mathrm{d}, \mathrm{C}}+C_{\mathrm{PCS}, \mathrm{C}}+C_{\mathrm{b}, \mathrm{C}}+C_{\mathrm{p}, \mathrm{C}}
$$

where,

The subscript $C$ indicates the capital cost for the relevant component [\$];

$C_{\mathrm{w}, \mathrm{C}}=$ wind turbine capital cost;

$C_{\mathrm{PV}, \mathrm{C}}=$ solar PV capital cost;

$C_{\mathrm{d}, \mathrm{C}}=$ diesel capital cost (for the stand-alone system configuration);

$C_{\mathrm{PCS}, \mathrm{C}}=$ power conditioning system capital cost;

$C_{\mathrm{b}, \mathrm{C}}=$ battery capital cost; and, 
$C_{\mathrm{p}, \mathrm{C}}=$ other project capital costs, such as engineering design, grid connection, and permitting.

In this thesis, the last term was neglected and instead assumed to be implicit in various other capital components. The first four terms in Eq. (12) were expressed on a per-kW of installed capacity basis, while $C_{\mathrm{b}, \mathrm{C}}$ was expressed on a per-kWh installed capacity basis. For a grid-connected system, net cash flow in period $t$ is given by:

$$
C_{\mathrm{t}}=C_{\mathrm{w}, \mathrm{O} \& \mathrm{M}}+C_{\mathrm{PV}, \mathrm{O} \& \mathrm{M}}+C_{\mathrm{b}, \mathrm{O} \& \mathrm{M}}+C_{\mathrm{b}, \text { replace }}+C_{\mathrm{PCS}, \mathrm{O} \& \mathrm{M}}+\left(C_{\mathrm{d}} * D\right)+(G * F)-\left(C_{\mathrm{s}} * S\right)
$$

where,

The subscript $O \& M$ indicates the periodic (annual) costs for the relevant component [\$];

$$
\begin{aligned}
& C_{\mathrm{b}, \text { replace }}=\text { battery replacement cost }[\$] ; \\
& C_{\mathrm{d}}=\text { grid-purchased diesel energy cost }[\$ / \mathrm{kWh}] ; \\
& D=\text { grid-purchased diesel energy }[\mathrm{kWh}] ; \\
& G=\text { greenhouse gas emission cost }[\$ / \text { litre }] ; \\
& F=\text { quantity of diesel fuel consumed }[\text { litres }] ; \\
& C_{\mathrm{s}}=\text { surplus power }[\mathrm{kWh}] ; \text { and, } \\
& S=\text { value of surplus power }[\$ / \mathrm{kWh}] .
\end{aligned}
$$

For a stand-alone system, where CHARS is outfitted with its own diesel generator, eq. (13) was modified as follows:

$$
\begin{aligned}
C_{\mathrm{t}}=C_{\mathrm{w}, \mathrm{O} \& \mathrm{M}}+ & C_{\mathrm{PV}, \mathrm{O} \& \mathrm{M}}+C_{\mathrm{b}, \mathrm{O} \& \mathrm{M}}+C_{\mathrm{b}, \text { replace }}+C_{\mathrm{PCS}, \mathrm{O} \& \mathrm{M}}+C_{\mathrm{d}, \mathrm{O} \& \mathrm{Mf}}+C_{\mathrm{d}, \mathrm{O} \& \mathrm{Mv}} \\
& +\left[\left(C_{\mathrm{F}}+G\right) * F\right]-\left(C_{\mathrm{s}} * S\right)
\end{aligned}
$$

where,

$$
\begin{aligned}
& C_{\mathrm{F}}=\text { cost of fuel }[\$ / \text { litre }] \\
& C_{\mathrm{d}, \mathrm{O} \& \mathrm{Mf}}=\text { fixed non-fuel diesel O\&M cost }[\$ / \mathrm{kW}] ; \text { and, } \\
& C_{\mathrm{d}, \mathrm{O} \& \mathrm{Mv}}=\text { variable non-fuel diesel O\&M cost }[\$ / \mathrm{kW} \text {-hour of runtime }]
\end{aligned}
$$


The final component of the financial model is escalation, which was applied to fuel and O\&M costs. When an escalation or de-escalation factor $d$ is applied, Eq. (11) becomes:

$$
N P C=\sum_{t=1}^{T} \frac{C_{\mathrm{t}}(1+d)^{t}}{(1+r)^{t}}+C_{\mathrm{C}}
$$

Different escalation factors (or none at all) can be applied to each component of Eq. (13) and (14) as desired. In order to determine appropriate escalation factors, year-over-year monthly changes to common price indices were reviewed, shown in Figure 34 and Figure 35 (Statistics Canada, 2017). The consumer price index (CPI) typically varies from 0-4\%, while the Industrial Product Price Index (IPPI), which includes chemicals, plastics, rubbers, machinery, and other industrial inputs, shows greater price volatility. Energy has very high price volatility.

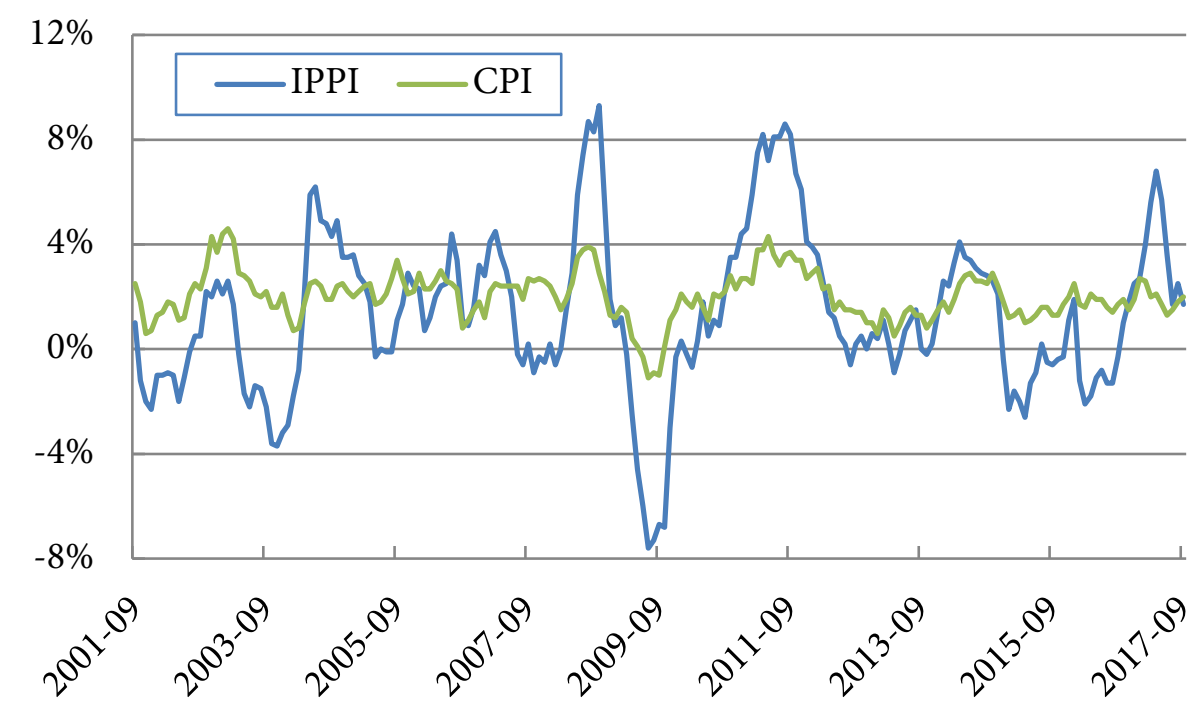

Figure 34: Monthly year-over-year change in Industrial Product Price Index and Consumer Price Index 


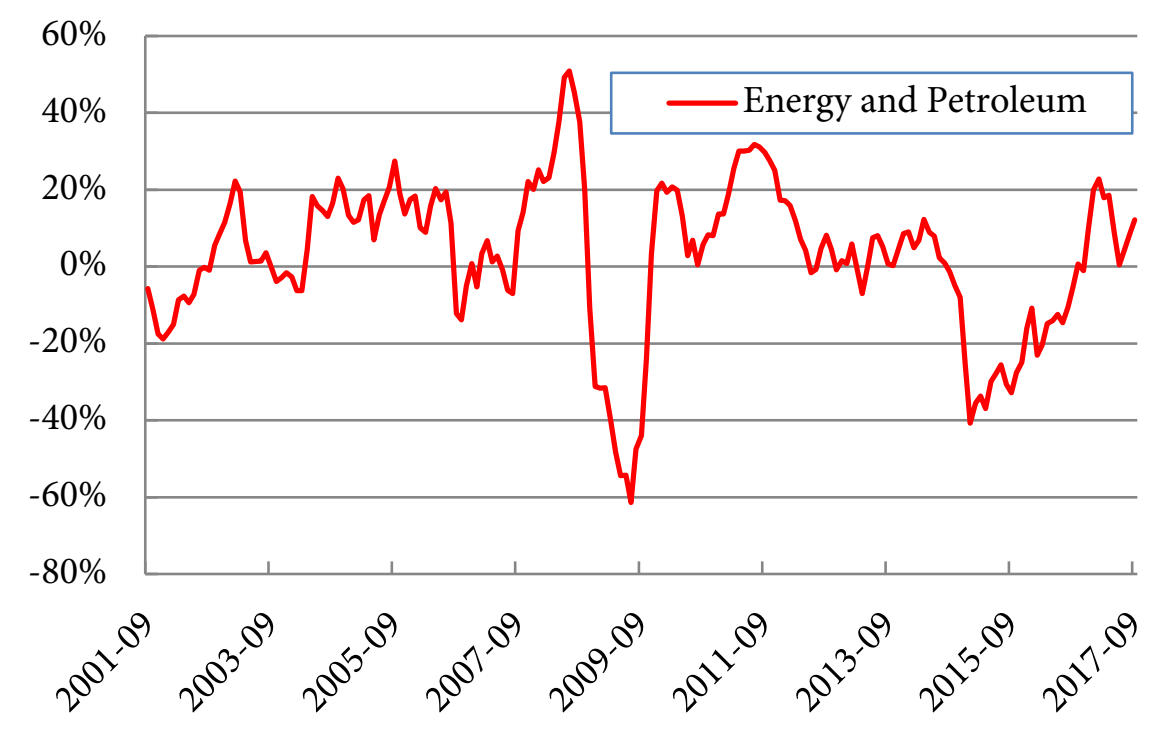

Figure 35: Monthly year-over-year change in Energy and Petroleum Price Index

Over the 17-year period shown, average inflation was $1.3 \%$ for IPPI, $2.7 \%$ for energy, and $2.0 \%$ for CPI. This aligns well with the Bank of Canada's 2\% target for CPI inflation (Bank of Canada, 2016), therefore $2.0 \%$ was used as the baseline for O\&M, fuel inflation, greenhouse gas emission costs, and the value of surplus power. The fuel cost and grid-purchased power inflation rates were increased over the baseline to $4.0 \%$, with the additional $2 \%$ serving as a proxy for system performance degradation and load growth. These inflation figures may be conservative, as the power corporation estimates fuel and O\&M inflation at 6.2\% and 5.2\%, respectively, since 2010 (QEC, 2013). Battery replacement costs were escalated at $-1.0 \%$ in anticipation of further improvements and cost savings in battery technology.

\subsection{Payback Period}

The payback period is a simple benchmark that expresses the number of years required to recoup the investment in an energy efficiency or generating system. In this thesis it was used in conjunction with NPC.

$$
\text { Payback }=\frac{\text { Capital Investment }[\$]}{\text { Annual Savings }\left[\frac{\$}{\text { year }}\right]}
$$




\subsection{Discount Rate}

The discount rate puts a value-of-time preference on money. Discounting future cash flows reflect the fact that money today can be invested in a 'risk-free' instrument (e.g., Government of Canada bonds) and earn interest. The discount rate for a project proposal reflects the risk-free rate plus a risk amount. The choice of the discount rate can vary by circumstance, location, and the time period considered, and may vary between technologies to reflect differing perceptions of financial risk.

In the Stern Review, an analysis of the economics of climate change, Stern et al. (2006) noted that discounting as used in economics is only relevant for marginal perturbations along a path. From the context of a company seeking to choose among potential investments, this may be valid. From the context of society choosing to invest in climate change mitigation, the path (such as the level of global damage due to climate change) may be very different based on the level of investment.

From a social welfare perspective, there are two reasons to discount future consumption (future cash flows). First, the marginal value of a unit of consumption decreases as consumption increases. If it is assumed that future generations are richer (have a higher level of consumption), the marginal value of consumption is lower than it is today. Second, people have a 'pure time preference' and would prefer to have things now rather than later (Stern, 2006). This is expressed by the Ramsey Equation:

$$
\rho=\eta g+\delta
$$

where,

$$
\begin{aligned}
& \rho=\text { social discount rate; } \\
& \eta=\text { marginal utility of consumption; } \\
& g=\text { growth rate of consumption along a specific path; and, } \\
& \delta=\text { pure time preference or time discount rate. }
\end{aligned}
$$

Stern et al. cited Amartya Sen and Robert Solow who argue that anything other than $\delta=0$ is unethical from an inter-generational perspective, excepting the possibility that future generations will not exist. In other words, Stern et al. argued that market interest rates should not dictate the discount rate as it applies 
to climate-change mitigation measures, as this definition of the discount rate represents intragenerational and not inter-generational preferences. In fact, Stern et al. utilized a very low time discount rate in their analysis, $0.1 \%$, justified by the possibility of future extinction. This has been controversial.

For example, Nordhaus (2007) criticized the assumptions and conclusions of the Stern Review, noting that capital markets use real interest rates, not a hypothetical, ethically-acceptable time discount rate dictated by a government. Nordhaus noted that a benchmark return on capital of around 6\% per year is common, and that in the absence of a centrally-planned economy, the time discount rate used in Stern is irrelevant. Additional criticisms included lack of consideration of alternative ethical frameworks that could lead to different conclusions about appropriate investment levels, and the interpretation of utility functions in the future, where there will likely be more advanced technology.

The appropriate social discount rate for use by policy makers is a contentious topic and further discussion is beyond the scope of this thesis. Regardless, it is important to note that a high discount rate favours projects with a higher proportion of life-cycle costs occurring in the future, e.g., relatively low-capital, fuel-intensive fossil fuel projects. In this thesis, $5 \%$ was chosen as the baseline and the impact of higher and lower discount rates was evaluated through parametric analyses.

\subsection{Externalities}

Fundamentally, the problem of climate change and other environmental damage is externalities: fossilfuel producers and consumers do not pay the full cost of their actions (Stern et al., 2006). This is sometimes referred to as the 'tragedy of the commons', first conceptualized by Lloyd in the mid-1800s (Hardin, 1968).

Externalities associated with diesel generators include carbon emissions contributing to anthropogenic climate change, fuel spills leading to ground and water contamination, damage from fuel extraction, and localized environmental issues such as air quality contributing to cancer, asthma, and other health impacts. These costs are not trivial. For example, Chapman estimated that environmental costs from emissions and spills from remote diesel generator operation were about \$0.80/litre (Chapman, 1996). When incorporating the impact of environmental tipping points, Cai et al. (2015) found the optimal 
initial year carbon tax price increased from about US\$12/ton ${ }_{\mathrm{CO} 2, \mathrm{eq}}{ }^{1}$ to as high as US\$100/ton $\mathrm{CO} 2 \mathrm{eq}$. In Nunavut, the territorial power corporation estimated ground remediation at their power plants would cost approximately $\$ 40 \mathrm{M}(\mathrm{QEC}, 2016 \mathrm{a})$, although the corporation is not legally required to include this liability in their accounting (nor does this figure include potential health impacts). This is almost a third of annual sales and greatly exceeds annual net income.

Governments are increasingly levying fees on fossil fuel consumption through mechanisms such as carbon taxes or cap-and-trade regimes. The intent of these fees is to incentivize reduced fossil fuel consumption and to raise revenue to invest in green technologies, to offset other taxes, or to fund new programs. The Government of Canada (2017) recently announced plans to introduce a carbon tax. The levy starts at $\$ 10 /$ ton $_{\mathrm{CO} 2 \text {,eq }}$ and increases at $\$ 10 /$ ton $_{\mathrm{CO} 2 \text {,eq }}$ per year until 2022 , when it caps at $\$ 50 /$ ton $_{\mathrm{CO} 2 \text {,eq }}$. This is equivalent to $\$ 0.1369 /$ litre diesel fuel, the baseline cost used in this thesis. One of the motivations to explicitly model the carbon tax is the concern of northerners over the cost impacts of the tax; see e.g., Government of Nunavut (2016).

Parametric analyses were conducted using a price of $\$ 0.00 /$ litre, in recognition that future governments could repeal the tax, and $\$ 1.00 /$ litre, to account for either the potential for increased carbon taxes in the future, or other environmental impacts not captured by the proposed Government of Canada rate (e.g., Chapman, 1996).

The greenhouse gas emissions of each system configuration were calculated using the implied emissions per litre from the government carbon tax: $2740 \mathrm{~g}_{\mathrm{CO} 2, \mathrm{eq}} / \mathrm{L}$ or 0.00274 ton $_{\mathrm{CO} 2, \mathrm{eq}} / \mathrm{L}$. This is similar to other sources which estimate about 2600-2700 $\mathrm{g}_{\mathrm{CO}, \mathrm{eq}} / \mathrm{L}$ for diesel combustion (Eriksson and Ahlgren, 2013) not including the 'well-to-tank' emissions, i.e., the emissions from fuel extraction and transportation which accounts for $10-20 \%$ of overall carbon emissions from diesel consumption. In addition, incremental carbon emissions from the manufacture, shipping, and installation of system components were neglected.

\footnotetext{
1 The term 'ton ${ }_{\mathrm{CO} 2 \text {,eq }}$ ' is used because other substances, such as methane $\left(\mathrm{CH}_{4}\right)$, contribute to the greenhouse effect. These substances are weighted based on their global warming potential (GWP), normalized to $\mathrm{CO}_{2}, \mathrm{GWP}=1$.
} 
For the stand-alone configuration, fuel consumption was an output of the model (see Section 5.5). For the grid-connected configurations, the average fuel efficiency observed by the power corporation, $3.73 \mathrm{kWh} /$ litre (QEC, 2016) (0.2681 litre/kWh) was used to calculate the cost of externalities.

\subsection{Surplus Power Value}

Renewable power in excess of demand and available battery charging capacity is referred to as surplus. When no secondary load is available, the surplus power is spilled and yields no economic benefit. Potential secondary loads include heating (space heating and water) and community demand. In the former case, this thesis assumed electric resistance heaters were available to serve the station heating demand. They were assumed to be $100 \%$ efficient, no incremental cost for installation was assumed, and time of use was ignored, since heating loads exist throughout the year. When selling power back to the community grid, two potential opportunities were initially considered: selling the surplus power to the grid at the avoided cost of fuel (about $45 \%$ of the power corporation's costs, or $\$ 0.2973 / \mathrm{kWh}$ ) or at the commercial rate of electricity $(\$ 0.6607 / \mathrm{kWh})$. Selling power at the full commercial rate is unlikely to be acceptable to the power corporation, since there are costs to generation not directly impacted by the volume of electricity sold (e.g., salaries). If the community or the power corporation were to purchase surplus power from CHARS at the commercial rate, it would reduce the corporation's net revenue and increase costs for other ratepayers in Nunavut. Therefore, in this thesis the commercial rate of electricity was not used as a potential surplus power value.

The baseline case was using surplus power for heating purposes. Parametric studies were used to quantify the impact of wasting the surplus (i.e., $\$ 0.00 / \mathrm{kWh}$ ) or selling it to the grid at the avoided cost of fuel $(\$ 0.2973 / \mathrm{kWh})$.

\subsection{Cost Summary}

Table 13 summarizes the financial variables. Baseline values were used for the optimization, while parametric analyses were conducted to evaluate the impact to the net present cost from the low and high 
values noted below. In general, low and high end were set to $75 \%$ and $125 \%$ of the baseline cost, except as noted for the value of surplus power and the cost of GHG emissions. Escalation and discount rates were typically adjusted by $+/-50 \%$ since the absolute value of the rates was small.

The system lifespan was assumed to be 25 years; replacement costs such as batteries and PV inverters was included in O\&M costs, while salvage/decommissioning costs were neglected.

Details including references are provided in Appendix B.

Table 13: Summary of costs and financial parameters

\begin{tabular}{|c|c|c|c|c|}
\hline \multirow{2}{*}{ Parameter } & \multicolumn{3}{|c|}{ Value } & \multirow{2}{*}{ Unit } \\
\hline & Low & Baseline & High & \\
\hline \multicolumn{5}{|l|}{ Financial Parameters } \\
\hline Discount rate & $2.5 \%$ & $5 \%$ & $7.50 \%$ & \\
\hline Periods & 25 & 25 & 25 & years \\
\hline Grid power escalation & $2.0 \%$ & $4.0 \%$ & $6.0 \%$ & \\
\hline Fuel cost escalation & $2.0 \%$ & $4.0 \%$ & $6.0 \%$ & \\
\hline Surplus power escalation & $0 \%$ & $2.0 \%$ & $3.0 \%$ & \\
\hline Battery cost escalation & $-2.0 \%$ & $-1.0 \%$ & $0 \%$ & \\
\hline O\&M escalation & $1.0 \%$ & $2.0 \%$ & $4.0 \%$ & \\
\hline Greenhouse gas escalation & $1.0 \%$ & $2.0 \%$ & $4.0 \%$ & \\
\hline Maximum battery cycles & 3000 & 4000 & 5000 & cycles \\
\hline \multicolumn{5}{|l|}{ Capital Costs } \\
\hline PV capital cost & $\$ 3,750$ & $\$ 5,000$ & $\$ 6,250$ & $/ \mathrm{kW}$ \\
\hline Wind turbine capital cost & $\$ 7,500$ & $\$ 10,000$ & $\$ 12,500$ & $/ \mathrm{kW}$ \\
\hline PCS capital cost & $\$ 3,000$ & $\$ 4,000$ & $\$ 5,000$ & $/ \mathrm{kW}$ \\
\hline Battery capital cost & $\$ 750$ & $\$ 1,000$ & $\$ 1,250$ & $/ \mathrm{kWh}$ \\
\hline Diesel capital cost & $\$ 1,500$ & $\$ 2,000$ & $\$ 2,500$ & $/ \mathrm{kW}$ \\
\hline \multicolumn{5}{|l|}{ Annual O\&M Costs } \\
\hline PV O\&M & $\$ 45$ & $\$ 60$ & $\$ 75$ & $/ \mathrm{kW}$ \\
\hline Wind turbine O\&M & $\$ 375$ & $\$ 500$ & $\$ 625$ & $/ \mathrm{kW}$ \\
\hline Diesel fixed O\&M & $\$ 450$ & $\$ 600$ & $\$ 750$ & $/ \mathrm{kW}$ \\
\hline Diesel variable O\&M & $\$ 0.01275$ & $\$ 0.017$ & $\$ 0.02125$ & $/ \mathrm{kW}$-hour of runtime \\
\hline Battery O\&M & $\$ 18.75$ & $\$ 25$ & $\$ 31.25$ & $/ \mathrm{kWh}$ \\
\hline PCS O\&M & $\$ 18.75$ & $\$ 25$ & $\$ 31.25$ & $/ \mathrm{kW}$ \\
\hline Diesel fuel cost & $\$ 0.908$ & $\$ 1.210$ & $\$ 1.513$ & /litre diesel fuel \\
\hline GHG cost & $\$ 0.00$ & $\$ 0.1369$ & $\$ 1.00$ & /litre diesel fuel \\
\hline Surplus power value & $\$ 0.00$ & $\$ 0.1324$ & $\$ 0.2973$ & $/ \mathrm{kWh}$ \\
\hline Utility electrical rate & $\$ 0.4955$ & $\$ 0.6607$ & $\$ 0.8259$ & $/ \mathrm{kWh}$ \\
\hline
\end{tabular}




\section{Results and Discussion}

The intent of the optimization was to find the system with the lowest net present cost (NPC) under five configurations:

1. Grid-integrated, where the community power plant supplied any shortfall in meeting demand;

2. Stand-alone, where an on-site diesel generator met any demand shortfall;

3. Low maintenance, a grid-integrated PV-battery system;

4. Highest renewable, in which the penetration rate was maximized; and,

5. Higher temporal resolution, identical to the grid-integrated configuration except with a 10min as opposed to hourly timestep.

For each system configuration, the lowest NPC using the particle swarm optimization metaheuristic was found for different scenarios of surplus power value and greenhouse gas (GHG) emission cost:

- Surplus power value of $\$ 0 / \mathrm{kWh}$, representing no economic use of surplus power, $\$ 0.1320 / \mathrm{kWh}$, representing displacement of diesel fuel for heating the station, and $\$ 0.2373 / \mathrm{kWh}$, representing selling the power back to the local community grid at the avoided cost of fuel. It was assumed that all surplus power could be used by the community or station.

- GHG costs of $\$ 0 /$ litre of diesel fuel, $\$ 0.1369 /$ litre, representing the impact of the planned Government of Canada carbon tax, and $\$ 1.00 /$ litre, in order to understand the impact of potential future increases to the tax or the cost of externalities not captured by the tax.

These figures are discussed in greater detail in Sections 7.4 and 7.5.

Parametric analyses were then conducted on the baseline scenario optimum to quantify potential impacts to the lifecycle net present cost (NPC) of higher or lower capital and operational costs, discount and escalation rates, and other factors of interest. 
For each scenario, the annual electrical renewable penetration rate was calculated using a slightly different form of Eq. (1). Instead of comparing the renewable energy generated to total energy demand, the amount of diesel energy generated was used instead:

$$
\text { Average penetration }=\frac{\text { Total energy demand }- \text { diesel energy generated }(\mathrm{kWh})}{\text { Total energy demand }(\mathrm{kWh})}
$$

This approach avoided counting surplus renewable power towards the electrical penetration rate. The calculation of the instantaneous penetration rate remained the same:

$$
\text { Instantaneous penetration }=\frac{\text { Renewable power generated }(\mathrm{kW})}{\text { Total power demand }(\mathrm{kW})}
$$

The simple payback was also reported for each scenario using the annual (first-year) cost savings compared to the diesel-only scenario with the same GHG cost.

\subsection{Grid-integrated: Wind/Photovoltaic with Grid-Purchased Power}

In this configuration, CHARS was connected to the local electrical grid. Wind, solar, and battery-stored energy was used to meet the electrical demand, with the community gensets making up any shortfall at the commercial rate of power $(\$ 0.6607 / \mathrm{kWh})$. This is the most likely configuration for any future renewable energy integration at CHARS, as noted in Section 1.2.

To calculate fuel consumption and GHG costs, the average plant efficiency of the power corporation was used (3.73 kWh/litre or 0.2681 litre/kWh) (QEC, 2016).

Figure 36 shows the typical progression of the optimization (duplicate solutions have been removed for clarity). The process obtained near-optimal solutions very quickly, within about 400 simulations. Of interest is the significantly sub-optimal solutions obtained even towards the end of the simulation. This shows the ability of the particle swarm algorithm to explore solutions far from the current optimum, helping to better explore the design space and to avoid getting stuck in a local optimum far from the global optimum. 


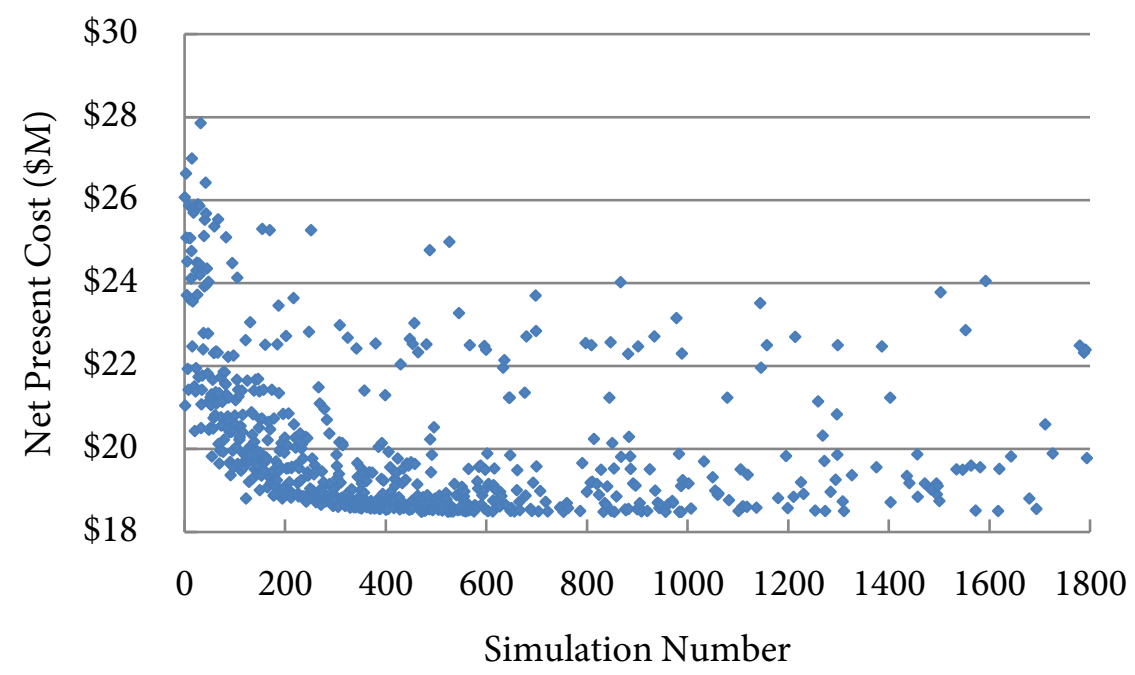

Figure 36: Example optimization run

There were many solutions near the global optimum. Typically, these involved minor deviations from the optimal photovoltaic (PV) array slope and azimuth. In some cases, a solution with an additional wind turbine yielded a similar NPC, lower diesel fuel consumption, and higher capital cost.

Table 14 shows the NPC and capital costs for each optimum, while Table 15 shows the first-year operational costs (note that costs escalate in each year). By convention, the value of surplus power was negative and cash outflows were positive; total first-year costs may not exactly equal the sum of the other columns due to rounding. The first three scenarios did not include any renewable power generators and hence there was no surplus power. Scenario 1.6 was the baseline scenario, highlighted in light blue.

Table 14: Grid-tied configuration capital and net present cost

\begin{tabular}{|c|r|r|c|r|r|}
\hline Scenario & $\begin{array}{c}\text { Surplus } \\
(\$ / \mathrm{kWh})\end{array}$ & $\begin{array}{c}\text { GHG } \\
(\$ / \text { litre })\end{array}$ & $\begin{array}{c}\text { NPC } \\
(\$ \mathbf{M})\end{array}$ & $\begin{array}{c}\text { Capital } \\
\text { Cost }(\mathbf{\$ K})\end{array}$ & $\begin{array}{c}\text { Payback } \\
\text { (years) }\end{array}$ \\
\hline 1.1 & N/A & $\$ 0$ & $\$ 24.4$ & $\$ 0$ & N/A \\
\hline 1.2 & N/A & $\$ 0.1369$ & $\$ 25.5$ & $\$ 0$ & N/A \\
\hline 1.3 & N/A & $\$ 1.00$ & $\$ 32.3$ & $\$ 0$ & N/A \\
\hline 1.4 & $\$ 0$ & $\$ 0$ & $\$ 18.1$ & $\$ 5,500$ & 10.9 \\
\hline 1.5 & $\$ 0$ & $\$ 0.1369$ & $\$ 18.5$ & $\$ 5,620$ & 10.5 \\
\hline 1.6 & $\$ 0.1324$ & $\$ 0.1369$ & $\$ 17.8$ & $\$ 6,000$ & 10.2 \\
\hline 1.7 & $\$ 0.2973$ & $\$ 0.1369$ & $\$ 15.7$ & $\$ 10,500$ & 11.3 \\
\hline 1.8 & $\$ 0.1120$ & $\$ 1.00$ & $\$ 19.9$ & $\$ 7,500$ & 8.2 \\
\hline 1.9 & $\$ 0.2973$ & $\$ 1.00$ & $\$ 17.1$ & $\$ 11,520$ & 9.0 \\
\hline
\end{tabular}


Table 15: Grid-tied configuration first-year operational cost

\begin{tabular}{|c|c|c|c|c|c|}
\hline Scenario & $\begin{array}{c}\text { Grid Power } \\
(\$ \mathrm{~K})\end{array}$ & GHG (\$K) & O\&M (\$K) & $\begin{array}{c}\text { Surplus } \\
\text { Power (\$K) }\end{array}$ & Total (\$K) \\
\hline 1.1 & $\$ 1,103.2$ & $\$ 0.0$ & $\$ 0.0$ & $\$ 0.0$ & $\$ 1,103.2$ \\
\hline 1.2 & $\$ 1,103.2$ & $\$ 61.3$ & $\$ 0.0$ & $\$ 0.0$ & $\$ 1,164.4$ \\
\hline 1.3 & $\$ 1,103.2$ & $\$ 447.6$ & $\$ 0.0$ & $\$ 0.0$ & $\$ 1,550.8$ \\
\hline 1.4 & $\$ 419.7$ & $\$ 0.0$ & $\$ 155.0$ & $\$ 0.0$ & $\$ 598.7$ \\
\hline 1.5 & $\$ 411.9$ & $\$ 22.9$ & $\$ 169.8$ & $\$ 0.0$ & $\$ 629.8$ \\
\hline 1.6 & $\$ 395.6$ & $\$ 22.0$ & $\$ 168.2$ & $-\$ 41.5$ & $\$ 574.3$ \\
\hline 1.7 & $\$ 254.2$ & $\$ 14.1$ & $\$ 270.1$ & $-\$ 363.6$ & $\$ 234.8$ \\
\hline 1.8 & $\$ 307.6$ & $\$ 124.8$ & $\$ 241.1$ & $-\$ 69.5$ & $\$ 637.6$ \\
\hline 1.9 & $\$ 226.4$ & $\$ 91.9$ & $\$ 322.6$ & $-\$ 435.5$ & $\$ 265.3$ \\
\hline
\end{tabular}

These results suggest that a high-penetration system can be implemented at CHARS at a lower NPC than the diesel-only solution. The first three scenarios showed how varying the GHG cost affects the NPC under the current system (no renewable energy). Without the tax, electricity costs in Year 1 were approximately $\$ 1.1 \mathrm{M}$; the planned Government of Canada carbon tax (Scenario 1.2) added about $\$ 60 \mathrm{~K} /$ year to that cost. This was a relatively small increase (5\%) but reflects increased pressure on operational budgets. A high cost of externalities on the other hand (Scenario 1.3) added about $40 \%$ to the cost of electricity.

Scenarios 1.4 and 1.5 compared the optimal solution to the grid power-only scenarios assuming surplus power was wasted (no economic benefit). In this case, the NPC was significantly lower (\$6-7M over 25 years) than the diesel-only solutions and required a capital expenditure of approximately $\$ 5.5 \mathrm{M}$. These scenarios reduced annual grid-power costs by about $\$ 700 \mathrm{~K}$; however, there were additional operations and maintenance (O\&M) costs associated with the renewable generators, storage, and associated power conditioning components, resulting in a total annual cost reduction of around $\$ 500 \mathrm{~K}$.

Scenarios 1.6 and 1.7 showed how using the surplus power for economic benefit affected the optimal solution. In Scenario 1.6, surplus renewable power displaced diesel fuel for heating the station. This approach had a relatively marginal impact, reducing the NPC by about $\$ 0.5 \mathrm{M}$ over 25 years and heating costs by $\$ 35 \mathrm{~K} /$ year. Surplus power was equivalent to about $19 \%$ of the load, indicating that the optimal solution does not favour using renewable energy to meet heating loads. Selling the surplus power back to 
the community (Scenario 1.7) resulted in a dramatic impact to the NPC and brought in more than $\$ 350 \mathrm{~K}$ in revenue per year. However, capital expenditures were significantly increased and the payback period was increased compared to Scenario 1.6. In this configuration, annual surplus power was much higher, about $73 \%$ of the load.

Finally, Scenarios 1.8 and 1.9 explored the impact of significantly higher GHG costs. The trend was the same as with Scenarios 1.6 and 17, however capital expenditures and the surplus power value were higher, since the higher GHG cost resulted in a higher capacity of renewable energy generators, as shown in Table 16.

Table 16: Grid-tied configuration design vector

\begin{tabular}{|c|c|c|c|c|c|c|}
\hline Scenario & $\begin{array}{c}\text { \# Wind } \\
\text { Turbines }\end{array}$ & $\begin{array}{c}\text { PV Array } \\
\text { Size }(\mathbf{k W})\end{array}$ & $\begin{array}{c}\text { PV } \\
\text { Azimuth }\left(^{\circ}\right)\end{array}$ & $\begin{array}{c}\text { PV } \\
\text { Slope }\left(^{\circ}\right)\end{array}$ & $\begin{array}{c}\text { Battery Size } \\
(\mathbf{k W h})\end{array}$ & $\begin{array}{c}\text { PCS Size } \\
(\mathbf{k W})\end{array}$ \\
\hline 1.1 & 0 & 0 & 0 & 0 & 0 & 0 \\
\hline 1.2 & 0 & 0 & 0 & 0 & 0 & 0 \\
\hline 1.3 & 0 & 0 & 0 & 0 & 0 & 0 \\
\hline 1.4 & 3 & 400 & 10 & 40 & 100 & 100 \\
\hline 1.5 & 3 & 420 & 10 & 40 & 120 & 100 \\
\hline 1.6 & 3 & 500 & 10 & 40 & 100 & 100 \\
\hline 1.7 & 5 & 1000 & 10 & 50 & 100 & 100 \\
\hline 1.8 & 4 & 560 & 10 & 40 & 300 & 100 \\
\hline 1.9 & 6 & 1000 & 10 & 50 & 120 & 100 \\
\hline
\end{tabular}

Scenarios 1.4, 1.5, and 1.6 had a zero or modest value of surplus power and GHG cost. Regardless, the optimal solution still included three wind turbines, a PV array of 400-500 KW, and the minimum battery and power conditioning system (PCS) size allowed - removing the constraint reduced the optimal size below $100 \mathrm{kWh}$ or $\mathrm{kW}$ respectively. This indicates that the primary benefit of renewable energy for CHARS is for direct reduction of diesel power consumption, as opposed to storing renewable energy for later use. The imposition of a carbon tax (from Scenario 1.4 to 1.5) did not significantly affect the optimal solution.

Interestingly, the optimal PV slope of $40^{\circ}$ resulted in slightly less PV energy than at $50^{\circ}$ but a lower NPC over the life of the system. This demonstrates the importance of time of production and use - the extra PV energy produced at a higher slope occurred at times when it could not be used as economically. 
However, the overall impact was marginal, and there are other good reasons for a slope of $50-60^{\circ}$, such as mitigating snow cover. Similarly, the NPC was relatively insensitive to the array azimuth, $+/$ - about $20^{\circ}$.

Scenarios 1.7 and 1.9, with a high value of surplus power, resulted in the maximum or near-maximum size of the wind farm and PV array allowed under the optimization constraints. Battery and PCS size was minimized since it was more economical to sell the power back to the community grid than to store it for later use at CHARS. The optimization constraints were not relaxed to include more wind turbines or a larger PV array, as the ability of the local electrical grid to absorb high amounts of renewable power input is unclear.

Finally, Scenario 1.8, with a high GHG cost and a surplus power value reflecting displaced heating fuel, resulted in a higher battery size. In this case, it was more economical to store the electricity for later use than to use it to meet heating demands.

Table 17 summarizes the renewable performance of each scenario, including annual hours where grid power is required (diesel run-time), fuel consumption, and the penetration rate. As noted, the penetration rate only refers to the diesel power for electricity displaced by renewable power and does not consider total (heat and electricity) energy consumption. Similarly, the annual fuel consumption only accounts for fuel used for electricity generation and does not include heating oil displaced by electric heat.

Table 17: Grid-tied configuration annual renewable performance

\begin{tabular}{|c|c|c|c|c|c|c|}
\hline \multirow[b]{2}{*}{ Scenario } & \multirow{2}{*}{$\begin{array}{c}\text { Diesel } \\
\text { Run-Time } \\
\text { (hours) }\end{array}$} & \multirow{2}{*}{$\begin{array}{c}\text { Fuel } \\
\text { (K litres) }\end{array}$} & \multirow{2}{*}{$\begin{array}{c}\text { GHG } \\
\text { Emissions } \\
\text { (ton }{ }_{\mathrm{CO} 2, \mathrm{eq}} \text { ) }\end{array}$} & \multicolumn{2}{|c|}{ Penetration Rate } & \multirow{2}{*}{$\begin{array}{c}\text { Peak Surplus } \\
(\mathrm{kW})\end{array}$} \\
\hline & & & & Annual & Instantaneous & \\
\hline 1.1 & 8,760 & 447.6 & 1,230 & $0 \%$ & $0 \%$ & $\mathrm{~N} / \mathrm{A}$ \\
\hline 1.2 & 8,760 & 447.6 & 1,230 & $0 \%$ & $0 \%$ & N/A \\
\hline 1.3 & 8,760 & 447.6 & 1,230 & $0 \%$ & $0 \%$ & N/A \\
\hline 1.4 & 5,520 & 170.3 & 470 & $61 \%$ & $352 \%$ & 430 \\
\hline 1.5 & 5,400 & 167.2 & 460 & $62 \%$ & $362 \%$ & 440 \\
\hline 1.6 & 5,246 & 160.5 & 440 & $63 \%$ & $403 \%$ & 510 \\
\hline 1.7 & 3,040 & 87.7 & 240 & $79 \%$ & $770 \%$ & 1130 \\
\hline 1.8 & 4,086 & 124.8 & 340 & $71 \%$ & $483 \%$ & 650 \\
\hline 1.9 & 3,080 & 91.9 & 250 & $78 \%$ & $817 \%$ & 1230 \\
\hline
\end{tabular}

Scenarios $1.4,1.5$, and 1.6 achieved a renewable penetration rate of over $60 \%$ with a corresponding 
reduction in fuel consumption, and grid power was only required about $60 \%$ of the year. The instantaneous penetration rate was about $350-400 \%$ of the load. The higher value of surplus power in Scenarios of 1.7 and 1.9 (coupled with a higher GHG cost in Scenario 1.9) resulted in the highest renewable penetration rate and greatest reduction in fuel cost. These scenarios had a very high maximum instantaneous penetration rate - the peak surplus power sold back to the grid was about $1100 \mathrm{~kW}$. The community grid has a peak power demand of about $2500 \mathrm{~kW}$, and as such it is not clear that it can absorb this level of renewable power input without tripping generators, blowing fuses, and causing other problems for power plant.

Figure 37 shows the results of the parametric analysis for the baseline optimal solution (cost details are provided in Appendix C). The diesel-only result with the same GHG cost is shown for comparison. All results were within $85 \%-120 \%$ of the baseline. High and low escalation and grid electricity and high GHG emission costs had the largest impact on the NPC, while the value of surplus power and O\&M costs had less impact. Note that the diesel-only cost would also be affected by some parameters, such as grid electricity costs, but this impact is not shown. The take-away from this analysis is that even if various parameters used in the optimization - capital costs, O\&M costs, etc. - were higher, the NPC was still substantially lower than the diesel-only scenario.

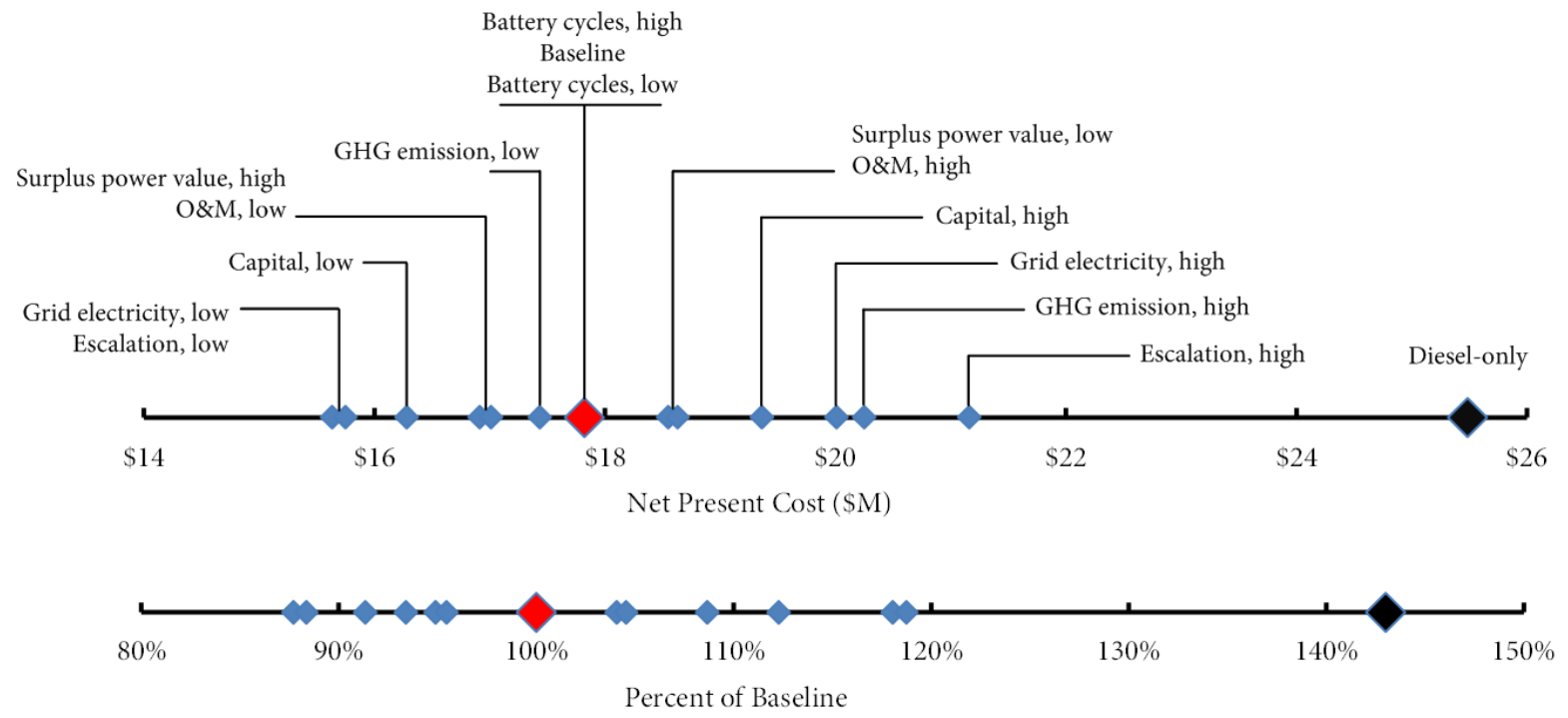

Figure 37: Parametric analysis, grid-tied configuration 


\subsection{Stand-alone: Wind and Photovoltaic with On-Site Diesel Power}

The stand-alone system was identical to the grid-integrated system except it did not draw power from the local electrical grid. Instead an on-site diesel generator met any power deficit, subject to minimum and maximum loading conditions. It is expected that CHARS will integrate into the local power grid and pay utility electricity rates; hence, this analysis is presented for academic purposes only. As such, considerations such as redundancy and spinning reserve were neglected from the analysis. A more sophisticated control strategy is needed to account for multiple generators and the requirement for spinning reserve capacity based on risk of loss of load and weather and load forecasting.

Like the grid-tied configuration, Scenarios 2.1, 2.2, and 2.3 were diesel-only systems. Although minimum loading on the diesel generator can result in surplus power, the magnitude was small over the course of the year and the value of the surplus was neglected. To calculate the payback, the capital cost of $t$

he diesel-only scenarios $(\$ 800 \mathrm{~K})$ was subtracted from the capital cost of each subsequent scenario.

Table 18: Stand-alone configuration capital and net present cost

\begin{tabular}{|c|r|r|r|r|r|}
\hline Scenario & \multicolumn{1}{|c|}{$\begin{array}{c}\text { Surplus } \\
(\$ / \mathrm{kWh})\end{array}$} & $\begin{array}{c}\text { GHG } \\
(\$ / \text { litre })\end{array}$ & $\begin{array}{c}\text { NPC } \\
\mathbf{( \$ M )}\end{array}$ & $\begin{array}{c}\text { Capital } \\
\text { Cost } \mathbf{( \$ )})\end{array}$ & $\begin{array}{c}\text { Payback } \\
\text { (years) }\end{array}$ \\
\hline 2.1 & $\$ 0$ & $\$ 0$ & $\$ 19.9$ & $\$ 800$ & N/A \\
\hline 2.2 & $\$ 0$ & $\$ 0.1369$ & $\$ 21.2$ & $\$ 800$ & N/A \\
\hline 2.3 & $\$ 0$ & $\$ 1.00$ & $\$ 29.0$ & $\$ 800$ & N/A \\
\hline 2.4 & $\$ 0$ & $\$ 0$ & $\$ 19.4$ & $\$ 5,100$ & 15.1 \\
\hline 2.5 & $\$ 0$ & $\$ 0.1369$ & $\$ 20.0$ & $\$ 5,100$ & 11.3 \\
\hline 2.6 & $\$ 0.1324$ & $\$ 0.1369$ & $\$ 19.7$ & $\$ 5,400$ & 11.1 \\
\hline 2.7 & $\$ 0.2973$ & $\$ 0.1369$ & $\$ 18.5$ & $\$ 10,100$ & 12.6 \\
\hline 2.8 & $\$ 0.1324$ & $\$ 1.00$ & $\$ 22.7$ & $\$ 6,580$ & 7.9 \\
\hline 2.9 & $\$ 0.2973$ & $\$ 1.00$ & $\$ 20.4$ & $\$ 12,180$ & 15.7 \\
\hline
\end{tabular}


Table 19: Stand-alone configuration first-year operational cost

\begin{tabular}{|c|r|r|r|r|r|}
\hline Scenario & Fuel (\$K) & GHG (\$K) & O\&M (\$K) & $\begin{array}{c}\text { Surplus } \\
\text { Power }(\$ K)\end{array}$ & Total (\$K) \\
\hline 2.1 & $\$ 625.6$ & $\$ 0.0$ & $\$ 299.6$ & $\$ 0.0$ & $\$ 925.1$ \\
\hline 2.2 & $\$ 625.6$ & $\$ 70.8$ & $\$ 359.6$ & $\$ 0.0$ & $\$ 1,055.9$ \\
\hline 2.3 & $\$ 625.6$ & $\$ 517.0$ & $\$ 359.6$ & $\$ 0.0$ & $\$ 1,502.1$ \\
\hline 2.4 & $\$ 300.4$ & $\$ 0.0$ & $\$ 340.1$ & $\$ 0.0$ & $\$ 640.5$ \\
\hline 2.5 & $\$ 300.4$ & $\$ 34.0$ & $\$ 340.1$ & $\$ 0.0$ & $\$ 674.5$ \\
\hline 2.6 & $\$ 289.3$ & $\$ 32.7$ & $\$ 339.4$ & $-\$ 20.6$ & $\$ 640.8$ \\
\hline 2.7 & $\$ 173.2$ & $\$ 19.6$ & $\$ 426.9$ & $-\$ 299.8$ & $\$ 319.8$ \\
\hline 2.8 & $\$ 229.3$ & $\$ 189.5$ & $\$ 392.1$ & $-\$ 40.0$ & $\$ 770.8$ \\
\hline 2.9 & $\$ 131.2$ & $\$ 108.4$ & $\$ 527.7$ & $-\$ 436.4$ & $\$ 330.9$ \\
\hline
\end{tabular}

Capital and operational costs were higher compared to the grid-tied configuration due to the cost of purchase and maintenance of the diesel genset, while the NPC was lower as the cost of diesel power ended up lower than in the grid-tied configuration under the financial model used in this thesis. Whether CHARS could actually generate its own power at a lower cost than the power corporation is debatable.

The simple payback period of Scenarios 2.6 and 2.7 was about 11-12 years compared to ten years in the grid-tied configuration. This was because of higher capital costs and lower savings compared to the dieselonly Scenario 2, again because CHARS-generated diesel power ended up costing less than the power corporation's cost of electricity.

The design solution is shown in Table 20. The trend was similar to the grid-connected configuration. The inclusion of renewable energy in Scenarios 2.4 onwards allowed the diesel genset to be sized smaller, saving some capital and operational costs. Because the cost of diesel power was less than in the grid-tied configuration, optimal solutions tended to incorporate less renewable energy - e.g., 2 wind turbines instead of 3 in Scenarios 2.4, 2.5, and 2.6. Scenarios 2.7 and 2.9, in which surplus power was sold back to the grid at the avoided cost of fuel, tended to maximize level of renewable energy generators allowed under the optimization constraints - 4 or 6 wind turbines and a $1000 \mathrm{~kW} \mathrm{PV} \mathrm{array.} \mathrm{Like} \mathrm{the} \mathrm{grid-tied}$ configuration, it is not clear if the local grid is able to accommodate this level of renewable power input. 
Table 20: Stand-alone configuration design vector

\begin{tabular}{|c|c|c|c|c|c|c|c|}
\hline Scenario & $\begin{array}{c}\text { \# Wind } \\
\text { Turbines }\end{array}$ & $\begin{array}{c}\text { Diesel Size } \\
(\mathrm{kW})\end{array}$ & $\begin{array}{c}\text { PV Array } \\
\text { Size }(\mathrm{kW})\end{array}$ & $\begin{array}{c}\text { PV } \\
\text { Azimuth }\left(^{\circ}\right)\end{array}$ & $\begin{array}{c}\text { PV } \\
\text { Slope }\left(^{\circ}\right)\end{array}$ & $\begin{array}{c}\text { Battery Size } \\
(\mathbf{k W h})\end{array}$ & $\begin{array}{c}\text { PCS Size } \\
(\mathrm{kW})\end{array}$ \\
\hline 2.1 & 0 & 400 & 0 & 0 & 0 & 0 & 0 \\
\hline 2.2 & 0 & 400 & 0 & 0 & 0 & 0 & 0 \\
\hline 2.3 & 0 & 400 & 0 & 0 & 0 & 0 & 0 \\
\hline 2.4 & 2 & 300 & 400 & 10 & 60 & 100 & 100 \\
\hline 2.5 & 2 & 300 & 400 & 10 & 60 & 100 & 100 \\
\hline 2.6 & 2 & 300 & 460 & 10 & 50 & 100 & 100 \\
\hline 2.7 & 4 & 300 & 1000 & 20 & 50 & 100 & 100 \\
\hline 2.8 & 3 & 300 & 480 & 10 & 50 & 180 & 100 \\
\hline 2.9 & 6 & 300 & 1000 & 20 & 50 & 100 & 100 \\
\hline
\end{tabular}

Finally, Table 21 summarizes the renewable performance of each scenario. Like the grid-tied configuration, every optimal solution involving renewable energy was a high-penetration system, as the diesel gensets were turned off for a period of time, ranging from $30-70 \%$ of the year.

Table 21: Stand-alone configuration annual renewable performance

\begin{tabular}{|c|r|r|r|r|r|r|}
\hline \multirow{2}{*}{ Scenario } & \multirow{2}{*}{$\begin{array}{c}\text { Diesel } \\
\text { Run-Time }\end{array}$} & \multirow{2}{*}{$\begin{array}{c}\text { Fuel } \\
\text { (hours) }\end{array}$} & \multirow{2}{*}{$\begin{array}{c}\text { GHG } \\
\text { (K litres) }\end{array}$} & $\begin{array}{c}\text { Emissions } \\
\text { (ton }\end{array}$ & & \multicolumn{2}{|c|}{ Penetration Rate } & \multirow{2}{*}{$\begin{array}{c}\text { Peak Surplus } \\
\text { (kW) }\end{array}$} \\
\hline 2.1 & 8,760 & 517.0 & 1,420 & $0 \%$ & $0 \%$ & N/A \\
\hline 2.2 & 8,760 & 517.0 & 1,420 & $0 \%$ & $0 \%$ & N/A \\
\hline 2.3 & 8,760 & 517.0 & 1,420 & $0 \%$ & $0 \%$ & N/A \\
\hline 2.4 & 5,981 & 248.3 & 680 & $51 \%$ & $307 \%$ & 350 \\
\hline 2.5 & 5,981 & 248.3 & 680 & $51 \%$ & $307 \%$ & 350 \\
\hline 2.6 & 5,802 & 239.1 & 650 & $53 \%$ & $340 \%$ & 400 \\
\hline 2.7 & 3,576 & 143.1 & 390 & $71 \%$ & $721 \%$ & 1,050 \\
\hline 2.8 & 4,614 & 189.5 & 520 & $63 \%$ & $398 \%$ & 500 \\
\hline 2.9 & 2,682 & 108.4 & 300 & $78 \%$ & $824 \%$ & 1,220 \\
\hline
\end{tabular}

Figure 38 shows the parametric analysis. Because of capital and O\&M costs associated with the diesel generator, more parametric runs were included in this analysis than for the stand-alone configuration. Higher and lower capital and O\&M costs were evaluated for the renewable systems, diesel genset, and both combined. 
Like the grid-tied configuration, most parametric runs were close to the optimum, within $+/-10 \%$. Escalation, the fuel cost, and high GHG cost had the highest impact, followed by the capital cost of the renewable generators and O\&M costs. The capital cost of the diesel generator had a minor impact on NPC, since the size of the diesel genset was small compared to the renewable generators.

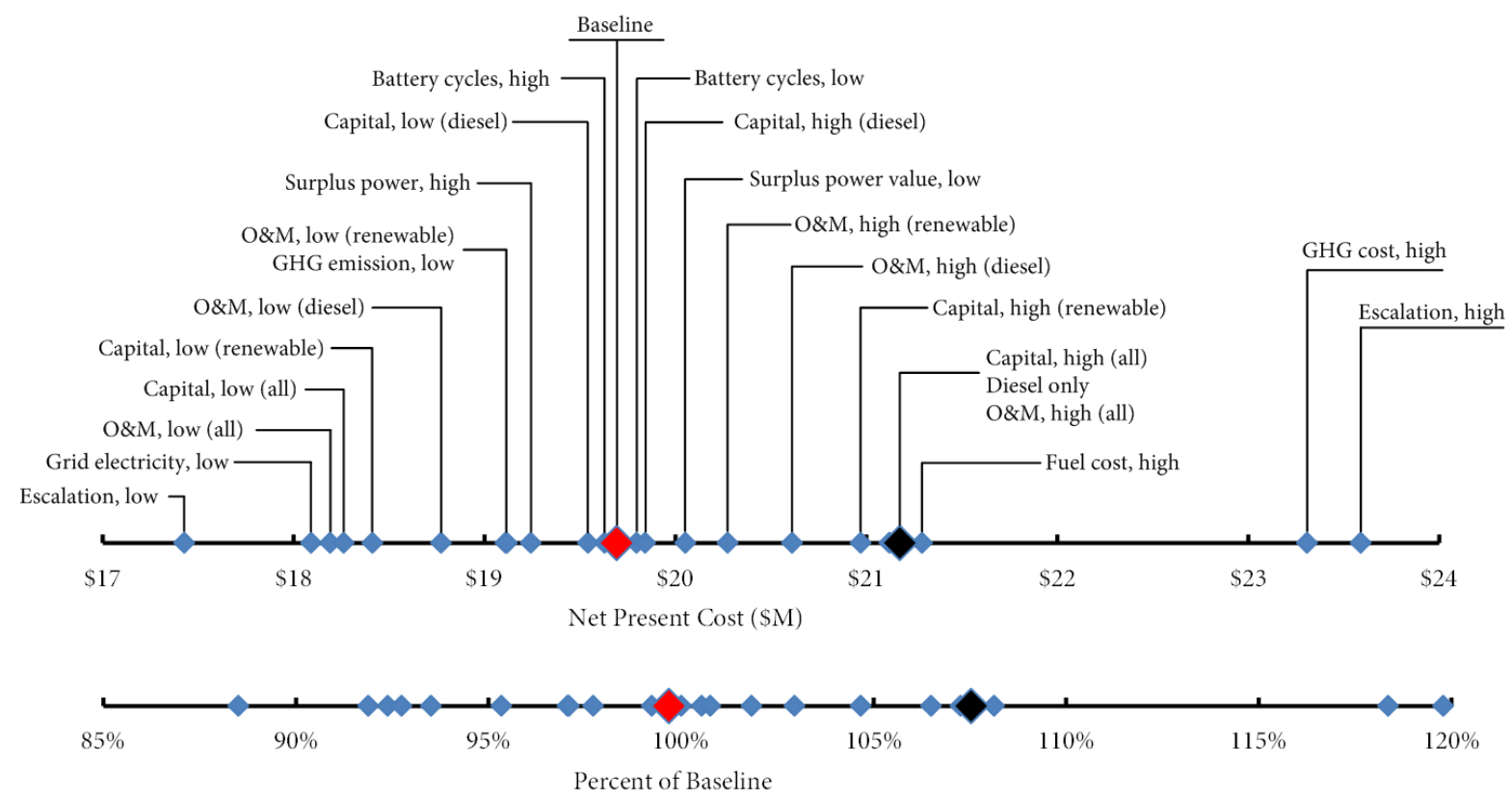

Figure 38: Parametric analysis, stand-alone configuration

\subsection{Low-maintenance: Photovoltaic-Battery Configuration}

The previous two system configurations included wind turbines in the solution. Given the harsh operating environment, higher maintenance requirements, and moving parts, wind turbines are higher-risk than a PV-battery system. To explore the potential for a lower-maintenance, lower-risk renewable system for CHARS, the third system configuration omitted the wind turbines and only included a PV array, battery, and PCS. Like the first configuration, any supply shortfall was met from the community diesel plant. Drawing on the results of Configurations 1 and 2, PV array azimuth and slope were restricted to $+/-30^{\circ}$ and $30^{\circ}-90^{\circ}$, respectively. The maximum PV array size was set to $1500 \mathrm{~kW}$ instead of $1000 \mathrm{~kW}$ to compensate for the lack of wind turbines in the solution. 
Table 22 shows the capital and NPC of each optimum. Compared to the grid-tied configuration with wind turbines, the NPC was significantly higher; however, due to the lower capital costs, the simple payback period was only marginally higher.

Table 22: PV-only configuration capital and net present cost

\begin{tabular}{|c|r|r|c|r|r|}
\hline Scenario & $\begin{array}{c}\text { Surplus } \\
(\$ / \mathbf{k W h})\end{array}$ & $\begin{array}{c}\text { GHG } \\
(\mathbf{\$} / \text { litre })\end{array}$ & $\begin{array}{c}\text { NPC } \\
\mathbf{( \$ M )}\end{array}$ & $\begin{array}{c}\text { Capital } \\
\text { Cost } \mathbf{( \$ K )}\end{array}$ & $\begin{array}{c}\text { Payback } \\
\text { (years) }\end{array}$ \\
\hline 3.1 & N/A & $\$ 0$ & $\$ 24.4$ & $\$ 0$ & N/A \\
\hline 3.2 & N/A & $\$ 0.1369$ & $\$ 25.5$ & $\$ 0$ & N/A \\
\hline 3.3 & N/A & $\$ 1.00$ & $\$ 32.3$ & $\$ 0$ & N/A \\
\hline 3.4 & $\$ 0$ & $\$ 0$ & $\$ 21.2$ & $\$ 3,500$ & 10.7 \\
\hline 3.5 & $\$ 0$ & $\$ 0.1369$ & $\$ 21.9$ & $\$ 3,600$ & 10.2 \\
\hline 3.6 & $\$ 0.1324$ & $\$ 0.1369$ & $\$ 21.5$ & $\$ 4,500$ & 10.5 \\
\hline 3.7 & $\$ 0.2973$ & $\$ 0.1369$ & $\$ 19.7$ & $\$ 8,000$ & 10.7 \\
\hline 3.8 & $\$ 0.1324$ & $\$ 1.00$ & $\$ 25.7$ & $\$ 6,060$ & 9.3 \\
\hline 3.9 & $\$ 0.2973$ & $\$ 1.00$ & $\$ 23.6$ & $\$ 8,020$ & 8.8 \\
\hline
\end{tabular}

The general trend of first-year operational costs, shown in Table 23, was similar to previous configurations. One exception was the O\&M cost in Scenario 3.8; due to the higher reliance on batteries and lack of expensive wind turbine O\&M, the replacement costs for batteries tended to dominate. This configuration may be interpreted as lower risk compared to the grid-tied configuration due to lower O\&M and capital costs; however, the pay-off in terms of lower life cycle costs was less (higher NPC).

Table 23: PV-only configuration first-year operational cost

\begin{tabular}{|c|r|r|r|r|r|}
\hline Scenario & Power (\$K) & GHG (\$K) & O\&M (\$K) & $\begin{array}{c}\text { Surplus } \\
\text { Power }(\$ K)\end{array}$ & Total (\$K) \\
\hline 3.1 & $\$ 1,103.2$ & $\$ 0.0$ & $\$ 0.0$ & $\$ 0.0$ & $\$ 1,103.2$ \\
\hline 3.2 & $\$ 1,103.2$ & $\$ 61.3$ & $\$ 0.0$ & $\$ 0.0$ & $\$ 1,164.4$ \\
\hline 3.3 & $\$ 1,103.2$ & $\$ 447.6$ & $\$ 0.0$ & $\$ 0.0$ & $\$ 1,550.8$ \\
\hline 3.4 & $\$ 761.3$ & $\$ 0.0$ & $\$ 13.4$ & $\$ 0.0$ & $\$ 774.7$ \\
\hline 3.5 & $\$ 755.7$ & $\$ 42.0$ & $\$ 13.7$ & $\$ 0.0$ & $\$ 811.4$ \\
\hline 3.6 & $\$ 715.8$ & $\$ 39.8$ & $\$ 15.5$ & $-\$ 35.2$ & $\$ 735.9$ \\
\hline 3.7 & $\$ 636.1$ & $\$ 35.3$ & $\$ 17.2$ & $-\$ 274.8$ & $\$ 413.8$ \\
\hline 3.8 & $\$ 639.0$ & $\$ 259.3$ & $\$ 57.1$ & $-\$ 52.9$ & $\$ 902.4$ \\
\hline 3.9 & $\$ 633.2$ & $\$ 257.0$ & $\$ 20.0$ & $-\$ 273.4$ & $\$ 636.8$ \\
\hline
\end{tabular}


The design vector is summarized in Table 24. Similar to previous configurations, the renewable energy generator size was maximized for scenarios with a high value of surplus power, and batteries did not feature prominently in the solution (with the exception of Scenario 3.8).

Table 24: PV-only configuration design vector

\begin{tabular}{|c|c|c|c|c|c|}
\hline Scenario & $\begin{array}{c}\text { PV Array } \\
\text { Size }(\mathrm{kW})\end{array}$ & $\begin{array}{c}\text { PV } \\
\text { Azimuth }\left(^{\circ}\right)\end{array}$ & $\begin{array}{c}\text { PV } \\
\text { Slope }\left({ }^{\circ}\right)\end{array}$ & $\begin{array}{c}\text { Battery Size } \\
(\mathrm{kWh})\end{array}$ & $\begin{array}{c}\text { PCS Size } \\
(\mathrm{kW})\end{array}$ \\
\hline 3.1 & 0 & 0 & 0 & 0 & 0 \\
\hline 3.2 & 0 & 0 & 0 & 0 & 0 \\
\hline 3.3 & 0 & 0 & 0 & 0 & 0 \\
\hline 3.4 & 600 & 10 & 40 & 100 & 100 \\
\hline 3.5 & 620 & 10 & 40 & 100 & 100 \\
\hline 3.6 & 800 & 10 & 40 & 100 & 100 \\
\hline 3.7 & 1500 & 10 & 50 & 100 & 100 \\
\hline 3.8 & 1040 & 10 & 40 & 460 & 100 \\
\hline 3.9 & 1500 & 10 & 50 & 120 & 100 \\
\hline
\end{tabular}

Consistent with the lower-risk, lower-payoff observation, Table 25 shows that the PV-only configuration had poorer renewable performance. The penetration rate did not rise above about a third, with a correspondingly lower reduction in fuel usage. The various scenarios would still be considered highpenetration, as the system was operating in renewable-only mode for part of the year. Critically, the instantaneous penetration rate was still high; this is consistent with the diurnal and seasonal concentration of available solar resource compared to wind, which is more evenly distributed.

The trend of surplus power was similar to Configuration 1. Scenarios 3.6 and 3.7 had annual surplus energy equivalent to $16 \%$ and $53 \%$, respectively, of the load. 
Table 25: Optimal solution annual renewable performance, PV-only configuration

\begin{tabular}{|c|c|c|c|c|c|c|}
\hline \multirow[b]{2}{*}{ Scenario } & \multirow{2}{*}{$\begin{array}{c}\text { Diesel } \\
\text { Run-Time } \\
\text { (hours) }\end{array}$} & \multirow{2}{*}{$\begin{array}{c}\text { Fuel } \\
\text { (K litres) }\end{array}$} & \multirow{2}{*}{$\begin{array}{c}\text { GHG } \\
\text { Emissions } \\
\text { (ton }{ }_{\mathrm{CO} 2 \text {,eq }} \text { ) }\end{array}$} & \multicolumn{2}{|c|}{ Penetration Rate } & \multirow{2}{*}{$\begin{array}{c}\text { Peak Surplus } \\
(\mathrm{kW})\end{array}$} \\
\hline & & & & Annual & Instantaneous & \\
\hline 3.1 & 8,760 & 447.6 & 1,230 & $0 \%$ & $0 \%$ & N/A \\
\hline 3.2 & 8,760 & 447.6 & 1,230 & $0 \%$ & $0 \%$ & N/A \\
\hline 3.3 & 8,760 & 447.6 & 1,230 & $0 \%$ & $0 \%$ & N/A \\
\hline 3.4 & 7,494 & 308.9 & 850 & $25 \%$ & $338 \%$ & 370 \\
\hline 3.5 & 7,452 & 306.7 & 840 & $26 \%$ & $350 \%$ & 390 \\
\hline 3.6 & 7,114 & 290.4 & 800 & $29 \%$ & $451 \%$ & 550 \\
\hline 3.7 & 6,546 & 258.1 & 710 & $35 \%$ & $872 \%$ & 1,260 \\
\hline 3.8 & 6,761 & 259.3 & 710 & $36 \%$ & $587 \%$ & 760 \\
\hline 3.9 & 6,518 & 257.0 & 700 & $35 \%$ & $872 \%$ & 1,260 \\
\hline
\end{tabular}

Figure 39 shows the results of the parametric analysis. The results show more clustering around the baseline optimum; most results were within $+/-5 \%$. This was because of the smaller size of renewable generators compared to Configuration 1 and 2 and again possibly indicates lower risk than configurations with wind turbines. Higher escalation and GHG emission cost resulted in an NPC higher than the dieselonly solution, reflecting lower operational savings and fuel consumption compared to the grid-connected configuration with wind turbines.

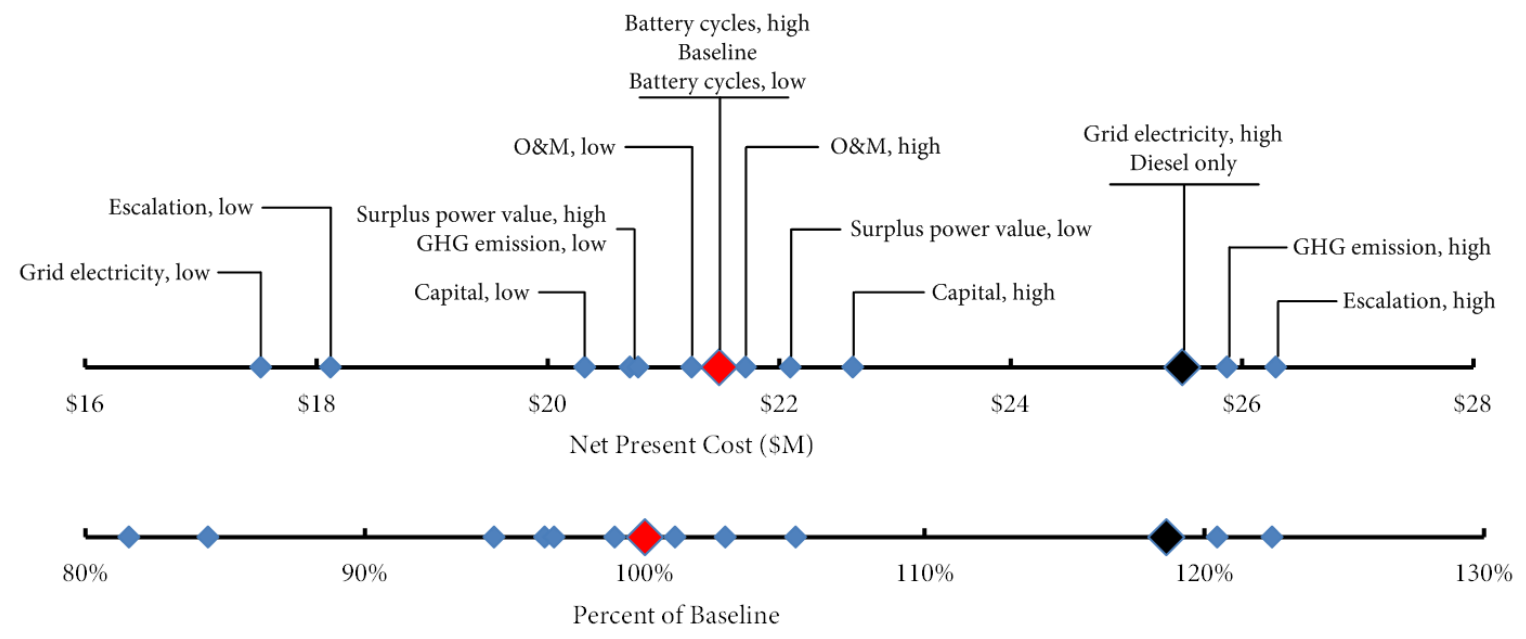

Figure 39: Parametric analysis, PV-only configuration 


\subsection{Highest Penetration: Maximizing Renewable Energy for CHARS}

The fourth system configuration explored the potential for very high levels of renewable energy. Based on Configuration 1 (grid-tied), a high cost $(\$ 100 / \mathrm{kWh})$ was applied to grid-purchased power. This had the effect of heavily favouring renewable energy.

Having established the general trend in previous configuration scenarios, only one scenario was evaluated: a surplus power value of $\$ 0 / \mathrm{kWh}$ and a GHG cost of $\$ 0.1369 /$ litre. The impact of selling power back to the grid was not evaluated, since previous results established the difficulty of integrating the surplus power into the grid, an issue that would be exacerbated in a very high renewable configuration. Similarly, the assumption of time-independence for displacing heating fuel with electricity is invalid with very high surplus renewable power.

Drawing on the restrictions on PV azimuth and slope from Configuration 3, and allowing for higher renewable generators and battery capacity, the design vector was adjusted as per Table 26. The maximum battery size was increased to approximately three days' electrical demand at CHARS. The step size was increased as TRNOPT limits the number of intervals for any design variable to 100 .

Table 26: Highest penetration configuration design variables

\begin{tabular}{|l|c|c|c|}
\hline Variable & Minimum & Maximum & Step \\
\hline Number of wind turbines $(\mathrm{kW})$ & 0 & 10 & 1 \\
\hline Size of PV array $(\mathrm{kW})$ & 0 & 3000 & 30 \\
\hline PV array slope (from horizontal) & $30^{\circ}$ & $90^{\circ}$ & $10^{\circ}$ \\
\hline PV array azimuth & $-30^{\circ}($ east $)$ & $+30^{\circ}($ west $)$ & $10^{\circ}$ \\
\hline Battery size $(\mathrm{kWh})$ & 100 & 10000 & 50 \\
\hline Power conditioning system size $(\mathrm{kW})$ & 100 & 2000 & 20 \\
\hline
\end{tabular}

Table 27 summarizes the optimal solution costs. For reporting financial metrics, the standard grid power cost $(\$ 0.6607 / \mathrm{kWh})$ was used: the higher cost was only used to force the optimization to favour renewable energy. Table 28 provides more detail on the high capital cost; the battery size and number of wind turbines were maximized, while the PV array and PCS size were also large. The high slope of the PV array indicates how the system optimized to maximize PV output when the solar resource is low: for example, near sunrise and sunset and during the winter months when the solar elevation angle is low. 
Table 27: Highest penetration configuration capital and net present cost

\begin{tabular}{|c|r|c|c|r|r|}
\hline Scenario & $\begin{array}{c}\text { Surplus } \\
(\$ / \mathrm{kWh})\end{array}$ & $\begin{array}{c}\text { GHG } \\
(\$ / \text { litre })\end{array}$ & $\begin{array}{c}\text { NPC } \\
(\mathbf{M})\end{array}$ & $\begin{array}{c}\text { Capital } \\
\text { Cost }(\$ \mathrm{~K})\end{array}$ & $\begin{array}{c}\text { Payback } \\
\text { (years) }\end{array}$ \\
\hline 4.1 & $\mathrm{~N} / \mathrm{A}$ & $\$ 0.1369$ & $\$ 25.5$ & $\$ 0$ & N/A \\
\hline 4.2 & $\$ 0$ & $\$ 0.1369$ & $\$ 55.5$ & $\$ 37,280$ & 154.8 \\
\hline
\end{tabular}

Table 28: Highest penetration configuration design vector

\begin{tabular}{|c|c|c|c|c|c|c|}
\hline Scenario & $\begin{array}{c}\text { \# Wind } \\
\text { Turbines }\end{array}$ & $\begin{array}{c}\text { PV Array } \\
\text { Size (kW) }\end{array}$ & $\begin{array}{c}\text { PV } \\
\text { Azimuth }\left(^{\circ}\right)\end{array}$ & $\begin{array}{c}\text { PV } \\
\text { Slope }\left(^{\circ}\right)\end{array}$ & $\begin{array}{c}\text { Battery Size } \\
(\mathbf{k W h})\end{array}$ & $\begin{array}{c}\text { PCS Size } \\
(\mathbf{k W})\end{array}$ \\
\hline 4.1 & 0 & 0 & 0 & 0 & 0 & 0 \\
\hline 4.2 & 10 & 2400 & 10 & 80 & 10000 & 1320 \\
\hline
\end{tabular}

The large renewable generator and battery size increased operational costs, as shown in Table 29; the battery replacement cost was also large, contributing to the high O\&M cost. The low annual savings compared to the reference case, Scenario 1, coupled with high capital costs explains the infeasible payback period of $150+$ years, well in excess of the system life.

Table 29: Highest penetration configuration first-year operational costs

\begin{tabular}{|c|r|r|r|r|r|}
\hline Scenario & Power $(\mathbf{K})$ & GHG (\$K) & O\&M (\$K) & $\begin{array}{c}\text { Surplus } \\
\text { Power }(\$ K)\end{array}$ & Total $(\mathbf{\$ K})$ \\
\hline 1 & $\$ 1,103.2$ & $\$ 61.3$ & $\$ 0.0$ & $\$ 0.0$ & $\$ 1,164.4$ \\
\hline 2 & $\$ 22.1$ & $\$ 1.2$ & $\$ 900.4$ & $\$ 0.0$ & $\$ 923.7$ \\
\hline
\end{tabular}

Finally, Table 30 indicates that, even with three days of battery autonomy and a renewable generator nominal capacity about ten times the peak electrical demand, grid power was still required for about nine days over the course of the year. The peak surplus power was in excess of peak community power demand, and total peak energy generated over the year was over twice the electrical load at CHARS.

Table 30: Highest penetration configuration annual renewable performance

\begin{tabular}{|c|c|c|c|c|c|c|}
\hline \multirow[b]{2}{*}{ Scenario } & \multirow{2}{*}{$\begin{array}{c}\text { Diesel } \\
\text { Run-Time } \\
\text { (hours) }\end{array}$} & \multirow{2}{*}{$\begin{array}{c}\text { Fuel } \\
\text { (K litres) }\end{array}$} & \multirow{2}{*}{$\begin{array}{c}\text { GHG } \\
\text { Emissions } \\
\text { (ton }{ }_{\mathrm{CO} 2, \mathrm{eq}} \text { ) }\end{array}$} & \multicolumn{2}{|c|}{ Penetration Rate } & \multirow{2}{*}{$\begin{array}{c}\text { Peak Surplus } \\
(\mathrm{kW})\end{array}$} \\
\hline & & & & Annual & Instantaneous & \\
\hline 1 & 8,760 & 447.6 & 1,230 & $0 \%$ & $0 \%$ & N/A \\
\hline 2 & 218 & 9.0 & 20 & $98 \%$ & $1723 \%$ & 2937.5 \\
\hline
\end{tabular}

These results show how difficult it would be for CHARS to go completely fossil fuel-free: multiple days of 
autonomy through electrical storage would be required as well as renewable energy generation significantly in excess of peak electrical demand. Given the amount of stored energy required, lithium-ion batteries are probably not the best solution; other storage technologies, such as flow batteries or hydrogen storage, may be a better alternative.

Adding a penalty to the cost of grid power likely did not produce the optimal solution, since the magnitude of the penalty favours maximizing the renewable generators even if the marginal usable output of another wind turbine or PV panel is very low. A more sophisticated approach is to use multi-objective optimization, in which two or more objectives are solved for simultaneously. However, multi-objective optimization is complex and GenOpt does not currently include the functionality. The results for this configuration demonstrate the limitations of single-objective optimization and suggest a need for more advanced tools to minimize carbon emissions while also considering other objectives such as life-cycle or capital cost.

Because of the infeasibility of this configuration, the parametric study was omitted.

\subsection{Higher Temporal Resolution}

The previous analyses were conducted with hourly simulation models, a common approach to modelling of hybrid renewable energy systems. Previous efforts have investigated the impact of sub-hourly timesteps on the optimal economic solution.

Hoevenaars and Crawford (2012) modelled wind, solar PV, diesel, load, and battery components down to 1s timesteps. It was noted that solar PV and diesel genset models typically do not have a strong temporal dependence. Wind turbine output on the other hand exhibited a variance of up to $7 \%$ when comparing $1 \mathrm{~s}$ and hourly energy output. This difference shrank to less than $0.5 \%$ when comparing 10 -min and hourly data. The optimal system configuration with respect to NPC with only diesel back-up was more strongly influenced than configurations with battery backup. This is primarily a result of intra-hourly spikes in the load, a single residence, which doubled the size of the diesel genset at higher temporal resolution. The variation in NPC was much lower, about 3-4\%, for a system configuration with wind, solar, batteries, and 
diesel. Overall no firm recommendation was made concerning the appropriate choice of temporal resolution.

Similarly, Kools and Phillipson (2016) noted minor differences in losses at higher temporal resolution than one hour and generally did not recommend smaller timesteps; however, the need to fully account for the intra-hourly stochastic profile was noted. In addition, when evaluating the state of the system (for example, worst-case performance) as opposed to economic optimization, a higher-resolution model may be required.

To evaluate the impacts of temporal resolution on the baseline optimal solution of Configuration 1 (Scenario 1.6), 10-min input data were used. For solar measurements, the minute data were averaged over the 10-min timestep. Wind and temperature measurements were already available as 10 -min data; both were averaged over the hour for previous configurations. The hourly load data were converted to a 10min timestep using linear interpolation.

The 10-min simulation, Configuration 5, did not result in a change to the optimal system configuration as compared to Scenario 1.6 and the NPC was virtually indistinguishable (less than $0.5 \%$ higher at higher resolution).

A histogram comparing surplus power production of Scenario 1.6 at both resolutions is shown in Figure 40. There is little appreciable difference in the frequency. Significantly, there is no surplus power for about $70 \%$ of the year. Surplus power up to about $200 \mathrm{~kW}$ occurs another $24 \%$ of the year, while surplus power above $200 \mathrm{~kW}$ occurs only about $6 \%$ of the year; however, these periods are responsible for almost $40 \%$ of surplus energy, further demonstrating the difficulty of making economic use of the surplus power. 


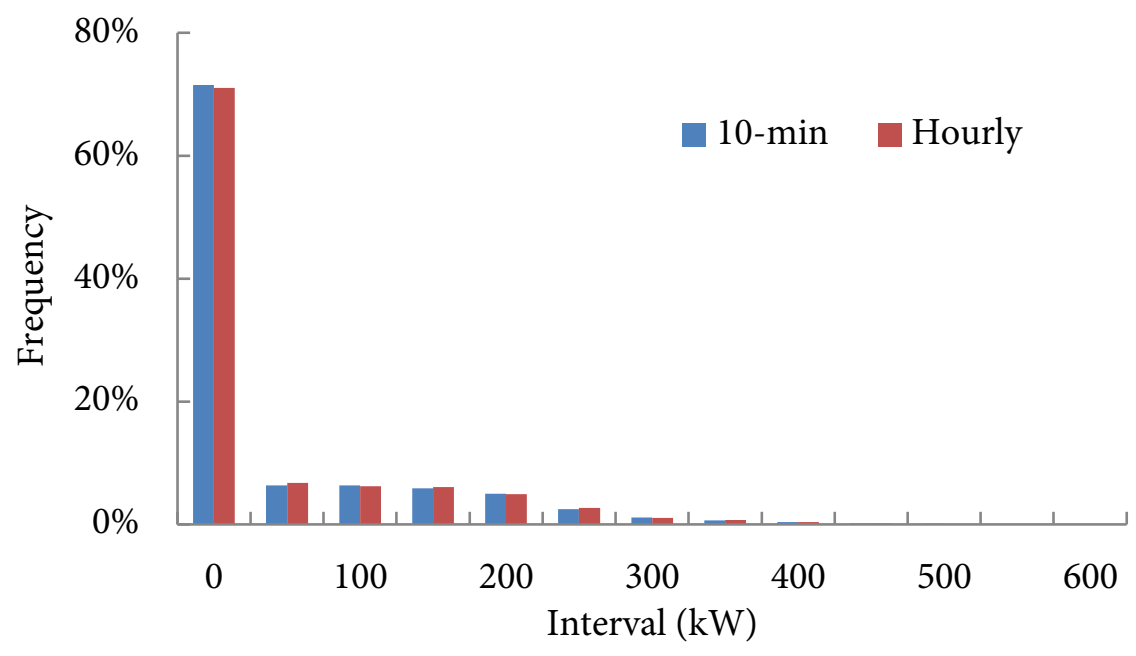

Figure 40: Histogram of optimal configuration total surplus power

Figure 41 compares the solar PV output at each temporal resolution. The annual results differ by about 1\%. This is consistent with observations that grid-connected PV systems with maximum power point tracking experience a quasi-linear relationship between annual energy output and solar irradiance, and hence energy output is relatively insensitive to temporal resolution (Hoevenaars and Crawford, 2011).

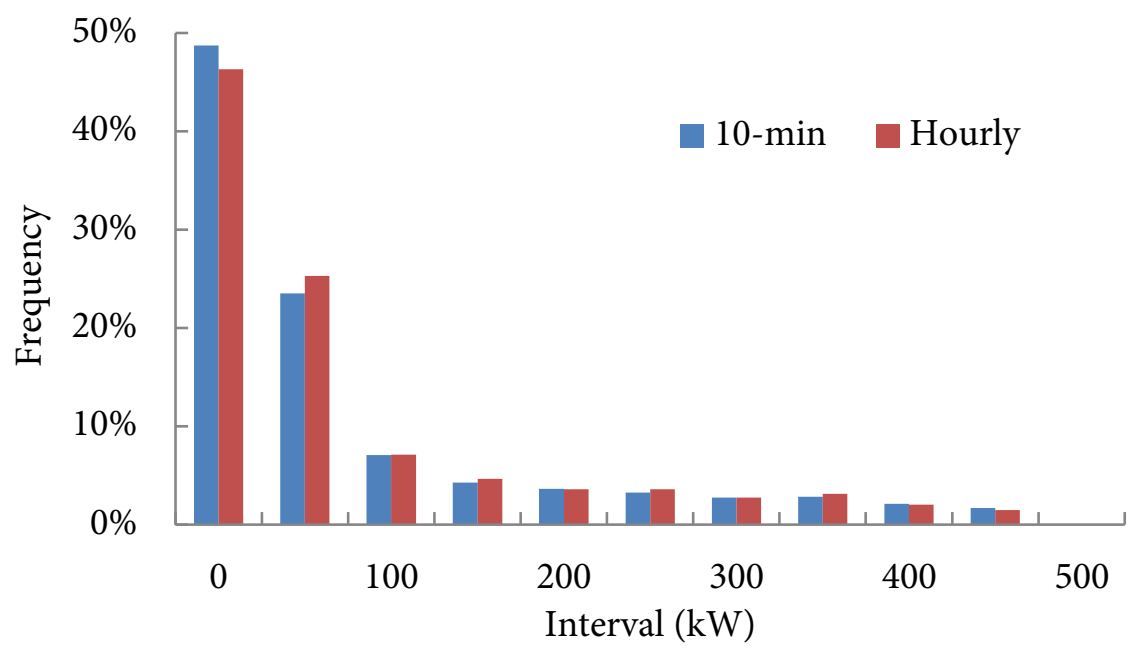

Figure 41: Histogram of optimal configuration solar PV output

Finally, Figure 42 compares the difference for wind output. The results are also very close, consistent with Hoevenaars and Crawford (2011) who showed little difference between the 10-min and hourly results. The authors noted however that wind turbine models using datasheet power curves are likely not 
appropriate for timesteps smaller than $10 \mathrm{~min}$, since the curves are generated using 10 -min wind data. Instead, a dynamic model that accounts for the turbine's inertia is needed for sub-10-min timesteps.

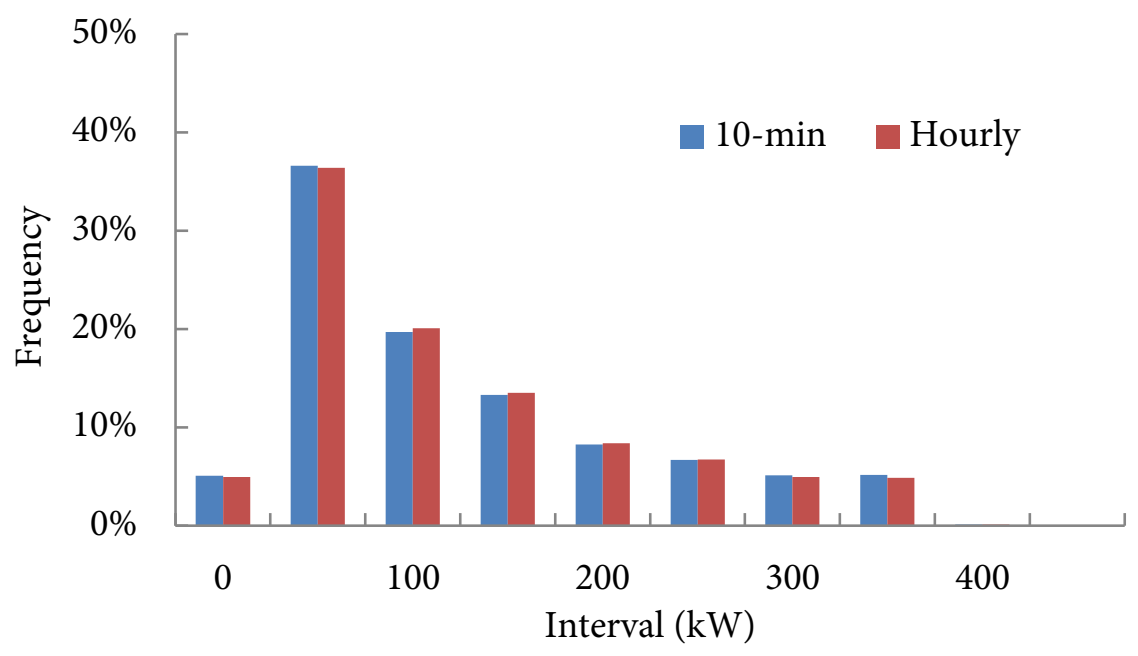

Figure 42: Histogram of optimal configuration wind turbine output

Overall these results show the model is relatively insensitive to a finer timestep down to 10 -min. One limitation is the interpolation of the hourly load data, which itself has a standard profile and which therefore may not capture higher intra-hour peaks. Furthermore, these results apply to the economic optimization and not to reliability assessments, evaluation of worst-case performance, or analysis of electrical transients, which require sub-minute timesteps (Kools and Phillipson, 2016). 


\section{Policy Considerations}

This section summarizes the policy and governance environment surrounding electricity generation in Nunavut, identifies some options for implementation of renewable energy, and outlines other important considerations such as the requirements and opportunities of the Nunavut Agreement (1993).

\subsection{Governance in Nunavut}

The framework for governance in Nunavut is a comprehensive land-claims agreement called the Nunavut Land Claims Agreement (NLCA) or simply the Nunavut Agreement (1993), a constitutional agreement between the Inuit of the Nunavut region and Her Majesty the Queen in right of Canada. The agreement laid the grounds for the partition of Nunavut from the Northwest Territories in 1999, and defines the rights and obligations of both the Crown (federal and territorial) and the Inuit of the region. Among other articles, it includes general provisions; rights of Inuit to harvest wildlife; the establishment of four comanagement regulatory agencies (Nunavut Planning Commission (NPC), Nunavut Water Board (NWB), Nunavut Impact Review Board (NIRB), and Nunavut Wildlife Management Board (NWMB)); the status of Inuit-owned land; and the obligations of the Crown with respect to government contracting with Inuitowned firms and direct employment of Inuit by government. It includes an objective of Inuit participation in government employment to a representative level, i.e., a level proportional to the percent of the population who are Inuit (about 85\%).

The Nunavut Agreement laid the grounds for a governance style unique in Canada. At the legislative level, the Government of Nunavut (GN) places high importance on consensus-style government - this has been noted as "an instance of Aboriginal political culture having transformed the Westminster cabinetparliamentary system"(White, 2009). For example, there are no political parties, the premier and cabinet are chosen directly by all members of the legislative assembly (MLAs), and all MLAs participate in closeddoor debates on issues in an effort to reach consensus. In other ways - such as the structure of the public service, with line departments and central agencies - the government resembles other jurisdictions in Canada. 
The Inuit land claims organization, Nunavut Tunngavik Incorporated (NTI) and the three regional Inuit associations (Kivalliq, Kitikmeot, and Qikiqtani Inuit Organizations), play an important role in governance in the territory. These organizations represent all Inuit in Nunavut and help ensure that Inuit rights under the Nunavut Agreement are respected. For example, NTI recently settled a billion-dollar claim for $\$ 255 \mathrm{M}$ against the federal government for failing to properly implement certain provisions of the Nunavut Agreement (NTI, 2015), particularly the article relating to employment and training in government (White, 2009).

Finally, in many ways the federal government is of greater importance in Nunavut than in other Canadian jurisdictions. As a territory (as opposed to a province), certain Crown responsibilities are invested in the federal as opposed to territorial government. The most significant of these is ownership of Crown lands and the attendant non-renewable resources, which are held by the federal government. Further, environmental regulation is ultimately the responsibility of the federal government, although the Nunavut regulatory agencies make recommendations that are usually followed (White, 2009).

The most prominent federal department is Indigenous and Northern Affairs Canada (INAC), which administers Crown lands in Nunavut; McDonald (2011) recommended that INAC take the lead on renewable energy projects in the territory. A recent Senate report also recommended increased involvement of the federal government in energy in the north (Government of Canada, 2015), including development of a strategic plan to improve energy efficiency, significantly increased funding of northern communities and organizations for energy initiatives, and supporting the modernization of legacy generating infrastructure at or past its design life.

The role of the federal government in funding the territory is also an important consideration. Because of the limited tax base and small private sector, the majority (about 80-90\%) of territorial funding comes from federal transfers, the size of which is determined by the federal government (White, 2009). In 201819 about $\$ 1.6 \mathrm{~B}$ in federal funding is expected out of a total of $\$ 75.4 \mathrm{~B}$ to other levels of government across the entire country, or $\$ 42 \mathrm{~K} /$ capita compared to a national average of about $\$ 2 \mathrm{~K} /$ capita (Government of Canada, 2018a). The territory's spending ability is further constrained by a debt ceiling determined by the federal government. As of $2017-18$, there was approximately $\$ 270 \mathrm{M}$ in debt room out of a total cap of 
\$650M (Government of Nunavut, 2017). The presence of this cap restricts the territory's ability to debtfinance large capital projects.

\subsection{Qulliq Energy Corporation}

The Qulliq Energy Corporation (QEC) is a Crown corporation that reports to, operates at arm's length from, and is wholly owned by the Government of Nunavut. It is the only producer and distributor of electricity in the territory. QEC is a regulated utility with electricity rates set by the Utility Rates Review Council through a process called a General Rate Application (QEC, 2017a).

Currently each community has a different rate for commercial and residential consumers, although the corporation is attempting to move to a unified rate across the entire territory. QEC cited several reasons for a unified rate, including a differential between current rates and actual cost of service, sharing the cost of large capital projects, and sharing the benefits of alternative energy.

The posted rates are not, however, what many consumers pay since direct subsidies significantly distort price signals. For example, residents of public housing pay only 6 cents/kWh. All other residential consumers are subsidized to half the rate of the capital, Iqaluit, up to a maximum beyond which the posted rate is charged. Commercial consumers on the other hand pay the full posted commercial rate. In 2016-17, these subsidies totaled about $\$ 23 \mathrm{M}$ for public housing and $\$ 10 \mathrm{M}$ for the residential subsidy, with another $\$ 10 \mathrm{M}$ charged directly to residential customers. Commercial customers and street lighting comprised another $\$ 74 \mathrm{M}$ and $\$ 1.7 \mathrm{M}$ respectively. Thus on total sales of about $\$ 120 \mathrm{M}$, direct subsidies accounted for $28 \%$ (QEC, 2017b).

QEC recently implemented (or plans to implement) a net-metering policy, where consumers with on-site renewable energy systems can receive financial credit for power sent to the grid. The allowable size is limited to $10 \mathrm{~kW}$ and the value of the credit is not clear from published information (e.g., the commercial rate versus the avoided cost of fuel). A larger-scale net-metering policy that would allow CHARS to deliver hundreds of $\mathrm{kW}$ to the grid does not exist. 
QEC noted the increasing demand for alternatives to diesel and has delivered some demonstration projects, including a small solar PV array and a wind power feasibility study. However, its primary responsibility is to provide safe and reliable power to communities (QEC, 2017b). Because of the lack of redundancy and harsh climate, a failure at the local power plant can have catastrophic consequences, including requiring an evacuation of the community. Whereas in the south power failures cause economic loss and increased safety risks, in the north it is literally a matter of life and death. This fact needs to be in the forefront of any planning for high-penetration renewable energy.

QEC's capital budget was \$22M in 2016 and \$35M in 2017, compared to cash from operating activities of $\$ 17 \mathrm{M}$ and $\$ 29 \mathrm{M}$, respectively (QEC, 2017b). The capital budget is almost completely allocated to upgrading, maintaining, and replacing existing diesel infrastructure (Taptuna, 2012). Current capital funding levels may not be sufficient, since as of 2014, 17 of the 25 generating plants were past their design life span (Government of Canada, 2015).

\subsection{Financing Renewable Energy}

Renewable energy is a means to achieving a policy objective, not an end in itself (Cullen, 2016). Objectives include offsetting externalities associated with fossil fuels; achieving health benefits by eliminating or reducing fossil fuel combustion; reducing energy supply risk and reliance on imported fuels; and promotion of green infrastructure jobs.

Mechanisms to achieve these objectives through the implementation of renewable energy systems include direct funding, such as capital grants or utility procurement, and market-creation mechanisms, such as feed-in tariffs (FIT), tax incentives, and tradable renewable power certificates (Abolhosseini and Heshmati, 2014). Market-creation mechanisms incentivize the generation and/or distribution of renewable electricity by non-utility independent power producers (IPPs). Potential IPPs in Nunavut include community groups, a private-sector firm, or an Inuit organization like NTI.

Yukon recently published a microgeneration policy (Government of Yukon, 2013) for small renewable energy systems up to $50 \mathrm{~kW}$, and a policy for IPPs (Government of Yukon, 2015), which covers larger systems through several mechanisms. System-wide generation limits are in place to limit the amount of 
energy produced annually through IPP sources and rates are intended to be set at the avoided cost of new generation. The policy also states that the program should be structured such that it will not lead to higher costs to consumers. Depending on how the cost of new generation is calculated, these objectives could conflict if new renewable power displaces existing hydropower (Yukon is primarily served by hydroelectricity).

Yukon's approach is a FIT, where the government pays a set rate for IPPs to produce renewable power for the grid. Under a FIT, long-term power purchase agreements are typically used to reduce the risk for project proponents. Prices can be based on the current electricity price or can be independent, and can also differentiate between generation technologies, e.g., wind power rates could be lower than solar PV due to the lower lifecycle costs of the former (Abolhosseini and Heshmati, 2014). This is not the approach used by Yukon's microgeneration policy, which has a set rate independent of the type of generator (the IPP policy does not specify the rate).

Tradable renewable certificates, also called a renewable portfolio standard (RPS), are a quantity-based approach as opposed to the price-based approach of a FIT. The RPS mechanism obligates utilities to buy a specific share of electricity from renewable energy IPPs; any shortfall is typically subject to a financial penalty.

Finally, tax incentives can be applied either to the production and consumption of renewable energy (tax credit) or to the production and consumption of fossil fuel energy (carbon tax), the latter of which is expected to be implemented in Canada and which was included in the financial analysis in this thesis. As noted in Section 8, the optimal system configuration for CHARS was not affected by the proposed carbon tax. This result is not necessarily generalizable, as the marginal system configuration could be affected and other studies have noted that a more modest carbon tax does in fact reduce fossil fuel consumption (Cullen, 2016).

Each of these approaches can suffer from poor design (Abolhosseini and Heshmati, 2014). For example, the level of financial support (e.g., tax credit value or price of FIT) can be too high, providing excessive profits at the expense of tax or ratepayers, or too low, resulting in little take-up by IPPs. A lack of 
consistency and long-term funding can result in boom/bust cycles. Poor balance of supply and demand can result, particularly for intermittent energy sources such as wind and solar.

If properly designed, these mechanisms incent private-sector IPPs to build and operate renewable energy generators at a cost that is acceptable to decision-makers (including the voting public). In Nunavut, currently only QEC is allowed to generate and distribute power (notwithstanding the small net-metering policy that was recently introduced) and there is no tradition of private-sector participation in power generation except through contracting by QEC (e.g., purchase of generators). Thus, new and welldesigned policies, including power production models, are required under this approach.

An alternative to market-creation mechanisms is direct funding by government. One example is direct project delivery by the federal government. Direct delivery of community-scale, high-penetration renewable energy systems by the federal government is highly unusual, and so the most likely approach is funding in the context of powering CHARS (with or without a connection to the Cambridge Bay grid). A stand-alone approach was considered early in the design of CHARS but was rejected, since the mandate is for scientific research and not for operating a power generation facility. To deliver a high-penetration system such as that proposed by this thesis would likely require a research justification: for example, CHARS could partner with other organizations to fund, implement, and operate a renewable energy system in order to demonstrate safe operation of a high-penetration renewable system in a Nunavut diesel grid.

While financial model inputs in this thesis resulted in a lower cost of diesel generation for the stand-alone configuration compared to the grid-tied configuraiton (see Section 8.2), this conclusion is by no means definitive and the federal government could very well incur a higher overall cost than a system delivered by QEC or an IPP. Furthermore, selling a significant amount of power to the grid makes the federal government an IPP to the GN, a role that doesn't necessarily makes sense given current funding arrangements.

The federal government also funds other organizations, and this may be a more appropriate role compared to direct project delivery. For example, since 2007 INAC has managed a program that funded renewable energy projects delivered by community groups, indigenous organizations, and territorial 
governments. Total funding was typically on the order of $\$ 5-\$ 10 \mathrm{M} /$ year and individual projects could be funded up to several hundred thousand dollars (Government of Canada, 2016). Going forward, the federal budget for 2018-19 identified \$141M over five years for 'Reducing the Reliance of Rural and Remote Communities on Diesel' and \$38M for an 'Arctic Energy Fund' (Government of Canada, 2018b).

The terms and conditions of these various federal funding programs - for example, the per-project funding maximum of the INAC-administered program - might not be sufficient to fully fund a capitalintensive high-penetration renewable system. A different approach that could potentially still involve federal program funding is utility procurement by QEC. Similar to how QEC delivers new and upgraded diesel generating infrastructure, the corporation would typically complete much of the design work inhouse, purchase equipment from suppliers, manage logistics, and contract out construction work. O\&M would also be delivered in-house. Additional design and construction support from firms with experience in wind and solar projects might be needed, and training of existing staff and/or hiring of new operations staff would also be required. These are important considerations given that QEC, like the GN and federal government, is subject to Nunavut Agreement articles, specifically those addressing government employment and contracting.

QEC is limited by the GN's debt cap (about $\$ 270 \mathrm{M}$ left) and, as noted, current levels of capital funding are insufficient to deliver a high-penetration renewable project while still addressing the needs of the existing diesel infrastructure. Access to debt or equity financing from the GN would need to be considered in the context of numerous other government priorities.

To summarize, market-based mechanisms such as a FIT could provision renewable energy through an IPP, an initiative that would be led by the GN and QEC; the federal government could directly implement a renewable energy system at CHARS; or, QEC could directly lead implementation. All three approaches require new policies surrounding the integration and control of non-dispatchable renewable power, in order to ensure safe operation of the most economically optimal system configuration. 


\subsection{Considerations for Implementation}

Aside from the financing mechanism, several important considerations include setting appropriate policy objectives, meeting Nunavut Agreement obligations including community consultation, and operations and maintenance planning.

The policy objective(s) for renewable energy either at CHARS or at a community level will influence the scope of new generation infrastructure. For example, an objective of reducing fuel consumption and hedging against future increases in fuel price does not necessarily imply a high-penetration system; however, this approach may not reap the full benefits of an economically optimal system configuration. An objective of fully transitioning away from diesel power (except as a backup) implies higher levels of capital spending, more detailed electrical integration studies, refined cost estimates, and the inclusion of ancillary components such as storage to manage the variability of renewable power output. These two goals could be characterized as 'slow and steady' and 'go big or go home': the choice depends on the level of risk the proponent (CHARS or the GN) is willing to accept.

Regardless of whether a market-based mechanism or direct funding were used, federal or territorial government implementation of a renewable energy project would be subject to the Nunavut Agreement. As noted, one objective of the agreement is employment of Inuit in government at representative levels; another is promotion of participation by Inuit-owned firms in government contracting.

One approach to contracting is to reduce the bid price of Inuit-owned firms by a set percentage for the purposes of bid evaluation only; however, this approach may not help meet other contracting goals, such as delivering the work at the lowest price to taxpayers, and may not fully realize opportunities to deliver work through local firms at a better price than larger southern firms who may be less familiar with the construction environment.

Another approach is for contractors to submit, as part of the point-rated bid criteria, an Inuit Benefits Plan (IBP) that details numerical targets for direct employment, subcontracting, and on-the-job training. Bonuses and penalties can be used to incent the successful bidder to meet those targets. This approach may be better suited to meeting dual objectives of Inuit participation in the work and delivering the work at the lowest cost; however, the IBP needs to be carefully structured in terms of targets and incentives. 
The Nunavut Agreement provides some insight into options for structuring an IBP. One recommended approach is to structure the work in a fashion that allows for smaller northern firms to bid. For example, work that could be delivered by local firms, such as civil and electrical works, could be packaged as separate bid or tender packages, with the more specialized renewable systems work delivered by southern firms with that specific experience. This approach to structuring is complementary with the use of a general contractor subject to IBP penalties and incentives. Another recommendation is to avoid artificially inflated requirements for employment skills - an implicit reminder of the value of local skills and knowledge, which should not be underestimated.

The Crown (federal and territorial) has a duty to consult with Indigenous people on matters of government conduct that could potentially have an adverse impact (Government of Canada, 2011c). The duty to consult was established in part through legal judgements arising from Section 35 of the Constitution Act (1982), in which Indigenous and treaty rights were affirmed (Stevenson, 2017). An 'Honour of the Crown' doctrine was established that requires the government to involve Indigenous people in decision-making processes arising from intended conduct, a co-management approach that help forms the basis of the Nunavut Agreement.

Planning and implementation of a high-penetration renewable energy system (whether delivered directly by the government or through market-creation mechanisms) would likely trigger that duty. Consultations are intended to be transparent, fair and reasonable, and include accommodation - meaning changing project scope - of Indigenous concerns 'where appropriate' (Government of Canada, 2011c). This statement acknowledges that Indigenous rights are not absolute and that the Crown could, in certain circumstances, engage in conduct that infringes those rights if justified (Stevenson, 2017). What constitutes a justified infringement can be determined through litigation; consultation is intended, in part, as a less costly and more inclusive alternative.

Potential concerns regarding a high-penetration renewable power project could include the specific technology or technologies to be used, the level of risk to a reliable power supply, the use of capital or debt financing for a power project instead of other priorities, environmental impacts including impacts to wildlife, the use of local labour for design, construction, and operations, and the role of the private sector (e.g., using IPPs compared to utility procurement). 
While community support for renewable sources of energy has been demonstrated, the specific nature of the technology can be a cause for concern: for example, the impact of hydropower on wildlife, the merit of solar power given significant seasonal variation in the solar resource, and the survivability of wind turbines in the harsh environment (McDonald, 2011). Affordability is likely to be of primary concern, as it was the number one-rated issue raised by participants in an 'energy charrette' in Northwest Territories (R. Marshall and Associates, 2014); however, participants suggested that the definition of affordability be expanded to include life-cycle impacts including health impacts. Benefits to the local labour force are also a high priority, as the private sector in the north is small relative to southern Canada.

Aside from the government, potential stakeholders for participation in community consultation include the host community, NTI and the relevant regional Inuit association, the Hunters and Trappers Organization (HTO), regulatory agencies such as the NIRB that may play a role in project evaluation and approval, and private-sector organizations that could participate in contracting opportunities. Consultation during the feasibility stage can help set the project scope and objectives - for example, whether to pursue market-creation mechanisms or direct funding, whether a 'slow and steady' or 'go big or go home' approach is best, targets for local employment and contracting participation, training objectives, funding, and the plan for operations and maintenance. Consultation should be ongoing during design, construction, and operation, to ensure community and Inuit priorities are heard and form an integral part of project planning and delivery.

Planning for operations and maintenance $(\mathrm{O} \& \mathrm{M})$ deserves special mention for two reasons. First, ongoing job creation is always a priority in northern communities and renewable energy systems likely entail maintenance jobs based in the community. Second, a hybrid system will fail if not properly maintained. Wind turbines in particular require ongoing maintenance - anecdotal evidence suggests that early wind projects in Nunavut due to a lack of O\&M (McDonald, 2011). O\&M planning should start in the feasibility stage and project implementation should not proceed until a coherent O\&M strategy has been articulated and funded. To do otherwise risks wasting significant capital investments, should the system fail due to lack of appropriate O\&M. 


\section{Conclusions and Future Work}

The Canadian High Arctic Research Station (CHARS) was designed to a high level of energy efficiency. However, there is interest in further reducing diesel fuel consumption through renewable energy sources. This thesis demonstrated the use of simulation and optimization techniques to model the lowest-cost hybrid energy system for CHARS. A weather monitoring station was installed in the community and relevant weather data, such as wind speed and solar radiation, were collected and served as inputs to the simulation model. Electrical demand data were obtained from a third-party building simulation model. Hybrid energy system consisting of wind turbines, a solar photovoltaic (PV) array, batteries, and either an on-site diesel generator or grid connection were modelled in TRNSYS to evaluate annual performance and cost. GenOpt was used to optimize the system configuration according to net present cost (NPC) using the particle swarm optimization. Optimizations were performed for a range of surplus power value and greenhouse gas (GHG) emissions cost, and the baseline scenario for each system configuration (gridtied, stand-alone, and low-maintenance) was subjected to parametric analyses to better quantify the potential range of costs.

The modelling results suggest that the optimal system configuration from an NPC perspective includes renewable energy generators. A grid-tied configuration is the most likely future system configuration, as there are no plans to isolate CHARS from the local community electrical grid. The baseline scenario optimal solution under a grid-tied configuration included wind turbines, solar PV, and a small battery bank, and reduced the NPC by about $\$ 8 \mathrm{M}$ or $30 \%$ compared to the diesel-only scenario; at the same time, greenhouse gas emissions were reduced by $2 / 3$ and the system achieved an annual renewable penetration rate of almost $65 \%$. For several thousand hours per year, no power was drawn from the community power plant. For the low-maintenance system configuration, which did not include wind turbines, benefits were more modest: the NPC was reduced by about $\$ 4 \mathrm{M}$ or $15 \%$ and the system achieved an annual renewable penetration rate of $30 \%$. This demonstrates the lower potential for solar power compared to wind due to the higher diurnal and seasonal periodicity; however, solar PV may still be an attractive solution as it can potentially reduce system NPC at lower risk compared to wind turbines. 
As an academic exercise, two additional system configurations were modelled: a stand-alone system with an on-site diesel generator, and a very high renewable configuration modelled by applying a high cost to diesel power. In the case of the stand-alone system, the diesel-only scenario had a lower NPC than the grid-tied configuration and the optimal renewable configuration resulted in only a marginal reduction in NPC. This was primarily because of fixed operations and maintenance (O\&M) costs of the diesel generator, which limited the financial benefit of displacing high amounts of diesel power. In the case of the very high renewable configuration, even with a large battery system providing three days of autonomy at full charge and a large renewable generating capacity, diesel power was still required for a total of a few days per year. In this configuration, the NPC was more than double the diesel-only scenario, demonstrating the decreasing and even negative returns to additional renewable generating capacity beyond a certain point. More sophisticated modelling techniques, such as multi-objective optimization, are required to determine the greatest reduction in greenhouse gas emissions in the most cost-effective manner. Furthermore, different technologies such as hydrogen storage, flow batteries, and larger wind turbines should be considered.

For Scenario 1.6, the grid-tied baseline system, a 10-min as opposed to hourly timestep did not result in a change to the optimal system configuration. The difference in NPC was insignificant. While the result is consistent with other work, results could vary with a smaller timestep, a dynamic wind turbine model not based on average wind speed/power curves, and more granular load data.

Modelling of the most likely system configurations - the grid-tied and lower maintenance configurations - exposed several challenges. First, a large capital outlay (on the order of $\$ 4-\$ 6 \mathrm{M}$ ) was required, resulting in an approximately 10-year payback despite annual savings. Second, proper management of surplus power is critical - the maximum instantaneous penetration was about $400 \%$ of the electrical demand. If this energy were to be used for heating the station, appropriately-sized thermal storage systems would need to be installed and controlled correctly. This detail was omitted from the modelling exercise, however given the magnitude of the surplus power it should not be considered trivial. Further, if the objective is to sell the surplus power back to the community, it cannot be assumed that the grid can integrate the magnitude and fluctuations of the surplus power without further system upgrades. In particular, the peak surplus power when selling back to the grid was about $1100 \mathrm{~kW}$, compared to a peak 
community load of about $2500 \mathrm{~kW}$. Further, the 10-min analysis revealed that much of the surplus energy (40\%) is generated at high (>200 kW) levels of surplus power, which only occur about $5 \%$ of the year, indicating the concentrated nature of surplus power.

System configurations were modelled with different costs of GHG emissions calculated from the quantity of fuel consumed. It was found that the proposed Government of Canada carbon tax, $\$ 50 /$ ton $_{\mathrm{CO} 2, \mathrm{eq}}$, modestly raised the NPC but did not affect the optimal system configuration. This demonstrates that renewable energy would be cost-effective for CHARS even in the absence of the tax.

It is possible that $\$ 50 /$ ton $(\$ 0.1369 /$ litre of diesel fuel) does not capture all externalities associated with combustion of fossil fuels. When a cost of $\$ 1.00 /$ litre of diesel fuel was applied to the optimization, the solution included significantly higher renewable energy generating capacity. More accurate estimates of the real cost of externalities would support more holistic decision-making with respect to the optimal energy generation mix.

While modelling assumptions, such as losses in the PV array and wind turbines, were assumed to be reasonable for this application, they have not been validated. For example, the accuracy of the Reindl models for tilted surface radiation may be different at a higher-latitude location such as Cambridge Bay. Icing of turbine blades, which has the potential to significantly reduce annual power output and increase wear and tear, was not explicitly modelled. The battery storage model used a simple power balance approach and did not include detailed battery physics such as self-discharge, rate of discharge, the impact of temperature on charging efficiency, or a detailed depth-of-discharge model. These are important considerations for more detailed system design but were omitted from this thesis for simplicity.

From a policy perspective, a renewable energy system could be implemented by a private-sector independent power producer through a feed-in tariff, renewable portfolio standard, or other financing mechanism. However, there is no tradition of private-sector power-generation in Nunavut and there are no policies to support large-scale feed-in of renewable energy. An alternative approach is direct funding by government, such as utility procurement by the power corporation; however, capital funding is currently lacking. 
Implementation of renewable energy by government (regardless of the financing mechanism) needs to meet obligations articulated by the Nunavut Agreement, in particular clauses relating to Inuit employment in government and participation of Inuit-owned firms in contracting. An Inuit Benefits Plan can help meet those obligations while still achieving value-for-money in government contracting. Implementation of a high-penetration system would require significant public consultation of stakeholders such as elders, Inuit organizations, local business, and other interested community members.

Capital and operating costs used in this thesis present a risk. While a thorough review of similar and hypothetical projects informed the cost estimates, significant uncertainty remains for a project at CHARS. Given the near-absence of renewable energy systems in Nunavut, any project would by definition be a demonstration project. As the experience of Alaska shows, costs for demonstration projects are usually significantly higher than commercial projects that are based not only on proven technology but also on proven approaches. These include the sound application of financial and project management principles, appropriate management of logistics and construction forces, construction of foundations in permafrost, interconnections with the local electrical grid, engagement with the community, utility, and other stakeholders early and throughout the project, and the planning and implementation of an operations and maintenance regime (including training) that is well-defined and funded prior to the start of construction.

These approaches have never been applied to a renewable energy project of scale in Nunavut, and as such the risk of cost overruns, system underperformance, early failure, schedule delays, and disappointment of stakeholders is higher than, for example, a diesel plant upgrade. This suggests an opportunity for CHARS as a research facility to implement renewable energy at its campus in Cambridge Bay and to fund and support renewable energy projects in diesel-grid communities across the Canadian Arctic, in order to demonstrate performance, build capacity, engage and educate the public, and de-risk renewable energy for future project proponents.

\subsection{Recommendations for Future Work}

Future work suggested by this thesis includes simulation model improvements, model validation, and using optimization techniques including multi-objective optimization for future project planning. 
Potential model improvements including components like the battery and wind turbine, a control strategy for multiple generators, expansion of model scope to include the whole community, using measured load data, and investigation and improvement of solar radiation transposition algorithms.

The battery component is arguably the most unrealistic component in the model and could be improved by inclusion of dynamic phenomena such as discharge curves, temperature, and depth-of-discharge. The wind turbine model, based on power curves generated from 10-min average wind speed data, could be improved by consideration of inertial effects at sub-10-min timesteps. Losses in the turbine and PV array were assumed to be constant; however, a dynamic model that includes icing of turbine blades and snow cover of the array could improve accuracy.

Further, the stand-alone configuration used only one diesel generator, an unlikely configuration considering the need for redundancy and efficient engine operation. A new control strategy is required to manage multiple generators and ensure the most economic dispatch of electricity - either for CHARS or the community.

A community model would require a multiple genset control strategy and a more detailed electrical model incorporating reserve electrical capacity and grid stability requirements. Use of measured load data - both from the community and operations of CHARS - would be a significant improvement over the generic building simulation model load profile used in this thesis, as measured data would more accurately reflect seasonal differences in electricity consumption. A community model could also be used to explore energy efficiency options in detail, which, considering the age of much of the built infrastructure in Cambridge Bay, could likely deliver lifecycle cost savings and greenhouse gas reductions at lower cost than new, expensive generators.

In this thesis, solar PV modelling relied on measured solar radiation on a horizontal plane, split into its constituent beam and diffuse components and transposed onto a tilted plane with the Reindl models. These are empirical models that may be less accurate at higher latitudes, where solar elevation angles are lower and consequently the air mass is higher. Installation of a solar tracker to measure beam and diffuse in addition to global horizontal radiation would permit a better assessment of sources of error and possible improvements to the models at high latitude. Assumptions of surface albedo, which were based 
only on the presence or absence of snow cover, could be improved through measurement and development of a model that includes other variables of interest such as time since last snowfall.

This thesis did not include model validation as no operational data were available. These data, preferably from a system in a similar climate zone to CHARS, could be used to validate discrete model components such as the wind turbine or PV array. The whole model could be validated with data from a renewable energy system with storage. The results could also be compared to the output from another simulation program such as HOMER. These approached would improve confidence in the model outputs and enhance its value for planning of future systems.

This thesis used time-series simulation with measured weather data and a standard demand profile. Potential extremes such as the maximum possible load were not investigated, nor were reliability metrics such as loss of load probability evaluated. In general, it was assumed the on-site generator or grid connection (depending on the system configuration) would provide the required reliability, an assumption that is not necessarily valid in a high-penetration system. Stochastic simulation can help quantify these metrics and could contribute to a more robust design.

Finally, this thesis demonstrated the application of optimization techniques to a fairly simple system design with only six or seven design variables. Future planning for a real system could include optimization for:

- A high-level proof of concept, such as that presented in this thesis, with a larger design space: wind turbines of different capacity and at different heights, different solar technologies such as amorphous silicon PV and solar thermal collectors, one- or two-axis tracking mechanisms, heat recovery, or multiple diesel gensets;

- Control strategies such as cycling of multiple generators, different battery charging strategies, demand-side management, and load and weather forecasting; and,

- Detailed design, including sizing of electrical control systems such as capacitor banks, inverters, and short-, medium-, and long-term electrical storage. 
This thesis used only single-objective optimization, with a penalty applied to diesel power in one configuration to drive the optimization towards greater use of renewable energy. A better approach is to use multi-objective optimization to simultaneously solve for net present cost, greenhouse gas emissions, and other objectives of interest.

Since optimization metaheuristics are problem-independent algorithmic frameworks, they can be adapted to these applications and others. Use of these techniques in planning and implementation of hybrid systems could help accelerate the adoption of renewable energy across the Arctic in order to lower costs, greenhouse gas emissions, and risk. 


\section{References}

Aarnio, E., and Partonen, S. 2000. Operational experience of Arctic wind farms. Presented at the Boreas V Conference on Wind Energy Production in Cold Climates, Levi, Finland, Nov 29 - Dec 1, 2000.

Abolhosseini, S., and Heshmati, A. 2014. The main support mechanisms to finance renewable energy development. Renewable and Sustainable Energy Reviews vol. 40 pp. 876-885.

Angelis-Dimakis, A., Biberacher, M., Dominguez, J., Fiorese, G., Gadocha, S., Gnansounou, E., Guariso, G., Kartalidis, A., Panichelli, L., Pinedo, I., and Robba, M. 2011. Methods and tools to evaluate the availability of renewable energy sources. Renewable and Sustainable Energy Reviews vol. 15 no. 2 pp. 1182-1200.

Askarzadeh, A., Klein, C. E., Coelho, L., and Mariani, V.C. 2016. A population-based simulated annealing algorithm for global optimization. IEEE International Conference on Systems, Man, and Cybernetics, Budapest, Hungary, October 9-12.

Avadhanula, V.K. 2015. Evaluation and parametric modeling of $50 \mathrm{~kW}$ organic Rankine cycle for waste heat recovery from rural Alaska diesel generator power plants. Ph.D. dissertation, University of Alaska Fairbanks, Alaska, USA.

Bacha, J., et al. 2007. Diesel fuels technical review. Chevron Corporation, San Ramon, USA.

Bailey, T. 2012. A comparison of methods for sizing energy storage devices in renewable energy devices. M.A.Sc. thesis, University of Victoria, Victoria, Canada.

Bank of Canada. 2016. Letter from the Governor to the Minister of Finance. 21 September 2016.

Baring-Gould, I., and Corbus, D. 2007. Status of wind-diesel applications in Arctic climates. Presented at the Arctic Energy Summit Technology Conference, Anchorage, Alaska, October 15-18, 2007.

Baring-Gould, I., Cattin, R., Durstewitz, M., Hulkkonen, M., Krenn, A., Laakso, T., Lacroix, A., Peltola, E., Ronsten, G., Tallhaug, L., and Wallenius, T. 2012. Expert group study on recommended practices - wind energy projects in cold climates. International Energy Agency.

Barley, C.D., Winn, C.B., Flowers, L., and Green, H.J. 1995. Optimal control of remote hybrid power systems part 1: simplified model. Presented at Windpower '95, Washington DC, March 27-30, 1995.

Barley, C.D., and Winn, C.B. 1996. Optimal dispatch strategy in remote hybrid power systems. Solar Energy vol. 58 no. 4-6 pp. 165-179.

Beaudin, M., Zareipour, H., Schellenberglabe, A., and Rosehart, W. 2010. Energy storage for mitigating the variability of renewable electricity sources: an updated review. Energy for Sustainable Development vol. 14 no. 4 pp. 302-314. 
Breeze, P. 2014. Power Generation Technologies 2nd edition. Newnes.

Brown, M.D., Pelletier, J.F., Castonguay, G., Cruickshank, C.A. 2018. Resilient design, commissioning and operation of the Canadian High Arctic Research Station. Presented at the Winter ASHRAE 2018 Conference, Chicago, USA, Jan 20-24, 2018.

Byrne, G., and Flood, I. 2015. NTPC renewable energy projects - success, challenges, and perseverance. Presented at the 2nd Conference on Renewables in Remote Microgrids, Yellowknife, Canada, Sept 15-17, 2015.

CanWEA. N.D. Diavik wind farm: wind energy helps reduce carbon footprint. Canadian Wind Energy Association.

Caterpillar. 2016. C32 ACERT 910 ekW/1137 kVA. Technical specification sheet. USA, 09/19/2016.

Cattin, R. 2012. Icing of wind turbines - Vindforsk projects, a survey of the development and research needs. Elforsk report 12:13.

Chade, D., Miklis, T., and Dvorak, D. Feasibility study of wind-to-hydrogen system for Arctic remote locations - Grimsey island case study. Renewable Energyvol. 76 p. 204-211.

Chapman, R.N. 1996. Hybrid power technology for remote military facilities. Powersystems World '96 Conference, Las Vegas, USA, Sept 7-13, 1996.

Chen, Y. 2012. Design and evaluation of façade-integrated solar technologies suitable for highlatitude applications. M.A.Sc. thesis, Concordia University, Montreal, Canada.

Choi, Y., and Song, J. 2017. Review of photovoltaic and wind power systems utilized in the mining industry. Renewable and Sustainable Energy Reviews vol. 75 pp. 1386-1391.

Clifton, A., Smith, A., and Fields, M. 2016. Wind plant preconstruction energy estimates: current practice and opportunities. National Renewable Energy Laboratory, Golden, USA.

Connolly, D., Lund, H., Mathiesen, B.V., and Leahy, M. 2010. A review of computer tools for analyzing the integration of renewable energy into various energy systems. Applied Energy vol. 87 pp. 1059-1082.

Cullen, R. 2016. Evaluating renewable energy policies. Australian Journal of Agricultural and Resource Economics vol. 61 pp. 1-18.

Cummings Power Generation. 2016. Model DQPAA technical data sheet.

Das, I., and Canizares, C. 2016. Renewable energy deployment in Canadian Arctic phase I: prefeasibility studies and community engagement report for Nunavut. World Wildlife Fund.

Devine, M.M. 2005. Analysis of electric loads for wind-diesel energy options for remote power stations in Alaska. Master's thesis, University of Massachusetts Amherst, Amherst, USA. 
Drouilhet, S. 2001. Preparing an existing diesel power plant for a wind hybrid retrofit: lessons learned in the Wales, Alaska, wind-diesel hybrid power project. Presented at the Windpower 2001 Conference, Washington, D.C., USA, June 4-6, 2001.

Dufó-Lopez, R., and Bernal-Agustín, J.L. 2008. Multi-objective design of PV-wind-diesel-hydrogenbattery storage systems. Renewable Energy vol. 33 pp. 2559-2572.

Duggal, I., and Venkatesh, B. 2015. Short-term scheduling of thermal generators and battery storage with depth of discharge-based cost model. IEEE Transactions on Power Systems vol. 30 no. 4 pp. 21102118.

He, P., Fushuan, W., Ledwich, G., Xue, Y., and Huang, J. 2015. Investigation of the effects of various types of wind turbine generators on power-system stability. Journal of Energy Engineering vol. 141 no. 3.

Eberhart, R.C., Shi, Y., and Kennedy, J. 2001. Swarm Intelligence. Morgan Kaufmann Series in Artificial Intelligence.

Eckstein, J.H. 1990. Detailed modelling of photovoltaic system components. Master's thesis, University of Wisconsin-Madison, Madison, USA.

Enevoldsen, P., and Sovacool, B.K. 2016. Integrating power systems for remote island energy supply: lessons from Mykines, Faroe Islands. Renewable Energy vol. 85 pp. 642-648.

ENF Solar. 2017. Available online: www.enfsolar.com. Accessed: 8 August 2017.

Environment Canada. 2015. Historical weather data. Available online: http://climate.weather.gc.ca/historical_data/search_historic_data_e.html.

Erdinc, O., and Uzunoglu, M. 2012. Optimum design of hybrid renewable energy systems: overview of different approaches. Renewable and Sustainable Energy Reviews vol. 16 pp. 1412-1425.

Fay, G., Schworer, T., and Keith, Katherine. 2010. Alaska isolated wind-diesel systems: performance and economic analysis. Prepared for the Alaska Energy Authority.

Fortin, G., Adomou, M., and Perron, J. 2011. Experimental study of hybrid anti-icing systems combining thermoelectric and hydrophobic coatings. SAE technical paper 2011-38-0003.

Freris, L., and Infield, D. 2008. Renewable Energy in Power Systems. John Wiley and Sons, Ltd., Chichester, United Kingdom.

Frye, J.A. 2006. Performance-objective design of a wind-diesel hybrid energy system for Scott Base, Antarctica. Master's thesis, University of Canterbury, Christchurch, New Zealand.

Fu, R., Feldman, D., Margolis, R., Woodhouse, M., and Ardani, K. 2017. U.S. solar photovoltaic system cost benchmark: Q1 2017. National Renewable Energy Laboratory, Golden, USA.

Gallardo, P.A.L. 2011. Static and fatigue analysis of wind turbine blades subject to cold weather conditions using finite element analysis. Master's thesis, University of Victoria, Victoria, Canada. 
Gardner, C.L. 1989. Investigation of a photovoltaic/battery hybrid system for powering the high Arctic data communications system. Department of National Defence, Ottawa, Canada.

Gassner, A. 2010. Sizing storage and wind generation capacities in remote power systems. Master's thesis, University of Victoria, Victoria, Canada.

Government of Canada. 2011a. Status of remote/off-grid communities in Canada. Ottawa, Canada. Natural Resources Canada.

Government of Canada. 2011b. Canadian High Arctic Research Station Feasibility Study. Indian and Northern Affairs Canada.

Government of Canada. 2011c. Aboriginal consultation and accommodation - updated guidelines for federal officials to fulfill the duty to consult. Indian Affairs and Northern Development Canada.

Government of Canada. 2013. Delivering on the mandate for the Canadian High Arctic Research Station - the Science and Technology Plan for 2014/15 to 2018/19. Aboriginal Affairs and Northern Development Canada.

Government of Canada. 2015. Powering Canada’s territories. Standing Senate Committee on Energy, the Environment, and Natural Resources.

Government of Canada. 2016. ARCHIVED - ecoENERGY for aboriginal and northern communities program. Available online: http://www.aadnc-aandc.gc.ca/eng/1100100034258/1100100034259. Accessed: 4 April 2018.

Government of Canada. 2017. Technical paper on the federal carbon pricing backstop. Environment and Climate Change Canada.

Government of Canada. 2018a. Federal support to provinces and territories. Finance Canada. Available online: https://www.fin.gc.ca/fedprov/mtp-eng.asp. Accessed 3 April 2018.

Government of Canada. 2018b. Equality growth - a strong middle class. Federal Budget 2018-19.

Government of Nunavut. 2016. Premier Taptuna reacts to imposed carbon price. October 4, 2016, Iqaluit. Department of Executive and Intergovernmental Affairs. Accessed May 9, 2018.

Available online: https://www.gov.nu.ca/eia/news/premier-taptuna-reacts-imposed-carbon-price.

Government of Nunavut. 2017. 2017-18 budget highlights.

Government of Yukon. 2013. Energy strategy for Yukon - micro-generation policy.

Government of Yukon, 2015. Energy strategy for Yukon - independent power production policy.

G., Schiettekatte, J., Deslauriers, J-C., and Bai, L. 2016. Optimal design of battery energy storage system for a wind-diesel off-grid power system in a remote Canadian community. Institution of Engineering and Technology Generation, Transmission, and Distribution vol. 10 no. 3 pp. 608-616.

H2RES. 2009. H2RES Model v2.8. http://h2res.fsb.hr. 
Häberlin, H. 2012. Chapter 4: Solar modules and solar generators. In Photovoltaics: System Design and Practice. John Wiley and Sons Ltd., Chichester, United Kingdom.

Hardin, G. 1968. The tragedy of the commons. Science vol. 162 pp. 1243-1248.

Hirsch, B. 2014. Remote community renewable energy partnership. Presented at the Alaska Wind Integration Workshop, Fairbanks, USA, March 20.

Hoevenaars, E.J, and Crawford, C.A. 2012. Implications of temporal resolution for modeling renewables-based power systems. Renewable Energyvol. 41 pp. 285-293.

Hoevenaars, E. 2012. Temporal resolution in time series and probabilistic models of renewable power systems. Master's thesis, University of Victoria, Victoria, Canada.

Holland, J.H. 1975/1992. Adaptation in Natural and Artificial Systems: An Introductory Analysis with Applications to Biology, Control, and Artificial Intelligence. First MIT Press edition 1992.

HOMER Energy LLC. 2018. Hybrid Optimization Model for Multiple Energy Resources HOMER Pro v. 3.11 .5

Homola, M.C., Virk, M.S., Nicklasson, P.J., Sundsbo, P.A. 2011. Modelling of ice induced power losses and comparison with observations. Presented at Winterwind 2011, Umea, Sweden, February 8-11, 2011.

I2SL. 2010. Labs21 Environmental Performance Criteria 3.0. International Institute for Sustainable Laboratories.

Ibrahim, H., Belmokhtar, K., and Ghandour, M. 2015. Investigation of usage of compressed air energy storage for power generation system improving - application in a microgrid integrating wind energy. Energy Procedia vol. 73 pp. 305-316.

IEA. 2014. Technology roadmap energy storage. International Energy Agency, Paris, France.

IEC. 2011. Electrical energy storage. International Electrotechnical Commission white paper. Geneva, Switzerland.

Ikkala, O., and Nieminen, A. 1990. Lead/acid batteries in Arctic photovoltaic systems. Journal of Power Sources vol. 31 pp. 321-327.

Isherwood, W., Smith, J.R., Aceves, S.M., Berry, G., Clark, W., Johnson, R., Das, D., Goering, D., and Seifert, R. 2000. Remote power systems with advanced storage technologies for Alaskan villages. Energy vol. 25 pp. 1005-1020.

Islam, K. 2011. Sizing and control of flywheel energy storage for Ramea wind-hydrogen-diesel hybrid power system. Master's thesis. Memorial University, St. John’s, Canada.

Kempener, R., and Borden, E. 2015. Battery storage for renewables: market status and technology outlook. International Renewable Energy Association. 
Kennedy, J., and Eberhart, R. 1995. Particle swarm optimization. IEEE International Conference on Neural Networks vol. 4 pp. 1942-1948.

Khezzar, R., Zereg, M., and Khezzar, A. 2014. Modeling improvement of the four parameter model for photovoltaic modules. Solar Energy vol. 110 pp. 452-462.

Kim, Y.M., Lee, J.H., Kim, S.K., and Favrat, D. 2012. Potential and evolution of compressed air energy storage: energy and exergy analyses. Entropyvol. 14 pp. 1501-1521.

Kirby, B.J., Dyer, J., Martinez, C., Shoureshi, R.A., Guttromson, R., and Dagle, J. 2002. Frequency control concerns in the North American electric power system. Oak Ridge National Laboratory, Oak Ridge, Tennessee.

Kirkpatrick, S., Gelatt Jr., C.D., and Vecchi, M.P. 1983. Optimization by simulated annealing. Science vol. 220 no. 4598 p. 671-680.

Klein, S.A. et al. 2010. TRNSYS 17 Volume 4: Mathematical Reference. University of WisconsinMadison.

Klein, S.A. et al. 2014. TRNSYS, a Transient Simulation Program v.17.02. University of WisconsinMadison Solar Energy Laboratory, Madison, USA.

Konkel, R.S. 2013. Renewable energy and sustainable communities: Alaska's wind generator experience. International Journal of Circumpolar Health vol. 72.

Kools, L., and Phillipson, F. 2016. Data granularity and the optimal planning of distributed generation. Energy vol. 112 pp. 342-352.

Kornelakis, A. 2010. Multiobjective particle swarm optimization for the optimal design of photovoltaic grid-connected systems. Solar Energy vol. 84 pp. 2022-2033.

Korppoo, A., Luukkanen, J., Vehmas, J., and Kinnunen, M. 2008. What goes up down must come up? Trends of industrial electricity use in the North-West of Russia. Energy Policy vol. 36 no. 9 pp. 3588-3597.

Korpas, M., and Greiner, C.J. 2008. Opportunities for hydrogen production in connection with wind power in weak grids. Renewable Energy vol. 33 pp. 1199-1208.

Krenn, A., Jordaens, P.J., Wadham-Gagnon, M., Davis, N., Clausen, N., Lehtomaki, V., Jokela, T., Kaija, S., Khadiri-Yazami, Z., Ronsten, G., Wickman, H., Klinstrom, R., and Cattin, R. 2016. Available technologies for wind energy in cold climates. International Energy Agency Wind Task 19.

Krischer, K., and Schönleber, K. 2015. Chapter 7: Electrochemical energy conversion. In Physics of Energy Conversion, Walter de Gruyter Inc., Boston/Berlin.

Krizan, J., Diepstraten, F., and Malcolm, D. 2011. Nunavut renewable and alternative energy resources inventory. IMG-Golder. 
Kyriakarakos, G., Dounis, A.I., Rozakis, S., Arvanitis, K.G., and Papadakis, G. 2011. Polygeneration microgrids: a viable solution in remote areas for supplying power, potable water, and hydrogen as transportation fuel. Applied Energy vol. 88 pp. 4517-4526.

Lacroix, A., and Manwell, J.F. 2000. Wind energy: cold weather issues. University of Massachusetts at Amherst.

Lazard. 2016. Lazard's levelized cost of energy analysis - version 10.0.

LBNL. 2016. GenOpt Generic Optimization Program v. 3.1.1 Lawrence Berkeley National Laboratory.

LEED Canada. 2010. Reference Guide for Green Building Design and Construction 2009. Ottawa: Canada Green Building Council.

Luke, S. 2015. Essentials of metaheuristic. Second edition, online version 2.2, available at http://cs.gmu.edu/ sean/book/metaheuristics.

Luna-Rubio, R., Trejo-Perea, M., Vargas-Vázquez, D., and Ríos-Moreno, G.J. 2012. Optimal sizing of renewable hybrid energy systems: a review of methodologies. Solar Energy vol. 86 pp. 1077-1088.

Luo, X., Wang, J., Dooner, M., Clarke, J., and Krupke, C. 2014. Overview of current development in compressed air energy storage technology. Presented at the International Conference on Sustainability in Energy and Buildings, Cardiff, UK, June 25-27, 2014.

Luukkonen, P., Bateman, P., Hiscock, J., Poissant, Y., Howard, D., and Dignard-Bailer, L. 2013. National survey report of PV power applications in Canada. International Energy Agency Co-operative Programme on Photovoltaic Power Systems Task 1: Exchange and dissemination of information on PV power systems.

Lydia, M., Kumar, S.S., Selvakumar, A.I, and Kumar, G.E.P. 2014. A comprehensive review on wind turbine power curve modeling techniques. Renewable and Sustainable Energy Reviews vol. 30 pp. 452 460.

Maissan, J.F. 2001. Wind power development in sub-Arctic conditions with severe rime icing. Circumpolar Climate Change Summit and Exposition, Whitehorse, Canada, March 19-21, 2001.

Malmsten, J.K. 2011. Wind turbine production losses in cold climate. Master's thesis, Gotland University, Gotland, Sweden.

Mathworks. 2018. Matlab R2018a.

McArthur, L.J.B. 2005. Baseline Surface Radiation Network Operations Manual Version 2.1. World Climate Research Programme.

McDonald, N.M. 2011. Reducing diesel dependence in Nunavut: integrating renewable energy technologies through policy actions. Master's thesis, Queen’s University, Kingston, Canada. 
Meteonorm. 2013. Meteonorm Global Meteorological Database Handbook part II: Theory, Version 7.0.20.

Mollenhauer, K., and Schreiner, K. 2010. Chapter 1: History and fundamental principles of the diesel engine. In K. Mollenhauer and H. Tschoke (Eds.), Handbook of Diesel Engines (pp. 636). Berlin Heidelberg, Springer.

Moran, M.J., and Shapiro, H.N. 2004. Fundamentals of Engineering Thermodynamics $5^{\text {th }}$ ed. John Wiley \& Sons, Inc. Hoboken, USA.

Morrison, L. 1923. Diesel Engines. McGraw-Hill Book Company, New York.

NERC. 2008. Accommodating high levels of variable generation. North American Electric Reliability Corporation, Princeton, USA.

Northern Power Systems. 2014. Northern Power 100-21 Arctic technical data sheet.

Niu, X., and Pinker, R.T. 2011. Radiative fluxes at Barrow, Alaska: a satellite view. Journal of Climate vol. 24 no. 21 pp. 5494-5505.

Nordhaus, W.D. 2007. A review of the Stern Review on the Economics of Climate Change. Journal of Economic Literature vol. XLV pp. 686-702.

Norling, J. 1999. Suorva - Arctic wind turbine in northern Sweden. Presented at the European Wind Energy Conference, Nice, France, March 1-5, 1999.

NREL. 1995. International Energy Agency wind energy annual report 1994. Golden, USA, National Renewable Energy Laboratory.

NTI. 2015. Settlement agreement signed in NTI lawsuit. Nunavut Tunggavik Incorporated. Available online: http://www.tunngavik.com/blog/news/settlement-agreement-signed-in-nti-lawsuit/. Accessed 3 April 2018.

Nukissiorfiit. 2014. Årsberetning (annual report) (in Danish).

Osler, C. 2011. Diesel and thermal electricity generation options - background paper. Yukon Energy Company Energy Planning Charrette, Whitehorse, March 6-9, 2011.

Parent, O., and Illinca, A. 2011. Anti-icing and de-icing techniques for wind turbines: critical review. Cold Regions Science and Technologyvol. 65 no. 1 pp. 88-96.

Pinard, J-P., Banjac, S., Maissan, J., and Rahemtulla, S. 2016. Potential for wind energy in Nunavut communities. Qulliq Energy Corporation, Nunavut.

Poissant, Y., Thevenard, D., and Turcotte, D., 2004. Performance monitoring of the Nunavut Arctic College PV system: nine years of reliable electricity generation. Proceedings of the 29th Conference of the Solar Energy Society of Canada, Waterloo, Canada, August 21-25, 2004. 
Power, B. 2017. Industrial energy storage solutions - case study. Solvest.

QEC. 2013. 2014/15 General Rate Application. Qulliq Energy Corporation, Nunavut.

QEC. 2014. Cambridge Bay electricity rates - as of May 2014. Available online: http://www.qec.nu.ca/node/176. Accessed 2018-02-27.

QEC. 2016a. 15th Annual Report 2015-2016. Qulliq Energy Corporation, Nunavut.

QEC. 2016b. Corporate Plan 2016-2020. Qulliq Energy Corporation, Nunavut.

QEC. 2017a. 2018/19 General Rate Application. Qulliq Energy Corporation, Nunavut.

QEC. 2017b. 16th Annual Report 2016-2017. Qulliq Energy Corporation, Nunavut.

Quinlan, P.J.A. 1996. Time series modeling of hybrid wind photovoltaic diesel power systems. Master's thesis, University of Wisconsin-Madison, Madison, USA.

R. Marshall and Associates. 2014. 2014 Northwest Territories energy charrette final report.

Rahn, C.D., and Wang, C.Y. 2013. Chapter 2: Electrochemistry. In Battery Systems Engineering, John Wiley and Sons Ltd., Chichester, United Kingdom.

Ray, M., Rogers, A., and McGowan, J. 2006. Analysis of wind shear models and trends in different terrains. AWEA Windpower 2005, Pittsburgh, 2006.

Reindl, D.T., Beckman, W.A., and Duffie, J.A. 1990a. Diffuse fraction correlations. Solar Energy vol. 45 no. 1 pp. 1-7.

Reindl, D.T., Beckman, W.A., and Duffie, J.A. 1990b. Evaluation of hourly tilted surface radiation models. Solar Energy vol. 45 no. 1 pp. 9-17.

Resun Solar. 2015. RS6C-M technical data sheet.

Rindeskar, E. 2010. Modelling of icing for wind farms in cold climate. Master's thesis, Uppsala University, Uppsala, Sweden.

Romero, A., Carvalho, M., and Millar, D. 2016. Optimal design and control of wind-diesel hybrid energy systems for remote Arctic mines. Journal of Energy Resources Technologyvol. 138 no. 6.

Ronsten, G., Wallenius, T., Hulkkonen, M., Baring-Gould, I., Cattin, R., Durstewitz, M., Krenn, A., Laakso, T., Lacroix, A., Tallhaug, L., Byrkjedal, O., and Peltola, E. 2012. State-of-the-art of wind energy in cold climates. International Energy Agency Wind Task 19.

Saldanha, N. 2010. Towards the assessment of a residential electric storage system: analysis of Canadian residential electricity use and the development of a lithium-ion battery model. Master's thesis, Carleton University, Ottawa, Canada.

Sankeymatic. 2017. Available online: www.sankeymatic.com. Accessed: November 12, 2017. 
Santiago, I., Montero, D.T., Rodriguez, J.J.L., Garcia, I.M.M., and Garcia, E.J.P. 2017. Graphical diagnosis of performances in photovoltaic systems: a case study in southern Spain. Energies vol. 10.

Sarma, M.S. 2001. Introduction to Electrical engineering. Oxford University Press, New York, USA.

Schienbein, L.A., Balducci, P.J., Nguyen, T.B., Brown, D.R., DeSteese, J.G., and Speer, G.A. 2004. Avoiding distribution system upgrade costs using distributed generation. Pacific Northwest National Laboratory, Richland, USA.

Seymour, J. 2010. The seven types of power problems. Schneider Electric Data Center Science Center white paper 18 rev. 1.

Simon, B. 2014. Transforming wind into fuel - Glencore to install hydrogen fuel-cell storage system at Raglan mine. CIM Magazine vol. 9 no.7 pp. 22-23.

Simpkins, T., Cutler, D., Hirsch, B., Olis, D., and Anderson, K. 2015. Cost-optimal pathways to 75\% fuel reduction in remote Alaskan villages. Presented at the 2015 IEEE Conference on Technologies for Sustainable Engineering and the Environment, Ogden, USA, Jul 30-Aug 1, 2015.

Sinha, S., and Chandel, S.S. 2014. Review of software tools for hybrid renewable energy systems. Renewable and Sustainable Energy Reviews vol. 32 pp. 192-205.

Soliman, A.S. and Al-Kandari, A. 2010. Chapter 3: Load modeling for short-term forecasting. In Electrical Load Forecasting Modeling and Model Construction. Elsevier, Burlington, USA.

Sörensen, K. 2015. Metaheuristics - the metaphor exposed. International Transactions in Operational Research vol. 22 pp. 3-18.

Stander, J.N. 2008. The specification of a small commercial wind energy conversion system for the South African Antarctic research base SANAE IV. Master's thesis, Stellenbosch University.

Stevenson, F.S.C. 2017. The duty to consult Inuit in Canada's black carbon policy inaction. Journal of Environmental Law and Practice vol. 30 no. 2.

Statistics Canada. 2014. Report on energy supply and demand - 2014 preliminary. Catalogue no. 57003-X.

Statistics Canada. 2017. Cansim tables 329-0074 and 326-0020.

Statistics Faroe Islands. 2016. Faroe Islands in figures 2016. Hagstova Føroya.

Stern et al. 2006. The economics of climate change. Cambridge University Press, Cambridge, UK.

Strommen, K. 2006. Introduction of renewable energy systems in remote communities in the Nordic region - a case study of Nolsoy, the Faroe Islands. Master's thesis, Norwegian University of Science and Technology, Trondheim, Norway. 
Taptuna, P. (2012). Proceedings of the Standing Senate Committee on Energy, the Environment and Natural Resources, Issue 17 - Evidence - March 15, 2012.

Thevenard, D., Dignard-Bailey, L., Martel, S., and Turcotte, D. 2000. Performance monitoring of a northern $3.2 \mathrm{kWp}$ grid-connected photovoltaic system. Proceedings of the 28th IEEE Photovoltaic Specialists Conference, Anchorage, USA, Sept 17-22, 2000.

Thompson, C. 2016. AC vs DC coupling in utility-scale solar plus storage projects. Eaton White Paper WP083023EN.

Tian, Y., and Crous, R. 2013. Reciprocating engine step load response in islanded power generation. Energy and Power Engineering vol. 5 no. 4B pp. 337-343.

Townsend, T.U. 1989. A method for estimating the long-term performance of direct-coupled photovoltaic systems. Master's thesis, University of Wisconsin-Madison, Madison, USA.

Traube, L.W. 2016. Calculation of constant power lithium battery discharge curves. Batteries vol. 2 no. 2 .

Tufte, E. D. 2014. Impacts of low load operation of modern four-stroke diesel engines in generator configuration. Master's report, Norwegian University of Science and Technology, Trondheim, Norway.

Tugliq Energy. N.D. Glencore Raglan Mine renewable electricity smart-grid pilot demonstration. ecoEnergy Innovation Initiative project GC 128296.

Ulleberg, O., and Morkved, Andreas. 2008. Renewable energy and hydrogen system concepts for remote communities in the west Nordic region - the Nolsoy case study. Institute for Energy Technology, Kjeller, Norway.

Ulleberg, O., Nakken, T., and Ete, A. 2010. The wind/hydrogen demonstration system at Utsira in Norway: evaluation of system performance using operational data and updated hydrogen energy system modeling tools. International Journal of Hydrogen Energy vol. 35 no. 5 pp. 1841-1852.

U.S. Energy Information Agency. 2015. International energy statistics. Online data: www.eia.gov. Accessed 8 March 2016.

Usher, E., Jean, G., and Howell, G. 1994. The use of photovoltaics in a northern climate. Solar Energy Materials and Solar Cells vol. 34 pp. 73-81.

Venables, J. 2014. Project snapshot: solar photovoltaic case study in Alaska's Northwest Arctic Borough. Alaska Center for Energy and Power.

Vignola, F., Michalsky, J., and Stoffel, T. 2012. Solar and infrared radiation measurements. Taylor and Francis Group, Boca Raton, United States.

Wang, H.S., Spohn, K.M., Piccard, L., and Yao, L. 2010. Feasibility study of wind power generation system at Arctic Valley. Engineering Management Journalvol. 22 no. 3 pp. 21-33. 
Wetter, M. 2011. GenOpt Generic Optimization Program User Manual Version 3.1.0 Lawrence Berkeley National Laboratory, Berkeley, USA.

White, G. 2009. Governance in Nunavut: capacity vs. culture? Journal of Canadian Studies vol. 43 no. 2 pp. 57-81.

Wilcox, S., and Marion, W. 2008. User's Manual for TMY3 Data Sets. National Renewable Energy Laboratory, Golden, USA.

Wolf Island Engineering et al. 2010. Energy for Yukon: the natural gas option. Eagle Plain case study. Yukon Department of Energy, Mines and Resources.

World Bank. 2010. Cost-benefit analysis in World Bank projects. Washington, D.C., USA.

Zakeri, B., and Syri, S. 2015. Electrical energy storage systems: a comparative life cycle cost analysis. Renewable and Sustainable Energy Reviews vol. 42 pp. 569-596.

Zhou, W., Yang, H., and Fang, Z. 2007. A novel model for photovoltaic array performance prediction. Applied Energy vol. 84 pp. 1187-1198.

Zomers, Adriaan. 2014. Remote access: context, challenges, and obstacles in rural electrification. IEEE Power and Energy Magazine vol. 12 pp. 26-34.

Zucchi, R. 2007. Final technical report, Kotzebue wind power project volume 1. U.S. Department of Energy, Golden, USA. 


\section{Appendix A. Cambridge Bay Weather Graphs, 2015}

The following graphs detail the monitored weather data collected in 2015. Global horizontal radiation, wind speed, and temperature were collected from the dedicated instrumentation as noted in Section 4.3; air pressure and relative humidity were from airport measurements downloaded from the Environment Canada website (Environment Canada, 2015); and the diffuse and direct normal radiation data were extracted from the global horizontal measurements using the Reindl Method as detailed in Section 4.3.

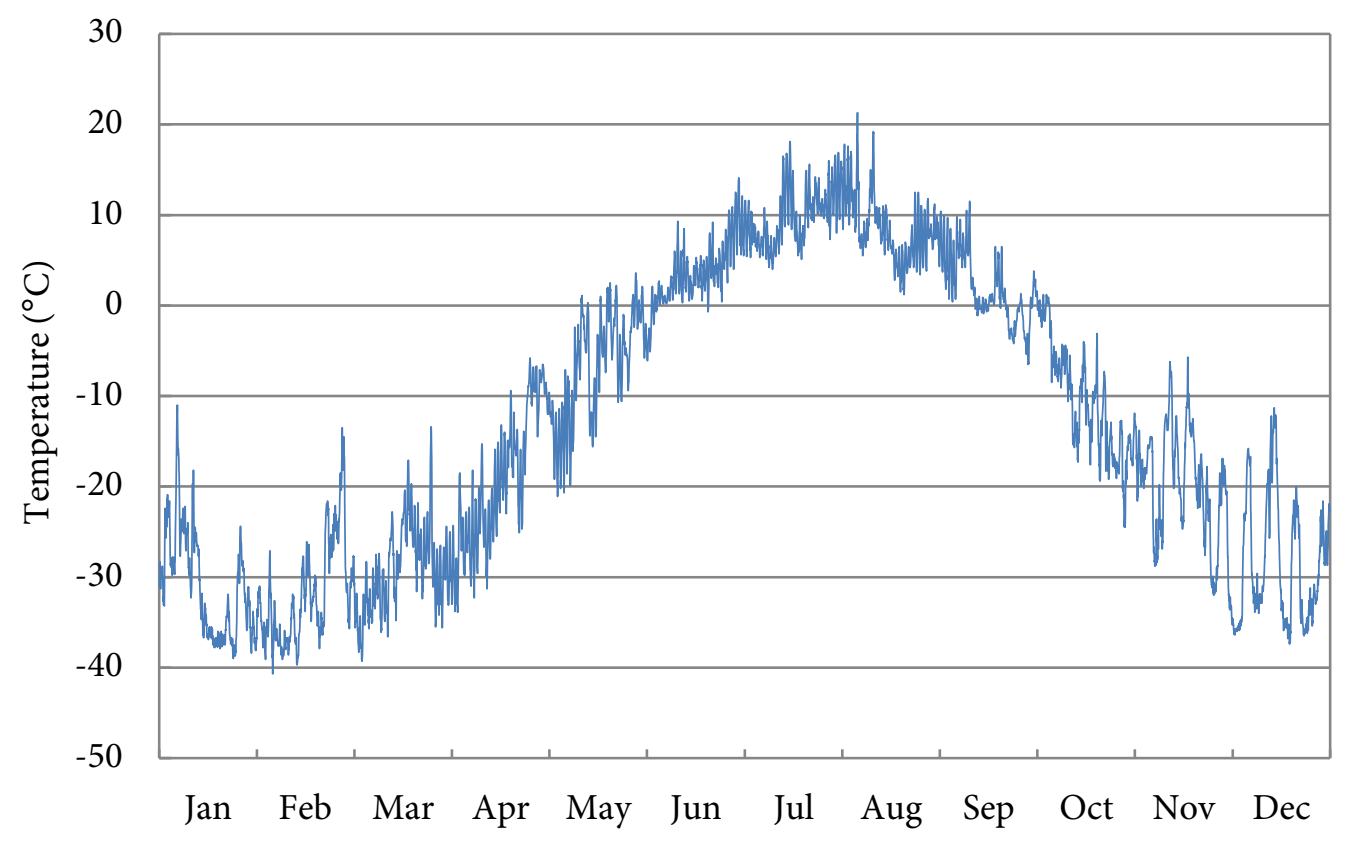

Figure A-1: Hourly temperature 


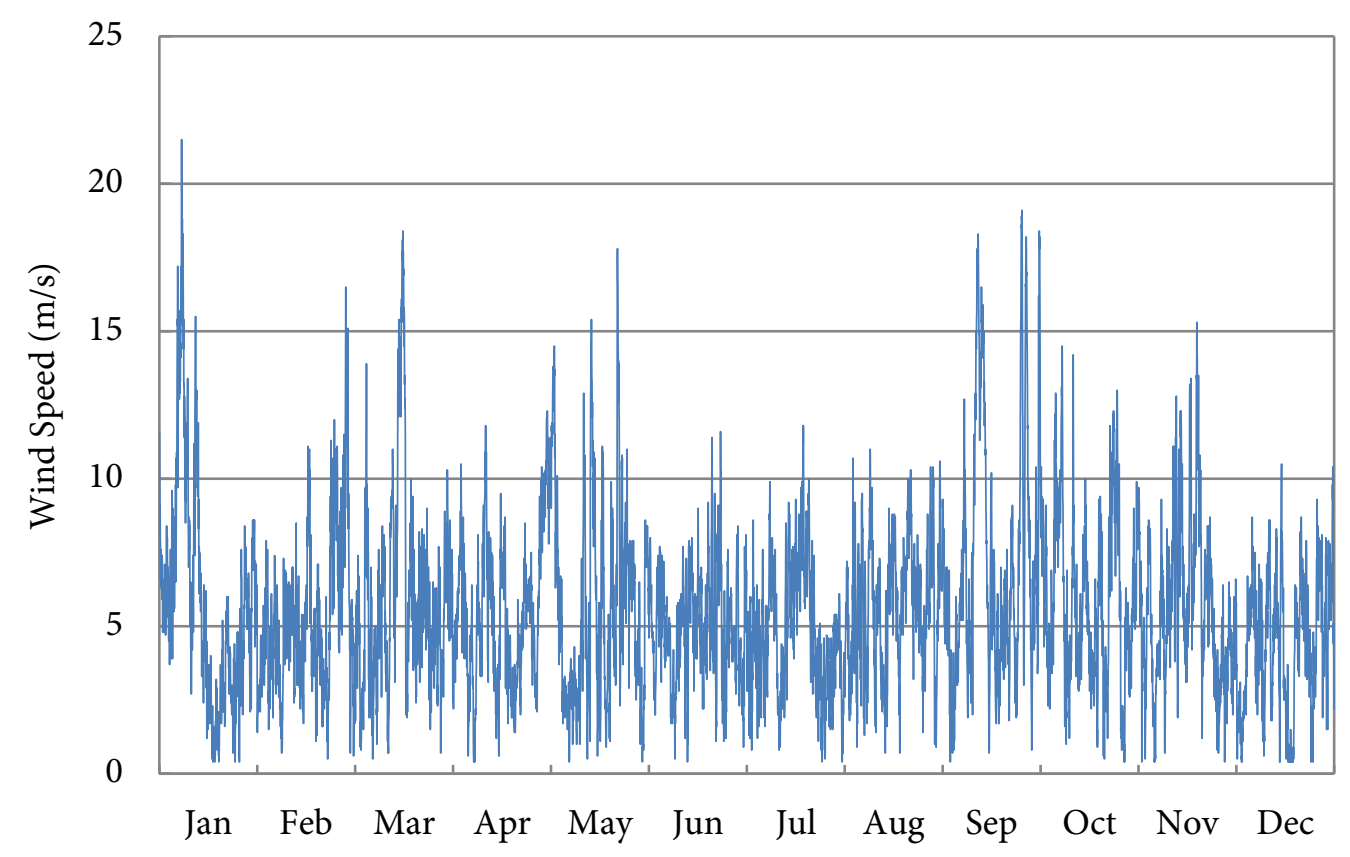

Figure A-2: Hourly wind speed

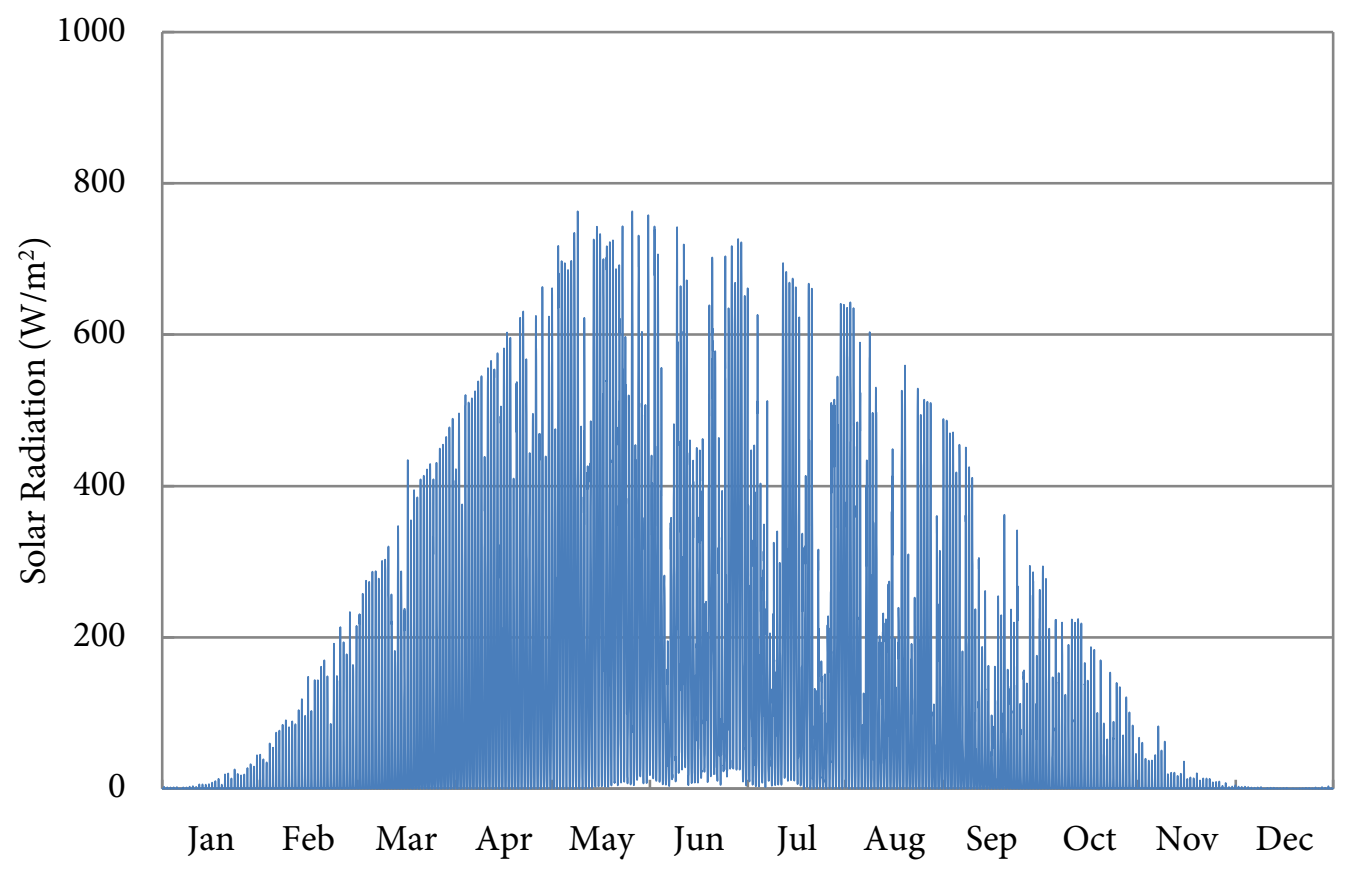

Figure A-3: Hourly global horizontal solar radiation 


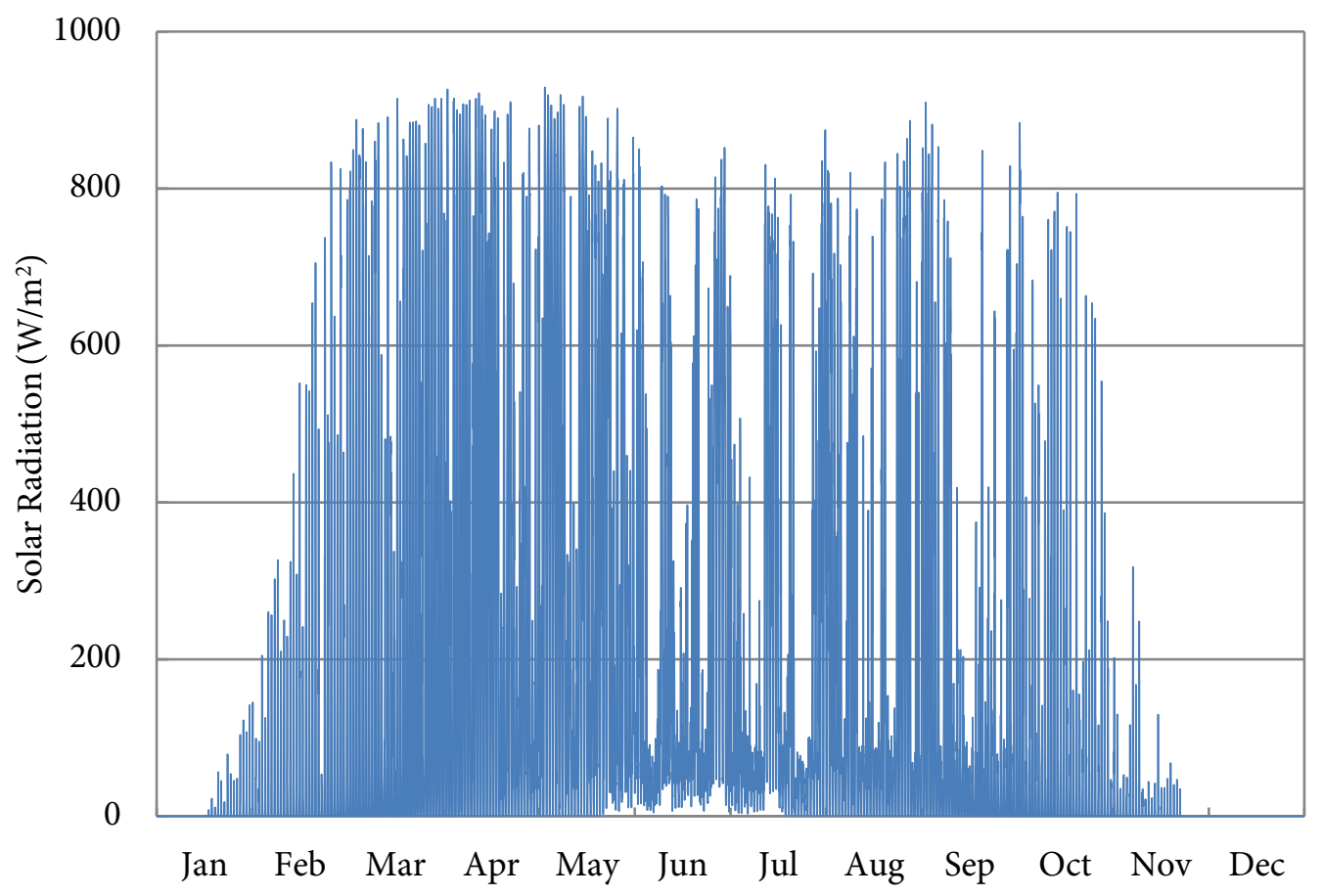

Figure A-4: Hourly direct normal solar radiation

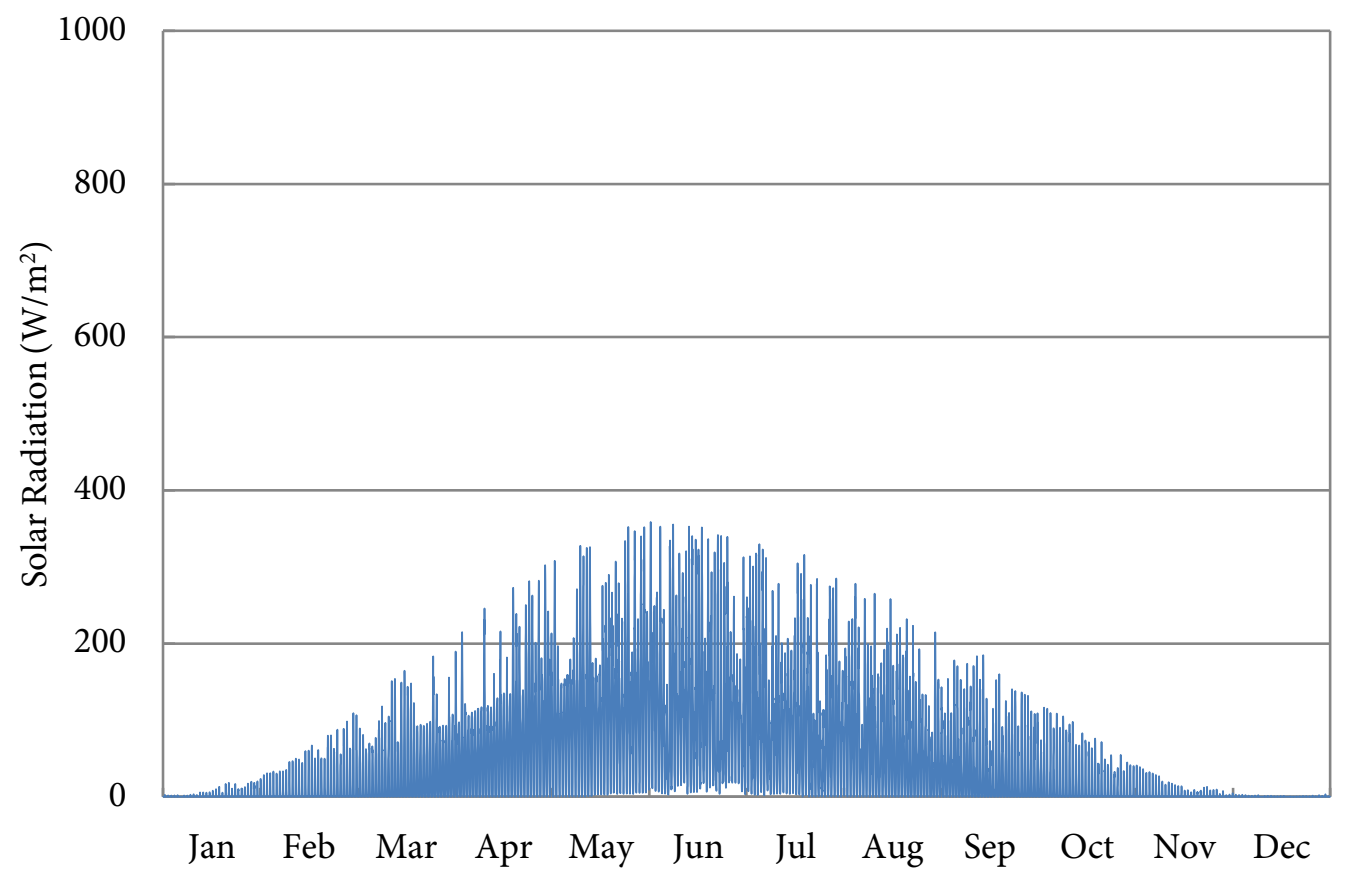

Figure A-5: Hourly diffuse horizontal solar radiation 


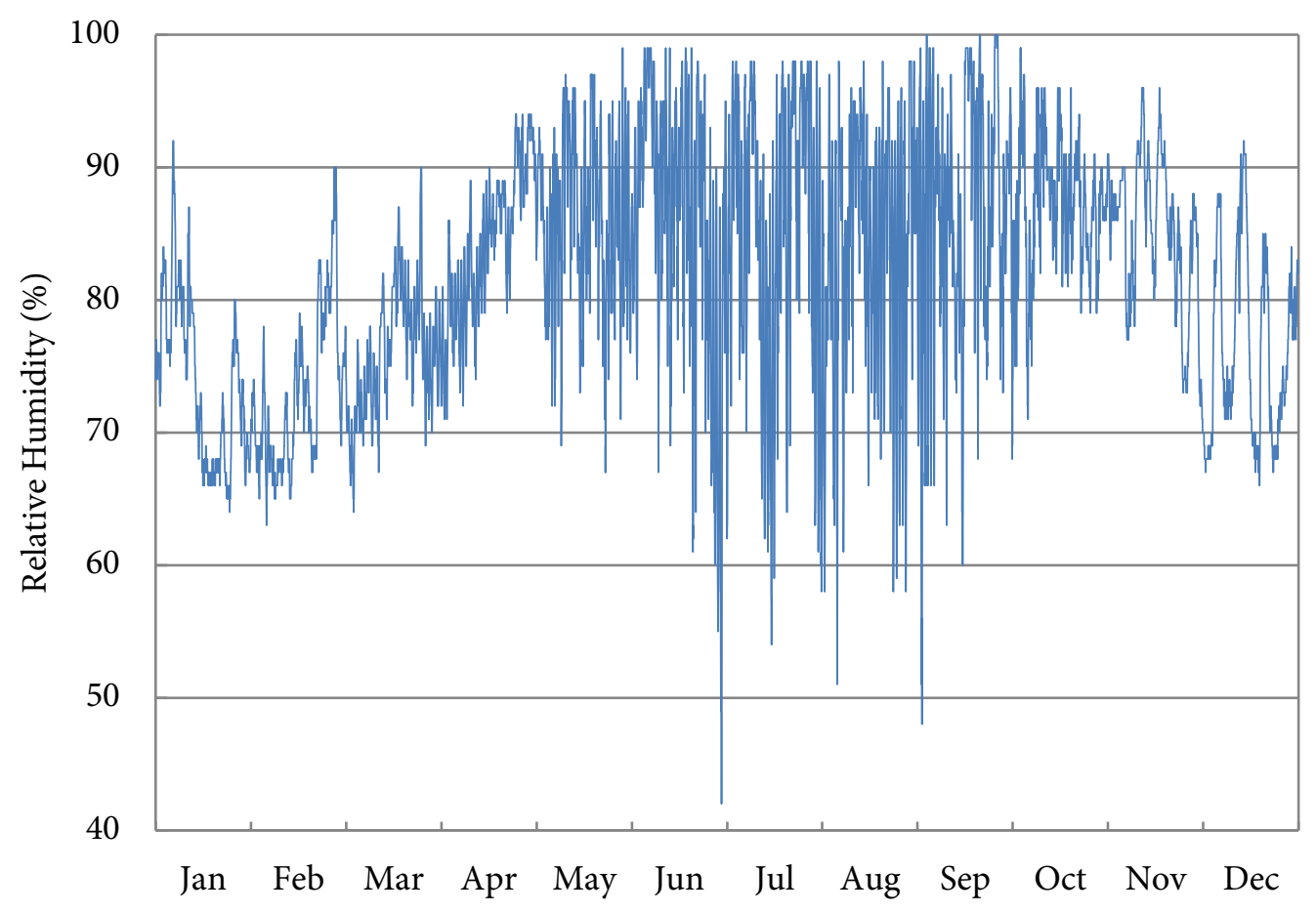

Figure A-6: Hourly relative humidity

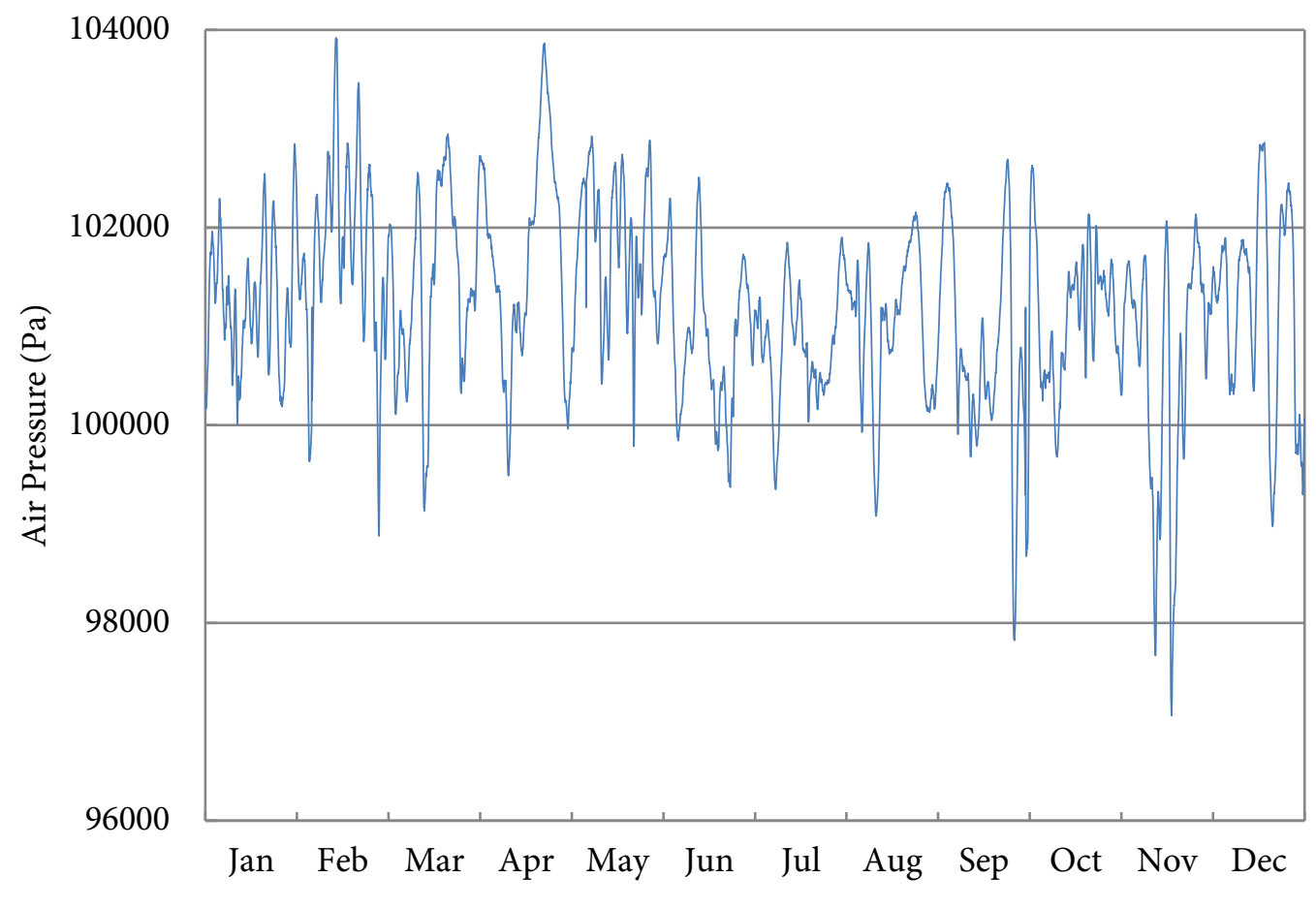

Figure A-7: Hourly air pressure 


\section{Appendix B. Cost Estimates}

Estimating costs for a hybrid renewable energy system in the Arctic is difficult, since there very few renewable energy projects in northern Canada to use as benchmarks. For existing projects, reliable and detailed cost data can be difficult to obtain. There may also be substantial differences between projects. As an example, the costs of the wind project at the Diavik Diamond Mine, which is connected by ice road to Yellowknife and which presumably had significant on-site technical capacity with which to execute the project, cannot simply be applied to a similar project in a community in Nunavut.

In Canada's Arctic, projects are substantially more expensive than in southern Canada. Many communities are not connected by road to the rest of Canada, meaning supplies and materials have to be shipped in by sea once a year in late summer or by air throughout the year. This dramatically increases both cost and scheduling complexity. Salaries for construction workers are higher than in the south and skilled trades often need to be 'flown in' on a rotational basis. Construction projects often involve additional complexity, for example construction in permafrost or the need to construct and maintain infrastructure in $-40^{\circ} \mathrm{C}$ temperatures. Macroeconomic conditions affect all infrastructure projects, but can be particularly acute in the Arctic: for example, a mining project opening nearby can deplete local labour pools and substantially increase labour costs.

Baseline cost estimates for this analysis were obtained from multiple sources, including benchmarks of previous related projects, high-level cost trends, and estimates by other authors on planned or hypothetical projects in the north. Higher-level costs on a per-kW or per-kWh basis are typically found in the literature; more granular cost data requires detailed information of market conditions, equipment and shipping costs, construction costs in Cambridge Bay, and other information that is out of scope for this thesis. Parametric analyses were conducted to evaluate the impact of deviation from the baseline costs.

Unless otherwise noted, all costs are in Canadian dollars. 


\section{Diesel generator and grid-purchased power costs}

The capital cost of a diesel generator of around $1 \mathrm{MW}$ or less appears to be between $\$ 1,000-\$ 2,000 / \mathrm{kW}$. Pinard et al. (2016) estimate $\$ 2,000 / \mathrm{kW}$ in Nunavut, while in Yukon, Osler (2011) estimates $\$ 1,000 / \mathrm{kW}$. In a Yukon mining environment, the capital cost was estimated at $\$ 1,200 / \mathrm{kW}$ (Wolf Island Engineering, 2010). Examining the Nunavut territorial power corporation capital plan for two communities, planned upgrades of a $1275 \mathrm{~kW}$ and $955 \mathrm{~kW}$ genset were estimated at $\$ 905 / \mathrm{kW}$, and $\$ 1,470 / \mathrm{kW}$, respectively (QEC, 2016b); however, it is not clear what is included in these costs. Replacing a genset is clearly much less expensive than building a new plant.

Comparing these figures to southern United States, Lazard (2016) estimates capital costs between CAD \$670-\$1,070/kW. Examining the Western United States, Schienbein et al. (2004) found that the per$\mathrm{kW}$ cost decreases as capacity increases, from about CAD $\$ 1,300$ for a $300 \mathrm{~kW}$ plant to CAD $\$ 1,090 / \mathrm{kW}$. These figures assume an exchange rate of US\$0.75 $=\mathrm{CAD} \$ 1.00$.

The literature therefore suggests that $\$ 1,000 / \mathrm{kW}$ is a floor for diesel generator cost in Nunavut. Depending on the supporting infrastructure required, such as the building, switchgear, transmission lines, and other components, the cost could be $\$ 2,000 / \mathrm{kW}$ or even higher. For a stand-alone system at CHARS, the generator could be located in the existing emergency generator room, minimizing required new infrastructure. Therefore the baseline diesel capital cost used in this thesis was $\$ 2,000 / \mathrm{kW}$; benchmark costs are summarized in Table B-1.

Table B-1: Diesel genset capital cost benchmarks

\begin{tabular}{|c|c|r|c|}
\hline Benchmark & Notes & $\$ / \mathrm{kW}$ & \multicolumn{1}{c|}{ Source } \\
\hline Nunavut estimate & Community application & $\$ 2,000$ & Pinard et al., 2016 \\
\hline \multirow{2}{*}{ Yukon } & Community application & $\$ 1,000$ & Osler, 2011 \\
\cline { 2 - 3 } & Mining application & $\$ 1,200$ & Wolf Island Engineering, 2010 \\
\hline \multirow{2}{*}{$\begin{array}{c}\text { Territorial power } \\
\text { corporation }\end{array}$} & $1275 \mathrm{~kW}$ & $\$ 905$ & \multirow{2}{*}{ QEC, 2016 } \\
\cline { 2 - 3 } & $955 \mathrm{~kW}$ & $\$ 1,470$ & \multirow{2}{*}{ Lazard, 2016 } \\
\hline USA & Low estimate & $\$ 670$ & \multirow{2}{*}{ Scheinbein et al., 2004 } \\
\cline { 2 - 3 } USA & High estimate & $\$ 1,070$ & \\
\hline \multirow{2}{*}{ Western USA } & $300 \mathrm{~kW}$ & $\$ 1,300$ & \\
\cline { 2 - 3 } & $1000 \mathrm{~kW}$ & $\$ 1,090$ & \\
\hline
\end{tabular}


To estimate the fixed O\&M expenses in a stand-alone scenario, the costs of the power corporation, Qulliq Energy Corporation (QEC), were referred to as a benchmark. QEC's expenses totaled almost \$140M in 2016 (QEC, 2016a). The breakdown by category is shown in Table B-2. As a regulated utility, QEC expects to earn a regulated rate of return; hence total revenues are typically several million dollars higher than the expenses shown in Table B-2, although in 2016 the corporation broke even. 'Supplies and service' is the cost of maintaining plant and equipment and includes materials, freight, contractors, professional development and administration.

Table B-2: Qulliq Energy Corporation allocation of expenses (\$)

\begin{tabular}{|c|l|r|r|r|}
\hline No. & \multicolumn{1}{|c|}{ Line Item } & \multicolumn{1}{c|}{2016} & \multicolumn{1}{c|}{2015} & \multicolumn{1}{c|}{2014} \\
\hline 1. & Fuels and Lubricants & $\$ 53,881,000$ & $\$ 55,982,000$ & $\$ 51,563,000$ \\
\hline 2. & Salaries, Wages, Benefits & $\$ 30,352,000$ & $\$ 29,623,000$ & $\$ 28,989,000$ \\
\hline 3. & Supplies and Services & $\$ 21,859,000$ & $\$ 19,707,000$ & $\$ 21,029,000$ \\
\hline 4. & Amortization and Disposal & $\$ 23,947,000$ & $\$ 11,046,000$ & $\$ 7,841,000$ \\
\hline 5. & Travel and Accommodations & $\$ 4,455,000$ & $\$ 4,770,000$ & $\$ 4,277,000$ \\
\hline 6. & Interest & $\$ 4,455,000$ & $\$ 4,519,000$ & $\$ 4,990,000$ \\
\hline 7. & Bad Debt & $\$ 278,000$ & $-\$ 126,000$ & $\$ 119,000$ \\
\hline & & & & \\
\hline & Total & $\$ 139,227,000$ & $\$ 125,521,000$ & $\$ 118,808,000$ \\
\hline
\end{tabular}

The same figures as a percentage of the total are outlined in Table B-3. Fuel and lubricants typically account for about $45 \%$ of the cost of generating power. This figure is lower in 2016 due to a fire that destroyed one power plant and abandoning further development of plans for a hydroelectric facility in Iqaluit, resulting in a higher percentage of amortization and disposal. This is for accounting purposes and does not represent typical expenditures by the corporation. 
Table B-3: Qulliq Energy Corporation allocation of expenses (\%)

\begin{tabular}{|c|l|r|r|r|}
\hline No. & \multicolumn{1}{|c|}{ Line Item } & $\mathbf{2 0 1 6}$ & \multicolumn{1}{c|}{$\mathbf{2 0 1 5}$} & \multicolumn{1}{c|}{$\mathbf{2 0 1 4}$} \\
\hline 1. & Fuels and Lubricants & $38.7 \%$ & $44.6 \%$ & $43.4 \%$ \\
\hline 2. & Salaries, Wages, Benefits & $21.8 \%$ & $23.6 \%$ & $24.4 \%$ \\
\hline 3. & Supplies and Services & $15.7 \%$ & $15.7 \%$ & $17.7 \%$ \\
\hline 4. & Amortization and Disposal & $17.2 \%$ & $8.8 \%$ & $6.6 \%$ \\
\hline 5. & Travel and Accommodations & $3.2 \%$ & $3.8 \%$ & $3.6 \%$ \\
\hline 6. & Interest & $3.2 \%$ & $3.6 \%$ & $4.2 \%$ \\
\hline 7. & Bad Debt & $0.2 \%$ & $-0.1 \%$ & $0.1 \%$ \\
\hline & & & & $100.0 \%$ \\
\hline & Total & $100.0 \%$ & $100.0 \%$ & \\
\hline
\end{tabular}

Finally, Table B-4 expresses the figures as $\$ / \mathrm{kW}$ installed generating capacity. In 2016, the total installed capacity was $76,848 \mathrm{~kW}$ or $3,074 \mathrm{~kW}$ per community, although this figure is skewed by Iqaluit which has a significantly higher population than any other community in the territory. Line 9 is included to show the component of costs related to non-fuel operations.

Table B-4: Qulliq Energy Corporation allocation of expenses (\$/kW installed capacity)

\begin{tabular}{|c|l|r|r|r|}
\hline No. & \multicolumn{1}{|c|}{ Line Item } & \multicolumn{2}{|c|}{$\mathbf{2 0 1 6}$} & \multicolumn{2}{c|}{$\mathbf{2 0 1 5}$} & \multicolumn{1}{c|}{$\mathbf{2 0 1 4}$} \\
\hline 1. & Fuels and Lubricants & $\$ 701$ & $\$ 728$ & $\$ 671$ \\
\hline 2. & Salaries, Wages, Benefits & $\$ 395$ & $\$ 385$ & $\$ 377$ \\
\hline 3. & Supplies and Services & $\$ 284$ & $\$ 256$ & $\$ 274$ \\
\hline 4. & Amortization and Disposal & $\$ 312$ & $\$ 144$ & $\$ 102$ \\
\hline 5. & Travel and Accommodations & $\$ 58$ & $\$ 62$ & $\$ 56$ \\
\hline 6. & Interest & $\$ 58$ & $\$ 59$ & $\$ 65$ \\
\hline 7. & Bad Debt & & $-\$ 2$ & $\mathbf{\$ 4}$ \\
\hline & & $\mathbf{\$ 1 , 8 1 2}$ & $\mathbf{\$ 1 , 6 3 3}$ & $\mathbf{\$ 1 , 5 4 6}$ \\
\hline & Total & $\mathbf{\$ 7 3 7}$ & $\mathbf{\$ 7 0 4}$ & $\mathbf{\$ 7 0 7}$ \\
\hline & $\mathbf{2 + 3 + 5}$ & & &
\end{tabular}

Referring to Table B-4, non-fuel O\&M (item no. 2, 3, and 5) for the corporation is on the order of $\$ 700$ $\$ 750 / \mathrm{kW}$ installed capacity (amortization and disposal is considered a capital cost in this thesis). While the corporation has certain administrative expenses that a stand-alone system would not incur at CHARS, such as managing customer accounts, the corporation can also leverage economies of scale. At $\$ 750 / \mathrm{kW}$, a $300 \mathrm{~kW}$ generator at CHARS would cost $\$ 225,000 /$ year. 
Variable O\&M was based on run-time. Pinard et al. (2016) estimate $\$ 0.035 / \mathrm{kW}$-hour of runtime, or about $\$ 300 / \mathrm{kW}$ if run for 8760 hours per year and $\$ 92,000$ for a $300 \mathrm{~kW}$ generator. However this approach does not account for fixed costs independent of the diesel run-time, such as salaries.

In order to estimate variable costs, the 'supplies and services' category was divided in two, yielding $\$ 150 / \mathrm{kW}$, or, if run for 8760 hours per year, about $\$ 0.017 / \mathrm{kW}$-hour runtime, half of Pinard et al.'s estimate. Fixed O\&M costs accounted for the remainder, or $\$ 600 / \mathrm{kW}$. By including variables costs, savings from turning the generator off during periods of high renewable power output were quantified in the model.

Fuel costs were equal to the current cost of diesel fuel in Cambridge Bay, $\$ 1.21 /$ litre. This is slightly more than the cost to the power corporation, and reflects CHARS purchasing fuel at the retail rate as opposed to a bulk annual purchase. Note that since the community annual fuel requirement is delivered through sealift and stored for the year, the price typically does not fluctuate throughout the year as it does in southern Canada.

For grid-connected scenarios where power is purchased from the utility, the commercial government rate was used: $\$ 0.6607 / \mathrm{kWh}(\mathrm{QEC}, 2014)$.

\section{Photovoltaic cost}

PV costs have experienced significantly declines in price over the last ten years, due to improvements in manufacturing and greater expertise in project delivery. The dramatic decrease in price is demonstrated in Figure B-1 for utility-scale installations in the contiguous (lower-48 states) United States (Lazard, 2016). 


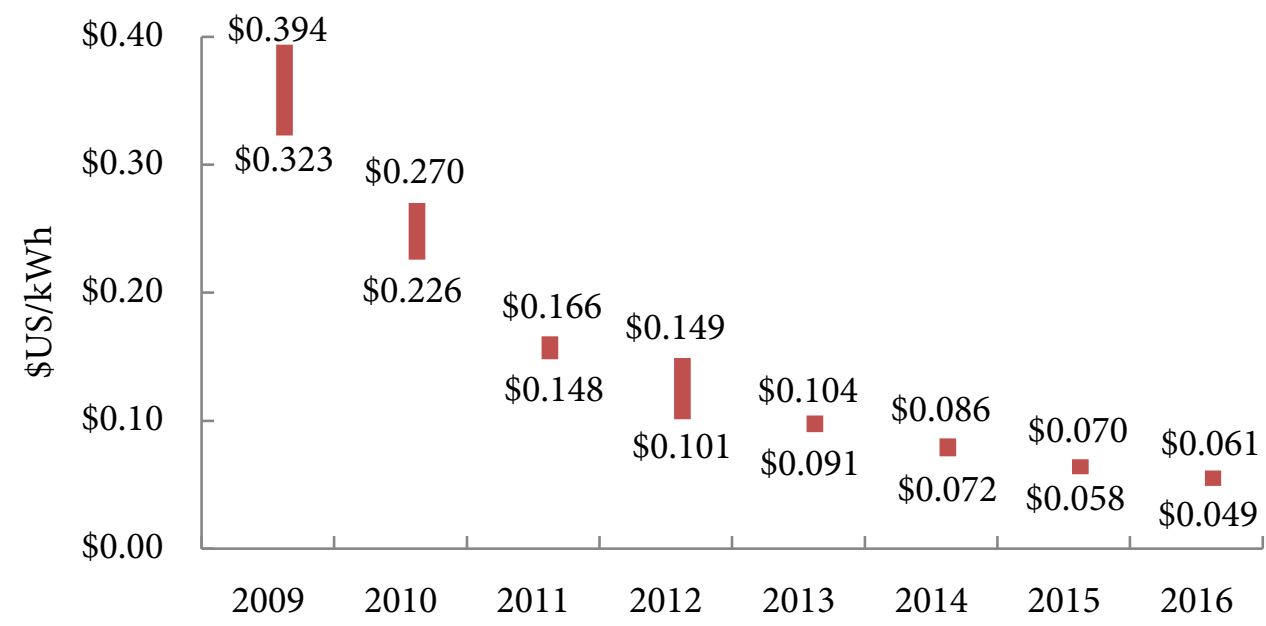

Figure B-1: Levelized cost of electricity of utility-scale solar PV power, contiguous United States

Feldman et al. (2014) modelled USA system prices based on validated tools and reported price data for 2013. Reported prices were significantly higher than modelled prices. For a $100 \mathrm{~kW}$-scale system, the modelled price was $\$ 3.48 / \mathrm{W}$, while reported prices were $\$ 5.19 / \mathrm{W}$. As expected, both methods showed a decreasing unit price $(\$ / \mathrm{kW})$ as the size of the installation increased. Updated modeling indicated reductions in cost, to $\$ 2.47$ for a commercial scale system $(<2,000 \mathrm{~kW})$ (Fu et al., 2017). Luukonen et al. (2012) analyzed the Canadian PV industry, providing historical system costs and costs in 2012. A wide range was reported in pricing for greater-than-10 $\mathrm{kW}$ scenarios, from $\$ 2.80 / \mathrm{W}$ to $\$ 4.00 / \mathrm{W}$. This might reflect cost differences between $\mathrm{kW}$ - and MW-scale installations. Krizan et al. (2011) estimated the installed price of a $5 \mathrm{~kW}$ system in Cambridge Bay to be $\$ 30,000$ for equipment and $\$ 8,300$ for installation, an installed price of $\$ 7.6 / \mathrm{W}$. Considering the cost of travel (approximately $\$ 3500$ for flights alone), this estimated cost of installation is low if outside contractors are required to perform the work.

To gain some perspective on the cost of equipment versus the installed cost, an online directory (ENF Solar, 2017) was consulted. The website features a list of promoted inverters, panels, and racking. The minimum, maximum, and average costs in terms of $\$ / \mathrm{kW}$ were extracted from this list.

Table B-5 summarizes the installed cost data, while component pricing is shown in Table B-6 (where prices were originally provided in US\$, they have been converted at an exchange rate of US\$1.00 = CAN\$0.75). The component pricing includes the number of data points ' $n$ ' from which the values are derived. 
Table B-5: Solar photovoltaic installed system capital cost benchmarks

\begin{tabular}{|c|c|c|c|}
\hline Benchmark & Size $(\mathrm{kW})$ & $\$ / \mathrm{kW}$ installed & Source \\
\hline \multirow{3}{*}{ Modelled installed price (USA) } & 5 & $\$ 4,947$ & \multirow{3}{*}{ Feldman et al. 2014} \\
\hline & 223 & $\$ 3,480$ & \\
\hline & 185,000 & $\$ 2,560$ & \\
\hline Reported installed price (USA) & $<10$ & $\$ 6,253$ & \multirow{3}{*}{ Feldman et al., 2014} \\
\hline Reported installed price (USA) & $>100$ & $\$ 5,187$ & \\
\hline Reported installed price (USA) & $>5000$ & $\$ 4,000$ & \\
\hline Modelled residential price (USA) & $3-10$ & $\$ 3,730$ & \multirow{3}{*}{ Fu et al., 2017} \\
\hline Modelled commercial price (USA) & $10-2000$ & $\$ 2,470$ & \\
\hline Modelled utility price (USA) & $>2000$ & $\$ 1,370$ & \\
\hline Cambridge Bay, equipment & 5 & $\$ 6,000$ & \multirow{3}{*}{ Krizan et al., 2011} \\
\hline Cambridge Bay, installation & 5 & $\$ 1,600$ & \\
\hline Cambridge Bay, total & 5 & $\$ 7,600$ & \\
\hline \multicolumn{3}{|c|}{ Average installed price, Canada, up to 2011} & \multirow{8}{*}{ Luukonen et al, 2013} \\
\hline Less than & 10 & $\$ 6,790$ & \\
\hline Greater than & 10 & $\$ 5,270$ & \\
\hline \multicolumn{3}{|l|}{ Average installed price, Canada, 2012} & \\
\hline Minimum, less than - & 10 & $\$ 3,000$ & \\
\hline Max, less than - & 10 & $\$ 5,000$ & \\
\hline Min, greater than - & 10 & $\$ 2,800$ & \\
\hline Max, greater than - & 10 & $\$ 4,000$ & \\
\hline
\end{tabular}

Table B-6: Solar photovoltaic equipment capital cost benchmarks

\begin{tabular}{|l|r|r|r|c|}
\hline \multirow{2}{*}{ Component } & \multicolumn{3}{|c|}{$\$ / \mathrm{kW}$} & \multirow{2}{*}{ Source } \\
\cline { 2 - 4 } & \multicolumn{1}{|c|}{ Min } & Average & \multicolumn{1}{c|}{ Max } & \\
\hline Panel $(\mathrm{n}=14)$ & $\$ 550$ & $\$ 720$ & $\$ 880$ & \multirow{2}{*}{ ENF Solar, 2017 } \\
\hline Inverter $(\mathrm{n}=10)$ & $\$ 110$ & $\$ 230$ & $\$ 420$ & \\
\hline Racking $(\mathrm{n}=10)$ & $\$ 40$ & $\$ 150$ & $\$ 270$ & \\
\hline Total & $\$ 700$ & $\$ 1,100$ & $\$ 1,580$ & \\
\hline
\end{tabular}

Comparing component prices to installed prices, it is evident that the significant reductions in equipment pricing (in particular the PV modules) mean that today, the majority of the cost is 'soft costs' engineering, project management, shipping, installation, etc. These costs are high in the Canadian Arctic. As such, this thesis approximately doubles the most recent data for commercial installations, to $\$ 5,000 / \mathrm{kW}$, for the baseline cost of the PV system. This estimate allocates about $75 \%$ of the installed cost to soft costs. 
Operations and maintenance for solar PV systems is minimal and includes periodic electrical safety checks, occasional cleaning of the panels and snow removal, and replacement of inverters every 5-10 years. The baseline PV O\&M cost for this thesis is $\$ 60 / \mathrm{kW}$ and includes periodic replacement of the inverters, based on the cost indicated in Table B-6.

\section{Wind turbine costs}

Wind power costs have experienced a similar, if less dramatic, trend as solar PV. The LCOE of wind projects in the contiguous (lower-48 states) United States is shown in Figure B-2. It is surmised that the spread in costs is greater than for PV because wind power is more site-specific, and sites with good wind resource might be located in more remote or difficult terrain regions, increasing construction costs and therefore LCOE. Note however that by 2016 , the LCOE of both wind and solar are similar.

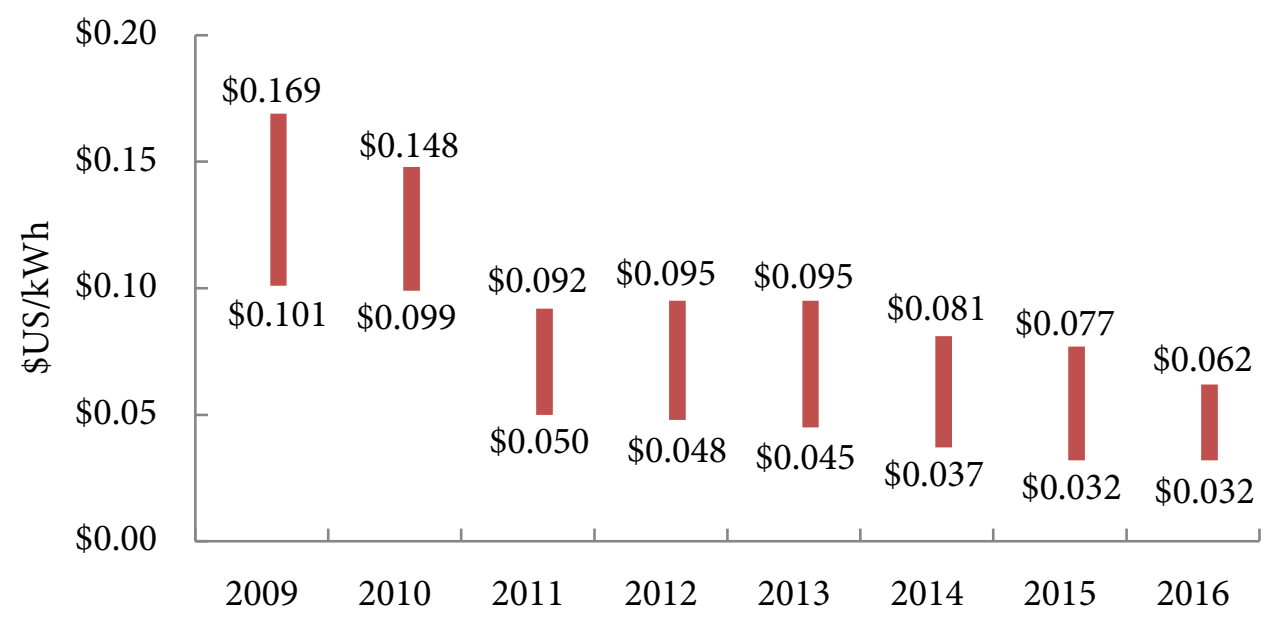

Figure B-2: Levelized cost of electricity of utility-scale wind power, contiguous United States

Across the United States, installed project costs (in US\$2013) were around $\$ 5,000 / \mathrm{kW}$ in 1983 . From 2009-2012 the capacity-weighted average project cost was around $\$ 2,000-\$ 2,200 / \mathrm{kW}$ (Wiser and Bolinger, 2014). A wide range was observed, however, from about $\$ 1,500 / \mathrm{kW}$ up to $\$ 4,000 / \mathrm{kW}$ and even $\$ 5,000 / \mathrm{kW}$ in extreme cases. Smaller projects are likely in the high range of this estimate.

Fay et al., (2010) provide figures for a range of wind projects in Alaska. Many of these projects were implemented in more remote regions of the state, often in diesel-based communities with no road access. The authors note an installed cost of $\$ 4,000-\$ 15,000 / \mathrm{kW}$, with the majority of projects in the hundreds of 
$\mathrm{kW}$ size range. The 'rural average' for turbines in the $65-225 \mathrm{~kW}$ range was $\$ 10,245 / \mathrm{kW}(\mathrm{n}=17)$. BaringGould and Dabo (2007) report that wind energy projects in Alaska typically cost between $\$ 2,500$ and $\$ 7,000 / \mathrm{kW}$, depending on community size, accessibility, and soil conditions. About $30 \%$ is due to the turbine and tower hardware, while typically those components make up $70 \%$ of the project cost. Wang et al. (2010) estimated the installed cost of a $30 \mathrm{MW}$ wind farm in Arctic Valley, Alaska at $\$ 2,550 / \mathrm{kW}$; the cost for the turbines was estimated at $\$ 1,550 / \mathrm{kW}$. Arctic Valley has good road and sea access, reducing the cost compared to remote regions of the state. In an inventory of renewable resources for Nunavut, Krizan et al. (2011) estimated the installed cost of a $100 \mathrm{~kW}$-scale wind turbine at $\$ 1,000,000$, or $\$ 10,000 / \mathrm{kW}$.

Although MW-scale turbines are typical for southern windfarms, there is little experience with this scale in the North American Arctic. One exception is the Diavik Diamond Mine in the Northwest Territories, Canada, which installed four 2.3 MW wind turbines in 2012 (CanWEA, n.d.). The project cost was listed as $\$ 33 \mathrm{M}$, or $\$ 3,600 / \mathrm{kW}$. Raglan Nickel Mine in northern Quebec installed a $3 \mathrm{MW}$ turbine in 2015 , complete with hydrogen, flywheel, and battery storage; the total cost of this system was reported as $\$ 7,530 / \mathrm{kW}$ of installed wind capacity (Simon, 2014).

Pinard et al. (2016) evaluated the wind potential in Nunavut communities, modeling both a $100 \mathrm{~kW}$ turbine and a 2.3 MW turbine. Both turbines were rated for extreme cold-climate operation. The $100 \mathrm{~kW}$ turbine, a tilt-up (craneless) installation model, was estimated to cost CAD $\$ 630,000$, plus a $\$ 30,000$ hydraulic tower raising mechanism. The $2.3 \mathrm{MW}$ was estimated to cost CAD $\$ 4.2 \mathrm{M}$ installed, using 2012 public domain data.

These figures are summarized in Table B-7. 
Table B-7: Wind turbine capital cost benchmarks

\begin{tabular}{|c|c|c|c|c|}
\hline Benchmark & Notes & Size $(\mathrm{kW})$ & $\$ / \mathrm{kW}$ & Source \\
\hline $\begin{array}{c}\text { US } 2013 \text { average } \\
\text { cost (US\$) }\end{array}$ & & $\mathrm{N} / \mathrm{A}$ & $\$ 4,000-\$ 5,000$ & Wiser and Bolinger, 2014 \\
\hline $\begin{array}{c}\text { Alaska rural } \\
\text { average (US\$) }\end{array}$ & $\begin{array}{l}\text { Typically } \\
\sim 100 \mathrm{~kW}\end{array}$ & $\mathrm{~N} / \mathrm{A}$ & $\$ 10,245$ & Fay et al., 2010 \\
\hline $\begin{array}{c}\text { Alaska total } \\
\text { average (US\$) }\end{array}$ & & 12,000 & $\$ 6,900$ & Fay et al., 2010 \\
\hline $\begin{array}{c}\text { Alaska rural } \\
\text { average (US\$) }\end{array}$ & $\begin{array}{l}30 \% \text { due to } \\
\text { turbine and } \\
\text { tower hardware }\end{array}$ & $\mathrm{N} / \mathrm{A}$ & $\$ 2,500-\$ 7,500$ & $\begin{array}{l}\text { Baring-Gould and Dabo, } \\
\qquad 2007\end{array}$ \\
\hline $\begin{array}{l}\text { Alaska modelling } \\
\text { study (US\$) }\end{array}$ & $2 \mathrm{MW}$, all-in & 30,000 & $\$ 2,550$ & Wang et al., 2010 \\
\hline $\begin{array}{l}\text { Alaska modelling } \\
\text { study (US\$) }\end{array}$ & $\begin{array}{l}2 \mathrm{MW} \text {, turbine } \\
\text { only }\end{array}$ & 30,000 & $\$ 1,550$ & Wang et al., 2010 \\
\hline $\begin{array}{c}\text { Cambridge Bay } \\
(\mathrm{CAD} \$)\end{array}$ & $100 \mathrm{~kW}$ & & $\$ 10,000$ & Krizan et al., 2011 \\
\hline $\begin{array}{c}\text { Diavik Diamond } \\
\text { Mine (CAD\$) }\end{array}$ & 2.3 MW, all-in & 9,800 & $\$ 3,600$ & CanWEA, n.d. \\
\hline Iqaluit (CAD\$) & $\begin{array}{l}\text { 2.3MW, } \\
\text { all-in }\end{array}$ & 4,600 & $\$ 5,380$ & Pinard et al., 2016 \\
\hline $\begin{array}{c}\text { Cambridge Bay } \\
(\mathrm{CAD} \$)\end{array}$ & $\begin{array}{c}100 \mathrm{~kW} \text { turbine, } \\
\text { turbine only }\end{array}$ & 1,300 & $\$ 6,300$ & Pinard et al., 2016 \\
\hline $\begin{array}{c}\text { Cambridge Bay } \\
(\mathrm{CAD} \$)\end{array}$ & $100 \mathrm{~kW}$, all-in & 1,300 & $\$ 11,000$ & Pinard et al., 2016 \\
\hline $\begin{array}{l}\text { Raglan Nickel } \\
\text { Mine (CAD\$) }\end{array}$ & $\begin{array}{l}3 \mathrm{MW}, \text { incl. } \\
\text { storage }\end{array}$ & 3,000 & $\$ 7,530$ & $\begin{array}{c}\text { Tugliq Energy Co, n.d. } \\
\text { Simon, } 2014\end{array}$ \\
\hline
\end{tabular}

There is a dearth of information on wind turbine O\&M in an Arctic environment. Pinard et al. (2016) estimate wind turbine O\&M at $\$ 125 / \mathrm{kW}$. However, for a $100 \mathrm{~kW}$ turbine, this amounts to $\$ 12,500$, which would only pay for a single technician flying in once a year and no spare parts or other preventative maintenance. Wang et al. (2010) estimate $\$ 15 / \mathrm{kW}$, but the scale of the wind farm was much larger than considered in this thesis - $30 \mathrm{MW}$ as opposed to 0-500 kW. Lazard (2016) suggests fixed O\&M costs of \$7/MWh but does not provide an estimate on a capacity basis.

To account for the need for an on-site technician working at least part-time on maintaining the wind turbine system, for this thesis the baseline cost of wind turbine O\&M was $\$ 500 / \mathrm{kW}$. This is about $80 \%$ of 
the fixed diesel genset O\&M, accounting for the higher level of consumables required for a diesel generator, such as lubricants and gaskets. In addition, there are no variable O\&M costs for the turbine.

\section{Battery and power conditioning costs}

Like solar PV and wind, battery and other storage system costs have decreased significantly in recent years. One difficulty in estimating energy storage costs is that sometimes costs are given in terms of power $(\mathrm{kW})$ capacity, sometimes in terms of $(\mathrm{kWh})$, and sometimes both. Sometimes it is not clear what the cost is based on. For this thesis, the energy capacity has been split from the power capacity, the latter of which is termed the power conditioning system (PCS). The PCS size is the maximum power that can flow into or out of the battery. It is also a proxy for other power conditioning equipment required to safely integrate the variability of intermittent renewable power into the diesel grid.

Zakeri and Syri (2015) reviewed a variety of storage technologies and provided cost estimates on both a power and energy basis. Cost estimates are summarized in Table B-8; an exchange rate of CAD $\$ 0.75=$ $€ 1.00$ was assumed. Regardless of the type of battery, it is clear that capital costs are higher on a power basis than on an energy basis.

Table B-8: Summary of battery costs for different technologies

\begin{tabular}{|l|c|c|c|r|r|r|}
\hline \multirow{2}{*}{ Battery Technology } & \multicolumn{3}{|c|}{ Total Capital Cost $/ \mathrm{kW}$} & \multicolumn{3}{c|}{ Total Capital Cost / kWh } \\
\cline { 2 - 7 } & Min & Average & \multicolumn{1}{c|}{ Max } & Min & Average & \multicolumn{1}{c|}{ Max } \\
\hline Advanced Lead-acid & $\$ 1,850$ & $\$ 2,850$ & $\$ 4,340$ & $\$ 460$ & $\$ 580$ & $\$ 960$ \\
\hline Sodium Sulphur & $\$ 2,480$ & $\$ 3,010$ & $\$ 3,150$ & $\$ 440$ & $\$ 460$ & $\$ 530$ \\
\hline Nickel Cadmium & $\$ 3,040$ & $\$ 4,500$ & $\$ 5,580$ & $\$ 790$ & $\$ 930$ & $\$ 1,080$ \\
\hline Sodium Nickel Chloride & $\$ 1,170$ & $\$ 1,550$ & $\$ 2,380$ & $\$ 1,300$ & $\$ 1,460$ & $\$ 1,610$ \\
\hline Lithium Ion & $\$ 2,810$ & $\$ 3,350$ & $\$ 3,660$ & $\$ 610$ & $\$ 730$ & $\$ 750$ \\
\hline Vanadium Redox Flow & $\$ 1,700$ & $\$ 1,810$ & $\$ 2,200$ & $\$ 340$ & $\$ 410$ & $\$ 580$ \\
\hline Zinc Bromie & $\$ 1,470$ & $\$ 1,510$ & $\$ 1,810$ & $\$ 230$ & $\$ 290$ & $\$ 370$ \\
\hline Polysulfide Bromide & $\$ 1,240$ & $\$ 1,460$ & $\$ 1,740$ & $\$ 1,430$ & $\$ 1,530$ & $\$ 1,540$ \\
\hline Iron Chromium & $\$ 1,830$ & $\$ 1,870$ & $\$ 1,900$ & $\$ 700$ & $\$ 760$ & $\$ 810$ \\
\hline Zinc-Air & $\$ 1,750$ & $\$ 1,820$ & $\$ 1,890$ & $\$ 350$ & $\$ 360$ & $\$ 560$ \\
\hline
\end{tabular}

Saldanha (2010) reported that lithium-ion batteries cost around US $\$ 1,000 / \mathrm{kWh}$ and were seen as too expensive for renewable systems when compared with lead-acid. However this has likely changed in recent years. Kempener and Borden (2015) estimated that sodium-sulphur (NaS) batteries were most 
common with about $400 \mathrm{MW}$ installed capacity, followed by lithium-ion (Li-ion) at around $200 \mathrm{MW}$ installed capacity. Lithium-ion batteries typically cost between $\$ 600-\$ 800 / \mathrm{kWh}$ (US\$2012), with significant price decreases expected by industry analysts. The US $\$ 2014$ price per kWh, energy density, and cycle life of six different lithium-ion battery chemistries is reproduced in Table B-9.

Table B-9: Cost of different Lithium-ion battery chemistries

\begin{tabular}{|l|c|c|c|}
\hline \multicolumn{1}{|c|}{ Battery } & $\begin{array}{c}\text { Energy Density } \\
(\mathrm{Wh} / \mathrm{kg})\end{array}$ & Cycle Life & $\mathbf{\$} / \mathrm{kWh}$ \\
\hline Lithium iron phosphate & $85-105$ & $200-2000$ & $550-850$ \\
\hline Lithium manganese spinel & $140-180$ & $800-2000$ & $450-700$ \\
\hline Lithium titanate & $80-95$ & $2000-25000$ & $900-2200$ \\
\hline Lithium cobalt oxide & $140-200$ & $300-800$ & $250-500$ \\
\hline Lithium nickel cobalt aluminum & $120-160$ & $800-5000$ & $240-380$ \\
\hline Lithium nickel manganese cobalt & $120-140$ & $800-2000$ & $550-750$ \\
\hline
\end{tabular}

Pinard et al. (2016) suggested that lithium-ion batteries were the storage technology of choice, and concluded that lead-acid batteries were not contenders. For use in Nunavut with a $100 \mathrm{~kW}$ wind turbine, the authors specified a $250 \mathrm{~kW} / 200 \mathrm{kWh}$ lithium-ion battery system with an estimated cost of \$1M; the breakdown of cost between power and energy was not detailed. For a northern mine application in Canada with a diesel plant capacity of 12 MW, Power (2017) suggested a 5 MW / 20 MWh lithium-ion solution. The total cost was estimated at $\$ 12 \mathrm{M}$; the batteries themselves constituted half the cost, bidirectional inverters and the system controller another $\$ 4 \mathrm{M}$, with the balance comprising engineering, shipping, and construction. This is equivalent to $\$ 300 / \mathrm{kWh}$ for the batteries and $\$ 1,200 / \mathrm{kW}$ if the balance is included in the PCS - significantly less expensive than the figures suggested by other authors.

Without validation of the numbers proposed by Power, costs for the battery and PCS were based upon other sources listed above for lithium-ion batteries. The baseline capital cost was set to $\$ 1,000 / \mathrm{kWh}$ for the battery and $\$ 4,000 / \mathrm{kW}$ for the PCS.

Excluding battery replacement costs, O\&M costs for the battery and PCS is low. It includes periodic checks of electrical systems for safety purposes. The baseline cost was $\$ 25 / \mathrm{kWh}$ and $\$ 25 / \mathrm{kW}$, respectively. Based on Table B-9 and the review by Zakeri and Syri (2015), the baseline number of cycles before 
replacement was 4000 . The annual replacement cost is equal to the battery capital cost with appropriate escalation as noted in Section 7.1. For an explanation of battery cycling, see Section 5.2.

\section{Economic value of surplus renewable power}

In a high-penetration system, there are typically periods where renewable power output exceeds demand and remaining storage capacity. If there are no secondary loads, this surplus power is spilled, yielding no economic benefit.

The potential for realizing economic benefit from surplus power at CHARS was summarized in Brown et al. (2018). Surplus power can be discarded, resulting in no economic benefit; it can be used for heating the facility with electric resistance heaters (assumed to be $100 \%$ efficient); or it can be sold back to the grid.

The boilers at CHARS are condensing-type, $85 \%$ efficient diesel-fueled. Using surplus renewable power for heating displaces diesel fuel for heating purposes. The volume of fuel consumed in time period is:

$$
V_{f u e l}=\frac{\dot{Q} T}{\eta * H H V}
$$

where $V_{\text {fuel }}$ is the volume of fuel in litres, $\eta$ is the boiler efficiency, $\dot{Q}$ is the heating load in $\mathrm{kW}, T$ is the time in seconds, and $H H V$ is the higher heating value of diesel fuel, $10.75 \mathrm{kWh} /$ litre (Turns, 2012). Using surplus renewable energy for heating, the volume of heating fuel saved can be expressed as:

$$
V_{f u e l, s a v e d}=\frac{Q}{\eta * H H V}
$$

where $Q$ is the renewable energy used for heating in $\mathrm{kWh}$. Therefore for every $\mathrm{kWh}$ of renewable energy used for heating, the volume of fuel saved is:

$$
V_{\text {fuel,saved }}=\frac{1 \mathrm{kWh}}{0.85 * 10.75 \mathrm{kWh} / \text { litre }}=0.1094 \text { litres }
$$

At a price of $\$ 1.21 /$ litre, this results in savings of $\$ 0.1324 / \mathrm{kWh}$ of renewable energy used for heating. Since the facility has space heating needs year-round and domestic hot water is stored in tanks, the ability of CHARS to use renewable energy for heating is assumed to be independent of the heating load at any point 
in time. Preliminary simulation results (Brown et al., 2018) indicate that, since renewable energy is an expensive way to meet the heating load compared to diesel, this assumption does not skew the optimization results to provide unrealistically large surplus power for heating.

$\$ 0 / \mathrm{kWh}$ was used as the low end in the parametric analysis, representing no use of surplus renewable power. The baseline cost, $\$ 0.1324 / \mathrm{kWh}$, assumes that surplus power displaces diesel fuel for heating. The high end cost, $\$ 0.2973$, assumes that surplus power is sold back to the community at the avoided cost of fuel: $45 \%$ of the cost as per Section 1.2, or $\$ 0.2973 / \mathrm{kWh}$. 


\section{Appendix C. Parametric Analysis Table}

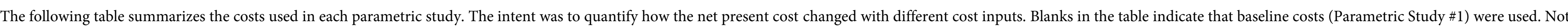
all studies were applicable for all system configurations; for example, studies \#4-7 were not evaluated for grid-tied configurations.

\begin{tabular}{|c|c|c|c|c|c|c|c|c|c|c|c|c|c|c|c|c|c|c|c|c|c|c|c|}
\hline \multirow[b]{2}{*}{$\begin{array}{l}\text { Parametric } \\
\text { Study \# }\end{array}$} & \multirow[b]{2}{*}{ Parametric Scenario } & \multicolumn{5}{|c|}{ Capital $(\$ / \mathrm{kW})$} & \multicolumn{6}{|c|}{ Annual O\&M (\$/kW, \$/kWh) } & \multirow[b]{2}{*}{$\begin{array}{l}\text { Discount } \\
\text { Rate (\%) }\end{array}$} & \multirow[b]{2}{*}{$\begin{array}{c}\text { GHG } \\
\text { Emission } \\
\text { Cost } \\
(\$ / L)\end{array}$} & \multicolumn{5}{|c|}{ Annual Escalation (\%) } & \multirow[b]{2}{*}{\begin{tabular}{|c|} 
Surplus \\
Power \\
Value \\
$(\$ / \mathrm{kWh})$
\end{tabular}} & \multirow[b]{2}{*}{$\begin{array}{l}\text { Fuel } \\
\text { Cost } \\
(\$ / L)\end{array}$} & \multirow[b]{2}{*}{$\begin{array}{c}\text { Grid } \\
\text { Power } \\
\text { Rate } \\
(\$ / \mathrm{kWh})\end{array}$} & \multirow[b]{2}{*}{$\begin{array}{l}\text { Battery } \\
\text { Cycles }\end{array}$} \\
\hline & & PV & $\begin{array}{l}\text { Wind } \\
\text { Turbines }\end{array}$ & PCS & Battery & Diesel & PV & $\begin{array}{l}\text { Wind } \\
\text { Turbine }\end{array}$ & PCS & Battery & $\begin{array}{l}\text { Diesel, } \\
\text { Fixed }\end{array}$ & $\begin{array}{c}\text { Diesel, } \\
\text { Variable }\end{array}$ & & & $\begin{array}{l}\text { Fuel / } \\
\text { Grid } \\
\text { Power }\end{array}$ & $\begin{array}{c}\text { Surplus } \\
\text { Power }\end{array}$ & Battery & $\mathrm{O} \& \mathrm{M}$ & GHG & & & & \\
\hline 1 & Baseline & 5000 & 10000 & 4000 & 1000 & 2000 & 60 & 500 & 25 & 25 & 600 & 0.017 & 0.05 & 0.1369 & 0.04 & 0.02 & -0.01 & 0.02 & 0.02 & -0.1324 & 1.21 & 0.6607 & 4000 \\
\hline 2 & Capital, high renewable & 6250 & 12500 & 5000 & 1250 & & & & & & & & & & & & & & & & & & \\
\hline 3 & Capital, low renewable & 3750 & 7500 & 3000 & 750 & & & & & & & & & & & & & & & & & & \\
\hline 4 & Capital, high diesel & & & & & 2500 & & & & & & & & & & & & & & & & & \\
\hline 5 & Capital, low diesel & & & & & 1500 & & & & & & & & & & & & & & & & & \\
\hline 6 & Capital, high (all) & 6250 & 12500 & 5000 & 1250 & 2500 & & & & & & & & & & & & & & & & & \\
\hline 7 & Capital, low (all) & 3750 & 7500 & 3000 & 750 & 1500 & & & & & & & & & & & & & & & & & \\
\hline 8 & O\&M, high renewable & & & & & & 75 & 625 & 31.25 & 31.25 & & & & & & & & & & & & & \\
\hline 9 & O\&M, low renewable & & & & & & 45 & 375 & 18.75 & 18.75 & & & & & & & & & & & & & \\
\hline 10 & O\&M, high diesel & & & & & & & & & & 750 & 0.02125 & & & & & & & & & & & \\
\hline 11 & O\&M, low diesel & & & & & & & & & & 450 & 0.01275 & & & & & & & & & & & \\
\hline 12 & O\&M, high (all) & & & & & & 75 & 625 & 31.25 & 31.25 & 750 & 0.02125 & & & & & & & & & & & \\
\hline 13 & O\&M, low (all) & & & & & & 45 & 375 & 18.75 & 18.75 & 450 & 0.01275 & & & & & & & & & & & \\
\hline 14 & Discount rate, high & & & & & & & & & & & & 0.075 & & & & & & & & & & \\
\hline 15 & Discount rate, low & & & & & & & & & & & & 0.025 & & & & & & & & & & \\
\hline 16 & GHG emission cost, high & & & & & & & & & & & & & 1 & & & & & & & & & \\
\hline 17 & GHG emission cost, low & & & & & & & & & & & & & 0 & & & & & & & & & \\
\hline 18 & Escalation, high & & & & & & & & & & & & & & 0.06 & 0.03 & 0 & 0.04 & 0.04 & & & & \\
\hline 19 & Escalation, low & & & & & & & & & & & & & & 0.02 & 0 & -0.02 & 0.01 & 0.01 & & & & \\
\hline 20 & Surplus power value, high & & & & & & & & & & & & & & & & & & & -0.2973 & & & \\
\hline 21 & Surplus power value, low & & & & & & & & & & & & & & & & & & & 0 & & & \\
\hline 22 & Fuel/grid electricity cost, high & & & & & & & & & & & & & & & & & & & & 1.513 & 0.82588 & \\
\hline 23 & Fuel/grid electricity cost, low & & & & & & & & & & & & & & & & & & & & 0.908 & 0.49553 & \\
\hline 24 & Battery cycles, high & & & & & & & & & & & & & & & & & & & & & & 5000 \\
\hline 25 & Battery cycles, low & & & & & & & & & & & & & & & & & & & & & & 3000 \\
\hline
\end{tabular}

